ENERGY BENCHMARKING AND VENTILATION RELATED ENERGY SAVING POTENTIALS FOR SMALL AND MEDIUM SIZED ENTERPRISES IN GREATER TORONTO AREA

\author{
By \\ Tamima Ahmed \\ B.Sc. (Agricultural Engineering) \\ Bangladesh Agricultural University, 2010
}

A thesis

presented to Ryerson University

in partial fulfillment of the

requirement of the degree of

Master of Applied Science

in the program of

Mechanical Engineering

Toronto, Ontario, Canada, 2015

(OTamima Ahmed, 2015 


\section{AUTHOR DECLARATION FOR ELECTRONIC SUBMISSION OF A THESIS}

I hereby declare that I am the sole author of this thesis. This is an original copy of the thesis including any required final revisions as accepted by my examiners.

I authorize Ryerson University to lend this thesis to other institutions or individuals for the purpose of scholarly research.

I further authorize to Ryerson University to reproduce this thesis by photocopying or other means in total or in part, at the request of other institutions or individuals for the purpose of scholarly research.

I understand that my thesis may be made electronically available to the public. 


\title{
ENERGY BENCHMARKING AND VENTILATION RELATED ENERGY SAVING \\ POTENTIALS FOR SMALL AND MEDIUM SIZED ENTERPRISES IN GREATER \\ TORONTO AREA
}

\author{
Tamima Ahmed \\ Master of Applied Science \\ Department of Mechanical and Industrial Engineering \\ Ryerson University, Toronto, Ontario, Canada, 2015
}

\begin{abstract}
In the past several years, energy benchmarking has become a very popular tool for the estimation of energy consumption and overall performance of buildings. More recently, industrial energy benchmarking has attracted attention all over the world, due to ever-increasing energy demands. Industrial facility ventilation is one of the most overlooked components in terms of overall industrial sector energy consumption. Therefore, a proper assessment and manage of energy can lead to a great reduction of energy usage, as shown in different small and medium industrial plant case studies. Although several articles and reports that have previously discussed ventilation analysis of industrial facilities in Ontario, energy benchmarking has never been conducted on ventilation. Therefore, the purpose of this thesis is to present a detailed energy benchmarking method and analyzing energy consumption and savings based on ventilation energy consumption. An energy benchmarking analysis was conducted in different small to medium sized facilities in the Greater Toronto Area (GTA), based on ventilation analysis. It was determined from the analysis that the typical and inefficient performing facilities can reduce average of $9 \%$ of their total natural gas consumption from total ventilation, $25 \%$ from transmission heat loss and $10 \%$ from infiltration loss compared to the top performing facility among all the audited facilities in this study.
\end{abstract}




\section{Acknowledgement}

The author would like to express her gratitude to her supervisor, Dr. Alan S Fung, for his kind support, guidance, supervision, and confidence in her ability. Without his enthusiasm and guidance, my academic career would not be this straight forward.

The author is grateful to Paul Morrison and Peter Goldman from Enbridge for liaising between their industrial customers and the Ryerson University team.

The author would like to acknowledge the financial support provided by Enbridge Gas Distribution Inc., Connect Canada and OCE.

The author would like to thank her colleagues, Farzin M. Rad, Altamash Ahmed Baig for conducting the energy audits and collecting the data and Md. Maniruzzaman Akan, Afarin Amirirad, Raghad Kamel, Edward Vuong and Navid Ekrami for helping in different ways.

Finally the author would like to thank her respected parents and husband for unconditional love and support and for allowing her to realize her own potentials. 


\section{Table of Contents}

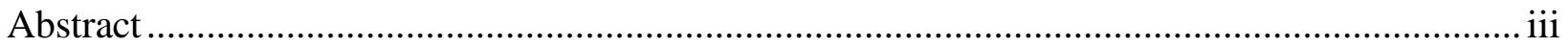

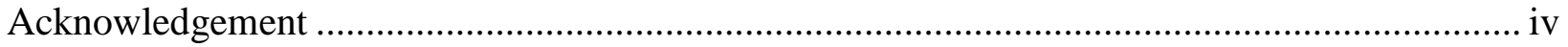

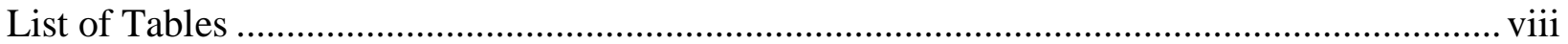

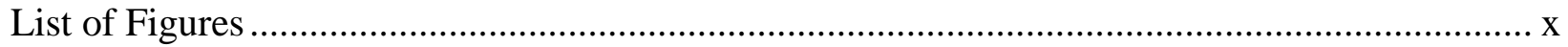

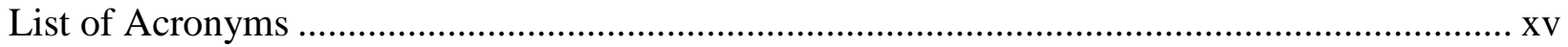

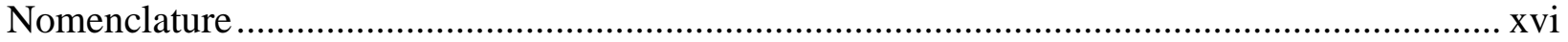

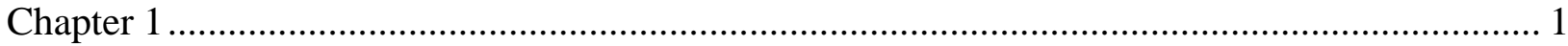

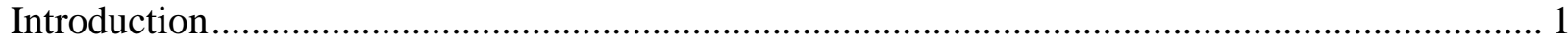

1.1 Overview of Industrial Energy Consumption by Sector in Canada..................................... 2

1.2 Overview of Natural Gas Reserves and Use ................................................................. 4

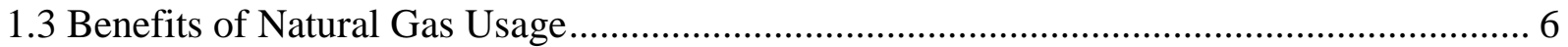

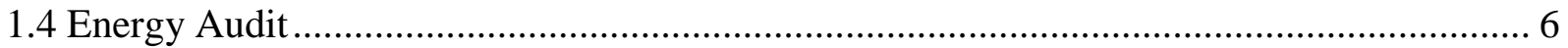

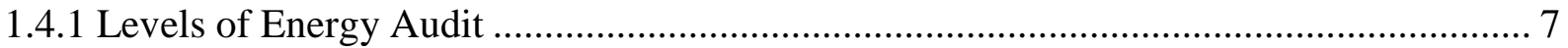

1.5 Enbridge Gas Distribution Incorporation's Demand Side Management Program ................ 7

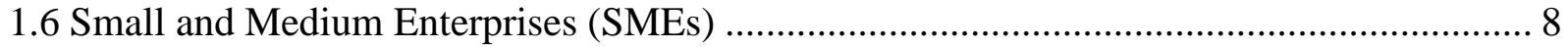

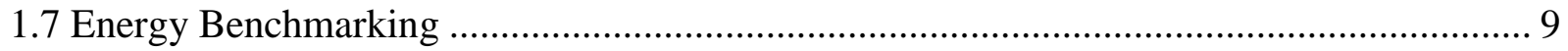

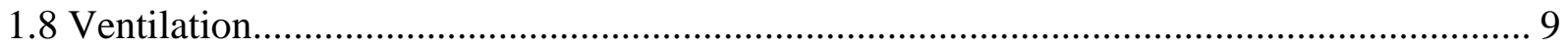

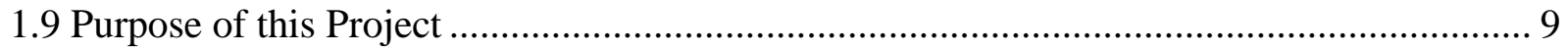

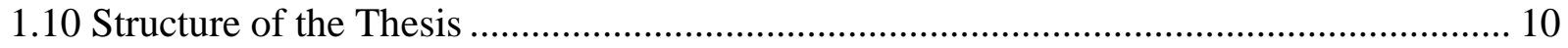

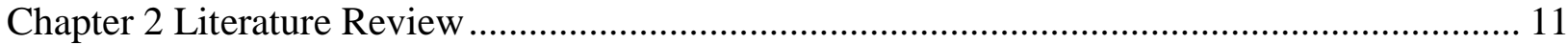

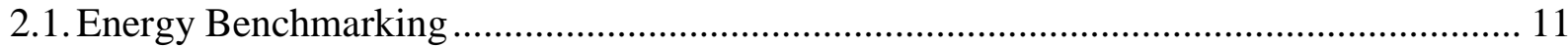

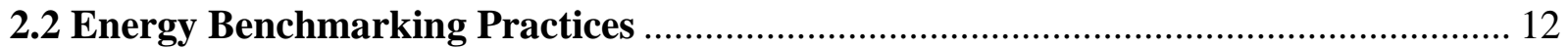

2.2.1 Green Energy Management Program Singapore …………………………………..... 12

2.2.2 Energy Efficiency Programs for Swedish SMEs .......................................................... 13

2.2.3. Denmark Energy Efficiency Agreement................................................................. 13

2.2.4. Netherlands: Long Term Agreements and Energy Benchmarking Contract .................. 14

2.2.5. Energy Start Portfolio Manager ........................................................................... 14

2.2.6. Real Property Association of Canada's Energy Benchmarking Program ...................... 15

2.3. Case Studies on Energy Auditing Programs and Developed Calculating Tools................ 16

2.4. Energy Conservation Opportunities in Industrial Ventilation System .............................. 19

2.5. Case Studies in Industrial Ventilation System …………............................................... 19

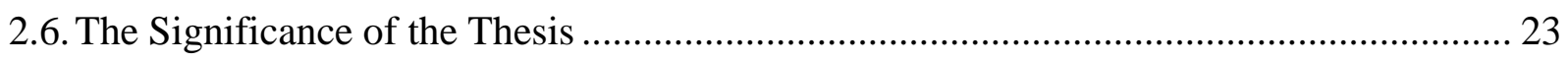

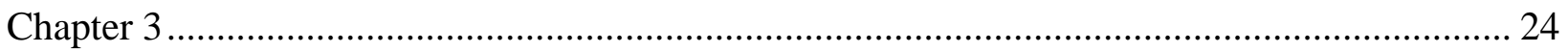




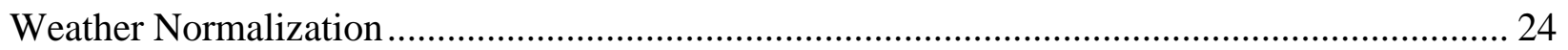

3.1. Heating Degree Days and Cooling Degree Days …………........................................ 25

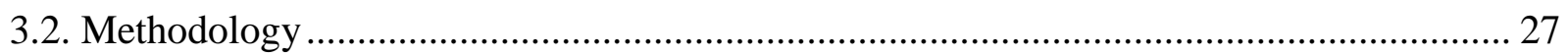

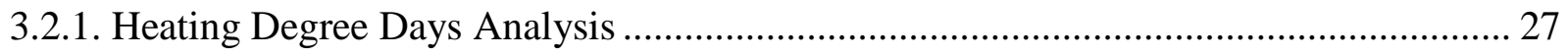

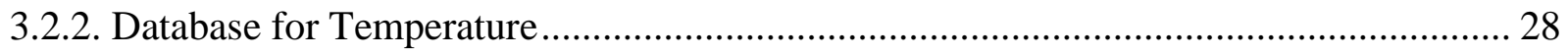

3.2.3. Normalized Energy Consumption Analysis............................................................... 29

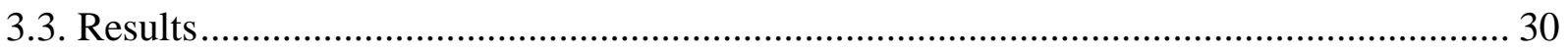

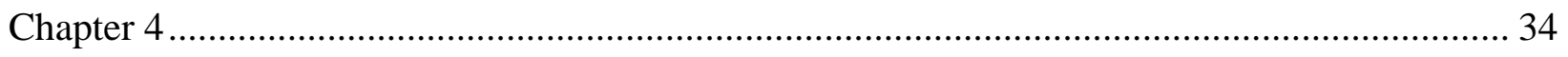

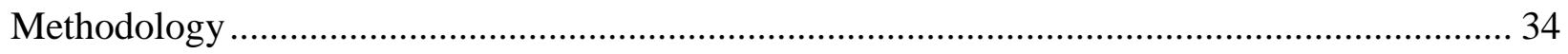

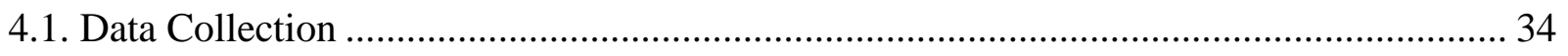

4.2. Energy Benchmarking of Normalized Energy Consumption ........................................... 36

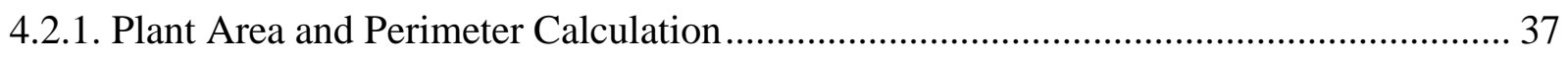

4.2.2. Energy Consumption and Cost Analysis ...................................................................... 37

4.2.3. Greenhouse Gas Emission (GHG) Calculation........................................................... 39

4.2.4. Ranking Distribution of Energy Performance Indicators ............................................... 40

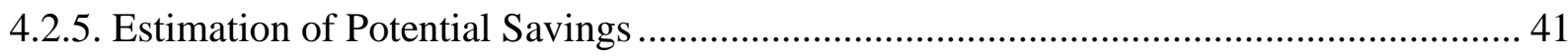

4.3. Ventilation Analysis and Benchmarking Ventilation Energy Consumption ..................... 42

4.3.1. Process Load and Seasonal Load Analysis ................................................................... 43

4.3.2. Ventilation Related Natural Gas Consumption Analysis................................................. 44

4.3.3. Multivariable Regression Analysis Using Microsoft Excel............................................... 45

4.3.4. Transmission Heat Loss Related Natural Gas Consumption.......................................... 49

4.3.5. Mechanical Ventilation Related Natural Gas Consumption .......................................... 51

4.3.6. Infiltration Loss Related to Natural Gas Consumption................................................ 52

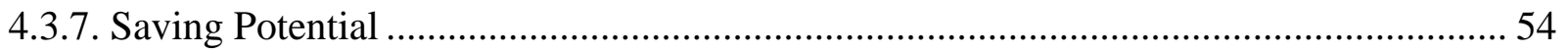

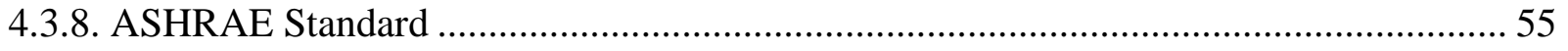

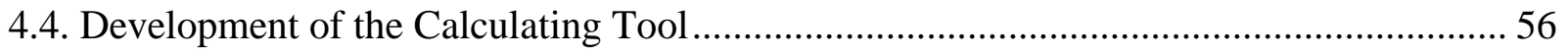

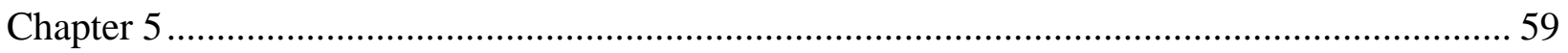

Result and Discussion ................................................................................................ 59

5.0. Energy Benchmarking of Normalized Energy Conservation ............................................ 59

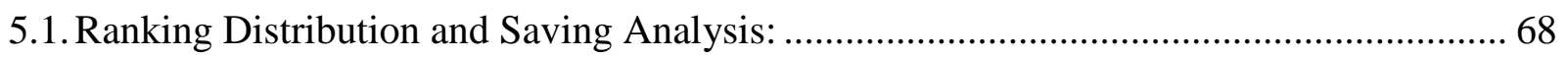

5.1.1. Ranking Distribution of Powder Coating Industries Based on Per Unit Area: ............... 68

5.1.1. Ranking Distribution of Powder Coating Industries Based on Area x Operational Hr. . 69

5.1.2. Ranking Distribution of Food Industries Based on Per Unit Plant Area: ...................... 71

5.1.3. Ranking Distribution of Food Companies Based on Plant Area x Operational Hour..... 72 


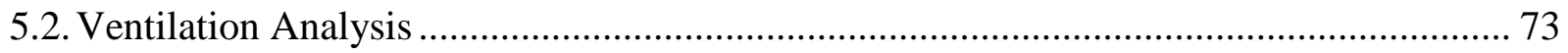

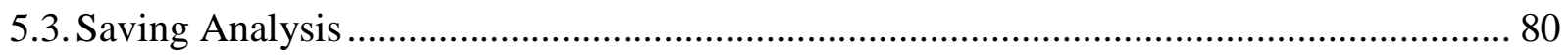

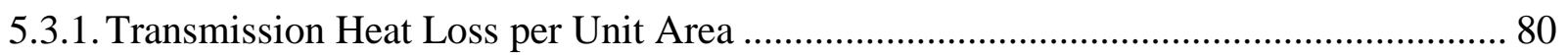

5.3.2. Transmission Heat Loss per Unit Area Multiplied With Operational Hour .................... 82

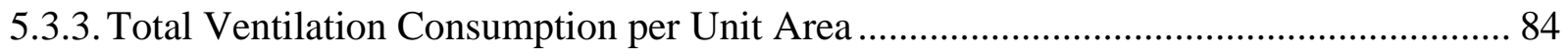

5.3.4. Ventilation Consumption per Unit Operational Hour .................................................... 87

5.3.5. Total Ventilation Consumption per unit Area Multiplied with Operational Hour .......... 89

5.3.6. Mechanical Ventilation Related Natural Gas Consumption per Unit Area .................... 91

5.3.7. Mechanical Ventilation Related NG Consumption per Unit Area X Operation Hr........ 93

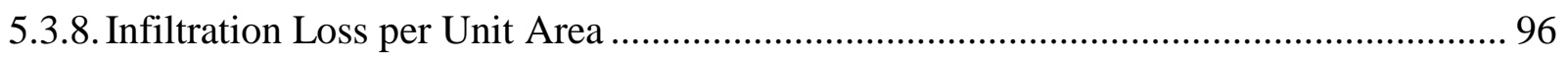

5.4. Energy and Cost Reduction by Improving Plant Wall and Roof Insulation ...................... 98

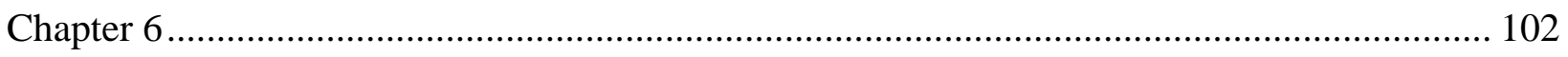

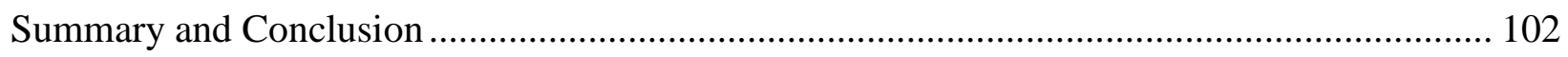

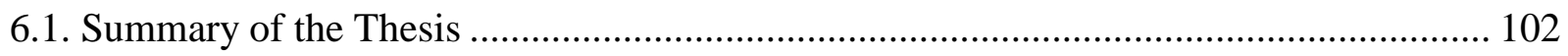

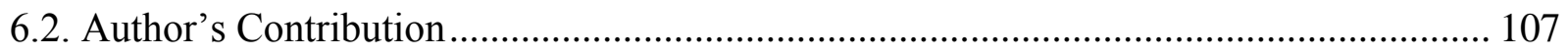

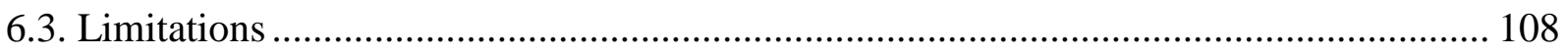

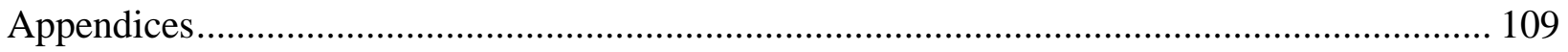

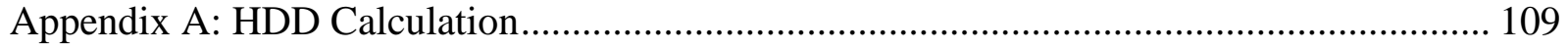

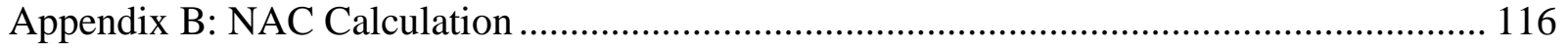

Appendix C: Seasonal and Process Load Analysis............................................................. 123

Appendix D: $1^{\text {st }}$ Level Multivariable Regression Analysis .................................................... 129

Appendix E: $2^{\text {nd }}$ Level Multivariable Regression Analysis .................................................. 135

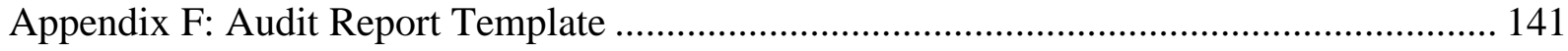

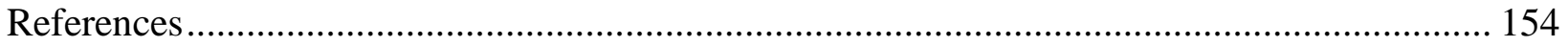




\section{List of Tables}

Table 3.1: Calculated reference temperature, HDD and normalized natural gas consumption of

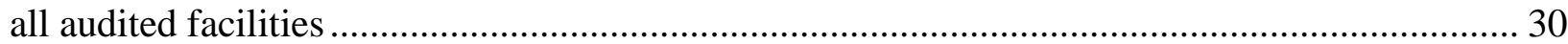

Table 4.1: The rate of natural gas price for the customers of enbridge gas distribution inc......... 38

Table 4.2: Breakdown of natural gas transportation cost to the customers ............................. 38

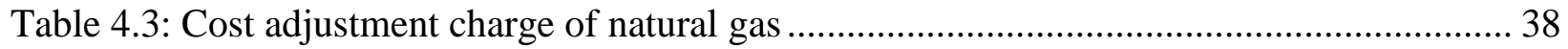

Table 4.4: Marginal cost of natural gas to the industrial customers of Enbridge ....................... 39

Table 4.5: Greenhouse emission factors for natural gas in Canada.......................................... 40

Table 5.1: Total normalized natural gas consumption, greenhouse gas emission, seasonal and

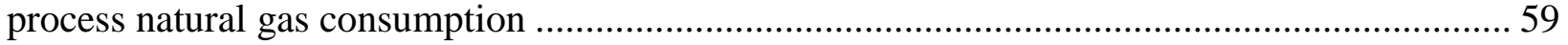

Table 5.2: Total calculated seasonal NG consumption, process consumption and percent seasonal

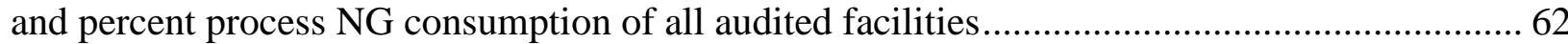

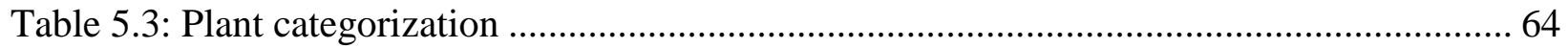

Table 5.4: Potential reductions of natural gas, cost and GHG emission................................... 69

Table 5.5: Potential reductions of natural gas, cost and GHG emission.................................. 70

Table 5.6: Potential reductions of natural gas, cost and GHG emission.................................. 71

Table 5.7: Potential reductions of natural gas, cost and GHG emission................................. 72

Table 5.8: Values of $x_{1}$ and $x_{2}$ for plant AAAL in winter months ....................................... 73

Table 5.9: Percent consumption for total ventilation and transmission heat loss ...................... 75

Table 5.10: Value of ventilation CFM/efficiency and ACH/efficiency .................................... 79

Table 5.11: Plant envelopes condition based on calculated ACH ........................................ 79

Table 5.12: Transmission heat loss benchmark range $\left(\mathrm{m}^{3} / \mathrm{ft}^{2}\right)$ for thirteen industries................. 80

Table 5.13: Potential reductions of natural gas, cost and GHG emission.................................. 81

Table 5.14: Transmission heat loss benchmark range $\left(\mathrm{m}^{3} / \mathrm{ft}^{2}-\mathrm{hr}\right)$ for thirteen industries ........... 83

Table 5.15: Potential reductions of natural gas, cost and GHG emission............................... 83

Table 5.16: Total ventilation consumption benchmark range $\left(\mathrm{m}^{3} / \mathrm{ft}^{2}\right)$ for thirteen industries ...... 85

Table 5.17: Potential reductions of natural gas, cost and GHG emission................................. 86

Table 5.18: Total ventilation consumption benchmark range $\left(\mathrm{m}^{3} / \mathrm{hr}\right)$ for thirteen industries ...... 87

Table 5.19: Potential reductions of natural gas, cost and GHG emission................................. 88

Table 5.20: Total ventilation related natural gas consumption benchmark range $\left(\mathrm{m}^{3} / \mathrm{ft}^{2}-\mathrm{hr}\right) \ldots . .89$

Table 5.21: Potential reductions of natural gas, cost and GHG emission................................ 90

Table 5.22: Mechanical ventilation related natural gas consumption per unit area benchmark

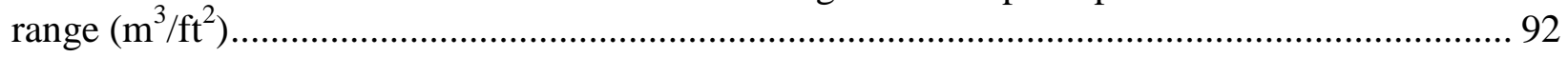

Table 5.23: The potential savings of natural gas, cost and GHG emissions............................ 93

Table 5.24: Mechanical ventilation related natural gas consumption per unit area $\mathrm{x}$ operational

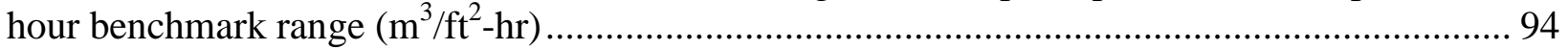

Table 5.25: The potential savings of natural gas, cost and GHG emissions............................. 95

Table 5.26: Infiltration loss related natural gas consumption per unit area benchmark range

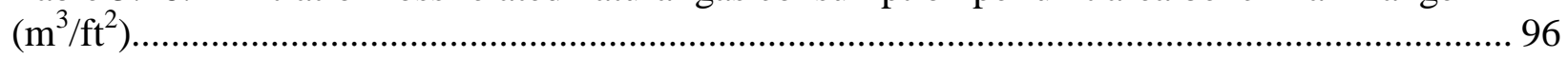

Table 5.27: The potential savings of natural gas, cost and GHG emissions............................ 97

Table 5.28: Amount of natural gas, cost reduction and payback period of all audited plants .... 100

Table 6.1: Summary of overall NG consumption, GHG emission and cost by different audited

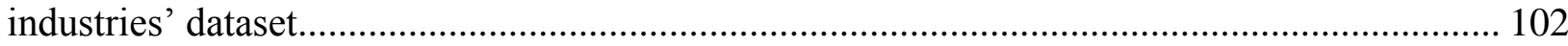

Table 6.2: Summary result of normalized natural gas, cost and GHG emission savings of food

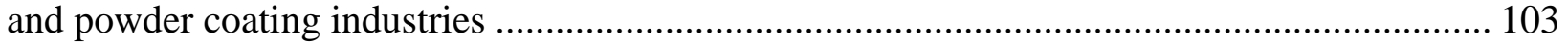

Table 6.3: Summary result of overall natural gas, cost and GHG emission savings ................. 105 
Table F.1: Annual gas consumption of plant AAAV ….................................................. 141

Table F.2: Cost saving per year by improving building insulation...................................... 141

Table F.3: Summary results for saving analysis ....................................................... 152

Table F.4: Summary result to improve building insulation R Value .................................... 153 


\section{List of Figures}

Figure 1.1 Historic and predicted energy demand in different sectors [7] ................................ 3

Figure 1.2: Energy consumption in Canada by sector in 2008 [8] ......................................... 3

Figure 1.3: World's natural gas reservation by 2012 [10] ......................................................... 4

Figure 1.4: Primary natural gas demand by sector [11] ...................................................... 5

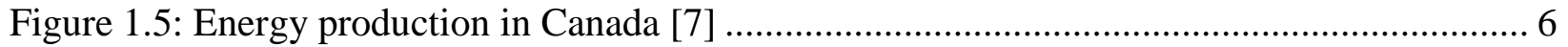

Figure 1.6: Energy efficiency in SMEs (Europe) [16] ......................................................... 8

Figure 2.1: Maximum wall and roof assembly over time in different cities [49] .......................... 22

Figure 2.2: Change of wall insulation in Canada over time [50] ............................................... 23

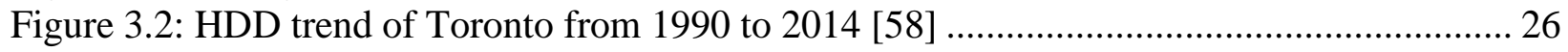

Figure 3.3: CDD trend of Canada and Ontario from 1990 to 2008 [58] ...................................... 26

Figure 3.4: Monthly weather data of Toronto from Environment Canada website [60] .............. 28

Figure 3.5 Statistical correlations between monthly natural gas consumption and HDD of plant

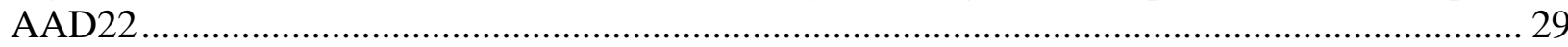

Figure 3.6: Calculated reference temperatures of selected companies ......................................... 31

Figure 3.7: Annual heating degree days of plants.................................................................. 32

Figure 3.8: Statistical correlations between plant natural gas consumption and HDD for different

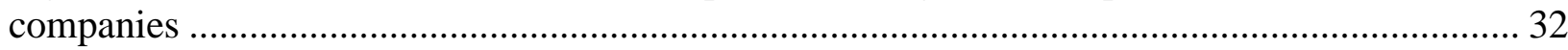

Figure 3.9: Normalized annual consumptions of companies........................................................ 33

Figure 4.1: Methodology of energy benchmarking of normalized natural gas consumption........ 36

Figure 4.2: Plant area calculations using daft logic software ....................................................... 37

Figure 4.3: The proposed methodology for ventilation related natural gas consumption analysis

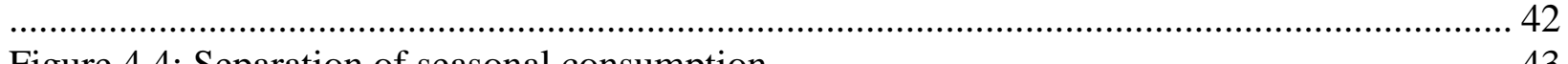

Figure 4.4: Separation of seasonal consumption .............................................................. 43

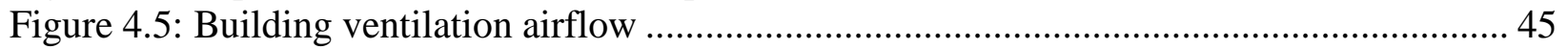

Figure 4.6: First step to conduct the regression analysis in Microsoft Excel ............................... 47

Figure 4.7: Second step of regression analysis in Microsoft Excel ............................................... 48

Figure 4.8: Final step of multivariable regression in Excel ....................................................... 48

Figure 4.9: Transmission heat loss of the building ................................................................ 50

Figure 4.10: Typical mechanical ventilation system of plant ................................................... 51

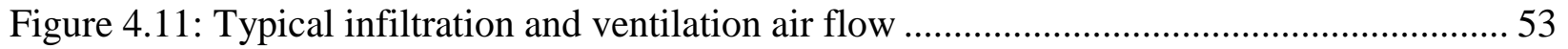

Figure 4.12: Developer tab in Microsoft Excel 2010 .................................................................. 57

Figure 4.13: Visual basic editor in Microsoft Excel 2010 ……………….................................... 57

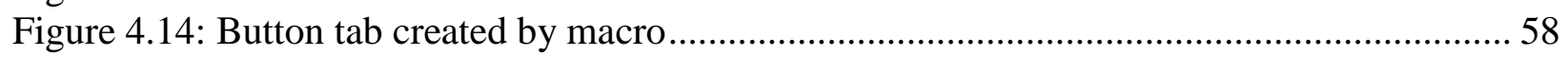

Figure 5.1: Normalized annual natural gas consumption of companies ........................................ 60

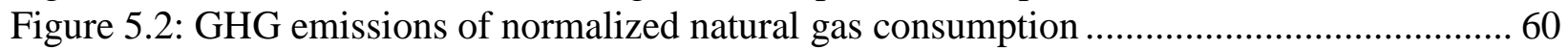

Figure 5.3: Annual cost of natural gas of companies.................................................................. 61

Figure 5.4: Seasonal and process annual consumption of company AAD22 ................................ 61

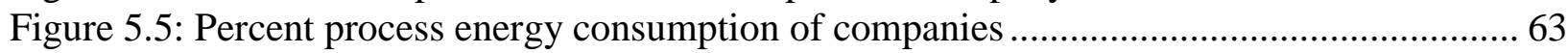

Figure 5.6: Percent seasonal energy consumption of companies .................................................. 63

Figure 5.7: Statistical correlations between plant areas and normalized total natural gas

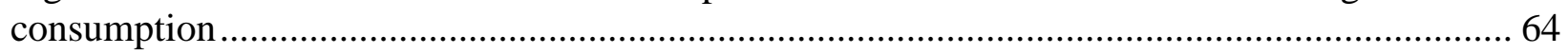

Figure 5.8: Statistical correlations between plant areas and normalized seasonal natural gas

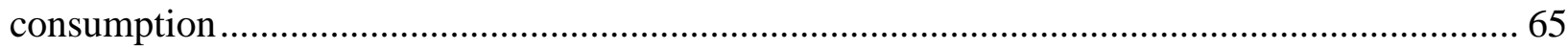

Figure 5.9: Statistical correlations between plant area and normalized process related natural gas consumption 
Figure 5.10: Statistical correlations between plant area multiplied with operational hour and normalized total natural gas consumption

Figure 5.11: Statistical correlations between plant area multiplied with operational hour and normalized seasonal natural gas consumption....

Figure 5.12: Annual normalized natural gas consumption benchmark per unit area of seven powder coating companies.

Figure 5.13: Annual normalized natural gas consumption benchmark per unit area multiplied with operational hour of seven powder coating companies 70

Figure 5.14: Annual normalized natural gas consumption benchmark per unit area of four food companies

Figure 5.15: Annual normalized natural gas consumption benchmark per unit area multiplied with operational hours of four food companies 72

Figure 5.16: $1^{\text {st }}$ Level multivariable regression analysis of plant AAAL .................................. 74

Figure 5.17: Percent consumption of plant total ventilation and transmission heat loss ............ 75

Figure 5.18: Comparison between plants calculated total transmission heat loss and Enbridge

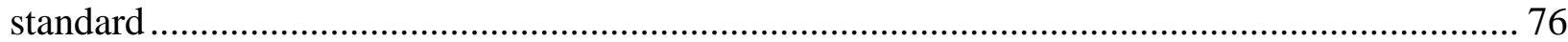

Figure 5.19: Plant calculated U Values/ equipment efficiency......................................... 77

Figure 5.20: Sensitivity analysis for plant's equipment efficiency ........................................ 77

Figure 5.21: Ontario building code for wall insulation of plants from 1975 to 2006 ................. 78

Figure 5.22: Comparison of calculated $\mathrm{u}$ values with Ontario Building Code ........................... 78

Figure 5.23: Scatter plot of transmission heat loss with plant area ...................................... 80

Figure 5.24: Annual transmission heat loss benchmark per unit area of thirteen audited industries

Figure 5.25: Scatter plot of transmission heat loss with area multiplied with operational hour... 82 Figure 5.26: Annual transmission heat loss benchmark per unit area multiplied with operational

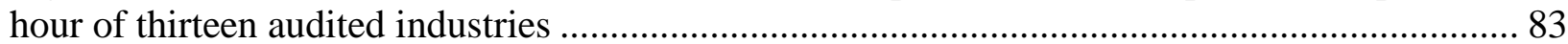

Figure 5.27: Scatter plot of total ventilation related natural gas consumption per unit area ....... 85 Figure 5.28: Total ventilation related natural gas consumption benchmark per unit area of

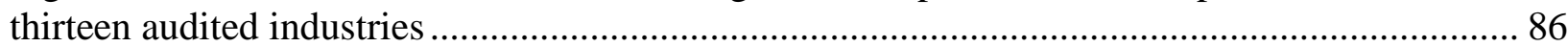

Figure 5.29: Scatter plot of total ventilation consumption with operational hour ..................... 87

Figure 5.30: Total ventilation related natural gas consumption benchmark per unit operational

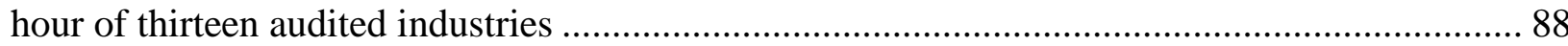

Figure 5.31: Scatter plot of total ventilation related natural gas consumption with area $\mathrm{x}$

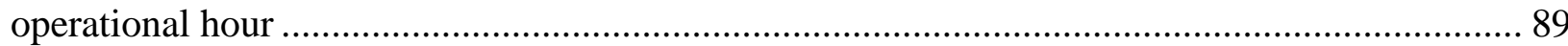

Figure 5.32: Total ventilation related natural gas consumption benchmark per unit area $\mathrm{x}$ operational hour of thirteen audited industries

Figure 5.33: Scatter plot of mechanical ventilation related natural gas consumption with plant

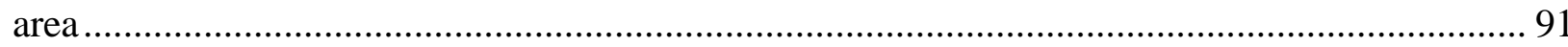

Figure 5.34: Annual mechanical ventilation related natural gas consumption benchmark per unit

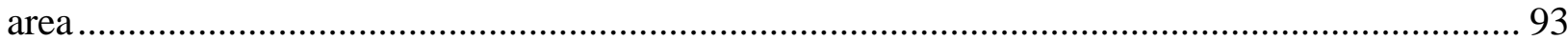

Figure 5.35: Scatter plot of mechanical ventilation related natural gas consumption with plant area $\mathrm{x}$ operational hour.

Figure 5.36: Annual mechanical ventilation related natural gas consumption benchmark per unit

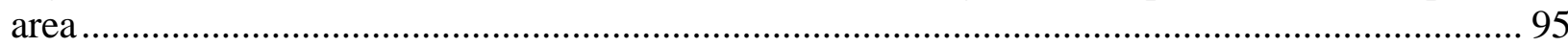

Figure 5.37: Scatter plot of infiltration loss with plant area .............................................. 96

Figure 5.38: Annual infiltration loss benchmark per unit area ....................................... 97 
Figure 5.39: Natural gas reduction by improving building insulation R value ........................ 98

Figure 5.40: Cost reduction by improving building wall insulation........................................ 99

Figure 5.41: Percent total natural gas reduction of audited plants........................................ 99

Figure 5.39: Payback period for improving insulation R Value.......................................... 101

Figure A.1: Monthly heating degree days of plant AAD78 ................................................. 109

Figure A.2: Monthly heating degree days of plant AAD22 ............................................. 109

Figure A.3: Monthly heating degree days of plant AAAL .............................................. 110

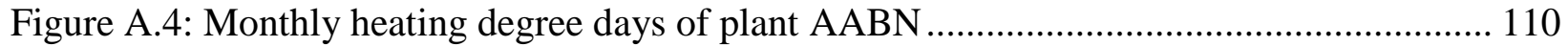

Figure A.5: Monthly heating degree days of plant AAGF ................................................ 111

Figure A.6: Monthly heating degree days of plant AAKK .................................................. 111

Figure A.7: Monthly heating degree days of plant AAKK2 …....................................... 112

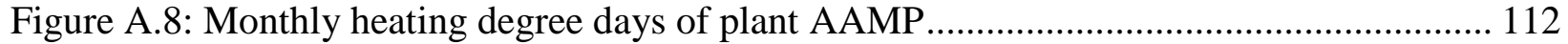

Figure A.9: Monthly heating degree days of plant AASN ................................................ 113

Figure A.10: Monthly heating degree days of plant AAWI ................................................ 113

Figure A.11: Monthly heating degree days of plant AASU ................................................. 114

Figure A.12: Monthly heating degree days of plant AASP ................................................ 114

Figure A.13: Monthly heating degree days of plant AAWR ............................................. 115

Figure B.1: Normalized monthly natural gas consumption of plant AAD78 ......................... 116

Figure B.2: Normalized monthly natural gas consumption of plant AAD22 ......................... 116

Figure B.3: Normalized monthly natural gas consumption of plant AAAL........................... 117

Figure B.4: Normalized monthly natural gas consumption of plant AABN .......................... 117

Figure B.5: Normalized monthly natural gas consumption of plant AAGF.......................... 118

Figure B.6: Normalized monthly natural gas consumption of plant AAKK .......................... 118

Figure B.7: Normalized monthly natural gas consumption of plant AAKK2 ….................... 119

Figure B.8: Normalized monthly natural gas consumption of plant AAMP ........................... 119

Figure B.9: Normalized monthly natural gas consumption of plant AASN .......................... 120

Figure B.10: Normalized monthly natural gas consumption of plant AAWI.......................... 120

Figure B.11: Normalized monthly natural gas consumption of plant AASU .......................... 121

Figure B.12: Normalized monthly natural gas consumption of plant AASP ......................... 121

Figure B.13: Normalized monthly natural gas consumption of plant AAWR ....................... 122

Figure C.1: Process and seasonal energy consumption of plant AAAL ................................ 123

Figure C.2: Process and seasonal energy consumption of plant AABN................................ 123

Figure C.3: Process and seasonal energy consumption of plant AAD78 ............................... 124

Figure C.4: Process and seasonal energy consumption of plant AAGF ................................ 124

Figure C.5: Process and seasonal energy consumption of plant AAKK1 ............................ 125

Figure C.6: Process and seasonal energy consumption of plant AAKK2 …......................... 125

Figure C.7: Process and seasonal energy consumption of plant AAMP ............................... 126

Figure C.8: Process and seasonal energy consumption of plant AASN ............................... 126

Figure C.8: Process and seasonal energy consumption of plant AASU ................................ 127

Figure C.9: Process and seasonal energy consumption of plant AASP ................................. 127

Figure C.10: Process and seasonal energy consumption of plant AAWI .............................. 128

Figure C.11: Process and seasonal energy consumption of plant AAWR ............................. 128

Figure D.1: Separation of seasonal consumption into total ventilation and transmission heat loss

of company AAAL .......................................................................................... 129

Figure D.2: Separation of seasonal consumption into total ventilation and transmission heat loss

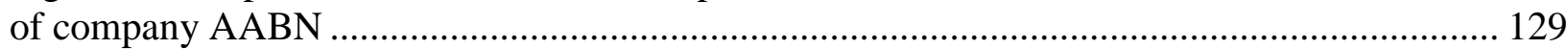


Figure D.3: Separation of seasonal consumption into total ventilation and transmission heat loss of company AAD22 ........................................................................................ 130 Figure D.4: Separation of seasonal consumption into total ventilation and transmission heat loss of company AAD78 ...................................................................................... 130 Figure D.5: Separation of seasonal consumption into total ventilation and transmission heat loss of company AAGF. 131 Figure D.6: Separation of seasonal consumption into total ventilation and transmission heat loss of company AAKK 131 Figure D.7: Separation of seasonal consumption into total ventilation and transmission heat loss of company AAKK2 132 Figure D.8: Separation of seasonal consumption into total ventilation and transmission heat loss of company AAMP....

Figure D.9: Separation of seasonal consumption into total ventilation and transmission heat loss of company AASN. 133 Figure D.10: Separation of seasonal consumption into total ventilation and transmission heat loss of company AASP 133 Figure D.11: Separation of seasonal consumption into total ventilation and transmission heat loss of company AASU. 134 Figure D.12: Separation of seasonal consumption into total ventilation and transmission heat loss of company AAWI. 134

Figure E.1: $2^{\text {nd }}$ level multivariable regression analysis of plant AABN................................ 135

Figure E.2: $2^{\text {nd }}$ level multivariable regression analysis of plant AAD22 ............................. 135

Figure E.3: 2nd level multivariable regression analysis of plant AAD78 ............................. 136

Figure E.4: 2nd level multivariable regression analysis of plant AAGF ............................... 136

Figure E.5: 2nd level multivariable regression analysis of plant AAKK ............................... 137

Figure E.6: 2nd level multivariable regression analysis of plant AAKK2 …....................... 137

Figure E.7: 2nd level multivariable regression analysis of plant AAMP .............................. 138

Figure E.8: 2nd level multivariable regression analysis of plant AASN ............................... 138

Figure E.9: 2nd level multivariable regression analysis of plant AASP............................... 139

Figure E.10: 2nd level multivariable regression analysis of plant AASU ............................. 139

Figure E.11: 2nd level multivariable regression analysis of plant AAWI ............................. 140

Figure E.12: 2nd level multivariable regression analysis of plant AAWR............................ 140

Figure F.1: Weather normalization of plant AAAV ........................................................ 142

Figure F.2: Seasonal and process natural gas consumption of plant AAAV .......................... 142

Figure F.3: Percent of seasonal and process natural gas consumption ................................. 143

Figure F.4: Percent total transmission heat loss and total ventilation consumption of plant AAAV

Figure F.5: Percent mechanical ventilation consumption and infiltration loss of plant AAAV . 144

Figure F.6: Annual Transmission Heat Loss Benchmark per Unit Area ................................ 145

Figure F.7: Annual transmission heat loss benchmark per unit area multiplied with operational

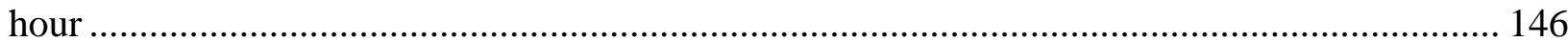

Figure F.8: Total ventilation related natural gas consumption benchmark per unit area .......... 147 Figure F.9: Total ventilation related natural gas consumption benchmark per unit operational hour ...................................................................................................... 148

Figure F.10: Total ventilation related natural gas consumption benchmark per unit area $\mathrm{X}$ operational hour . 
Figure 11: Annual mechanical ventilation related natural gas consumption benchmark per unit

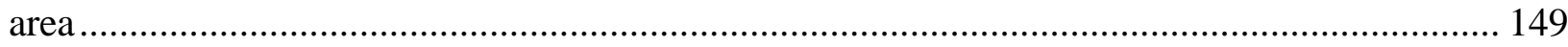
Figure 12: Annual mechanical ventilation related natural gas consumption benchmark per unit

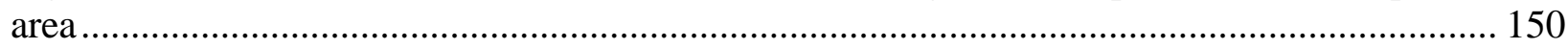
Figure 13: Annual Infiltration Loss Benchmark per Unit Area ........................................... 151 


\section{List of Acronyms}

$\mathrm{ACH}$

ASHRAE American Society of Heating and Air Conditioning Engineers

BTU British Thermal Unit

CDD Cooling Degree Days

CFM Cubic Feet per Minute

DSM Demand Side Management

EGD Enbridge Gas Distribution

GHG Greenhouse Gas

GTA Greater Toronto Area

HDD Heating Degree Days

HVAC Heating Ventilation and Air Conditioning

MVR Multivariable Regression

NAC Normalized Annual Consumption

NDA Non-Disclosure Agreement

OEB Ontario Energy Board

OBC Ontario Building Code

PRISM Princeton Scorekeeping Method

PJ Peta Joule

SME Small and Medium Enterprises

WMO World Metrological Organization 


\section{Nomenclature}

$\alpha \quad$ Daily based load consumption

$\delta_{c} \quad 1$ for CO (cooling only) and HC (heating cooling) model in PRISM otherwise 0.

$\beta_{h} \quad$ Heating slope is equal to heat loss rate of the house

$\beta_{1} \quad$ Heat transfer coefficient $U$ value for transmission heat loss (wall + roof) / efficiency

$\beta_{2} \quad$ Building ventilation CFM x ACH for infiltration heat loss / equipment efficiency

$\beta_{21} \quad$ Building ventilation CFM / equipment efficiency

$\beta_{22} \quad$ Air change per hour of the plant/ equipment efficiency

$\delta_{h} \quad 1$ for HO (heating only) and HC (heating cooling) model in PRISM otherwise 0.

$\beta_{c} \quad$ Cooling slope is equal to heat gain rate of the house

$\eta \quad$ Efficiency of equipment

$\Delta \mathrm{T} \quad$ Temperature difference $\left({ }^{\circ} \mathrm{F}\right)$

A Area of the building, $\left(\mathrm{ft}^{2}\right)$

$C_{T} \quad$ Constant, 60 for english unit

$C_{o}\left(\tau_{c}\right) \quad$ Long term cooling degree days $\left({ }^{\circ} \mathrm{F}\right.$ - Day) per year calculated by Microsoft Excel

$H_{o}\left(\tau_{h}\right) \quad$ Long term heating degree days $\left({ }^{\circ} \mathrm{F}\right.$ - Day) per year calculated by Microsoft Excel

$q_{1} \quad$ Transmission heat loss (Btu)

$q_{2} \quad$ Ventilation energy consumption (Btu) 
$T_{m} \quad$ Daily mean temperature occurring in the month $\left({ }^{\circ} \mathrm{F}\right)$

$T_{b} \quad$ Base reference temperature $\left({ }^{\circ} \mathrm{F}\right)$

$\mathrm{U} \quad$ Building heat transfer co-efficient $\left(\mathrm{Btu} / \mathrm{hr}-\mathrm{ft}^{2}-{ }^{\circ} \mathrm{F}\right)$

V Gross space volume $\left(\mathrm{ft}^{3}\right)$

$\mathrm{X}_{11}$ Transmission heat losses (wall) without building insulation U value (Btu)

$\mathrm{X}_{12}$ Transmission heat losses (roof) without building insulation U value (Btu)

$\mathrm{X}_{21} \quad$ Ventilation consumption without CFM (Btu)

$\mathrm{X}_{22}$ Infiltration losses without ACH (Btu)

Y Seasonal consumption of plants (Btu) 


\section{Chapter 1}

\section{Introduction}

The main purpose of energy management is to increase the energy efficiency in order to decrease the cost of energy usage; specifically by focussing on improving operational techniques and introducing new energy efficient equipment. Recently, energy management in residential and industrial buildings has become a concern. Building energy performance is regulated through the decision stage and action stage. These two stages encompass the four different phases: design, construction, operation, and maintenance of buildings. Weather and climatic conditions are related in each phase. For example, the design phase is responsible for determining heating and cooling requirements and annual average energy consumption; on the other hand, weather forecast is important in the construction phase. An observation is also required to verify whether the energy consumption of the building, which is conducted during the design phase, has been maintained [1]. To analyze the energy consumption pattern of the building, energy benchmarking is one of several suitable methods.

In residential buildings, energy is mostly used for heating, ventilation and air-conditioning (HVAC) systems; however, in industrial buildings energy is mostly used for production/service purposes. For this reason, the energy consumption pattern of an industrial building is quite different and complicated. For instance, energy consumption patterns of an industrial building are regulated by the activity levels. These levels are termed structural efficiency and energy efficiency [2]. To identify the energy saving potentials, it is necessary to separate the effects of energy efficiency from structural efficiency. Phylipsen et al. [2] developed a procedure to separate them. According to Phylipsen, the bulk of human diversion issued for each unit of energy was known as energy efficiency. On the other hand, structural efficiency is defined as the mixture of production processes in the industries [3]. After separating these two sectors, the calculation of any potential saving in energy of an industrial building becomes easier.

In 1992, ENERGY STAR program was introduced by the US Environmental Protection Agency (EPA) to reduce environmental pollution by increasing energy efficiency [4]. The purpose of this agency was to create awareness about energy consumption and to protect the environment for future generations. To do so, they introduced the ENERGY STAR standard. 
Almost all types of products and appliances for industrial or residential buildings are available with the ENERGY STAR label. These products undergo an energy benchmarking. That is, the EPA has accepted that energy benchmarking is one of the best ways to find energy saving potentials. The EPA has different energy management tools. Among them, is the Energy Performance Indicator (EPI); that is used for manufacturing plants. According to Boyd [4], "It is a statistical tool that gives a bird's eye view of industrial energy consumptions and provides a clear concept to the plant manager about their energy saving opportunities". EPI uses energy benchmarking calculations and regression analyses to calculate plant energy consumptions [4].

This thesis will discuss energy benchmarking of industrial plants and analyze energy saving potentials.

\subsection{Overview of Industrial Energy Consumption by Sector in Canada}

The main purpose of energy management is to observe and supervise building performance to reduce the waste of energy by making the building facilitators' aware of their energy consumptions [5]. According to Statistics Canada, 1.4 million TJ of energy was consumed by Canadian households in 2011, which was a 4\% increase from 2007 [6]. In 2011, 1,173.2 PJ of natural gas was consumed by the industrial sector, which was a $40.1 \%$ increase from 1990 [6]. Therefore, the energy consumption in the industrial sector has been increasing every year. According to the National Energy Board of Canada, this growing trend will continue until 2035, but in a controlled manner due to the introduction of energy management programs. Figure 1.1 depicts the energy demand by sectors [7]. Figure 1.1 shows that the expected output of energy consumption in all sectors will decrease, except in the industrial sector. Thus, it is a concern of the industrial sector to further reduce their energy consumption. 


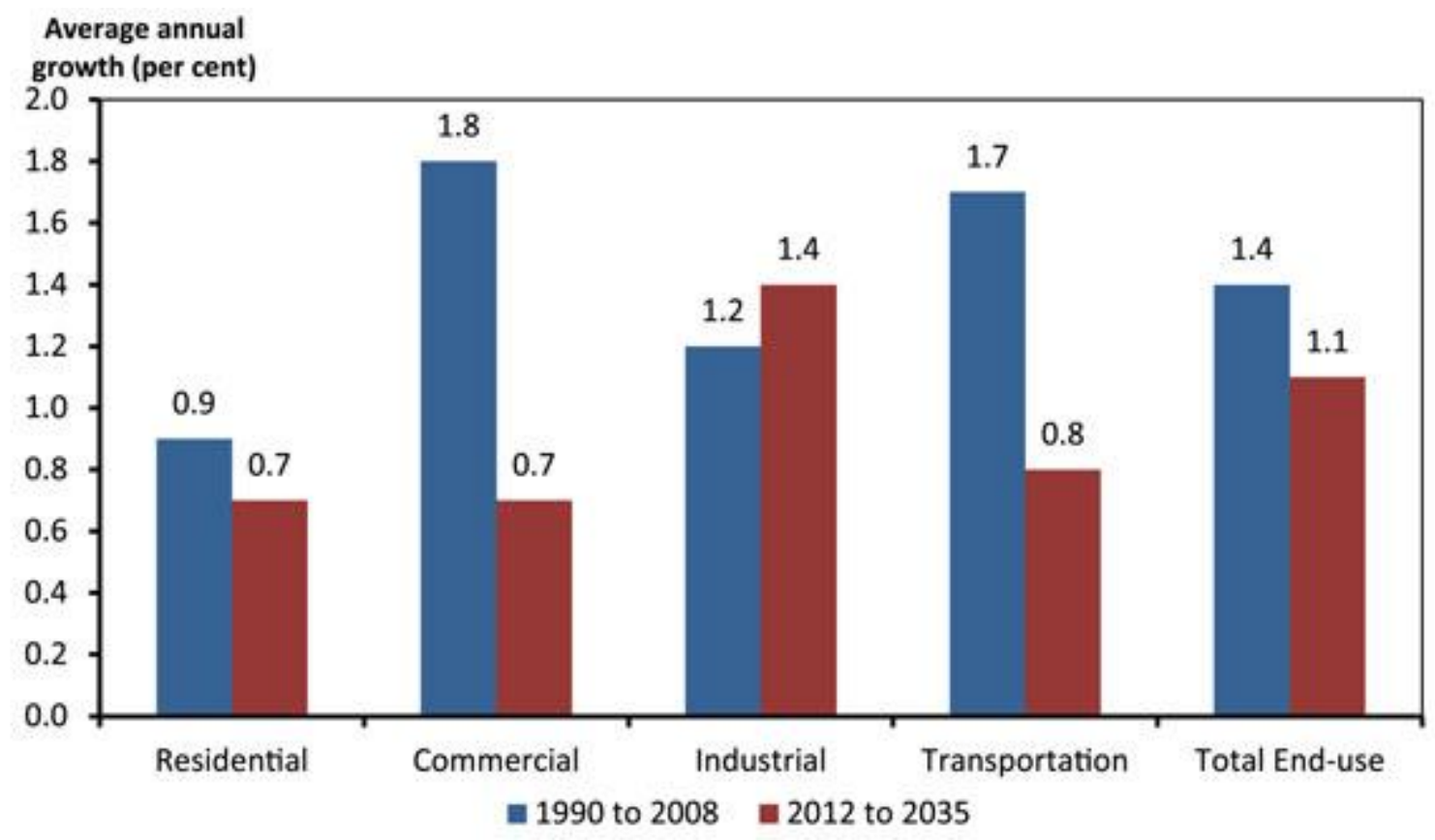

Figure 1.1 Historic and predicted energy demand in different sectors [7]

It is important to know that 19 percent of Canada's total energy is consumed by the industrial sector, which is over $5000 \mathrm{PJ}$ according to the Natural Resources Canada (NRCan) [8]. Figure 1.2 depicts that the industrial sector is the third highest energy consumer. For this reason, the reduction of energy consumption is quite urgent in this sector. Energy efficiency and potentials can be determined by using an energy benchmarking method, which was discussed further.

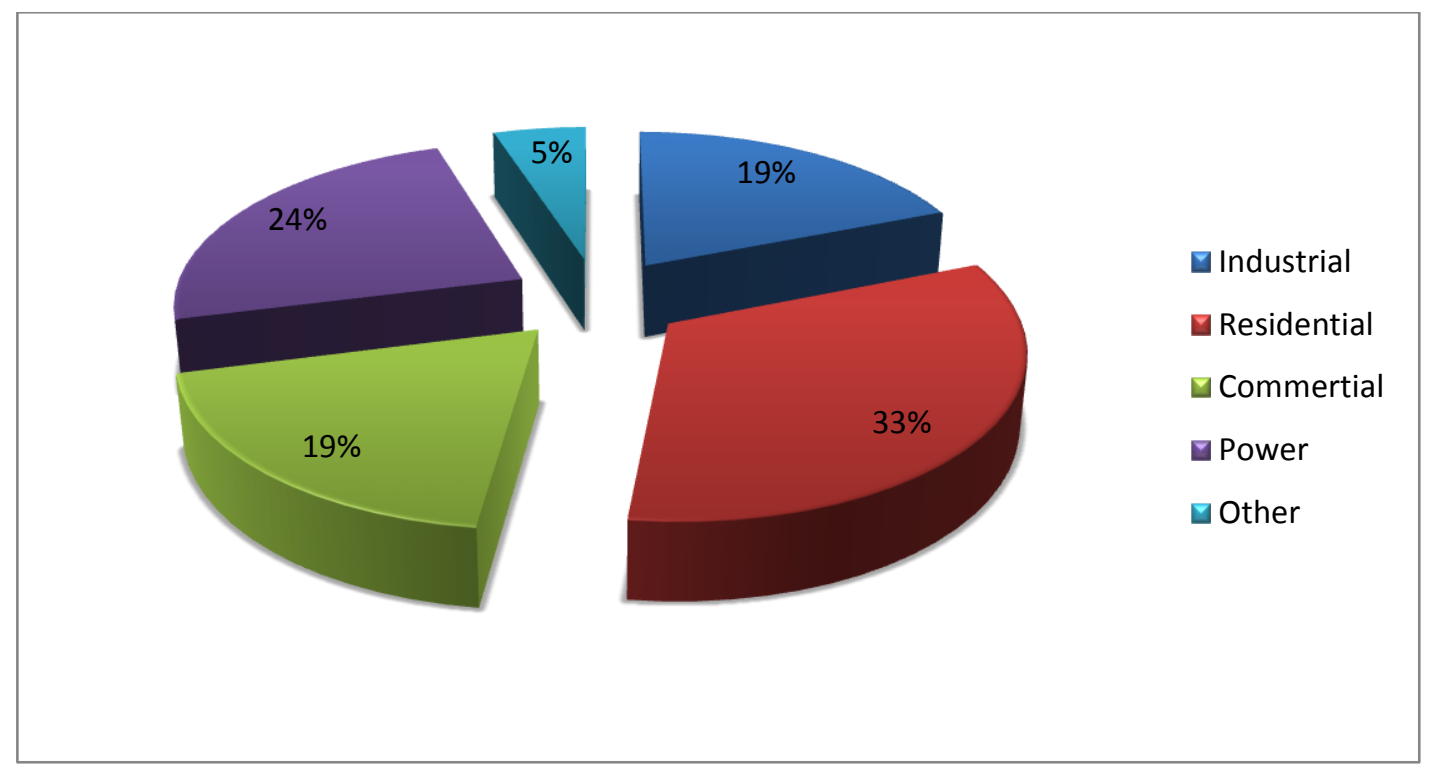

Figure 1.2: Energy consumption in Canada by sector in 2008 [8] 
According to Statistics Canada, in 2009, total natural gas was consumed by all sectors was 563,127 terajoules and in 2013 was 716,758 terajoules which is $27 \%$ more than 2009 consumption record [9].

\subsection{Overview of Natural Gas Reserves and Use}

The demand for natural gas is constantly increasing because it is used by every sector. According to the International Energy Agency (IEA) [10], the world's reserve of natural gas is sufficient to satisfy the growing demand beyond 2035. However, it does not mean that all regions of the world will have access to natural gas. The greatest amount of natural gas reserves are in Russia and will remain the highest until 2035 [10]. The natural gas reserves of the world in 2012 are shown in Figure 1.3.

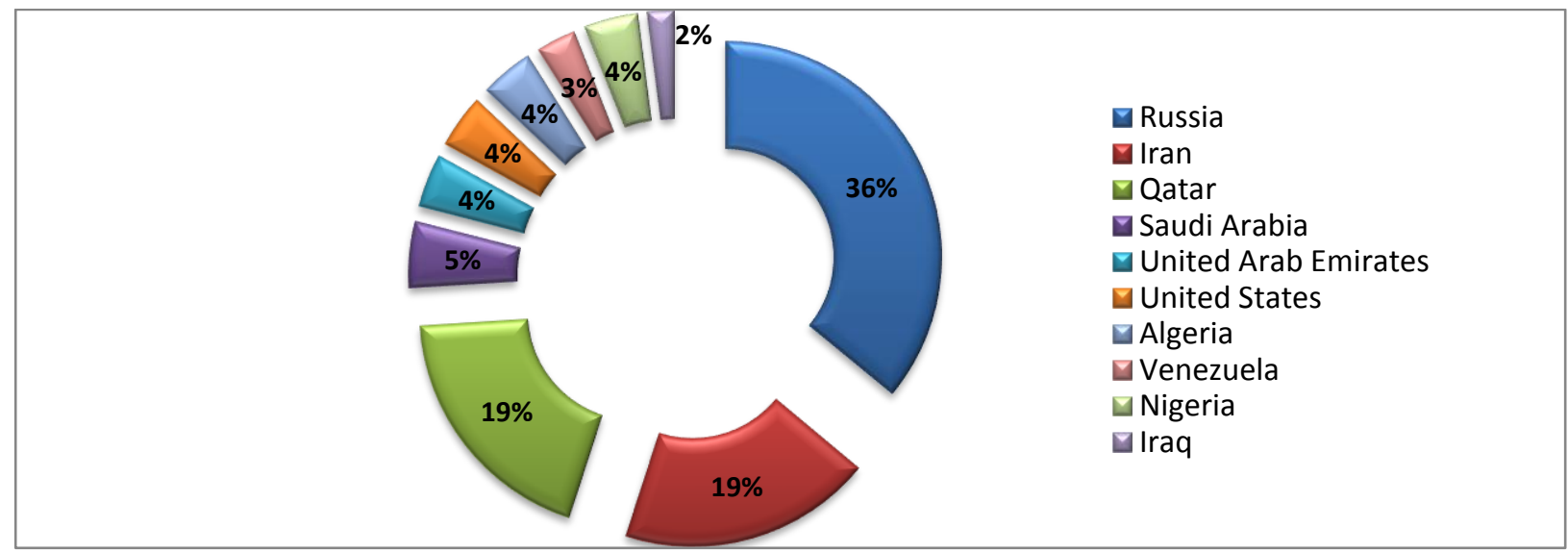

Figure 1.3: World's natural gas reservation by 2012 [10]

Figure 1.3 shows that Russia, Iran and Qatar currently possess approximately $74 \%$ of the natural gas reserves in the world. According to IEA [10], the global demand of naural gas rose by $6.6 \%$ in 2010 due to a cold winter in Europe and North America, and tropical summer in Pacific region. Figure 1.4 represents the increasing trend of natural gas utilization by 2035 . Figure 1.4 shows that the industrial sector consumes a large portion of natural gas for their production; a consumption of 535 billion cubic meter ( $\mathrm{bcm}$ ) in 2009 and has been predicted to rise to $890 \mathrm{bcm}$ in 2035 [11]. Figure 1.4 also presents the natural gas demand by sector in 2009 and the predicted demand by 2035. 
Figure 1.4 demonstrates that the highest amount of energy consumption will be in the industrial sector. In 2035, the natural gas consumption will be increased by $59 \%$, $39 \%$ and $66 \%$ for the electricity and heat sector, residential sector and industrial sector, respectively. This increasing trend makes people concerned, and as a result, they feel interested to reduce their natural gas consumption.
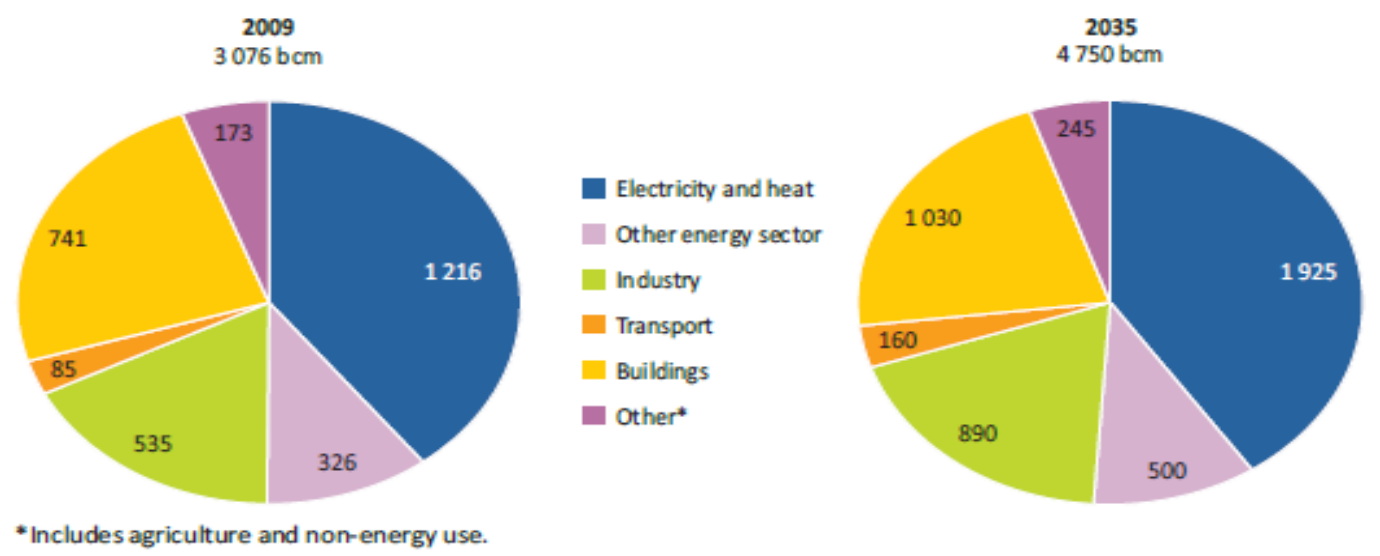

Figure 1.4: Primary natural gas demand by sector [11]

According to the National Energy Board of Canada, the production of natural gas (NG) in Canada will increase substantially and it will increase $25 \%$ by 2035 [7]. The energy production in Canada is shown in Figure 1.5; it predicts that oil and gas production will increase at a high rate and electricity will remain steady. However, with the increasing rate of production, the consumption rate will also increase. This is the time to be concerned with natural gas consumption and its future savings. 


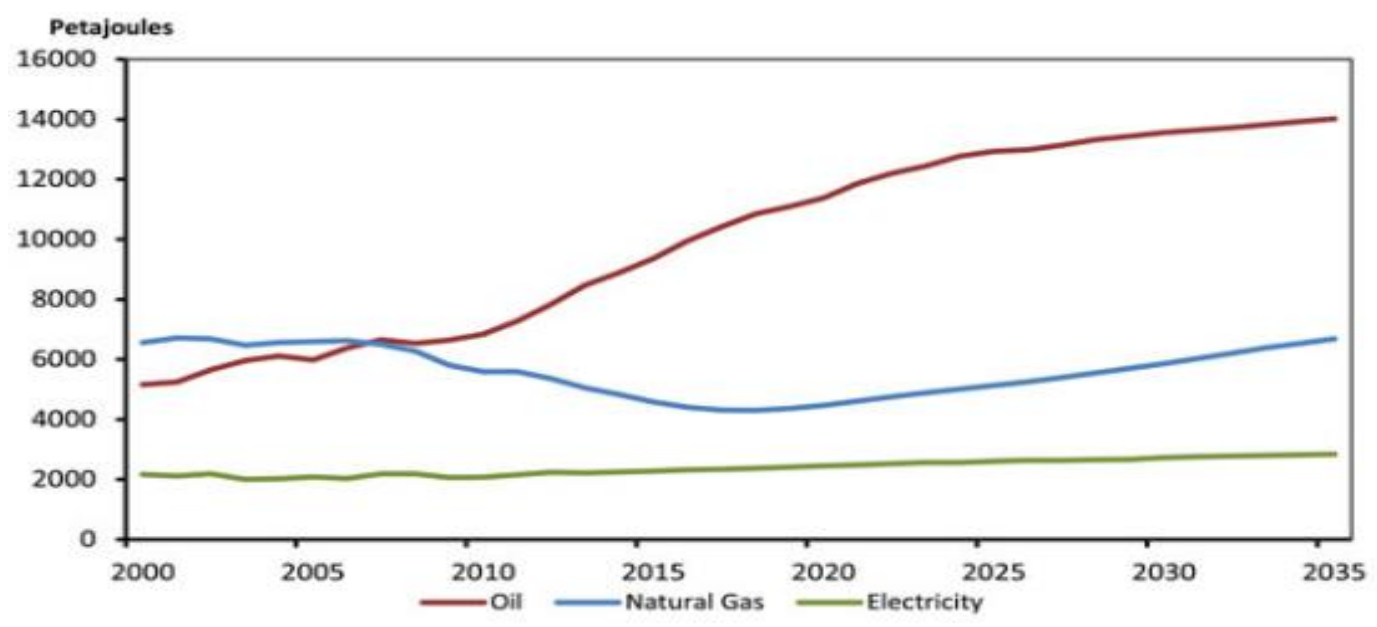

Figure 1.5: Energy production in Canada [7]

In this thesis, natural gas consumption of Small and Medium Enterprises in Canada will be thoroughly discussed.

\subsection{Benefits of Natural Gas Usage}

In industries, natural gas is one of the most popular sources of energy. But recently, natural gas becomes a more popular source than electricity due to its low cost. According to the US Department of Energy [12], one cubic meter $\left(\mathrm{m}^{3}\right)$ of natural gas provides $37.3 \mathrm{MJ}$ of energy, whereas one kilowatt hour $(\mathrm{kWh})$ electricity provides 3.6 MJ of energy. That is, the energy content of natural gas is approximately 10 units greater than the electricity, yet the price of electricity is $30 \%$ greater than natural gas [12].

The best characteristic of natural gas is that it is environmentally friendly. It is mainly composed of methane, which emits less carbon emission after burning. In Ontario, the amount of carbon dioxide $\left(\mathrm{CO}_{2}\right)$ emission by burning natural gas is $1879 \mathrm{~g} / \mathrm{m}^{3}$ [13], which is $30 \%$ less than oil. Furthermore, it does not produce any smoke, smell or ash as it burns. It is due to these beneficial reasons, that natural gas is widely used in the residential and industrial buildings as a major source of energy.

\subsection{Energy Audit}

Energy audit is defined as the determination of energy use (where, when, why, how) and identification of potential saving opportunities. Energy audit is also known as energy assessment or energy study. Basically, energy audit companies or firms offer energy audits. Energy auditors 
lead the energy audit by collecting the utility bills and other required data (e.g., building height, operational hours and area) to conduct the analysis [12]. To improve the energy consumption in small and medium enterprises (SMEs) in Ontario, energy supplier companies are offering free energy audits to SMEs in order identify energy saving opportunities.

Depending on collected data and analysis, energy audits are typically one of two types. The first type of energy audit focuses on the whole building, for example, building envelops, operational hours and maintenance. The second type of energy audit focuses on the specific system, for example, lighting, heating, ventilation, and air-conditioning. In this thesis, the energy audit focused on ventilation systems of different powder coating and food industries in the GTA.

\subsubsection{Levels of Energy Audit}

According to the American Society of Heating, Refrigerating and Air-conditioning Engineers (ASHRAE), there are three levels of energy audit. Each level depends on the previous level and the complexity of the analysis. The cost of an audit increases with the progression of each level. The levels of energy audits are given below [12]:

Level 1: Site assessment or preliminary audit

Level 2: Energy survey and energy analysis audits

Level 3: Detailed analysis of capital - intensive modification audit

Site assessment or preliminary audit: The preliminary audit provides utility bill analysis and briefs site inspection.

Energy survey and energy analysis audit: Level 2 provides detailed analysis of energy cost, usage and building characteristics.

Detailed analysis of capital-intensive modification audit: Level 3 includes all previous levels. It provides site inspection, data collection and engineering analysis. This thesis focuses on level 2 energy audits.

\subsection{Enbridge Gas Distribution Incorporation's Demand Side Management Program}

Enbridge Gas Distribution Incorporation's Demand Side Management (DSM) program is designed for industrial clients. It provides energy solution and energy assessment in order to 
adopt the best practice, strategy, and equipment to reduce energy consumption. The main purposes of Enbridge's DSM program are [14]:

Identifying the greatest cost savings of natural gas

$>$ Preventing lost opportunities

$>$ Providing deep energy savings

Small and medium enterprises are more interested in production and quality rather than the energy efficiency program. Therefore, Enbridge Demand Side Management program arranges free energy audits to small and medium enterprises in order to identify energy saving opportunities. The energy audit includes energy assessment, analysis and business case development.

\subsection{Small and Medium Enterprises (SMEs)}

Recently, SMEs are playing an important role in world business sectors. $90 \%$ of the world's businesses are classified as small and medium enterprises and $50 \%$ to $60 \%$ of employment opportunities are provided by SMEs [15]. Notably, most of them are not concerned about their energy consumption. According to the European Commission report in 2008, more than half of European SMEs (63\%) do not have a simple device for energy savings and only $4 \%$ have comprehensive energy efficient systems; $29 \%$ have some resources to maintain the energy consumption [16]. According to Cagno [17], almost 99\% of Italy's industries are small and medium enterprises and they are consuming more than $60 \%$ of the total domestic industrial energy. The same condition is happening all over the world.

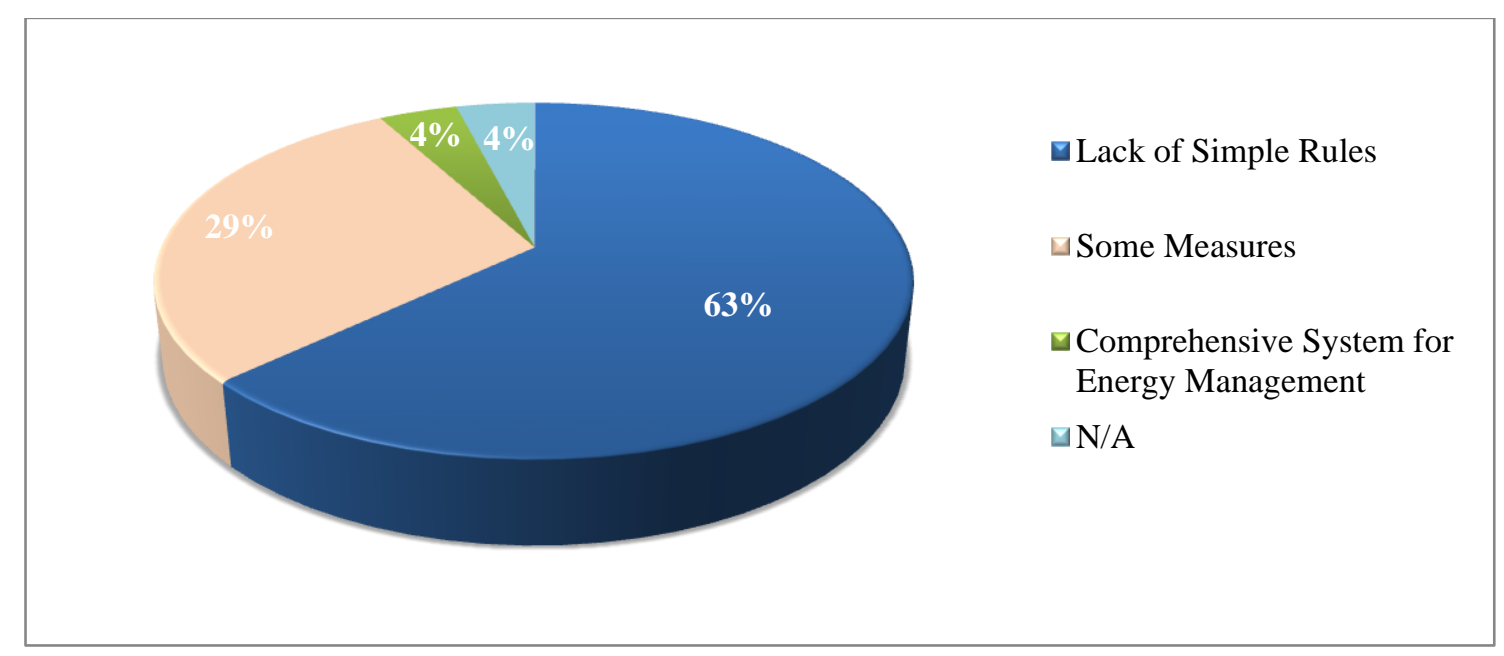

Figure 1.6: Energy efficiency in SMEs (Europe) [16] 
Figure 1.6 depicts that most industries are not energy efficient due to the lack of concern and proper equipment. 63\% of SMEs in Europe do not have simple rules for energy efficiency, $29 \%$ have some measures, and only $4 \%$ have comprehensive energy management tools. Therefore, there is a great potential to apply energy management in SMEs. Realizing this current situation, Enbridge Gas Distribution Inc. in Toronto, Canada arranged energy audits for different small and medium enterprises in the GTA to identify energy saving potentials. In this thesis, energy benchmarking and ventilation analysis were conducted in order to determine energy saving opportunities in industrial plants.

\subsection{Energy Benchmarking}

Energy benchmarking is defined as the identification of inefficiencies in using energy, potential savings, and further improvement of energy consumption for residential or industrial buildings based on the best practices of similar type of buildings. The basic properties of energy benchmarking processes are physically realizable, highly-energy efficient and comparable [18].

\subsection{Ventilation}

Ventilation systems are responsible for providing a comfortable environment for the occupants inside the building. In the case of industrial buildings, the ventilation system is not only used to provide a comfortable environment for occupants, but also used for maintaining safe operations for different processes. However, it is one of the most overlooked areas in terms of energy consumption. There are several possibilities to reduce the energy consumption at minimum cost within the shortest payback period [19].

\subsection{Purpose of this Project}

The main purpose of this thesis was to develop an energy roadmap for the small and medium enterprises and to compare their energy consumption pattern with similar types of industries. Another objective was to make the plant managers aware of their energy consumption, in order to increase the energy efficiency of the facility. Ventilation analysis was also conducted here to identify energy saving opportunities. This project was divided into the following steps:

Target industries were selected in the Greater Toronto area for energy benchmarking. 
Utility bills were collected from the selected industrial partners of Enbridge Gas Distribution Inc. and the pre-benchmarking analysis was conducted in order to have an initial picture of energy consumption patterns.

$>$ The energy audit was arranged in the selected industries with a small group of energy auditors (3-4 Ryerson students and an Energy Solution Consultant from Enbridge) for the purpose of collecting essential data.

$>$ After gathering all required data, benchmarking analysis and ventilation load analysis were conducted to identify energy saving potentials.

At the end, a comparison with similar types of industries was done to determine the natural gas (NG) consumption conditions of industries.

\subsection{Structure of the Thesis}

This thesis is organized into the following six chapters:

Chapter 1: Introduction and background of research and outline of overall research objectives.

Chapter 2: Brief literature review on energy benchmarking, ventilation analysis, and developed calculating tool for energy benchmarking.

Chapter 3: Methodology, analysis and results for weather normalization of natural gas consumption.

Chapter 4: Proposed methodology for energy benchmarking of normalized NG consumption, ventilation related natural gas consumption potential saving analysis.

Chapter 5: Result and Discussion on energy benchmarking and potential saving analysis.

Chapter 6: Conclusions and limitations of the thesis. 


\section{Chapter 2 \\ Literature Review}

Recently, natural gas conservation has become a concern for modern society. To ensure proper usage of natural gas, different research projects, audits, and case studies were conducted at different times for different industries and residential buildings. Additionally, to make industrial audits easier and more convenient, different tools were established by different auditors or companies. In this chapter, a literature review is presented on industrial energy benchmarking practices, current calculating tools, and probable energy saving opportunities in ventilation energy conservation.

\subsection{Energy Benchmarking}

Benchmarking is referred to the technique that is "characterized by the systematic search for efficient procedures and better solutions to complicated problems and processes" [20]. Benchmarking was originated in military logistics and assembly lines in 1979, however, it is now widely used in the industrial sector. The main purpose of energy benchmarking is to establish the best practice for industries and for those who lack these criteria to educate themselves and to accept the best practice for their institutions [21].

According to Kinney [22], "energy benchmarking of a building provides, the relative comparison of energy use of whole building with respect to a set of similar building". Energy benchmarking contributes an idea to target buildings for energy auditing and measuring energy saving potentials. Energy suppliers and their distributers compare energy saving potential with "typical" and "best practice" benchmarks. Both building managers and energy suppliers are always interested in comparing their energy performances with each other [22]. Benchmarking is also an excellent analytical tool to provide information about energy consumption along with the production capacity of different sectors. The benchmarking method can be used to measure the sectorial energy efficiency all over the country, as well as the world [23].

To determine the energy efficiency of industrial buildings, energy indicator or energy benchmarking is widely used. Energy benchmarking helps energy auditors understand energy consuming patterns of buildings with energy saving potentials. It also contributes to improve the 
energy economy. Energy benchmarking of an industrial building measures energy consumption of a plant against the standard one [18].

The benchmarking method in industrial sector was introduced by the petroleum refining and petrochemical industry for evaluating consumption in an individual plant. Energy Intensity Index (EII) method was utilized in petrochemical industry to find energy saving potentials [3]. The energy consumption benchmark is defined as the total energy standard of the plant, and EII is the comparison between benchmark energy consumption and the actual energy consumption [24]. In energy provider companies, energy saving potentials is known as "best-practice" benchmarks. Energy benchmarking is used in different sectors, for example residential premises, industries, schools and hospital buildings to compare their energy patterns with one another [23].

\subsection{Energy Benchmarking Practices}

Different energy benchmarking studies have been conducted in various places at different times. The process and effectiveness of those programs were thoroughly studied in order to find gaps and future research opportunities.

\subsubsection{Green Energy Management Program Singapore}

The Green Energy Management Program in Singapore was conducted by $\mathrm{Wu}$ [25] in hotel buildings. Hotel buildings are considered one of the most energy intensive types of buildings. In Singapore, a national survey was carried out for 103 gazette hotels, which included three stars, four stars, and five star hotels. Different fuel consumptions, building physical and operational characteristics, and other related information were gathered to determine energy consumption trends of buildings [25]. Regression based benchmarking analysis was conducted, and potential energy saving opportunities were determined. At the end, the Green Energy Management Program was successful at reducing the annual electricity consumption by 8 million

and resulted yearly savings of \$1 million (Singapore Dollar) [25]. The study showed regression based energy benchmarking is a suitable method to identify energy saving opportunities. 


\subsubsection{Energy Efficiency Programs for Swedish SMEs}

The first energy efficiency program in Sweden was conducted in 1994. A voluntary energy audit program EKO Energy ran from 1994 to 1997 and audited seventy energy intensive companies [26]. A second energy efficiency program began in 2005 named PFE, and third, Project Highland, ran from 2003 to 2009. In 2009, after understanding the importance and benefits of energy management programs, a Swedish Government Bill was proposed to establish a national energy benchmarking program for small and medium enterprises. To develop this program, a group of national energy efficiency specialists were gathered, and it was decided that the companies who used more than $500 \mathrm{MWh}$ of energy per year will be a target company and a walk-through audit would be performed. The primary goal of the program was to gather 900 companies' energy audits within 2010 to 2014 and to save 700 to $1400 \mathrm{GWh}$ of energy annually. Due to the high volume of audits the project was extended until 2020 [26].

\subsubsection{Denmark Energy Efficiency Agreement}

The Denmark Energy Efficiency Agreement was established in 1996 by the Danish Parliament. The purpose of this agreement was to reduce total energy consumption and related Greenhouse Gas (GHG) emission of the country. From 1996 to 2001 almost 300 companies in Denmark signed the agreement. Together, they consumed approximately $60 \%$ of the country's total industrial energy consumption. According to the agreement, the companies were bound to adopt all energy efficient projects with a four year payback period. In order to identify energy saving opportunities, energy audits were conducted at selected companies. These energy audits introduced energy management practices to the companies and made company managers more aware of new energy efficient equipment. The Danish government subsidized 30\%-50\% of the cost of these energy audits. After three years from the start of agreement, the country was able to reduce their total energy consumption by $9 \%$. This success expedited the adoption of more energy efficient measures for the country and encouraged companies to adopt energy efficient measures [27]. 


\subsubsection{Netherlands: Long Term Agreements and Energy Benchmarking Contract}

The long term agreement (LTA) in Netherlands was between the Dutch Ministry and industrial sectors in 1992 [27]. The purpose of the agreement was to reduce energy consumption by $20 \%$ from 1992 to 2000 . Almost 1000 industries signed this agreement and energy audits were conducted. According to the agreement, all of these industries adopted all energy saving projects with a three year payback period. The agreement ended in 2000 with $22.3 \%$ improvement in energy efficiency. The program also helped industries to focus on energy efficiency opportunities. The calculated cost reduction of the program was $\$ 10$ per ton of carbon dioxide [27].

Monitoring the success of the LTA program, the Dutch Government introduced the LTA2 program for small and medium enterprises. The LTA-2 program ran from 2000 to 2012. The LTA-2 program was different from the LTA program. In the LTA program, agreement was signed between the ministry and sectors but, in LTA-2 program agreement was signed between individual business and accomplished authorities. Based on an independent research assessment, target companies energy potential opportunities were evaluated. Within 2005, 34 sectors and 905 companies joined the program. Industrial companies achieved $19.1 \%$ energy efficiency in comparison to 1998 energy consumption and reduced $2.8 \mathrm{Mt} \mathrm{CO}_{2} \mathrm{eq}$.

The Dutch Government also introduced an Energy Benchmark Covenant Program for large energy intensive industries. Companies who used 0.5 petajoule or more energy per year were the target for this agreement. A total of 232 facilities, 6 power generation companies, and 97 industrial companies joined the program. It was expected that the program would have saved $94 \mathrm{PJ}$ of energy and 5.8 $\mathrm{Mt} \mathrm{CO}_{2}$ emissions by 2012 [27].

\subsubsection{Energy Start Portfolio Manager}

The ENERGY STAR program began in 1992 as an elective program by the U.S Environmental Protection Agency (EPA). The purpose of this program was to help facility owners save on energy costs and protect the environment by having facilities with greater energy efficiencies [28]. 
The Energy Star Portfolio Manager is a calculating tool. It estimates facility consumption and scores it from 1 to 100 . It also presents energy performances of facilities in a bell curve and indicates the position where the plant falls on the energy efficiency curve. In this calculating tool, energy performances are divided into three percentiles. If the score of building is more than 75 , then it is considered that the facility is in top $25^{\text {th }}$ percentile. The tool was developed based on the statistical regression analysis using independent variable data of thousands of buildings. A large volume of data set is already stored in the tool. Therefore, the individual facility can easily benchmark its performance with respect to the stored dataset. Another advantage of this calculating tool is that, data input is flexible; that is, if the exact data is not available then users can use default data set stored in the tool and score their facility. The most important thing is that the calculating tool is public (free to access by everyone). Due to this reasons, Energy Star Portfolio Manager has become a very popular calculating tool to evaluate building performances.

The Energy Star Portfolio manager was administered by the U.S. until May 2013. According to 2003 report, the bell curve of Energy Star Portfolio Manager was used to generate scores based on thousands of the U.S. buildings' dataset. The tool was established based on U.S. building data, but it was suitable to benchmark hundreds of Canadian buildings. The Natural Resource Canada launched a Canadian version of the ENERGY Star Portfolio Manager in 2013. However, the tool can provide scores only for office buildings and k-12 schools [28].

\subsubsection{Real Property Association of Canada's Energy Benchmarking Program}

Energy Benchmarking Program of the Real Property Association of Canadas was introduced in September, 2009. The association collaborated with the Canada Green Building Council (CaGBC) and the Building Owners and Managers Association of Canada (BOMA Canada). The purpose of this program was to reduce energy use to "20 equivalent kilowatt-hours of total energy use per square foot of building area per year (20 ekWh/ $\mathrm{ft}^{2} /$ year) for office buildings" [29]. The program is also known as "20 by 15". The REAL Pac developed a calculating tool to determine the energy consumption trend of real estate industries in Canada. The calculating tool was launched in summer 2010, which was established based on the normalized energy consumption and was standardized based on building gross floor areas, different heating powers, occupant densities, vacancies and operational hours. The purpose of 
using normalized energy consumption, was to identify a more meaningful and robust energy consumption picture of Canadian buildings.

In 2009, the first energy benchmarking survey was conducted of residential buildings to establish a baseline for residential buildings' energy use in Canada. The established baseline for residential building attracted peoples' attention to reduce energy consumption and save money. Understanding the growing interest and importance of benchmarking program, REAL Pac decided to collect data annually for upgrading the data set of the calculating tool. Currently, REAL Pac has three year's of data sets to compare building performances to [29].

\subsection{Case Studies on Energy Auditing Programs and Developed Calculating Tools}

Energy benchmarking has become a popular calculating tool in recent time. Different case studies were conducted in the various countries in various times.

A case study was conducted in 23 Dutch paper mills to benchmark energy consumption in similar processes in various paper mills [3]. Tremendous amount of energy is required to produce paper and board. In 2005, paper and pulp industries are responsible for consuming $6 \%$ of the total world's energy [30]. To solve this issue, an energy benchmarking program was introduced in Dutch paper mills and the best practice energy consumption in this sector was determined to be a maximum of 5.4 petajoule per year [3].

Another case study was conducted by Mohammad in a Jordanian pharmaceutical industry in 2012 [31]. The main purpose of the study was to develop an energy conserving model for Jordanian pharmaceutical industries. Another purpose was to provide recommendations for improvement of energy saving opportunities. To proceed in the study, an energy audit was conducted to collect all required data and a simulation method was used to analyze. The hourly data analyzing program, carrier HAP 4.41 was used to calculate energy saving opportunities. In this study, $6608 \mathrm{kWh}$ per year of energy savings was estimated using a simulation retrofit method [31].

Kabir [32] conducted energy auditing in Portland cement production plants in north-east Nigeria. Generally, cement production is energy intensive and expensive. The energy cost for cement production is considered to range from $40 \%$ to $60 \%$ of the total production cost. To 
produce one ton of cement, $2.9 \mathrm{GJ}$ of energy is required for modern faciliy and 5.5 GJ of energy is required for old facilities. Therefore, it seems that, an enormous amount of energy is required for cement production. Considering the situation, an energy audit was conducted to determine significant heat loss from equipment and other major heat consuming segments of the plant. In this study, the primary focus was on dry process kiln system. The thermal energy audit was conducted and concluded that 5.30 MW per year of power savings that was equal to $10.4 \%$ of total input energy and cost for this amount of energy was US \$2318.18 per year [32].

A joint energy audit program was conducted in Mexico by the students of the University of Missouri-Rolla (UMR) and Universidad Autonoma Metropolitana-Izdapalapa (UMAI) in 1998 [33]. This international exchange audit was conducted to determine the potentiality of technology transfer. This program was sponsored by the U.S Department of Energy Office of Industrial Technologies (IAC-DOE) program. An automotive industry in Mexico was selected to conduct the first energy audit, and the second audit was at a paper industry. A detail energy audit was carried out in these two industries from September 1997 to October 1997; billing period and major energy consuming sectors were determined. Air compressors, lightings, and motors were considered to be major energy consuming items for both industries. The project concluded by determining the cost for energy to have been $\$ 12.32 / \mathrm{MMBtu}$, the demand for the selected period was $\$ 38.06 / \mathrm{kW}$, and the average simple payback period was 14 months [33].

An energy audit case study was conducted in Titan America in 2009 [34]. The program was carried out to assess monthly productions, energy conservation equipments, and utility bills. The program consisted of 2 cement plants, 5 cement distribution terminals, 102 ready mixed concrete plants, 7 concrete block plants, 6 fly ash separation plant, and 4 aggregate plants. Energy audit was conducted and energy saving potentials were determined. The program was a success, considering it resulted in $99 \%$ of the audited facilities obtaining the ENERGY STAR label [34].

RETSCREEN is a unique software to calculate energy consumption, costs, savings, GHG emissions and financial viabilities. The software is suitable for both residential and industrial buildings. In a case study, RETSCREEN was used by Lalita [35] to analyze the energy consumption in the laboratory for lightings, fans, and computers. After analyzing the equipment, 
it was found that the proper and efficient equipment can save $32.2 \%$ of energy consumption with 8.3 years of payback period [35].

An energy balance calculating tool was developed by Lailhacar [36] in Florida. The software provides Graphical User Interface (GUI) which makes data entering easier, with a smaller chance of error. The software is able to evaluate potential energy savings and to provide recommendations. This graphical user interface based software is known as Interactive Energy Balance program (IEB); it was developed by using Microsoft Access and Visual Basic. The developed software was used to analyze 340 different companies' data collected by the University of Florida Industrial Assessment Center (UF-IAC). The developed software is used "to combine the energy data into a single application database and analyzed the cost savings for different energy efficient projects" [36]. IEB can easily calculate the electricity consumption, natural gas, propane and fuel oil. In the case study, IEB was used to calculate electrical consumption and related savings for 340 facilities in Florida and identified opportunities that could result in $20 \%$ - $40 \%$ energy savings [36]. The IEB software was designed, based on six categories of the building such as, lighting, air conditioning, motors, air compressors, and chillers and miscellaneous. The initial required data for IEB is monthly utility bills. Based on the input data, IEB performs analyses and presents average energy costs, demand costs, and other savings and recommendations [36].

Another calculating tool was developed by Hasimah [37] in Malaysia to calculate the electrical energy consumption in small and medium enterprises. The computing tool was developed using Microsoft Visual Basic. The software was used to evaluate motor transformers, lightings, cable sizings, air-conditioning, and power factors improvement and determind the energy saving opportunities. The software is also suitable for considering the benefits and tradeoffs of capital costs, operating costs, and payback period. The software was named as "Energy Audit Program". The software was divided into 5 menu categories: the introduction to energy audit program, tariff information, project analysis, website link, and exit [37].

Computer based simulation energy audit was conducted by Zhu [38] in Florida. A simulation software eQuest was used to promote a "virtual environment" to evaluate building HVAC systems and lighting systems. The software eQuest was developed by $\mathrm{DOE}_{2}$.com, which 
is a sophisticated and user friendly software and gives reliable results. A case study was conducted in a high rise tower (25 storied), midrise tower (12 storied) and a historic Rich's department store named 1924. Geometric models of buildings were created to perform building energy simulations and characterized building specifications. Then energy intensity of buildings were determined and scored based on the ENERGY STAR ranking range [38].

\subsection{Energy Conservation Opportunities in Industrial Ventilation System}

To provide a comfortable working environment for employees of industries, ventilation system is one of the key points. It maintains safe indoor air quality for stakeholders of the facility but, it is one of the most overlooked sectors in terms of energy consumption. However, there are several possibilities available to reduce energy consumptions at minimum cost within the shortest payback period [19]. The analysis examines, airflow pattern of the building, the air velocity and temperature, the global ventilation effectiveness, and air distribution effectiveness [39].

Due to reduced air conditioning energy consumption in sub-tropical climatic zones, engineers have adopted different practices to reduce outdoor ventilation and increase indoor set point temperature [40]. The reduction of outdoor ventilation and increase of indoor set point temperature creates "system-efficiency-bias" [40], which overlooks the healthy building environment. In the 1960's, the US Occupational Safety and Health Administration (OSHA), the US National Institute for Occupational Safety and Health (NIOSH), the American Conference of Governmental Industrial Hygienists (ACGIH), and the World Health Organization (WHO) identified Sick Building Syndrome (SBS) and that it is caused by "system-efficiency-bias" [41]. Therefore, ventilation plays an important role in maintaining building indoor air quality.

\subsection{Case Studies in Industrial Ventilation System}

A case study was conducted in a Toronto coffee industry by Bhattacharjee [19] in order to determine energy saving opportunities in ventilation systems. The industry had 3 make-up air (MUA) units that were equipped with natural gas-fired heaters and refrigeration compressors for cooling in summer. The MUA unit was used to operate $24 \mathrm{~h} / 7$ days a week. A decision was made to shut down the MUA unit on Sundays and to restart it on Mondays. Natural gas savings was calculated to be $52,363\left(\mathrm{~m}^{3} /\right.$ year $)$ by executing this approach [19]. 
Sorensen [42] measured heat transmission coefficient of buildings in Denmark using heat loss measuring device. To reduce energy use of buildings for heating or cooling purpose, heat transmission coefficient plays an important role. Heat loss measuring devices are known as $\mathrm{U}$ value meter. $\mathrm{U}$ value meters were developed to measure the heat transfer from walls, windows, and doors of buildings in units of Watt. The considered test building in this case study was built in 1964. The U-value for wood parapet was determined to be $1.44 \mathrm{~W} / \mathrm{m}^{2} \mathrm{~K}$, for outdoor wall next to window/door was $0.8 \mathrm{~W} / \mathrm{m}^{2} \mathrm{~K}$ and insulated outer wall was $0.32 \mathrm{~W} / \mathrm{m}^{2} \mathrm{~K}$. The $\mathrm{U}$ value meter was further used in Energy Technological Development and Demonstration Program for renovating buildings built in 1960s to 1970s [42].

A detailed study was conducted on air infiltration through building envelop by Younes [43] for evaluating techniques, models and quantifying the interaction of infiltration with different heat transfer conditions. According to ASHRAE, residential buildings infiltration loss should not compose more than $40 \%$ of the heating and cooling load, and for commercial buildings it should not be more than $15 \%$. In this case study, the air change method was used to calculate the infiltration loss of the building and air change per hour was calculated. Based on the results a decision was made that, if the average air change per hour ranges between 0.2-0.6 the building envelop is tight, if the range between $0.6-1.0$ then the building envelop is medium and if it ranges between 1.0-2.0 the building envelop is loose. Finally, different methods (e.g., Zonal model, CFD method) were studied to calculate the infiltration and heat recovery [43].

Ventilation rate was measured by Fletcher [44] in a small factory unit. Tracer gas technique was used in different units of the factory to measure the infiltration rate when mechanical ventilation was turned off. In this case dichlorodifluoromethane was used as tracer gas and was injected to the fan outlet. Wind speed was measured and infiltration rate was calculated. In this case the air change rate was proportional to the wind speed and the amount of air change rate per hour was $0.49-0.88$ [44].

Multiple regression analysis was conducted by Jia [45] to determine the effect of changing airflow in mine ventilation systems. In this case, using muliple regression analysis, air flow amount in major airways was explored and anlyzed [45]. 
Oner [46] used multiple regression analysis in Turkey to predict a model that reaches the ends of leaky ventilation duct in a simple mine ventilation system. The coefficient of predicted model $\mathrm{R}^{2}$ was calculated to be 0.93 that proves the validity of the model and t-test was also done to prove the validity. Using multiple regression analysis, an emperical equation was derived to determine the volume flow rate that reaches the end of leaky ventilation duct. In this case Minitab ${ }^{@ R}$ was used to conduct the multiple regression analysis and a relationship was found between duct size and volume flow rate [46].

An on demand ventilation system was adopted by Litomisky [47] in California. Usually, industries use classical/traditional ventilation system. Traditional ventilation system consists of a large central fan,a duct system to connect all the workstations, and it runs 24/7. A decision was made to implement the on demand ventilation system. An on demand ventilation system provides a sensor at each work station and detects the ventilation requirement. Motor operate gates are connected to the ventilation duct; gates and sensors are connected to a central computer and operates with the ventilation requirement. After implementing the on demand ventilation system in the facility, it was able to save 70,000 therms of natural gas per year [47].

Jones [48] conducted a joint frequency bin temperature analysis for calculating four different types of HVAC systems in four different cities in the USA. Two separate weather variables of dry bulb temperature and humidity ratio were used in this study. Using bin weather data, ventilation load Indexes were calculated. Ventilation Load Index is defined as "the annual capacity promoted by one cubic foot per minute of outdoor fresh air brought from the weather to the space neutral condition" [48]. Finally, ventilation load index was calculated using different bin weather data such as full load weather, joint bin, temperature bin and humidity bin and a comparison was made [48].

Dieckman [49] described thermal performances of the building by specifying wall and roof insulations. Wall and roof insulation U-values were changed in the past few decades to improve building thermal envelop. ASHRAE 90.1 specified standard U-values for wall and roof insulation based on climate characteristics. U-values for wall and roof in different cities in the USA was measured to determine the variation with different climatic zone. Seven cities were considered in this case from cold - humid to hot - dry weather conditions and U-values were 
determined. Figure 2.1 presents ASHRAE 90.1 standard maximum U-values for wall assembly and roof assembly for different cities in the USA. According to Figure 2.1 the U-values for wall and roof assembly decreased almost $30 \%$ during the time period [49].
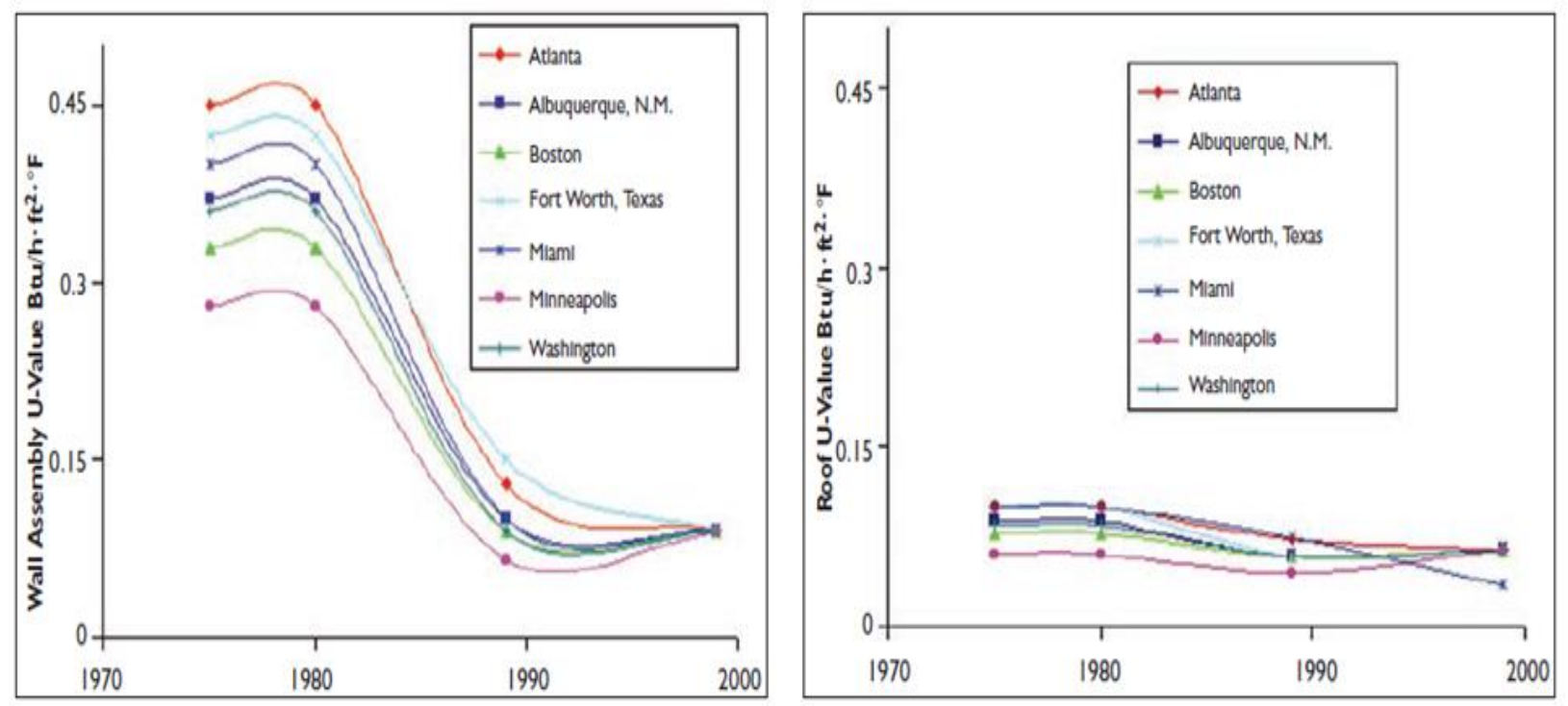

Figure 2.1: Maximum wall and roof assembly over time in different cities [49]

Kraljevska [50] studied the structure and insulation of Ontario buildings. The study was also conducted on the insulation thickness and thermal conductivity. It was shown that, proper insulation of building improves airtightness and reduces thermal bridge. The study was also conducted on different years' wall and roof insulation in Canadian houses to determine the change of insulation requirements and to identify the barriers and drivers that influences the setting of higher building envelop standards. Figure 2.2 presents the change of wall $U$ values in Canada from 1975 to 2006. According to Figure 2.2 the wall insulation in Canada has improved 50\% compared to 1975 data [50]. 


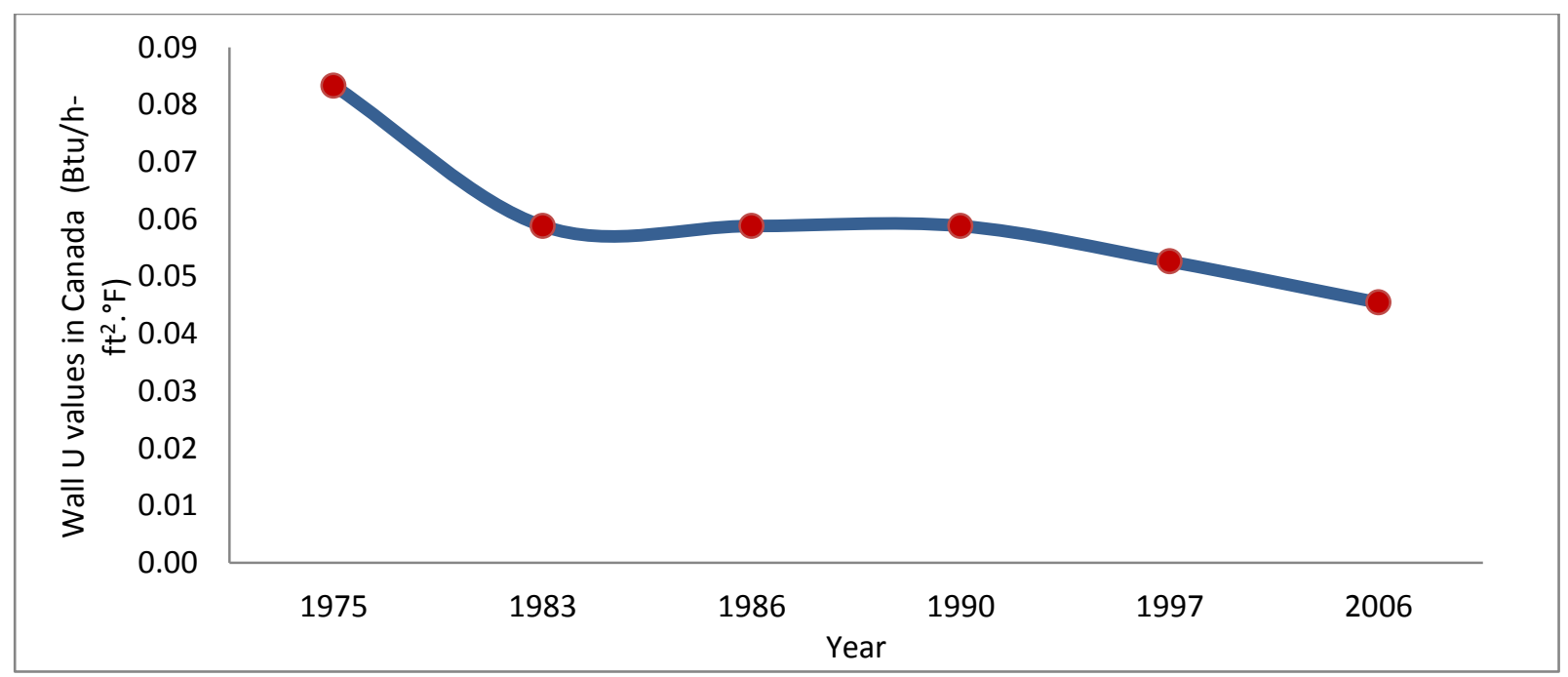

Figure 2.2: Change of wall insulation in Canada over time [50]

\subsection{The Significance of the Thesis}

Several research studies have been conducted on the Ontario industrial energy management sector. According to literature review eleven studies was found for Ontario small and medium sized enterprises. However, there are still opportunities to improve the industrial sector to make energy usage more efficient. From the literature review, it was found that few works have been done on energy benchmarking of small and medium-sized enterprises (SME) based industries in Ontario. Hence, a focused study is required in this sector in order to improve natural gas conservation. In addition, although several studies have been previously conducted on ventilation analysis of industrial facilities in Ontario, energy benchmarking based on ventilation energy consumption has not been reported so far. Therefore, to fill this gap, this thesis reports a detailed energy benchmarking that is based on ventilation energy consumption analysis of different audited industries in GTA.

In the meantime, different calculating tools have been reported for energy benchmarking analysis in different sectors and countries but the benchmarking calculating tool for the Ontario small and medium enterprises natural gas consumption has not been reported so far. To address this gap, a benchmarking calculating tool based on ventilation natural gas consumption was developed. 


\section{Chapter 3 \\ Weather Normalization}

Weather conditions have an influence on energy consumption because space heating is required in cold climate regions and space cooling is required in hot and tropical regions. In both cases, energy is required to maintain a comfortable indoor environment and for this reason, energy data analysis is strongly related with outside weather. If the weather is abnormal then it distorts the energy consumption trend and creates noise in energy data. Without adjusting energy data with weather conditions, it may provide erroneous results for any kind of energy analysis [51]. To develop an efficient HVAC system of a plant, it is necessary to conduct a proper energy analysis. There are several methods to conduct the energy analysis. The degree day method is one of the simplest methods to analyze building energy consumption. The degree days' value presents the energy demand of buildings for heating and cooling purpose. According to the degree day method, energy requirements of buildings are proportional to the difference between mean daily temperatures and reference temperatures [52]. The reference temperature of building is defined as the outdoor temperature when no heating and cooling is required. According to ASHRAE standards, the range of reference temperature is $50^{\circ} \mathrm{F}$ to $65^{\circ} \mathrm{F}$ [53].

Buyukalaca [52] used the degree day method to calculate heating and cooling degree days in Turkey. Long term weather data was used to find more accurate and reliable results. Elkhafiff [51] adjusted Ontario residential, commercial and industrial natural gas sales data with outside weather. A regression analysis was conducted to determine the effect of abnormal weather conditions on sales of natural gas. The conclusion of the study was that the sales of natural gas in industrial sector have the least influence from abnormal weather condition. Huang [54] conducted weather normalization analysis using PRISM software for benchmarking high rise multi-unit residential buildings in Toronto. PRISM is a regression-based software tool that used to calculate building normalized energy consumption [55]. The degree day method was also used by Joseph [56] to calculate normalized annual consumption of two office buildings in the United States of America. Building energy simulation model was developed to normalize the actual consumption with respect to the long term weather data. 


\subsection{Heating Degree Days and Cooling Degree Days}

According to the Natural Resources Canada, Canada is a cold climate country. Almost eight to nine months of the year is cold in Canada and space heating is required to maintain proper indoor air temperature. The term Heating Degree Day (HDD) plays an important role in the cold climatic zone [53]. The Heating Degree Day (HDD) can be defined as "the annual sum of the degree days of the average daily temperature for all days below $18{ }^{\circ} \mathrm{C}$ " [57]. HDD is calculated as a difference between the reference temperature $\left(18{ }^{\circ} \mathrm{C}\right)$ and the outside temperature.

According to mean yearly temperature index, the Heating Degree Days of Canada are divided into four climatic zones (see Figure 3.1). Among these four zones, Toronto is located in Zone ' $\mathrm{B}$ '. The division of these zones were done according to outside weather conditions of different regions. For example Zone ' $A$ ' is the mildest zone; on the other hand Zone ' $D$ ' is the coldest one.

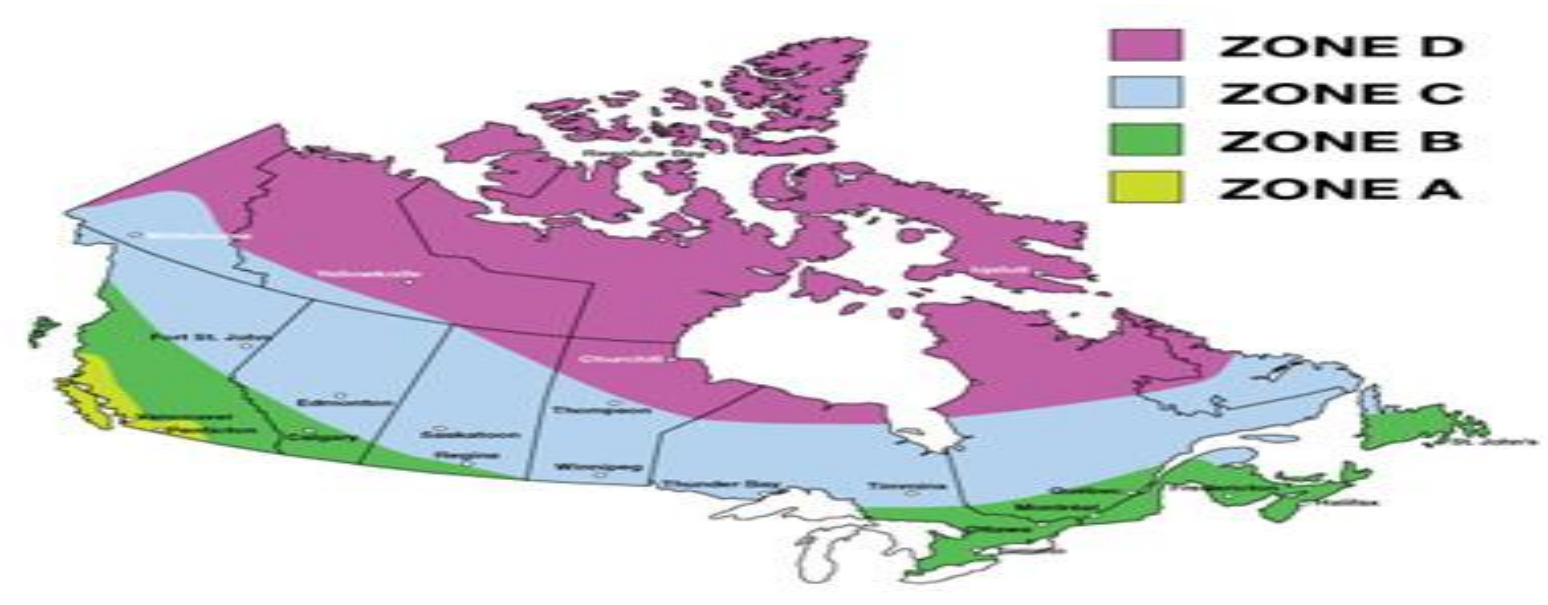

Figure 3.1: Map of Canada's climatic zone [58]

Zone 'A' has maximum 3500 HDD per year, Zone 'B' has 3500-5500 HDD per year, Zone ' $\mathrm{C}$ ' has 5500-8000 HDD per year and Zone 'D' has more than 8000 HDD per year. Figure 3.2 presents the trend of HDD in Toronto from 1990 to 2014 [58]. The coldest winter in Toronto was in 2013. 


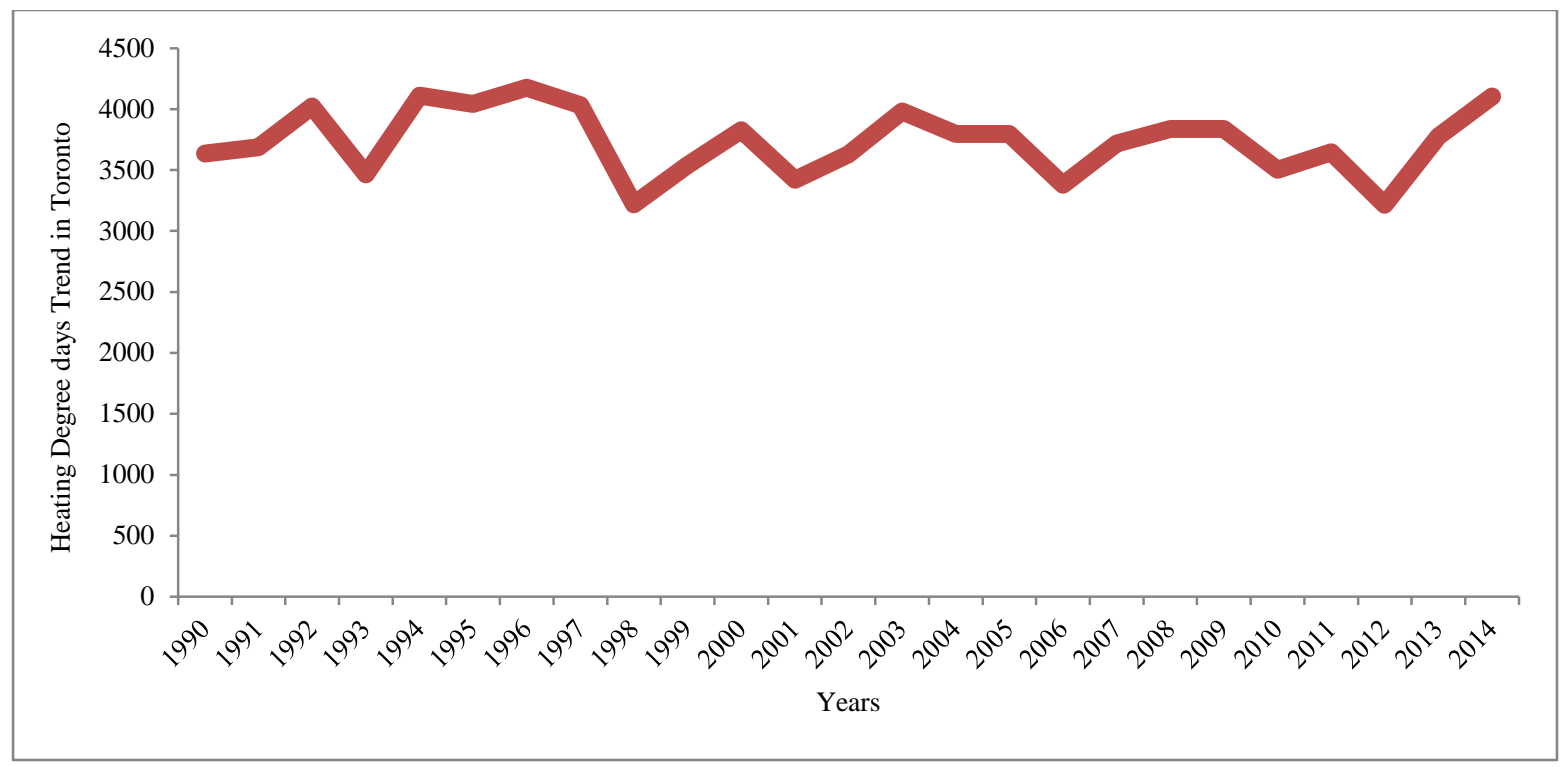

Figure 3.2: HDD trend of Toronto from 1990 to 2014 [58]

Similarly, Cooling Degree Day (CDD) is measured in summer time when the temperature goes up from the reference temperature $\left(18{ }^{\circ} \mathrm{C}\right)$. According to Natural Resources Canada, Only three months (June, July and August) in Canada are considered summer months. Based on Zone division, Toronto is located in Zone B and contains mild weather conditions. For this reason, CDD has similar importance as HDD in Toronto.

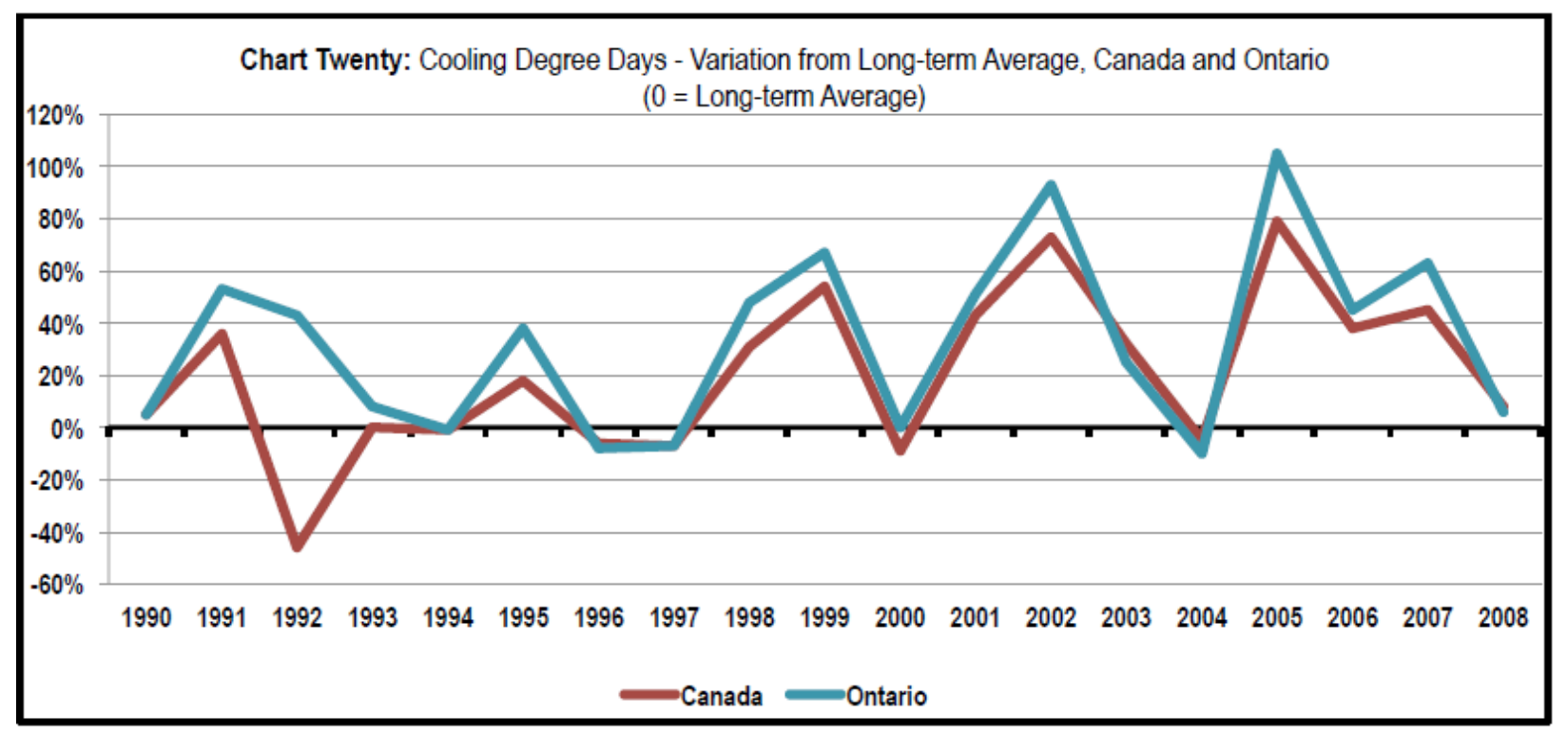

Figure 3.3: CDD trend of Canada and Ontario from 1990 to 2008 [58] 
According to Figure 3.3, 2005 was the hottest summer in the time period. Weather normalization was conducted in this study to estimate normalized NG consumption of facilities for seasonal natural gas consumption and conduct ventilation analysis more accurately.

\subsection{Methodology}

Weather normalization is defined as a process to estimate energy consumption based on the outside weather conditions [55]. Weather normalization gives a real picture of building performances in different weather conditions and provides comparison between plant energy use performances and weather conditions for different years.

\subsubsection{Heating Degree Days Analysis}

In this thesis, Heating Degree Days of plants were calculated using reference/base temperature method. In the method, the base temperature for heating degree days was calculated using trial and error method in Microsoft Excel. In this case, the correlations $\left(\mathrm{R}^{2}\right)$ between plants' monthly energy consumption and heating degree days (HDD) were used to define the best reference temperatures of plants. The reason to calculate reference temperature was that, the reference temperature varies from building to building for the setting temperature of thermostat. The base temperature also depends on building thermal insulation, air leakage and solar gain. So, considering constant reference temperature can mislead the analysis [52]. Equation 3.1 was used to calculate Heating Degree Days of plants using calculated reference temperature [52].

$H D D=\sum_{D A Y S}\left(T_{b}-T_{m}\right)^{+}$

Where,

$T_{m}=$ Daily mean temperature occurring in the month $\left({ }^{\circ} \mathrm{F}\right)$

$T_{b}=$ Base reference temperature $\left({ }^{\circ} \mathrm{F}\right)$

The plus sign in the equation means only the positive values will be considered. 


\subsubsection{Database for Temperature}

To conduct building energy analysis, it is important to collect accurate and reliable weather data which provides accuracy and reliable characteristics of the results. Long term weather data should be used to reduce the effect of distorted weather conditions on building energy analysis [52]. Monthly weather data (dry bulb temperature) was collected from the Environment Canada website. The data was collected based on the Toronto Pearson Weather Station. The location of the weather station is 4340'38.000" $\mathrm{N}$ latitude and 173.40 meter elevation. The WMO ID is 71624 [60].

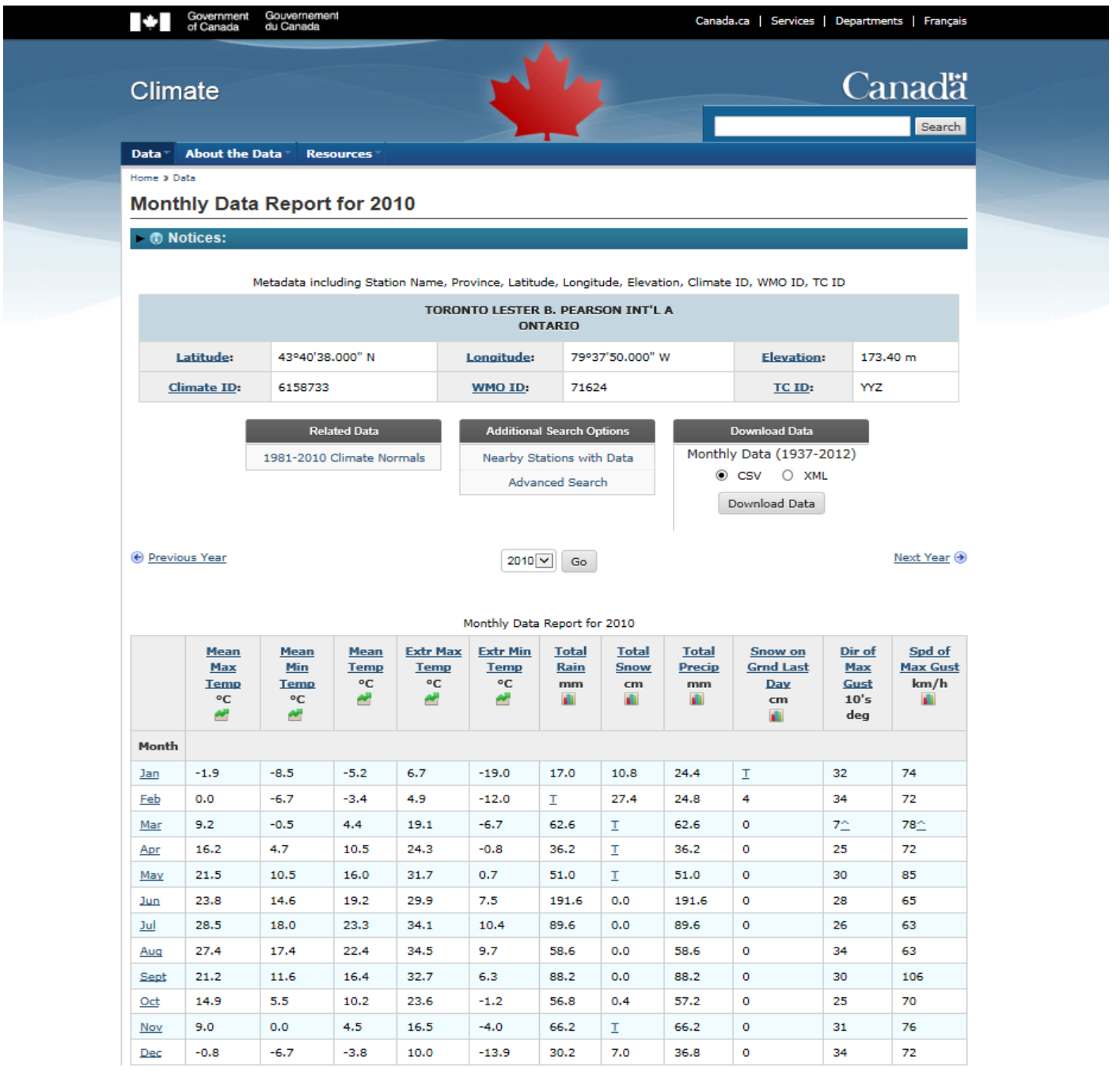

Figure 3.4: Monthly weather data of Toronto from Environment Canada website [60] 
Using Environment Canada website, long term weather data from 1983 to 2013 were collected. The average HDD were calculated based on long term weather data.

\subsubsection{Normalized Energy Consumption Analysis}

Based on outdoor temperature database and estimated reference temperature, normalized energy consumption was calculated. A simple regression analysis was conducted between monthly energy consumption and heating degree days using Microsoft Excel. Figure 3.5 presents the correlation between plant energy consumption and outside weather

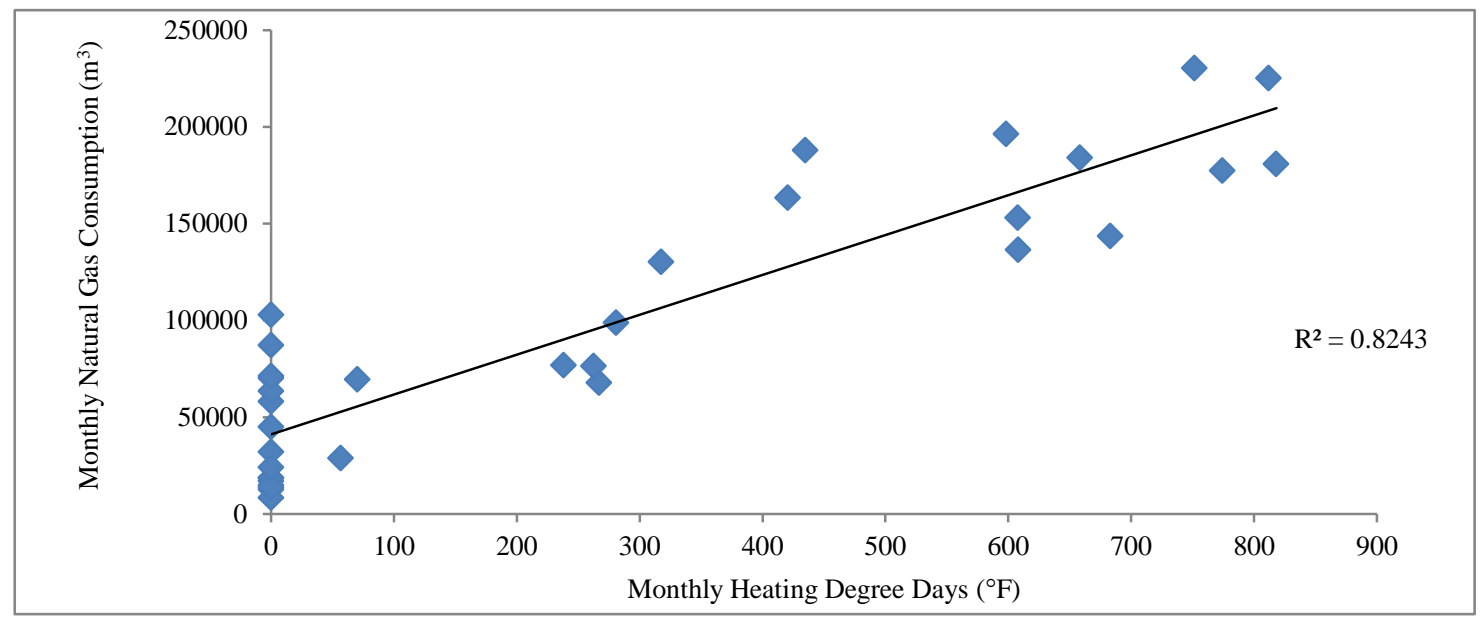

Figure 3.5 Statistical correlations between monthly natural gas consumption and HDD of plant AAD22

Then normalized annual energy consumption was calculated using Equation 3.2 [54].

$$
\mathrm{NAC}=365 \alpha+\delta_{h} \beta_{h} H_{o}\left(\tau_{h}\right)+\delta_{c} \beta_{c} C_{o}\left(\tau_{c}\right)
$$

Where,

$\alpha=$ Daily based load consumption

$\delta_{h}=1$ for HO (heating only) and HC (heating cooling) model in PRISM otherwise 0.

$\beta_{h}=$ Heating slope is equal to heat loss rate of the house

$\beta_{c}=$ Cooling slope is equal to heat gain rate of the house

$\delta_{c}=1$ for CO (cooling only) and HC (heating cooling) model in PRISM otherwise 0. 
$H_{o}\left(\tau_{h}\right)=$ Long term average heating degree days per year calculated by Microsoft Excel estimated reference temperature $\tau_{h}$

$C_{o}\left(\tau_{c}\right)=$ Long term average cooling degree days per year calculated by Microsoft Excel estimated reference temperature $\tau_{c}$

Equation 3.2 can be written as

$\mathrm{NAC}=$ Process consumption + Seasonal consumption

\subsection{Results}

The utility bills for different audited companies' were analyzed to determine reference temperatures. Table 3.1 presents the calculated reference temperature, HDD and normalized natural gas consumption of all audited facilities.

Table 3.1: Calculated reference temperature, HDD and normalized natural gas consumption of all audited facilities

\begin{tabular}{|c|c|c|c|c|c|c|}
\hline Company & $\begin{array}{c}\text { Reference } \\
\text { Temperature } \\
\left({ }^{\circ} \mathrm{F}\right)\end{array}$ & $\begin{array}{c}\text { Reference } \\
\text { Temperature } \\
\left({ }^{\circ} \mathrm{C}\right)\end{array}$ & $\begin{array}{c}\text { Statistical } \\
\text { co-relation } \\
\left(\mathrm{R}^{2}\right)\end{array}$ & $\begin{array}{c}\text { Calculated } \\
\text { HDD } \\
\left({ }^{\circ} \mathrm{F}-\text { day }\right)\end{array}$ & $\begin{array}{c}\text { Calculated } \\
\text { HDD } \\
\left({ }^{\circ} \mathrm{C}-\text { day }\right)\end{array}$ & $\begin{array}{c}\text { Normalized } \\
\text { Annual NG } \\
\text { Consumption } \\
\left(\mathrm{m}^{3}\right)\end{array}$ \\
\hline AAD78 & 60 & 16 & 0.78 & 5,626 & 3,126 & 958,063 \\
\hline AAD22 & 53 & 12 & 0.82 & 4,015 & 2,231 & $1,305,238$ \\
\hline AAAL & 65 & 18 & 0.70 & 7,861 & 4,367 & 580,121 \\
\hline AABN & 52 & 11 & 0.68 & 3,803 & 2,113 & 353,505 \\
\hline AAGF & 59 & 15 & 0.61 & 5,383 & 2,991 & $3,335,223$ \\
\hline AAKK & 60 & 16 & 0.89 & 5,626 & 3,126 & $1,020,934$ \\
\hline AAKK2 & 56 & 13 & 0.64 & 4,439 & 2,466 & 642,106 \\
\hline AAMP & 64 & 18 & 0.90 & 6,685 & 3,714 & 512,046 \\
\hline AASN & 57 & 14 & 0.42 & 4,897 & 2,721 & 544,373 \\
\hline AASU & 54 & 12 & 0.45 & 4,439 & 2,466 & 666,810 \\
\hline AASP & 69 & 21 & 0.88 & 4,227 & 2,348 & 369,742 \\
\hline AAWI & 55 & 13 & 0.65 & 8,164 & 4,536 & 297,987 \\
\hline AAWR & 65 & 18 & 0.50 & 6,685 & 3,714 & $1,049,464$ \\
\hline AAKI & 52 & 11 & 0.45 & 4,049 & 2,249 & $1,216,737$ \\
\hline
\end{tabular}

According to Table 3.1 average reference temperature from fourteen facilities was calculated $58^{\circ} \mathrm{F}$, average $\mathrm{HDD}$ was calculated $5,421^{\circ} \mathrm{F}$-day and average normalized natural gas 
consumption was calculated $918,025 \mathrm{~m}^{3} /$ year. In all analysis in this thesis, temperature was considered in ${ }^{\circ} \mathrm{F}$ and natural gas consumption was considered in $\mathrm{m}^{3}$. The reason is industrial plants and utility companies are using two different types of unit for their measurement. This thesis was conducted with real company data and the developed calculating tool is for real industries use. For those reason, two different types of unit was used here for industries convenience to use the calculating tool. Figure 3.6 presents calculated reference temperatures of plants using trial and error method in Microsoft Excel.

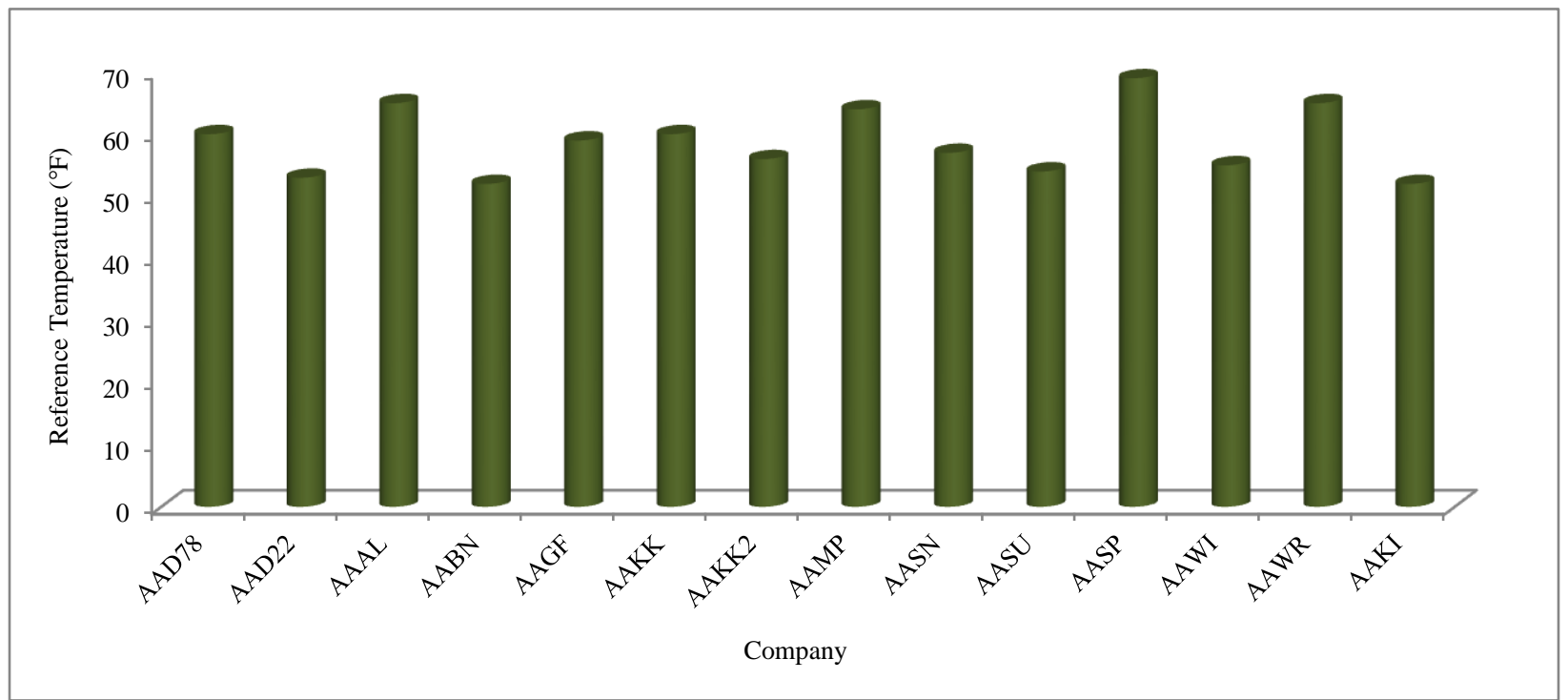

Figure 3.6: Calculated reference temperatures of selected companies

According to ASHRAE standard 55-2013, the range of reference temperature to maintain the thermal comfort inside residential buildings should be $50^{\circ} \mathrm{F}$ to $65^{\circ} \mathrm{F}$ depending on building insulation, relative humidity, clothing worn and season [53]. In this analysis, reference temperatures were calculated and ranged between $52^{\circ} \mathrm{F}$ to $73^{\circ} \mathrm{F}$. The calculated range of reference temperature is close to ASHRAE standard range.

After calculating reference temperatures, heating degree days of plants were calculated (shown in Appendix A) using the long term weather data. Due to variation of reference temperatures, annual heating degree days of plants were different even though they all located in GTA. 


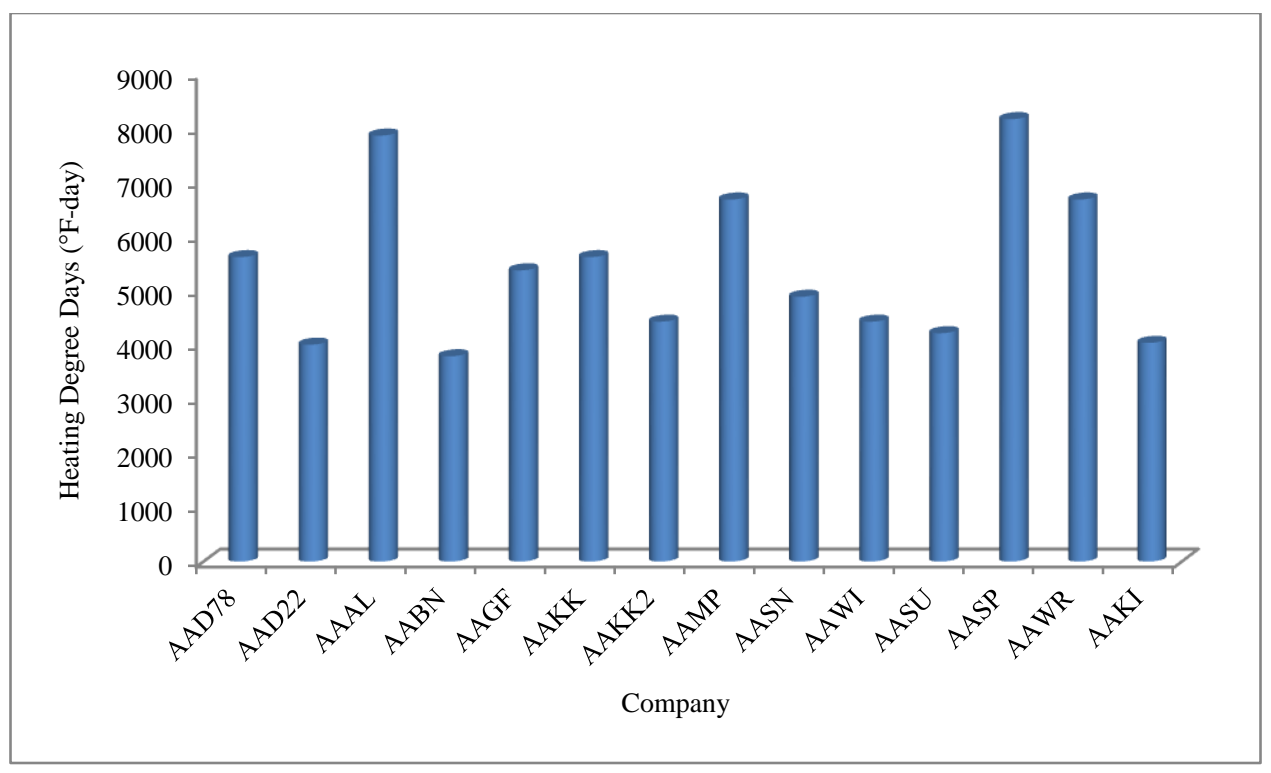

Figure 3.7: Annual heating degree days of plants

Figure 3.7 depicts the annual heating degree days of the selected plants. The calculated long term Heating Degree Days of plants ranged from 3800 to $8100{ }^{\circ} \mathrm{F}$ - day. Since Toronto is located in zone B and the range of HDD for Toronto is 6300 - 9900 [58], most of companies HDD fall between this ranges. After calculating HDD, it was plotted against plant monthly energy consumption to determine the statistical correlation between plant natural gas consumption and heating degree days.

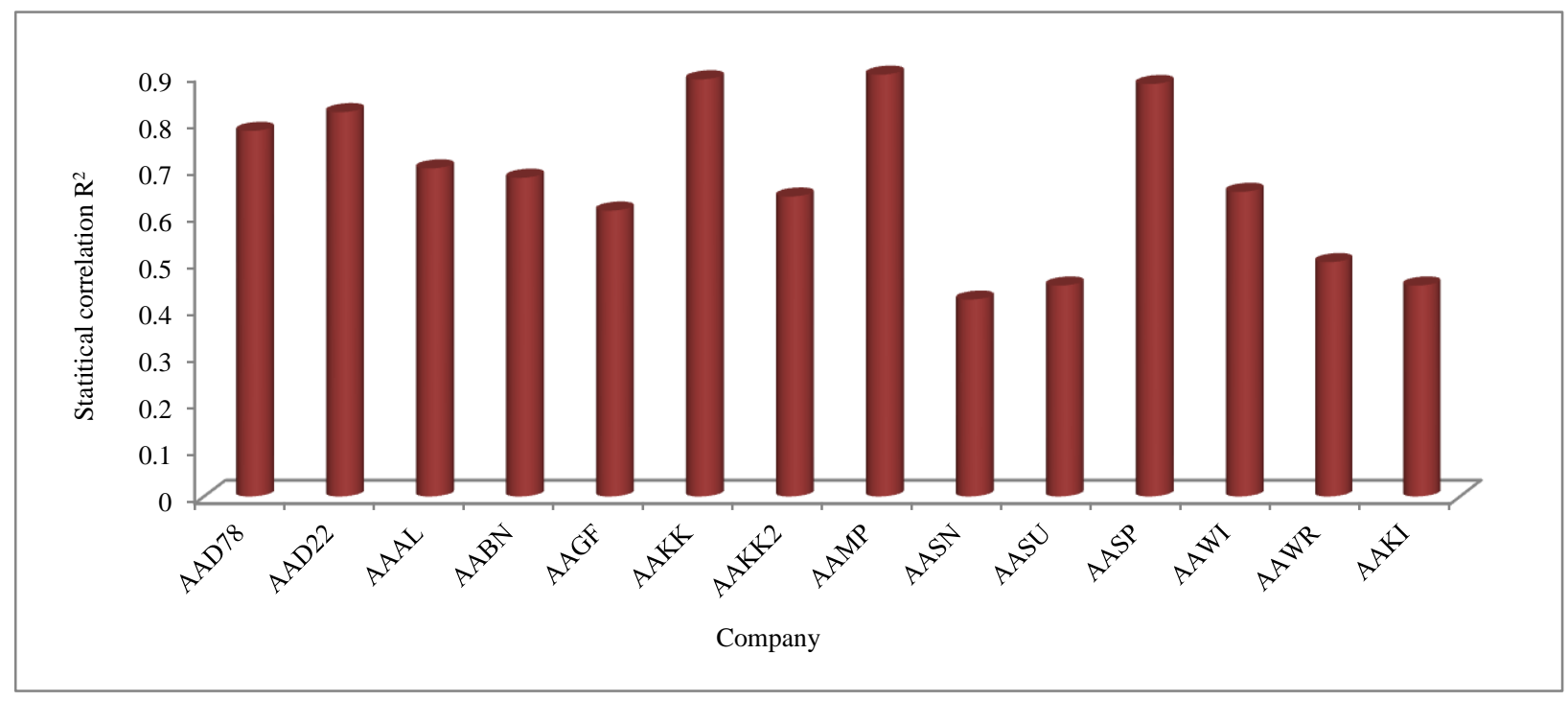

Figure 3.8: Statistical correlations between plant natural gas consumption and HDD for different companies 
Figure 3.8 presents statistical correlations between plant monthly natural gas consumption and heating degree days. According to Figure 3.8, the natural gas consumption of some companies' has strong statistical relationship with heating degree days and some companies did not have strong relationship. The reason of not having good statistical relation of those companies was that the natural gas consumption data for three complete years was not available. Finally plant normalized natural gas consumption was calculated (shown in Appendix B).

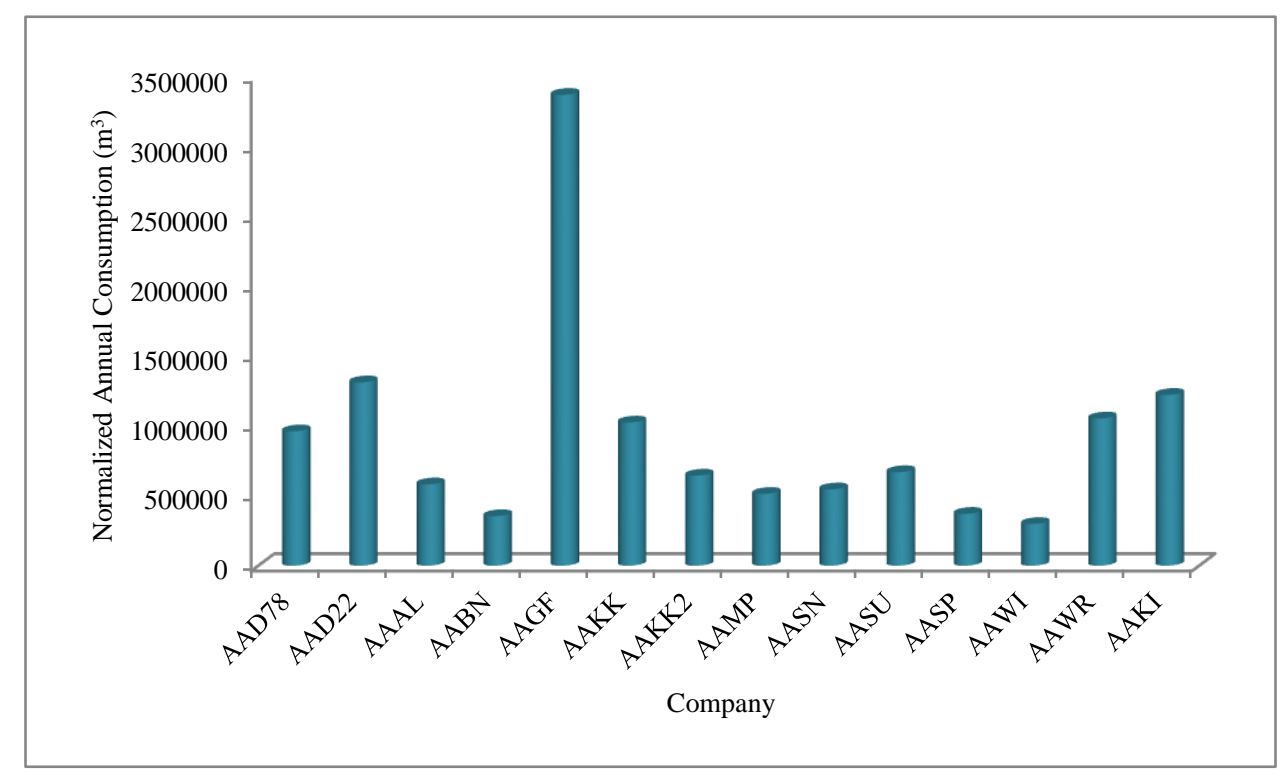

Figure 3.9: Normalized annual consumptions of companies

This calculated normalized natural gas consumption was used for further benchmarking analysis and ventilation analysis. 


\section{Chapter 4 \\ Methodology}

The proposed methodology was established based on data collection from energy audits conducted on small and medium enterprises in the Greater Toronto Area. A small group of energy auditors from Enbridge Gas Distribution Inc. and Ryerson University conducted the energy audit. An energy audit is defined as a planned and organized method for identifying opportunities to reduce the waste of energy in facilities and to implement energy conservation practices at a reasonable cost within a suitable time limit. Energy audit is the stepping stone for establishing an energy management program for facilities. An energy audit helps to identify the highest and lowest energy consuming portions of buildings and contributes ideas to reduce energy waste by implementing energy conservation practices. The proposed methodology is as follows:

> Performing weather normalization of plants' utility energy consumption

$>$ Conducting energy benchmarking of normalized energy consumption

$>$ Developing performance ranking of plants (identifying efficient and inefficient plants in the database) and determining potential savings.

$>$ Conducting ventilation analysis using multivariable regression analysis

$>$ Establishing ranking based distribution based on ventilation analysis and identifying potential saving opportunities from plant ventilation energy conservation.

\subsection{Data Collection}

Each building's utility bills were required to conduct the analysis. Enbridge Gas Distribution Inc. provided the utility bills and plant locations as initial data. To quantify energy use pattern and variation of seasonal energy consumption, a minimum of three years of utility bills were collected. For most of the companies, a set of monthly utility bills were provided. But for some companies hourly utility bills were provided; hourly utility bills give more opportunity to conduct detailed energy analysis. Due to confidentiality reasons of industrial data, a nondisclosure agreements (NDA) was signed. For this reason, utility bills of industrial plants were collected by the Enbridge Industrial Energy Consultant and were provided to the Ryerson 
students who were related to this project with identification information removed. The Ryerson students did not have authority to contact the companies/facility for data or any other information. Due to confidentiality, the sites in this study were referred by generic code names, i.e., AAAL, AABN, AAAM, etc.

After collecting the initial data, energy audits were conducted on selected sites to collect more detailed information of the plant. Enbridge Gas Distribution Inc.'s industrial energy consultant guided the team of energy auditors from Ryerson University. A small meeting was held in the facility with the plant manager in order to gain an idea about the plant's energy usage pattern, operational hours, and type of production. After that, major energy consuming end users of plants' were visited, and all the necessary data were gathered.

The thesis includes energy audits and potential energy saving analyses of fourteen audited industrial plants. The selected audited sites consisted of eight powder coating facilities, four food facilities, and two packaging facilitate. Among these fourteen industries, one powder coating industry did not have area, operational hour so ventilation analysis was not possible with that facility. So, first level multivariable regression analysis was conducted with thirteen facilities. In second level multivariable regression analysis, two powder coating industries' result was calculated negative so those two companies were eliminated in $2^{\text {nd }}$ level multivariable regression and ranking distribution and saving analysis was conducted with eleven audited industries.

The primary purpose of energy audits was to make the plant manager more aware of energy conservation and to adopt energy efficient practices. An energy audit report was submitted to the plant manager with detailed analysis of energy conservation opportunities and potential savings. 


\subsection{Energy Benchmarking of Normalized Energy Consumption}

Figure 4.1 demonstrates the proposed methodology for energy benchmarking of normalized natural gas consumption.

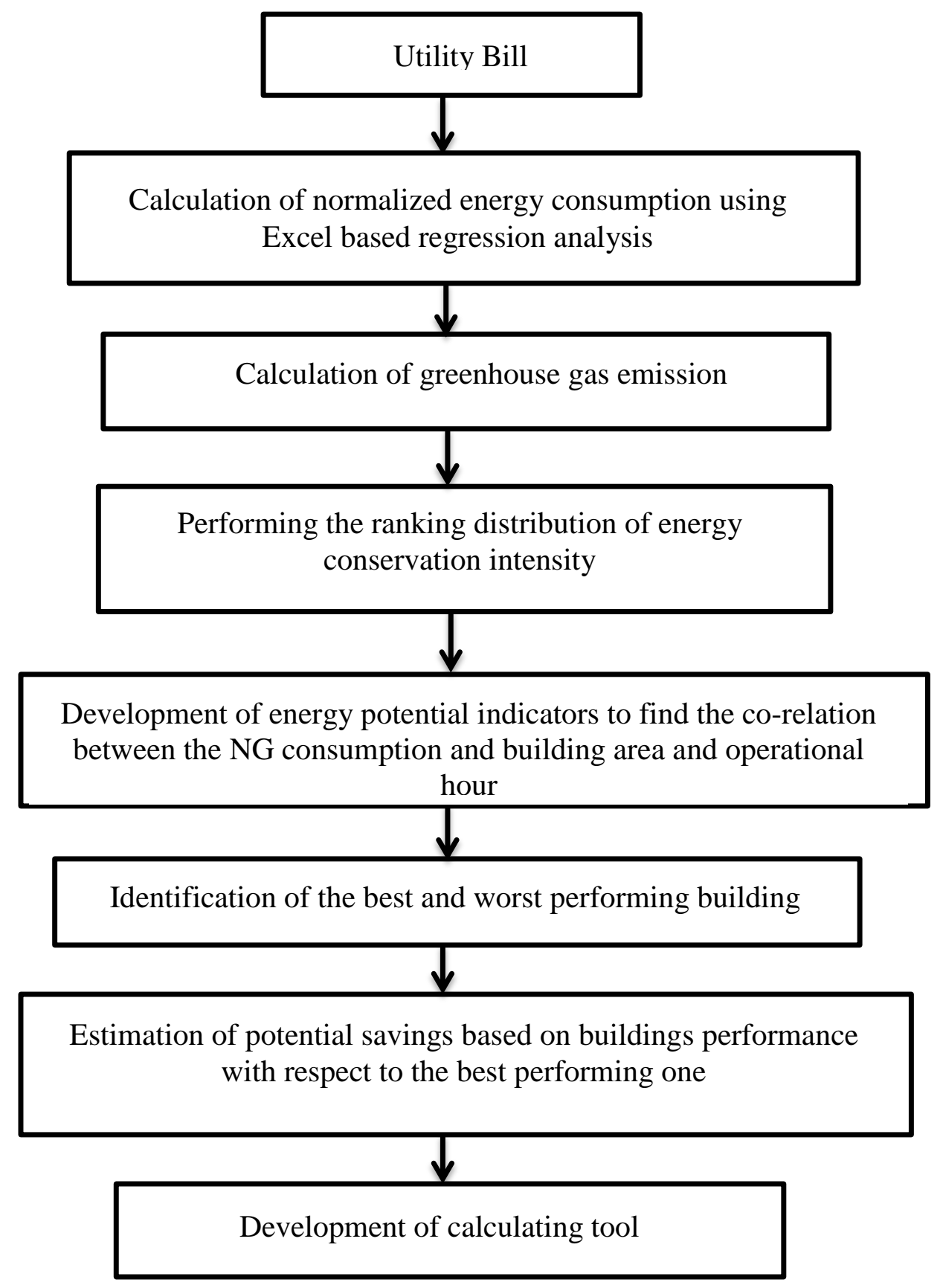

Figure 4.1: Methodology of energy benchmarking of normalized natural gas consumption 


\subsubsection{Plant Area and Perimeter Calculation}

Plant area (square footage) was required to calculate the energy potential indicators, energy consumption per unit area and ventilation analysis. Sometimes, building owners were not interested to provide building area specifications due to privacy concerns. For this reason, plant areas were calculated using the Daft Logic software, which is an online area calculator. If the location of the plant was provided then the program automatically calculated the area of the selected region. This software gives an approximate area of the building which is quite reliable. Figure 4.2 presents area calculation using the Daft Logic software.

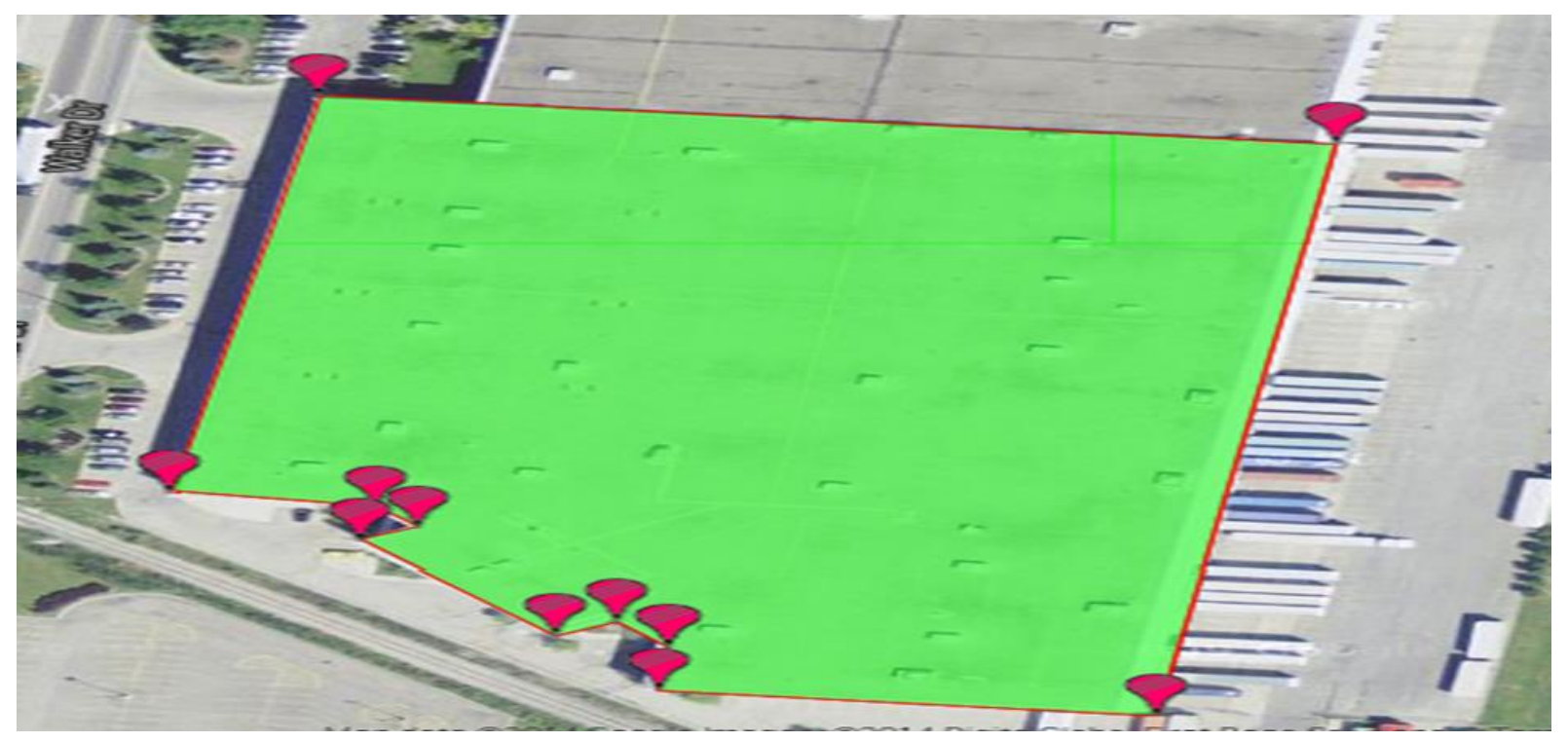

Figure 4.2: Plant area calculations using daft logic software

To calculate plant transmission heat loss, plant length and width is required. Due to irregular shapes of plants' length and width it was difficult to consider plants' length and width. In this case, a decision was made to measure plant perimeter rather than using length and width. Using Daft Logic software's distance calculating menu, building perimeters were calculated and used for ventilation analysis.

\subsubsection{Energy Consumption and Cost Analysis}

Customers are always interested to know their saving in money, therefore cost analysis is essential. In order to calculate the annual energy cost of plants, the marginal cost of natural gas price was required. The "marginal cost" is defined as the charge in cost per unit of gas 
consumption. It is the summation of the gas supply price, cost adjustment price, transportation price, storage, and delivery price. Table 4.1 demonstrates the rate of natural gas price in Enbridge Gas Distribution Inc. [61].

Table 4.1: The rate of natural gas price for the customers of enbridge gas distribution inc.

\begin{tabular}{|c|c|}
\hline Monthly prices & Monthly Rates October 22 ${ }^{\text {nd }}, 2014$ \\
\hline Customer price & $\$ 20$ \\
\hline Gas Supply price & $14.6243 \phi / \mathrm{m}^{3}$ \\
\hline Delivery to You & See breakdown in Table 4.2 \\
\hline Transportation to Enbridge & $5.0013 \phi / \mathrm{m}^{3}$ \\
\hline
\end{tabular}

The transportation of natural gas cost varies with the monthly natural gas consumption. If the monthly consumption is higher than the transportation cost is lower. The breakdown of natural gas cost is shown in Table 4.2 [61].

Table 4.2: Breakdown of natural gas transportation cost to the customers

\begin{tabular}{|c|c|}
\hline Monthly natural gas consumption $\left(\mathrm{m}^{3}\right)$ & Cost of natural gas $\left(\phi / \mathrm{m}^{3}\right)$ \\
\hline First 30 & $7.533 \phi / \mathrm{m}^{3}$ \\
\hline Next 55 & $7.0964 \phi / \mathrm{m}^{3}$ \\
\hline Next 85 & $6.7545 \phi / \mathrm{m}^{3}$ \\
\hline Over 170 & $6.4996 \varnothing / \mathrm{m}^{3}$ \\
\hline
\end{tabular}

Cost adjustment charge is defined as the cost that includes gas supply charge, transportation cost from the production source to gas supply company and delivery cost from gas supply company to the end customer. The cost adjustment charge is shown in Table 4.3 [61].

Table 4.3: Cost adjustment charge of natural gas

\begin{tabular}{|c|c|}
\hline Components of Cost Adjustment & Cost of natural gas $\left(\phi / \mathrm{m}^{3}\right)$ \\
\hline Gas Supply & $3.0512 \varnothing / \mathrm{m}^{3}$ \\
\hline Transportation & $0.1005 \phi / \mathrm{m}^{3}$ \\
\hline Delivery & $-2.5886 \phi / \mathrm{m}^{3}$ \\
\hline Total & $3.1512 \varnothing / \mathrm{m}^{3}$ \\
\hline
\end{tabular}

It was assumed that all bills were paid timely and no extra cost was incurred. Considering all charges the marginal cost of natural gas was calculated. Marginal cost is defined as the cost that will be charged to the customer for per unit natural gas consumption. The marginal cost of natural gas is shown in Table 4.4 [61]. 
Table 4.4: Marginal cost of natural gas to the industrial customers of Enbridge

\begin{tabular}{|c|c|}
\hline Charge & Rate \\
\hline Gas Supply Charge & $12.6243 \phi / \mathrm{m}^{3}$ \\
\hline Transportation to Enbridge & $3.15665 \phi / \mathrm{m}^{3}$ \\
\hline Over 170 m & $6.4996 \phi / \mathrm{m}^{3}$ \\
\hline Cost Adjustment & $3.1512 \phi / \mathrm{m}^{3}$ \\
\hline Total & $25.43175 \phi / \mathrm{m}^{3}$ \\
\hline
\end{tabular}

The marginal cost of natural gas was calculated $25.43 \phi / \mathrm{m}^{3}$. Using the marginal cost of natural gas the annual costs of natural gas consumption of plants were calculated. Annual natural gas consumption of plants was determined from utility bills. Then total annual cost was determined by multiplying annual consumption and cost per $\mathrm{m}^{3}$. Equation 4.3 shows the calculation of annual cost [58].

Estimated Annual cost $(\$ /$ year $)=$ Estimated Consumption $\left(\mathrm{m}^{3} / \mathrm{year}\right) \times$ Marginal Cost $\left(\$ / \mathrm{m}^{3}\right)$

\subsubsection{Greenhouse Gas Emission (GHG) Calculation}

GHG emission is mainly associated with energy uses (natural gas and electricity). The reduction of GHG emission will not only help to save the environment but will also reduce energy costs. The publication of Greenest City and Upper Village Improvement Area in Toronto's report introduced the automatic sensor for lighting in SMEs in Canada which was able to reduce 1.5 tons of greenhouse gas and an associated $\$ 150$ per year. If one million of SMEs in Canada adapted this sensor they would be able to reduce 1.5 million tons of GHG emission and an associated $\$ 150$ million per year [62].

In December 2009 Canada signed the Copenhagen agreement. According to the agreement, Canada has committed to reducing 17\% of its GHG emission from 2005 levels. According to the National Inventory Report (NIR), Canada was able to reduce $8 \%$ of its GHG emission by 2011 [62].

To calculate the GHG emission, it was necessary to consider the emission factor. The emission factors in different provinces in Canada are different. The greenhouse gas emission 
factors are presented in terms of grams of carbon dioxide per $\mathrm{m}^{3}$ of natural gas. Table 4.5 gives the greenhouse gas emission factors for natural gas in Canada [63].

Table 4.5: Greenhouse gas emission factors for natural gas in Canada.

\begin{tabular}{|c|c|}
\hline Province & Emission Factor $\left(\mathrm{gCO}_{2} / \mathrm{m}^{3}\right)$ \\
\hline Newfoundland and Labrador & 1891 \\
\hline Nova Scotia & 1891 \\
\hline New Brunswick & 1891 \\
\hline Quebec & 1878 \\
\hline Ontario & 1879 \\
\hline Manitoba & 1877 \\
\hline Saskatchewan & 1820 \\
\hline Alberta & 1918 \\
\hline British Columbia & 1916 \\
\hline Yukon & NO \\
\hline Northwest Territories & 2454 \\
\hline
\end{tabular}

According to Table 4.5, the emission factor in Ontario is $1879 \mathrm{gm} \mathrm{CO}_{2} / \mathrm{m}^{3}$. Equation 4.4 was used to calculate the greenhouse gas emission of plants [58].

Greenhouse gas emission $=$ Converted NG consumption $(\mathrm{GJ}) *$ Emission Factor $(\mathrm{kg} / \mathrm{GJ})$

(Eq. 4.4)

\subsubsection{Ranking Distribution of Energy Performance Indicators}

To perform energy benchmarking of plants ranking distributions are helpful. Ranking distribution describes a comparison of plant's performance with respect to the top performing one. The ranking distribution of industrial plants shows the standard energy performance of buildings within the database. The complete data set was divided into three different percentiles: efficient, typical and inefficient. The ranking percentile was chosen arbitrarily in this thesis based on Mahssa [58]. If the building energy performance was determined $25^{\text {th }}$ percentile or below then the building was considered efficient, if the building performance is between 26 to $50^{\text {th }}$ percentile then the building was considered typical and if the performance was determined above $50^{\text {th }}$ percentile the building was considered inefficient. Microsoft Excel Rank and Percentile Analysis was used to rank plants. 


\subsubsection{Estimation of Potential Savings}

Potential savings of natural gas consumption, cost, and related GHG emission were calculated. The saving potentials of considered plant were calculated based on the most efficient one. In this case, saving potentials were determined in three different categories; for example: per unit area natural gas consumption, per unit operational hour natural gas consumption, and per unit area multiplied with operational hour natural gas consumption. Therefore, different buildings can be the best in various categories and conserve energy in other categories. Equation 4.5, 4.6 and 4.7 present the potential saving analysis [58].

Potential Savings $(\%)=\left(\right.$ Considered plant normalized consumption $\left(m^{3} / f t^{2}\right)-$ Top performer plant normalized consumption $\left.\left(\mathrm{m}^{3} / \mathrm{ft}^{2}\right)\right) /$ Considered plant normalized consumption $\left(\mathrm{m}^{3} / \mathrm{ft}^{2}\right) \times 100$

Potential Savings $\left(\mathrm{m}^{3}\right)=$ Annual normalized consumption of considered building $\left(\mathrm{m}^{3} / \mathrm{ft}^{2}\right) x$ Annual saving potential (\%) $x$ Plant gross area $\left(f t^{2}\right)$

Potential Savings $(\$)=$ Annual normalized consumption of considered building $\left(\mathrm{m}^{3} / \mathrm{ft}^{2}\right) x$ Annual saving potential (\%) x Plant gross area $\left(f t^{2}\right) x$ per unit charge of natural gas $\left(\$ / \mathrm{m}^{3}\right)$

(Eq. 4.7) 


\subsection{Ventilation Analysis and Benchmarking Ventilation Energy Consumption}

Figure 4.3 demonstrates the proposed methodology of ventilation analysis.

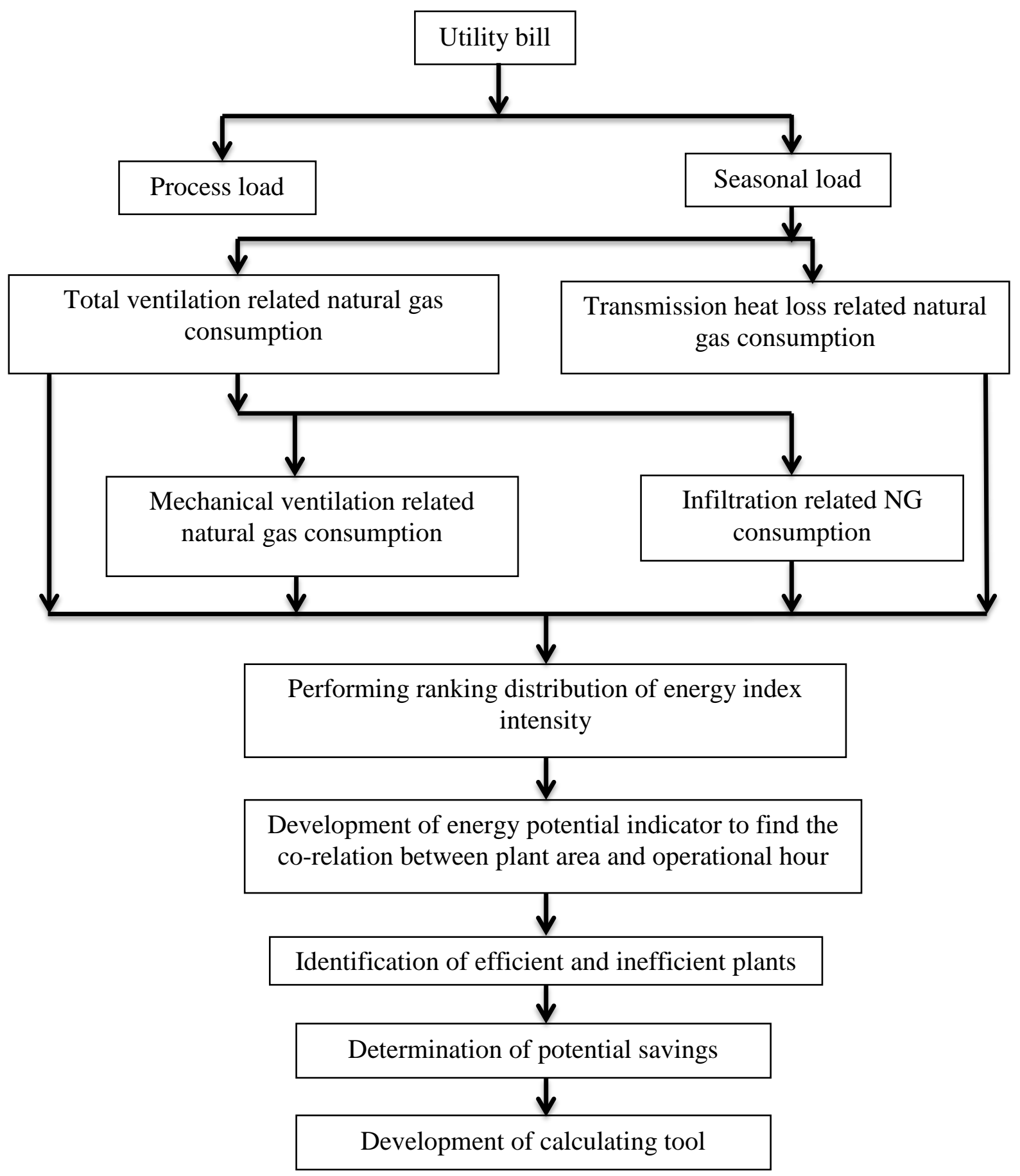

Figure 4.3: The proposed methodology for ventilation related natural gas consumption analysis 


\subsubsection{Process Load and Seasonal Load Analysis}

Industrial plant energy consumption is mainly divided into two different end users. One is process consumption and another is seasonal consumption. Process energy consumption is defined as the energy consumed by different manufacturing and commercial processes in industrial buildings. Seasonal consumption comprise of transmission heat loss, mechanical ventilation consumption and infiltration loss of buildings. Process loads were calculated from the average summer month consumption (according to Natural Resource Canada, June; July and August are considered as summer months in Canada). According to Natural Resources Canada, during this time no space heating is required, so the natural gas consumption is only used for production purposes. The seasonal load was calculated by subtracting the processing load from the monthly energy consumption. Seasonal consumption was further divided into transmission heat loss, infiltration loss and mechanical ventilation of plants. Figure 4.4 presents the separation of utility bill and seasonal energy consumption.

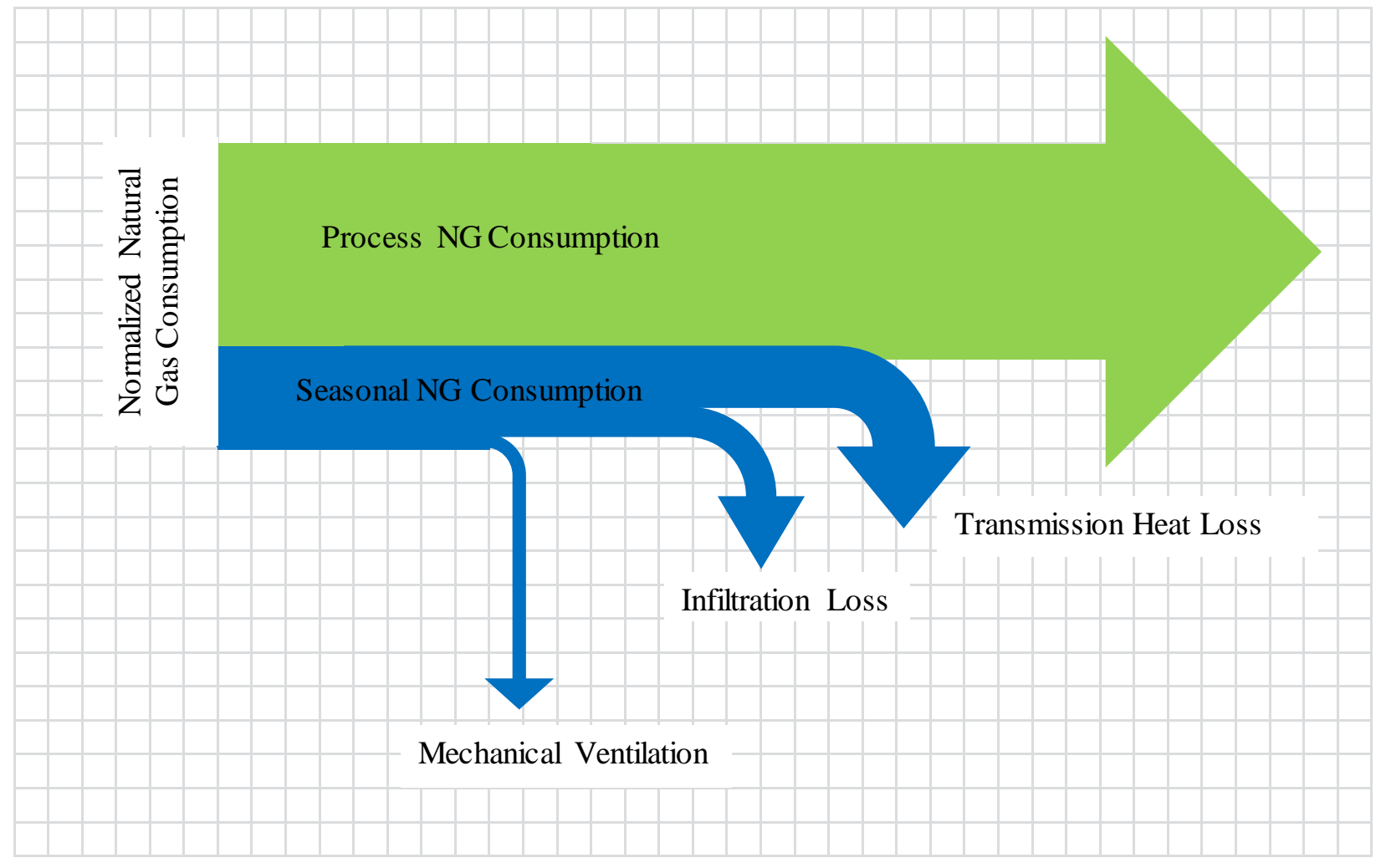

Figure 4.4: Separation of seasonal consumption 
According to Figure 4.4 plants are using average 59\% of their total energy consumption for process purpose and $41 \%$ for seasonal purpose. From this $41 \%$ seasonal energy consumption, $28 \%$ is using for transmission heat loss, $12 \%$ for infiltration loss and $1 \%$ for mechanical ventilation. Equation 4.9 and 4.10 are used to calculate process energy consumption and seasonal energy consumption.

Total Natural Gas Consumption $=$ Process + Seasonal

Process Load $=\frac{\text { Average Summer } \text { Month Consumption }}{\text { Number of Years }}$

Seasonal Load $=$ Monthly Consumption- Process Load

Seasonal Consumption $=$ Transmission Heat Loss + Ventilation

Seasonal Consumption (unit) $=\mathrm{m}^{3}$

Seasonal Consumption $(B t u)=\mathrm{m}^{3} \times 35000 \quad\left[1 \mathrm{~m}^{3}=35000 \mathrm{Btu}\right]$

\subsubsection{Ventilation Related Natural Gas Consumption Analysis}

To ensure a comfortable environment for humans inside, building ventilation plays a significant role. Ventilation is the key to maintaining building indoor air quality but, if the building is over ventilated, it will increase the heating and cooling loads during the winter and summer time. Heat loss occurs from different portions of the building. Sometimes heat loss is intentional and sometimes it is not. Intentional heat loss occurs from building air exhaust but unintentional heat loss occurs from walls, roofs and cracks of building. Figure 4.5 presents the cross ventilation of building. 


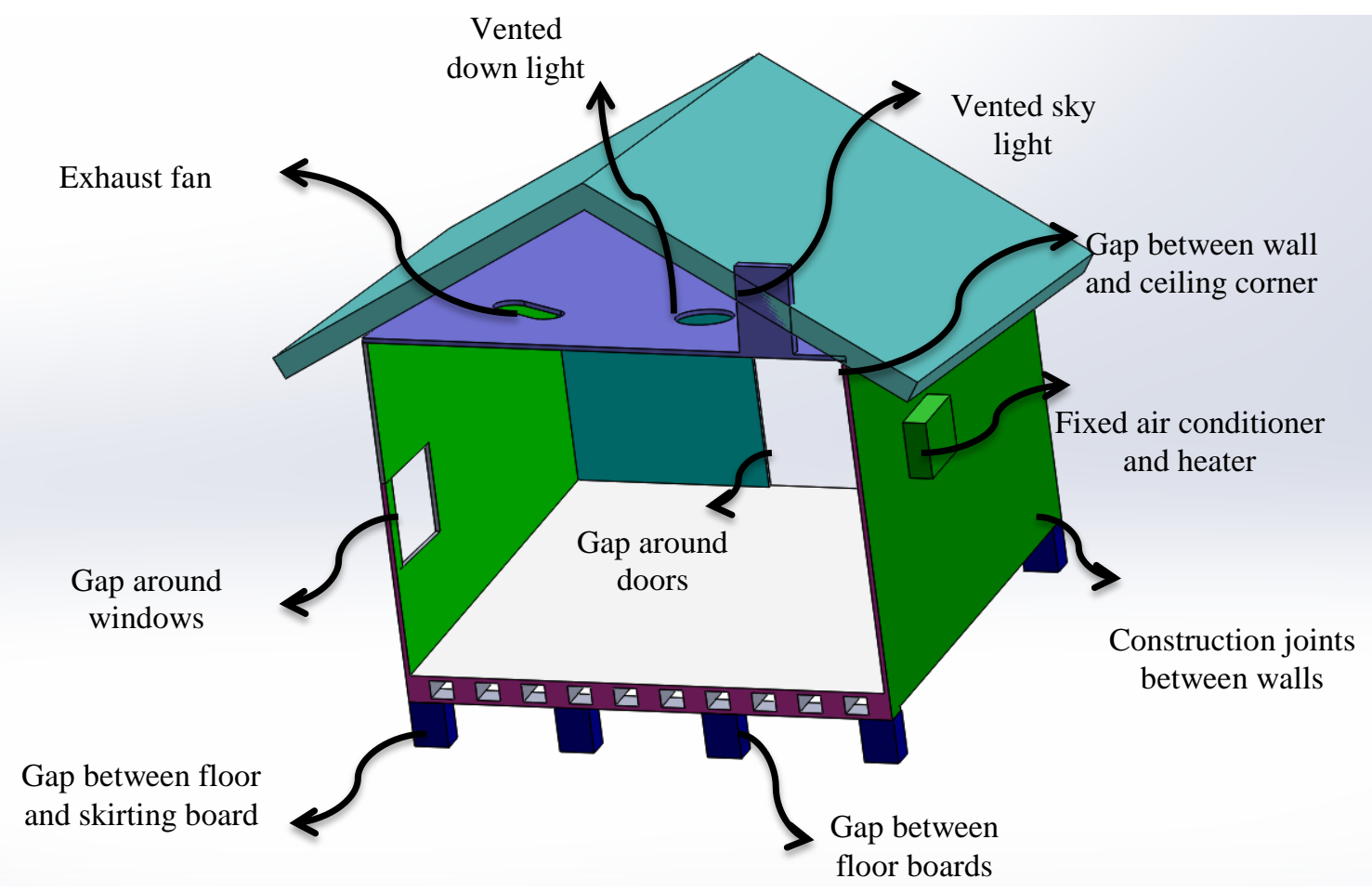

Figure 4.5: Building ventilation airflow

Figure 4.5 presents that, heat loss occurs from different portions of the building. In this thesis multivariable regression analysis was used to determine the ventilation, infiltration and transmission heat loss related natural gas consumption and compared them with ASHRAE standard.

\subsubsection{Multivariable Regression Analysis Using Microsoft Excel}

According to Wakkee [64] multivariable regression analysis is defined as a statistical technique that can be used for exploring multiple factors (independent variables) related to the certain outcome. The type of regression analysis depends on available data and outcome variables. The most familiar type of multi variable regression analysis is linear multivariable regression analysis. If the outcome of analysis is continuous; multivariable liner regression is used. The unknown variable in multivariable regression analysis is presented by beta $(\beta)$ coefficient [64]. In this thesis, linear multivariable regression analysis was used to conduct ventilation analysis. 
Multivariable regression analysis is one of the most widely used statistical tools [75]. When there is more than one independent variable in the equation and linear relationship between them, multivariable regression analysis is used to calculate the intercept of the plane. In this case $\mathrm{Y}$ is dependent variable and $x_{1}$ and $x_{2}$ are independent variables. Equation 4.12 presents the equation for multiple regression analysis:

$$
\begin{aligned}
\mathrm{Y} & =\beta_{1} x_{1}+\beta_{2} x_{2} \\
& =\beta_{1}\left(x_{11}+x_{12}\right)+\beta_{2}\left(x_{21}+x_{22}\right)
\end{aligned}
$$

Here, $\mathrm{Y}=$ Seasonal consumption $(\mathrm{Btu})$

$$
\begin{aligned}
& \beta_{1}=\mathrm{U} \text {-value for transmission heat loss (wall + roof) / equipment efficiency } \\
& x_{11}=\text { Transmission heat loss (wall) without U-value (Btu) } \\
& x_{12}=\text { Transmission heat loss (roof) without U-value (Btu) } \\
& \beta_{2}=\text { Building ventilation CFM x ACH for infiltration heat loss / equipment efficiency } \\
& x_{21}=\text { Ventilation consumption without CFM (Btu) } \\
& x_{22}=\text { Infiltration loss without ACH (Btu) }
\end{aligned}
$$

In this thesis two levels of multivariable regression analysis was conducted. In the first level of multivariable regression analysis, total ventilation consumption includes mechanical ventilation related natural gas consumption and infiltration loss. In the second level a decision was made to separate mechanical ventilation related natural gas consumption and infiltration heat loss. Equation 4.13 was used for conducting $2^{\text {nd }}$ level multi variable regression analysis.

Ventilation Consumption $=\beta_{21} x_{21}+\beta_{22} x_{22}$

Where,

$\beta_{21}=\mathrm{CFM}$ for building ventilation/ equipment efficiency

$x_{21}=$ Mechanical ventilation consumption without CFM (Btu) 
$\beta_{22}=$ Air change per hour of the plant/ equipment efficiency

$x_{22}=$ Infiltration loss without $\mathrm{ACH}(\mathrm{Btu})$

Using multivariable regression analysis air change per hour for infiltration loss, heat transmission coefficient for transmission heat loss and mechanical ventilation consumption in cubic feet per minute (CFM) were estimated.

There are different software available in the market to conduct regression analysis, for example, Microsoft Excel, SPSS, Minitab, XLSTAT and NCSS. In this thesis Microsoft Excel based multivariable regression analysis was employed. Microsoft Excel is a widely used calculating tool and very popular tool for small and medium sized enterprises. Therefore, a decision was made to conduct all preliminary analysis using Microsoft Excel.

Microsoft Excel is reliable and useful calculating tool to conduct regression analysis. There are only three easy steps to conduct very complex regression analysis. The steps for multivariable regression analysis using Microsoft Excel is given below:

Step 1: Under the data tab data analysis was clicked. Figure 4.6 presents the $1^{\text {st }}$ step.

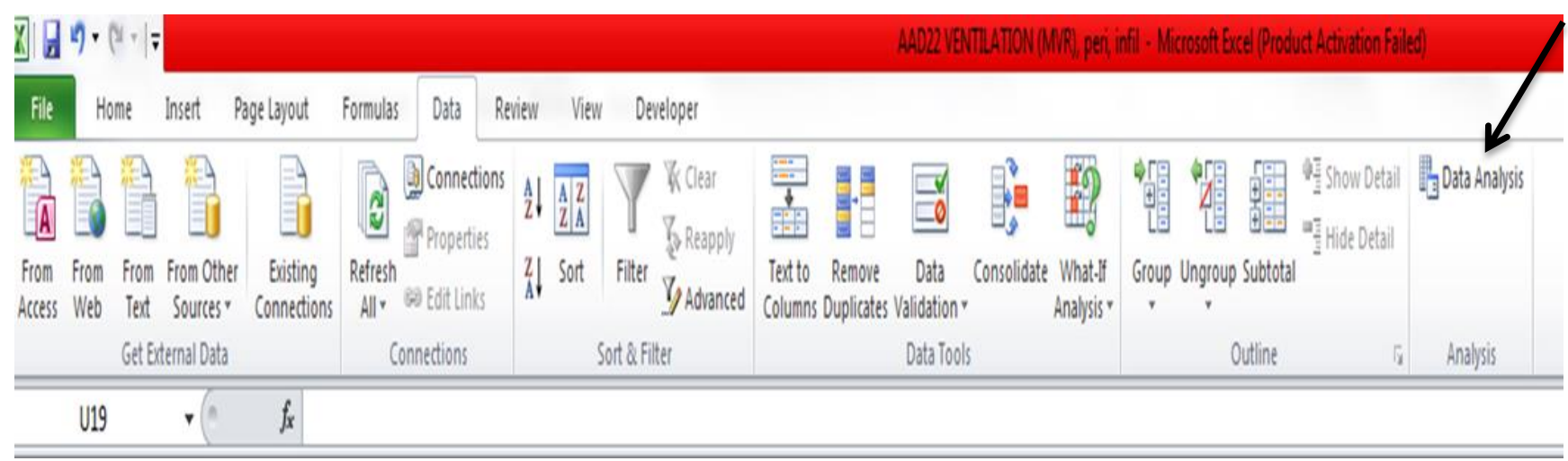

Figure 4.6: First step to conduct the regression analysis in Microsoft Excel

Step 2: After clicking the data analysis and a small box appeared, the regression analysis option was selected. Figure 4.7 presents the second step. 
Data Analysis

\begin{tabular}{l|l|l|}
\hline & 8 \\
\hline
\end{tabular}

Analysis Tools

Covariance

Descriptive Statistics

Exponential Smoothing

F-Test Two-Sample for Variances

Fourier Analysis

Histogram

Moving Average

Random Number Generation

Rank and Percentile

Rearession

Figure 4.7: Second step of regression analysis in Microsoft Excel

Step 3: After selecting regression option, regression box appeared and the required data was entered. Figure 4.8 presents step 3 of regression analysis.

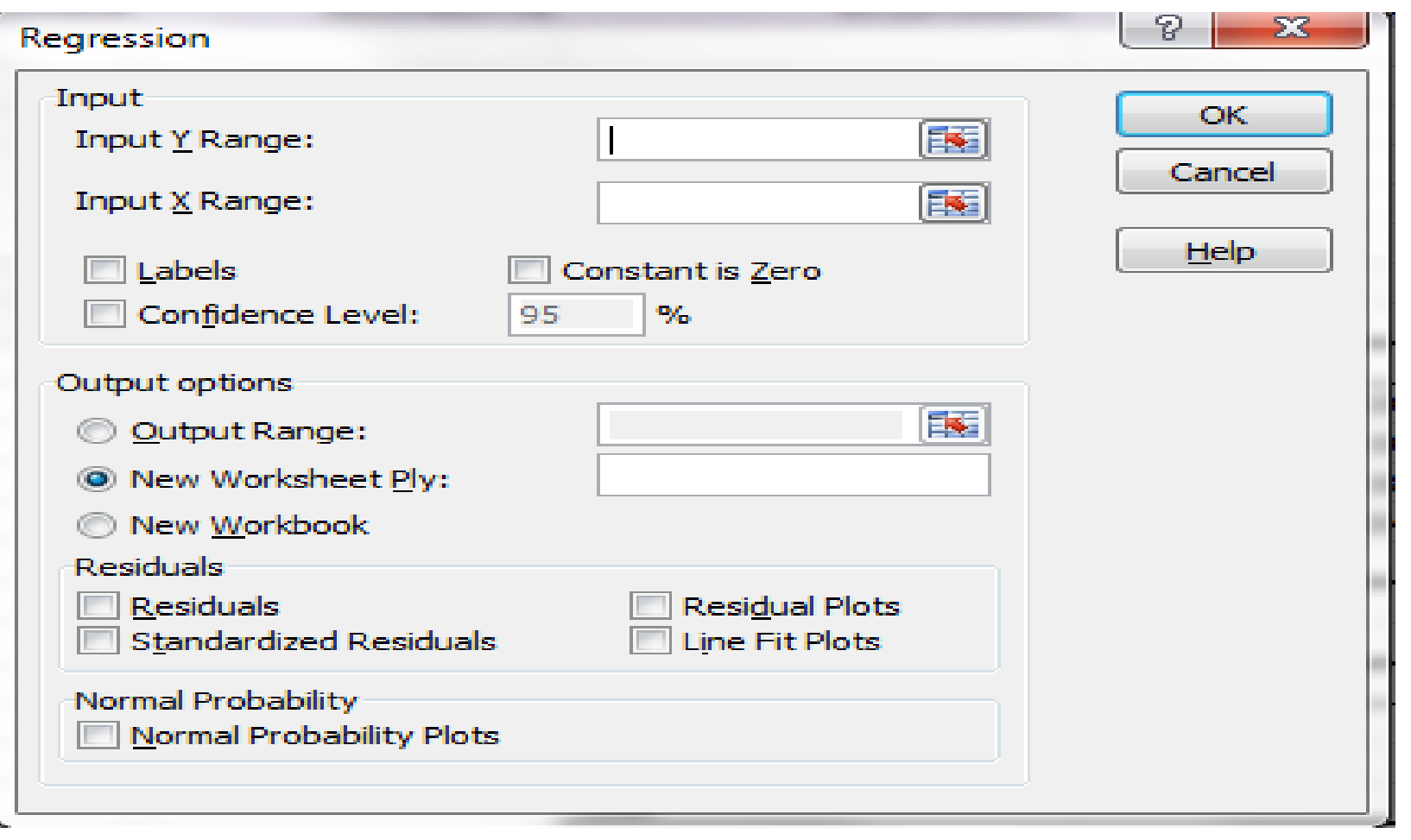

Figure 4.8: Final step of multivariable regression in Excel 
Conducting these three simple steps very complex regression analysis can be solved within very short period of time

\subsubsection{Transmission Heat Loss Related Natural Gas Consumption}

Building envelope includes wall, roof, floor, and all fenestration of the building. All of these components are responsible for building heat entrance and loss by heat transfers; which are known as heat transmissions. To determine the building space heat load, it is necessary to estimate the heat losses from the walls and roofs. To calculate the building transmission heat loss, the heat transfer coefficient is one of the key points [65]. According to Hill [66], heat transfer coefficient is defined as "the amount of heat passes through a unit area of a medium or system in a unit time when the temperature difference between the boundaries of the system is 1 degree". In this thesis heat transfer coefficients of the building was calculated using the multivariable regression analysis.

The main purpose of conducting transmission heat loss related natural gas consumption analysis was to identify the building thermal envelop condition and to compare with the ASHRAE standard. Another purpose was to determine space heat load per unit area of the building and to compare with Enbridge Gas Distribution Inc. standard $1 \mathrm{~m}^{3} / \mathrm{ft}^{2} /$ year. Enbridge Gas Distribution Inc. uses $1 \mathrm{~m}^{3} / \mathrm{ft}^{2} /$ year for space heat analysis of industrial plant which is a very rough estimation. A decision was made to analyze the building space heat systematically and compare with the standard one. 


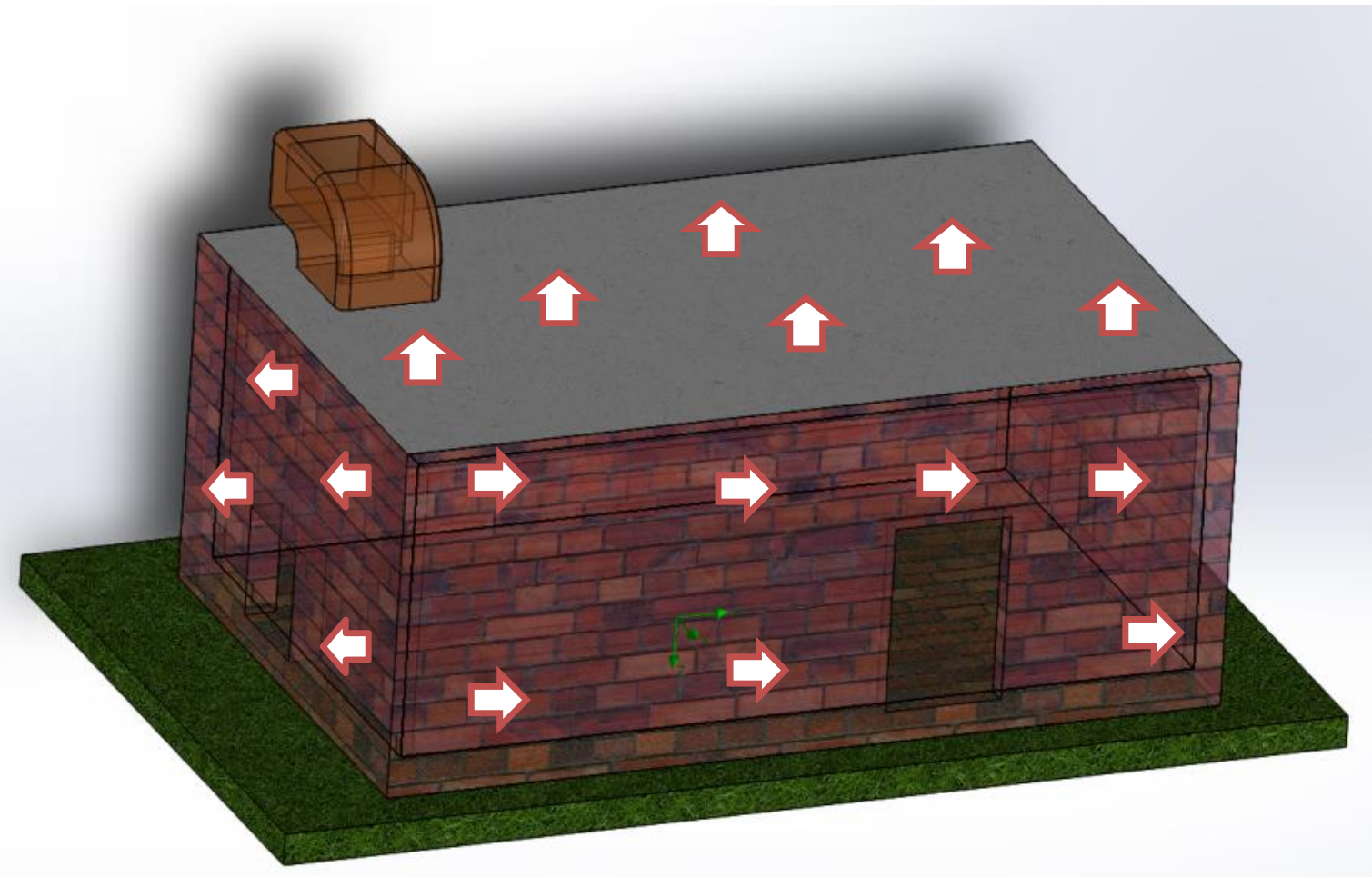

Figure 4.9: Transmission heat loss of the building

The transmission heat loss was calculated using the Equation 4.14 [65]

$q_{1}=\frac{U x A \times \Delta T \times \text { No of operational } h r}{\eta}$

In this equation, $q_{1}=$ Transmission heat loss $(\mathrm{Btu})$

$$
\begin{aligned}
& \mathrm{A}=\text { Gross envelop (roof }+ \text { wall) area of the building, }\left(\mathrm{ft}^{2}\right) \\
& \Delta \mathrm{T}=\text { Temperature difference }\left({ }^{\circ} \mathrm{F}\right) \\
& \mathrm{U}=\frac{1}{R}=\text { Heat transfer co-efficient }\left(\mathrm{Btu} / \mathrm{hr}-\mathrm{ft}^{2}-{ }^{\circ} \mathrm{F}\right)
\end{aligned}
$$

Unit for $q_{1}(\mathrm{Btu})=\frac{B t u}{h r-f t^{2}-^{\circ} F} \times \mathrm{ft}^{2} \mathrm{X}^{\circ} \mathrm{F} \mathrm{xhr}$

Space heating runs around the winter months. So, number of operational hour is $24 / 7$ ( 9 winter months). 
In this case building overall insulation information was unknown. Multivariable regression analysis was used to determine the building insulation value.

\subsubsection{Mechanical Ventilation Related Natural Gas Consumption}

Mechanical ventilation is defined as the Heating, Ventilation and Air Conditioning (HVAC) system controlled by the mechanical air handling system. Most building uses mechanical ventilation systems because it is more controllable and effective than natural ventilation systems. Mechanical ventilation system is also more energy efficient than the natural ventilation system [67].

To ensure comfortable environment inside the building, it is necessary to replace the exhaust air from workplace with the outside clean air. This occurs either by "passive infiltration or by mechanically, through the make-up air supply system" [68]. Currently, facilities' infiltration systems are not sufficient in replace the polluted air. If the exhaust air of the industries is not properly replaced, the workplace becomes "air starved" [68]. This non-proper exhaust air hampers the building air exhaust system as well as the temperature regulation system. Figure 4.10 presents the mechanical ventilation system of the plant

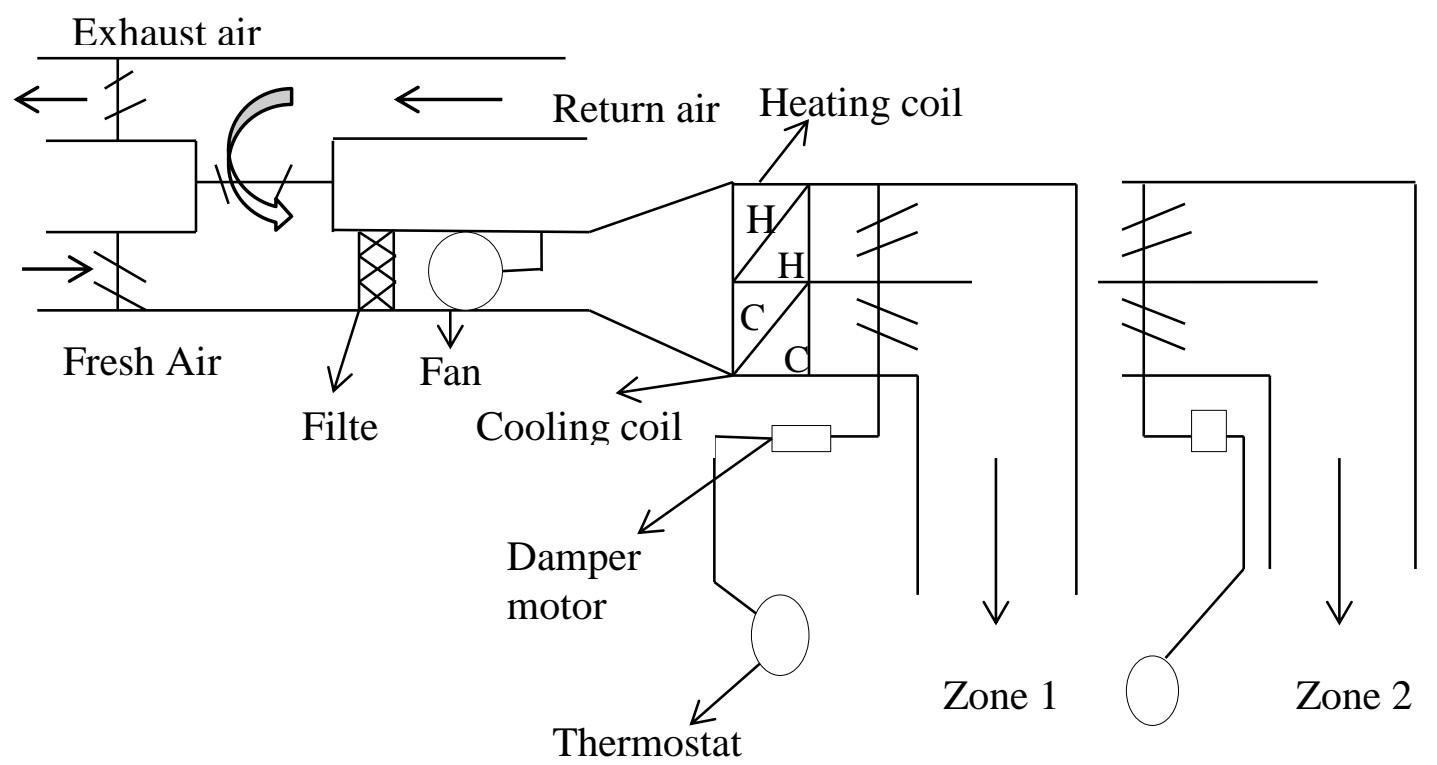

Figure 4.10: Typical mechanical ventilation system of plant 
Total ventilation consumption of the industrial building was again divided into mechanical ventilation and infiltration loss. Mechanical ventilation consumption of the building was calculated using the Equation 4.15 [65]

$q_{2}=\frac{C F M \times 1.08 \times \Delta T \times \text { No of operational hour }}{\eta}$

Here, $\quad q_{2}=$ ventilation energy consumption $(\mathrm{Btu})$

$\Delta \mathrm{T}=$ Temperature difference ${ }^{\circ} \mathrm{F}$ (outdoor temperature was adjusted by calculated Reference temperature)

$\eta=$ Efficiency of equipment

No of operational $\mathrm{hr}=$ Industrial operational hour

Unit for $q_{2}(\mathrm{Btu})=\frac{f t^{3}}{\min } \times \frac{B t u \times \min }{h r \times f t^{3} x^{\circ} F} x^{\circ} F \times h r$

In this case, operational hour was considered 3 hours more than the hours of running the company according to the data provided by the plant manager. Because, the machine needs some start up time and shut down time. In this case, it was considered that the machine starts 2 hours before the company starts and shut down one hour after the company shut down. Ventilation consumption CFM was calculated from $2^{\text {nd }}$ level multivariable regression.

\subsubsection{Infiltration Loss Related to Natural Gas Consumption}

According to Jokisalo [69], the infiltration of buildings is defined as "uncontrolled airflow through building envelop [which] depends on the air permeability of the building envelop and pressure difference between indoor and outdoor air across the building envelope". Wind, stack effect, and ventilation system are mainly responsible for creating pressure difference. The supply and exhaust air in mechanical ventilation system create positive and negative pressure difference in the building. In case of equal supply and exhaust air, the pressure difference depends on crack size and openings between rooms. Figure 4.11 presents the typical infiltration and ventilation air flow of building. 


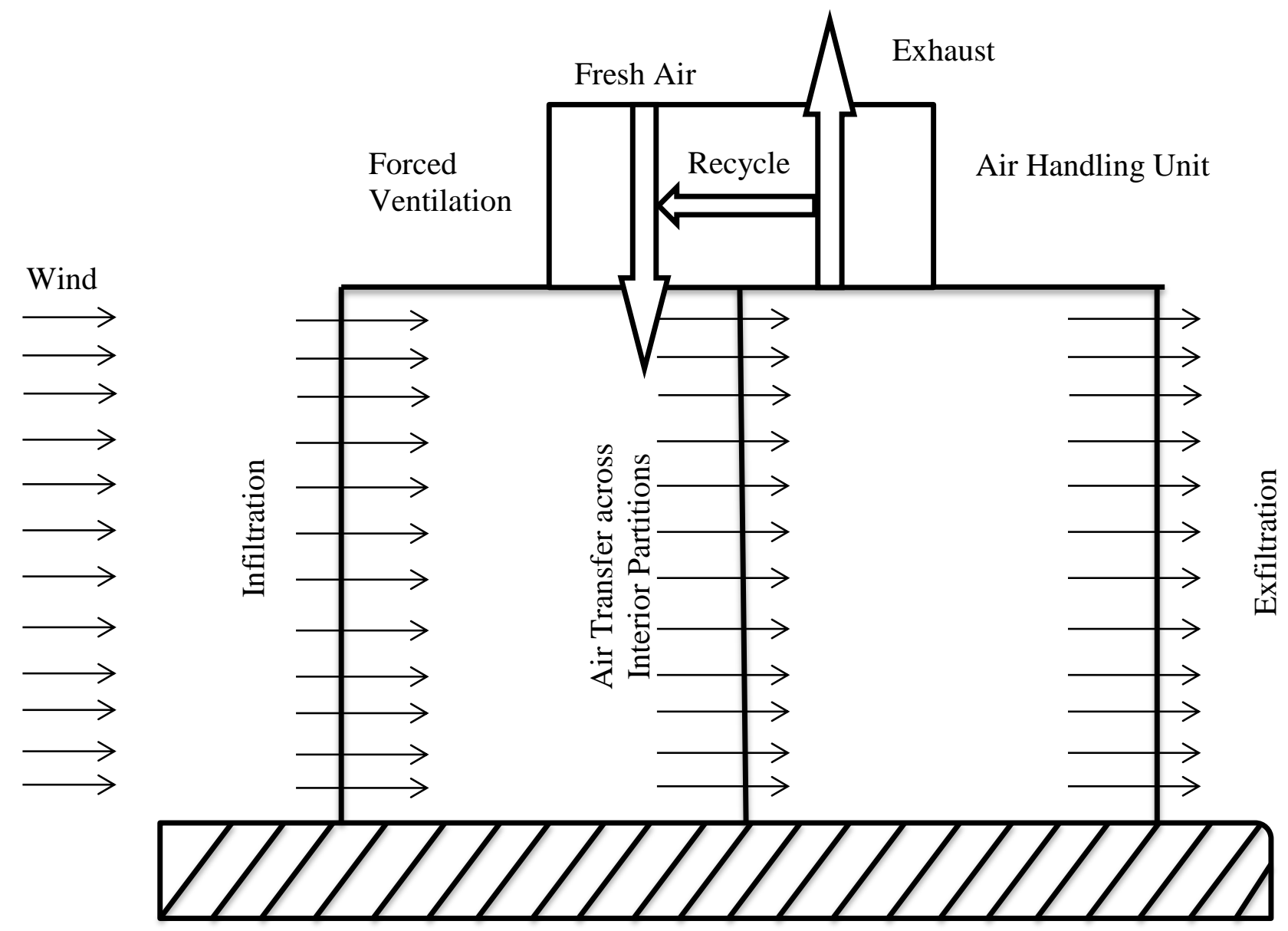

Figure 4.11: Typical infiltration and ventilation air flow

Air leakages through building envelope (for example: crack, openings in doors, windows and crevices) are known as infiltration. Most buildings have air leakage through the building envelop which has a major impact on energy and related cost. In addition, infiltration has an impact on indoor air quality as well. Infiltration loss can be determined using the crack method and the air change method. In this thesis, infiltration losses are calculated using the air change method. Equation 4.16 presents the infiltration rate of building as described in the air change method [65]

$q_{3}=\frac{A C H \times V}{C_{T}}$

Here,

$q_{3}=$ Infiltration rate, (Cubic feet per minute)

$A C H=$ Air change per hour 
$V=$ Gross space volume $\left(\mathrm{ft}^{3}\right)$

$C_{T}=$ Constant, 60 for English unit

In this case, the air change per hour of buildings calculated in the $2^{\text {nd }}$ level of multivariable regression analysis. Using Equation 4.17 infiltration loss of the plant was calculated.

Infiltration loss $=\left(q_{3} \times 1.08 \times \Delta \mathrm{t} \times\right.$ operational hour $) / \eta$

Here,

$q_{3}=$ Infiltration rate, $(\mathrm{CFM})$

$\Delta \mathrm{t}=$ Temperature difference $\left({ }^{\circ} \mathrm{F}\right)$

$\eta=$ Thermal efficiency of make up air unit

Outdoor temperature was adjusted with indoor set point temperature.

In this case operational hour is $24 / 7$ around the winter months.

\subsubsection{Saving Potential}

After conducting the ventilation analysis, a performance based ranking distribution was conducted. In this case Microsoft Excel Rank and Percentile Analysis was conducted to perform the benchmarking analysis. The company who uses the least amount of energy for ventilation was the benchmark company and the energy savings of other companies were calculated based on the benchmark company. Three types of energy saving analysis were conducted. The plant consumption was compared with respect to plant area, operational hour and area multiplied with operational hour.

Equation 4.18, 4.19, 4.20 [58] presents potential savings per unit area of ventilation with respect to natural gas consumption

Potential Savings $(\%)=\left(\right.$ Considered plant ventilation consumption $\left(\mathrm{m}^{3} / \mathrm{ft} \mathrm{t}^{2}\right)-$ Top performer plant ventilation consumption $\left.\left(\mathrm{m}^{3} / \mathrm{ft}^{2}\right)\right) /$ Considered plant ventilation consumption $\left(\mathrm{m}^{3} / \mathrm{ft}^{2}\right) \times 100$

Potential Savings $\left(\mathrm{m}^{3}\right)=$ Annual ventilation consumption of considered building $\left(\mathrm{m}^{3} / \mathrm{ft}^{2}\right) \times$ Annual saving potential (\%) x Plant gross area $\left(f t^{2}\right)$

Potential savings $(\$)=$ Annual ventilation consumption of considered building $\left(\mathrm{m}^{3} / \mathrm{ft}^{2}\right) x$ Annual saving potential (\%) x Plant gross area $\left(\mathrm{ft}^{2}\right) x$ per unit charge of natural gas $\left(\$ / \mathrm{m}^{3}\right)$

Equation 4.21, 4.22, 4.23 presents potential saving analysis per unit operational hour of ventilation with respect to natural gas consumption [58]. 
Potential Savings $(\%)=\left(\right.$ Considered plant ventilation consumption $\left(\mathrm{m}^{3} / \mathrm{hr}\right)-$ Top performer plant ventilation consumption $\left.\left(\mathrm{m}^{3} / \mathrm{hr}\right)\right) /$ Considered plant ventilation consumption $\left(\mathrm{m}^{3} / \mathrm{hr}\right) \times 100$

Potential Savings $\left(\mathrm{m}^{3}\right)=$ Annual ventilation consumption of considered building $\left(\mathrm{m}^{3} / \mathrm{hr}\right) x$ Annual saving potential (\%) x Plant operational hour (hr) (Eq. 4.22)

Potential savings $(\$)=$ Annual ventilation consumption of considered building $\left(\mathrm{m}^{3} / \mathrm{hr}\right) x$ Annual saving potential (\%) x Plant operational hour (hr) x per unit charge of natural gas $\left(\$ / \mathrm{m}^{3}\right)$

Equation 4.24, 4.25, 4.26 presents potential saving analysis per unit area multiplied with operational hour of ventilation with respect to natural gas consumption [58].

Potential Savings $(\%)=\left(\right.$ Considered plant ventilation consumption $\left(\mathrm{m}^{3} / \mathrm{hr}-\mathrm{ft} \mathrm{t}^{2}\right)-$ Top performer plant ventilation consumption $\left.\left(\mathrm{m}^{3} / \mathrm{hr}-\mathrm{ft} \mathrm{t}^{2}\right)\right)$ / Considered plant ventilation consumption $\left(\mathrm{m}^{3} / \mathrm{hr}-\mathrm{ft}^{2}\right)$ $x 100$

Potential Savings $\left(\mathrm{m}^{3}\right)=$ Annual ventilation consumption of considered building $\left(\mathrm{m}^{3} / \mathrm{hr}-\mathrm{ft} \mathrm{t}^{2}\right) x$ Annual saving potential (\%) x Plant operational hour (hr.) x Plant gross area $\left(\mathrm{ft}^{2}\right) \quad$ (Eq. 4.25) Potential savings $(\$)=$ Annual ventilation consumption of considered building $\left(\mathrm{m}^{3} / \mathrm{hr}-f t^{2}\right) x$ Annual saving potential (\%) x Plant operational hour (hr.) x Plant gross area $\left(\mathrm{ft}^{2}\right) \times$ per unit charge of natural gas $\left(\$ / m^{3}\right)$

\subsubsection{ASHRAE Standard}

The American Society of Heating, Refrigerating and Air-conditioning Engineers (ASHRAE) have standards for assessing the energy conservation of HVAC systems. The purpose of this standard was to determine the energy consumption of buildings and to provide a guideline to facility owners for understanding the best practice of energy conservation with an HVAC system. It also suggests the best practice of energy conservation for energy auditors. The standards were designed for residential and commercial buildings, but they are also applicable for industrial buildings [70]. ASHRAE has three levels of standards (e.g. standard 62.2, 119 and 136); these three standards specify different requirements for the building HVAC system. Standard 62.2 (2007) is used to determine the acceptable indoor air quality for residential buildings. The standard specifies the minimum ventilation requirements, mechanical ventilation rate and infiltration air change rate. Standard 136 (1993) determines ventilation, utilizing weather 
factor and air tightness of buildings. It uses normalized leakage to determine the impact of infiltration loss over ventilation consumption. Finally, standard 119 (1988) utilizes the normalized leakage and standardizes the infiltration loss [71].

In this thesis, ventilation consumption, infiltration air change per hour, building wall and roof insulation was calculated and compared with ASHRAE standards.

\subsection{Development of the Calculating Tool}

Finally, an Excel-based automated calculating tool was developed to perform the benchmarking analysis. Microsoft Excel is the most versatile and user-friendly software which is widely used in the industry. In most case, monthly/hourly energy consumption records are also supplied in Microsoft Excel format. Microsoft visual basic can help with macro coding which contributes to task automation and save time from repetitive tasks.

Microsoft Excel 2010 is a highly robust software that was used to calculate, manipulate and present data. Although, it has a powerful set of features and commands to analyze data, it is unable to perform the repetitive task without manual manipulation. In this case, Microsoft Visual Basic programming language is used to carry out the analysis. Microsoft Visual Basic works by running macro files. Programs are written in macro files and saved in a particular.xlms format. Visual Basic for Applications (VBA) is not only suitable to perform a repetitive task but is also suitable for generating graphs and charts with a single command.

In order for Microsoft Excel to read the code and perform the analysis, the code must be written in the macro code page located under Developer tab. Microsoft Excel 2010 uses a ribbon for its features. One of them is Developer tab. Developer tab does not appear by default. It must be activated by following procedure:

- File tab was clicked and option tab was selected then, excel options dialog box was opened

- Customize ribbon option was selected then popular command box was popped up.

- Under the popular command box the main tab was selected and the developer option was check marked and clicked ok. Figure 4.12 presents the developer tab. 


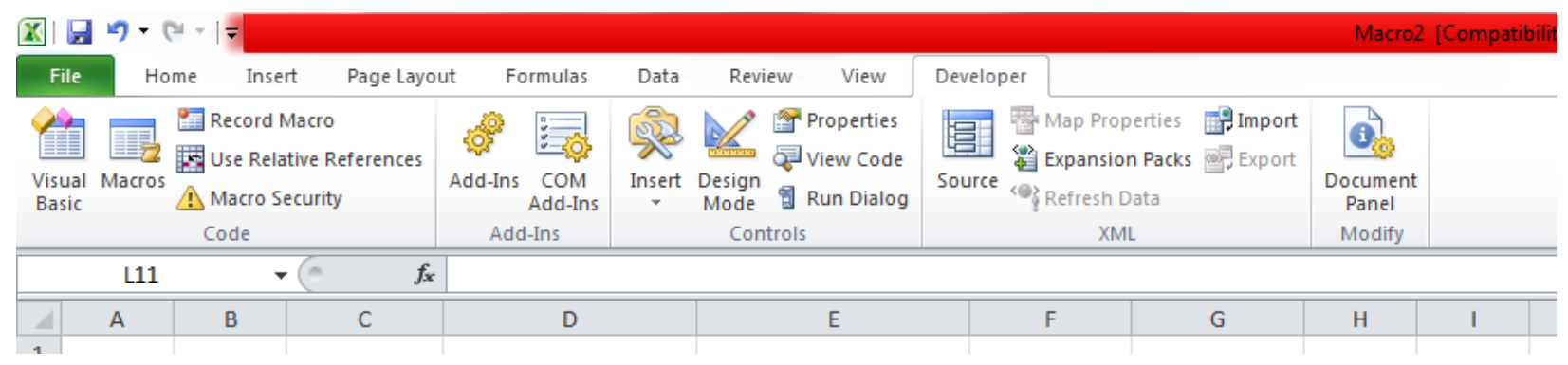

Figure 4.12: Developer tab in Microsoft Excel 2010

To write the code following steps have to be followed.

- First of all Developer tab was clicked and the Macro tab was selected.

- Under Macro tab macro name was created and Edit option was selected then the Visual Basic Editor file was opened to write the code. Figure 4.13 shows the visual basic editor.

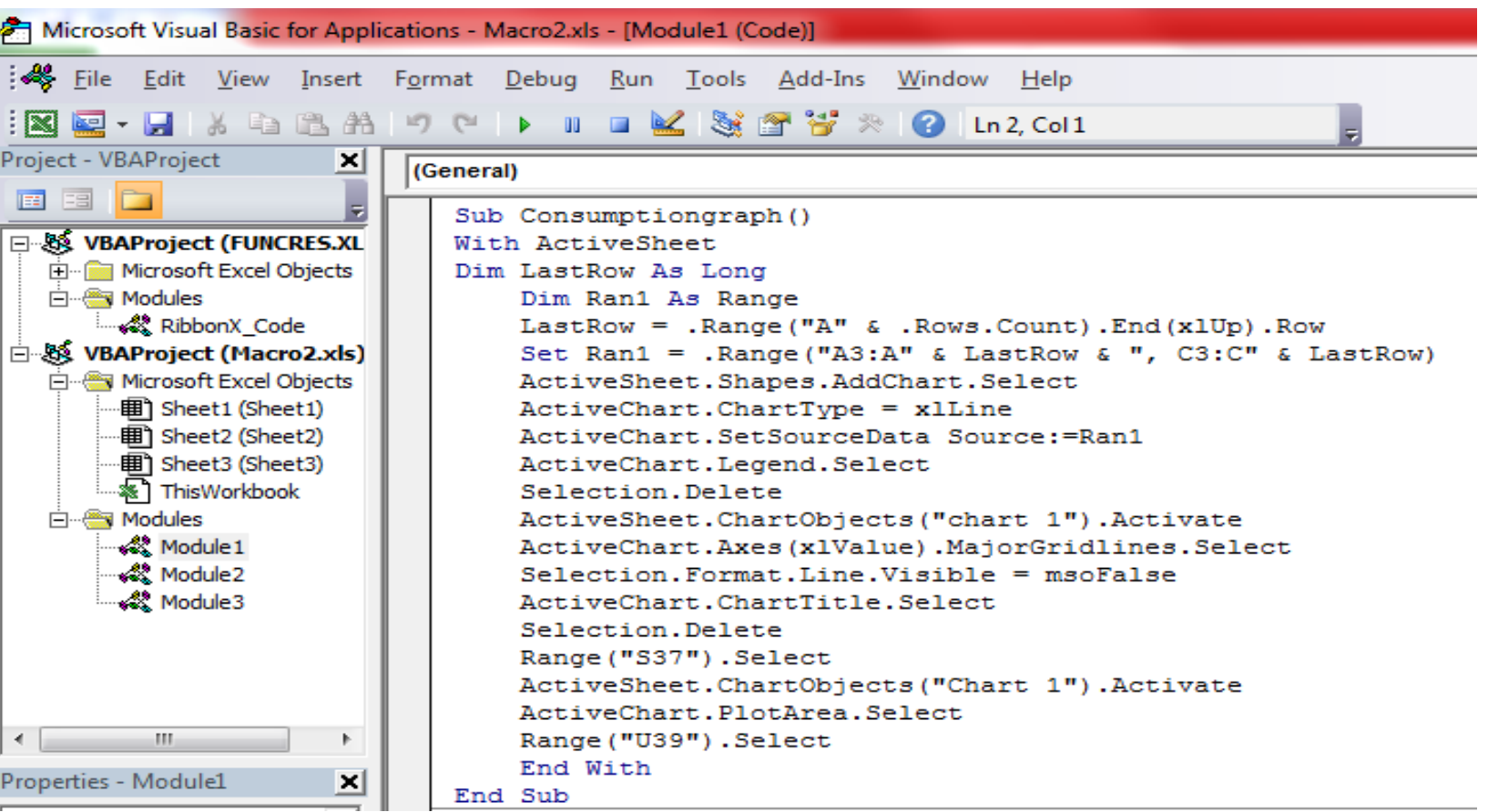

Figure 4.13: Visual basic editor in Microsoft Excel 2010

After writing the code, the code must be connected with the Excel sheet. The procedure is described below: 
- Under the Developer insert tab was clicked on and button option was selected

- A button was created on Excel sheet and was connected with the required macro file.

Figure 3.14 depicts the button created by macro in Microsoft Excel 2010. By clicking the button, macro EXCEL will run the code and will presents the result in the required format.

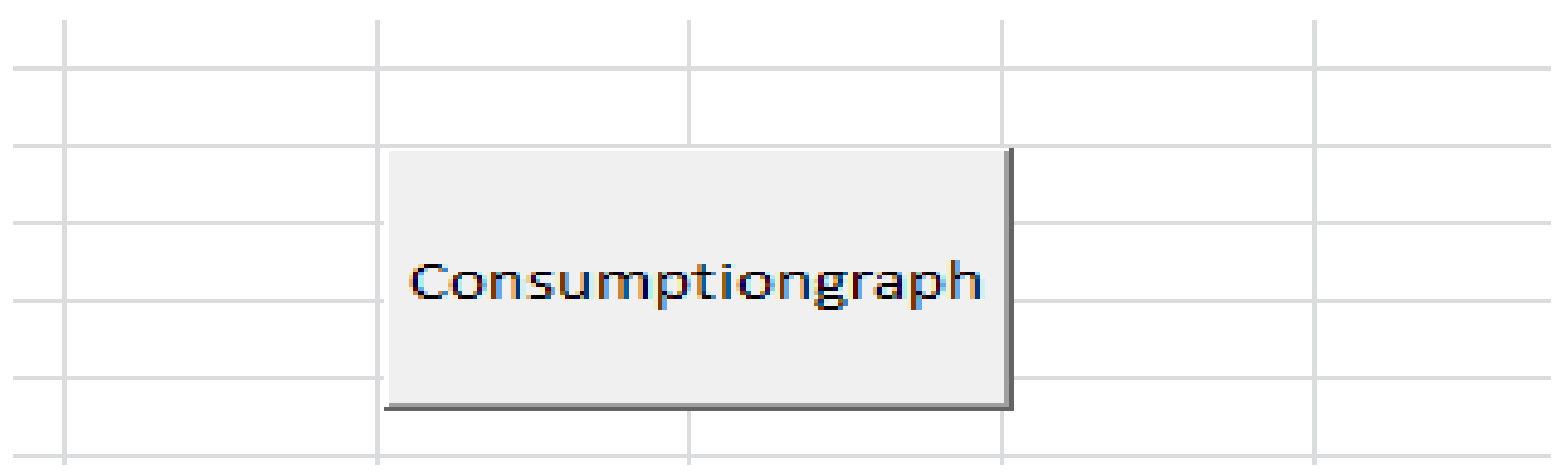

Figure 4.14: Button tab created by macro 


\section{Chapter 5}

\section{Result and Discussion}

Analysis was conducted with the data of thirteen audited industries in the Greater Toronto Area. All necessary data was collected from Level 1 and Level 2 energy audits. The analyses of the thesis were divided into four major sections.
a) Weather normalization
b) Energy benchmarking of normalized energy consumption and potential saving analysis
c) Ventilation analysis
d) Energy benchmarking of ventilation energy consumption and potential saving analyses.

The results are presented in the following sections.

\subsection{Energy Benchmarking of Normalized Energy Conservation}

Normalized Annual Consumption (NAC) of plants was calculated using Microsoft Excel. Then, the annual cost and GHG emissions were determined. Table 5.1 presents total normalized natural gas consumption of plants, GHG emission, process energy consumption, and seasonal energy consumption

Table 5.1: Total normalized natural gas consumption, greenhouse gas emission, seasonal and process natural gas consumption

\begin{tabular}{|c|c|c|c|c|}
\hline Company & $\begin{array}{c}\text { Total NAC } \\
\left(\mathrm{m}^{3}\right)\end{array}$ & $\begin{array}{c}\text { GHG Emission } \\
\left.\text { (tonne } \mathrm{CO}_{2} \mathrm{eq}\right)\end{array}$ & $\begin{array}{c}\text { Process NG } \\
\text { Consumption }\left(\mathrm{m}^{3} / \text { year }\right)\end{array}$ & $\begin{array}{c}\text { Seasonal NG } \\
\text { Consumption } \\
\left(\mathrm{m}^{3} / \text { year}\right)\end{array}$ \\
\hline AAD78 & 969,032 & 69,664 & 183,540 & 785,492 \\
\hline AAD22 & $1,320,182$ & 94,908 & 493,392 & 826,790 \\
\hline AASP & 373,975 & 26,885 & 85,198 & 291,617 \\
\hline AAWI & 301,399 & 21,668 & 195,744 & 105,655 \\
\hline AAAL & 586,763 & 42,183 & 464,270 & 123,401 \\
\hline AAMP & 517,909 & 37,233 & 323,640 & 194,269 \\
\hline AABN & 357,552 & 25,705 & 247,800 & 109,752 \\
\hline AACF & 437,959 & 31,485 & 403,905 & 34,419 \\
\hline AASU & 674,445 & 48,486 & 585,984 & 88,461 \\
\hline AASN & 550,606 & 39,583 & 484,380 & 66,226 \\
\hline AAGF & $3,373,410$ & 242,516 & $2,782,068$ & 591,342 \\
\hline AAKK1 & $1,032,623$ & 74,236 & 577,620 & 455,003 \\
\hline AAKK2 & 649,458 & 46,690 & 441,060 & 208,398 \\
\hline
\end{tabular}


Figure 5.1 presents annual normalized natural gas consumption of plants.

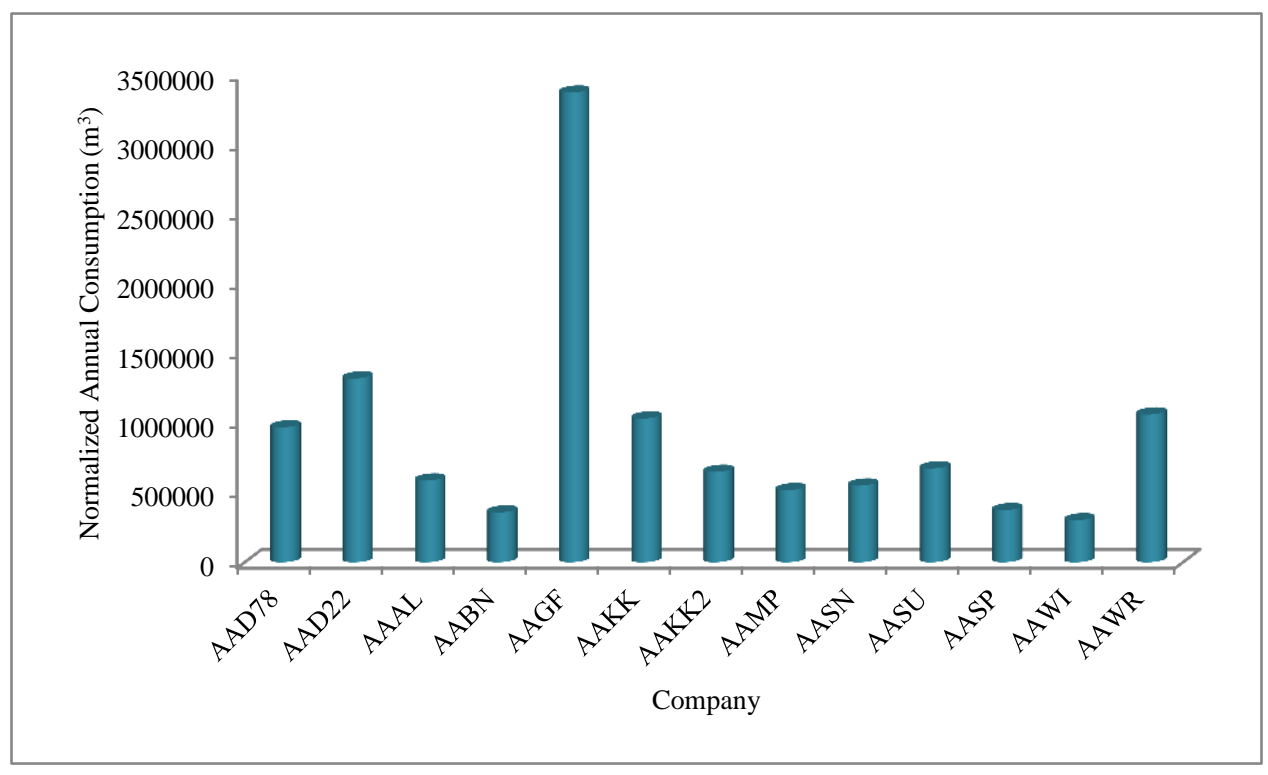

Figure 5.1: Normalized annual natural gas consumption of companies

Figure 5.2 presents the GHG emissions of plants.

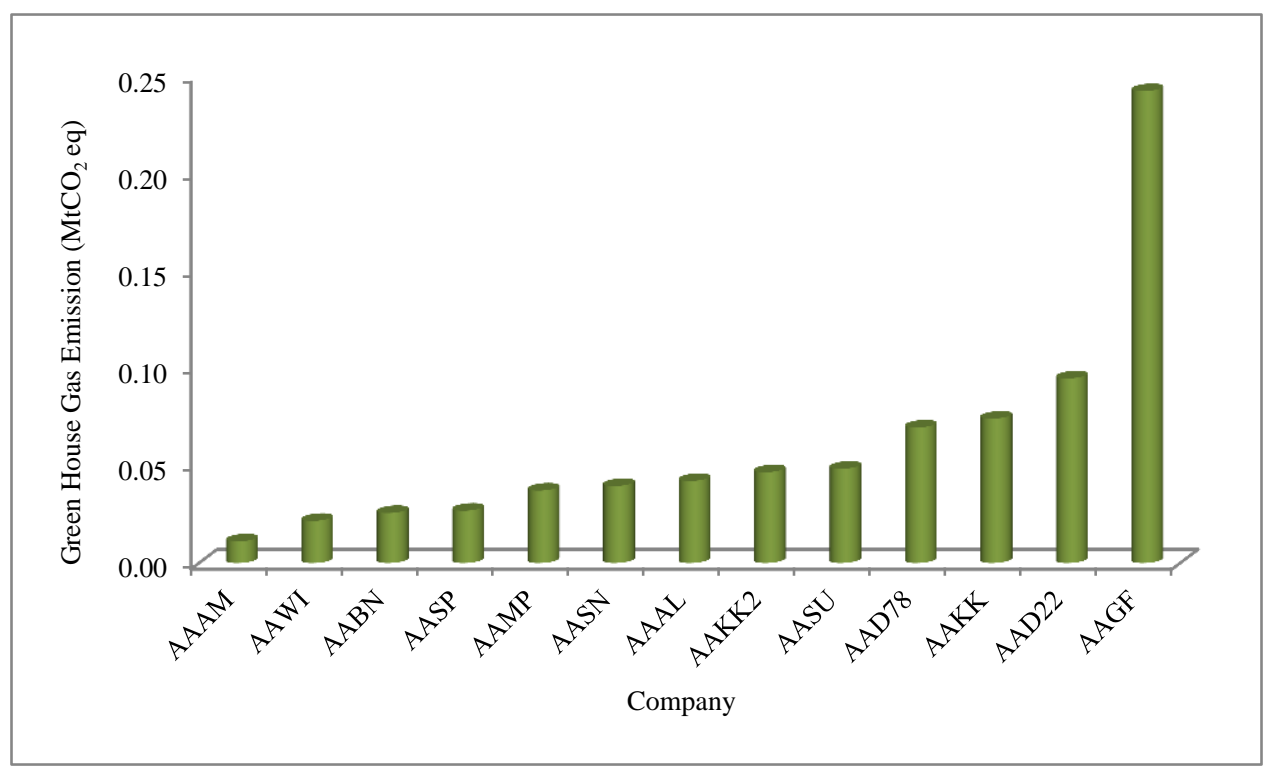

Figure 5.2: GHG emissions of normalized natural gas consumption

According to Figure 5.2, the GHG emission of all audited plants ranges between $0.01-0.24$ $\mathrm{MtCO}_{2}$ eq. Figure 5.3 presents the annual cost of natural gas of thirteen audited companies. 


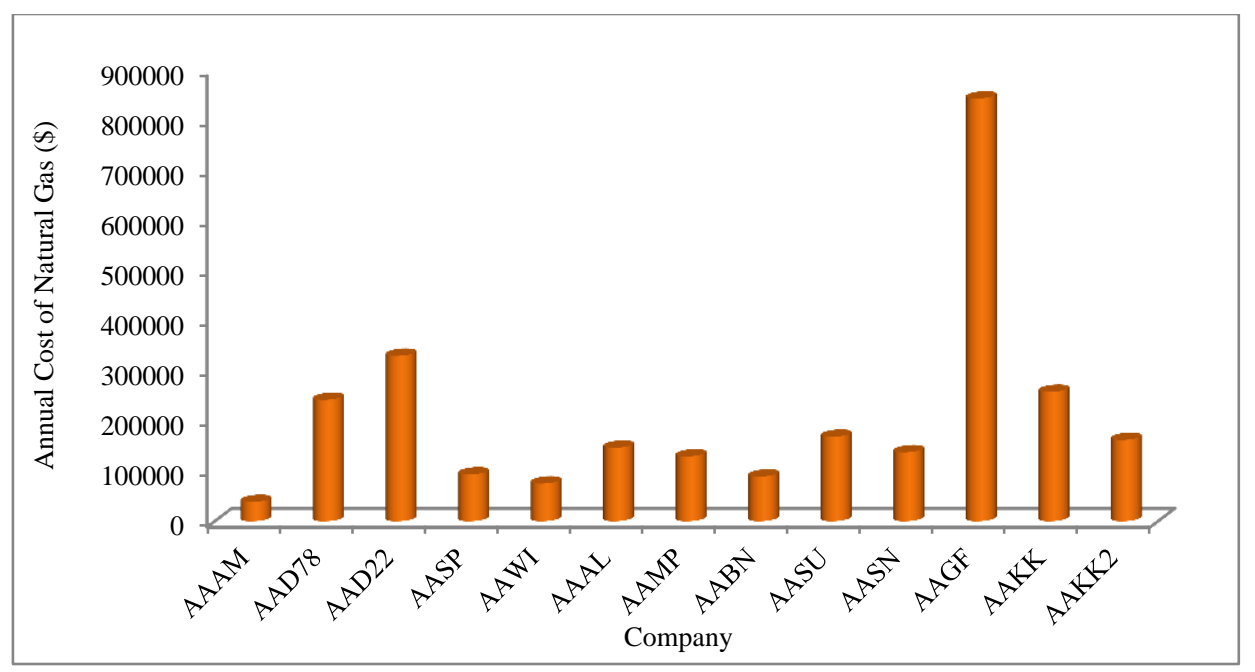

Figure 5.3: Annual cost of natural gas of companies

According to Figure 5.3 the range of natural gas cost for thirteen audited industries was to be $\$ 38,585$ - $\$ 843,353$ per year. After that total monthly natural gas consumption of plants were separated to seasonal natural gas consumption and process natural gas consumption using Equation 4.9 and 4.10 .

Figure 5.4 presents the seasonal natural gas consumption and process natural gas consumption.

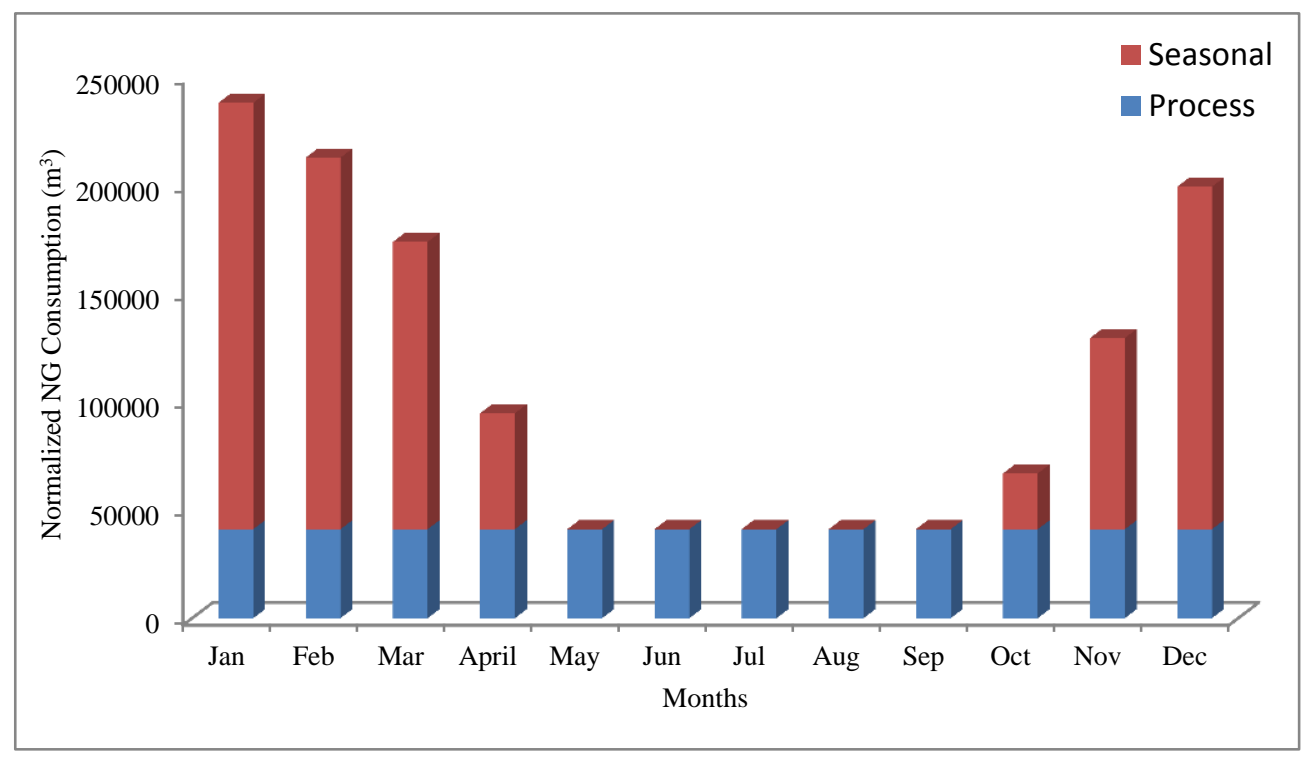

Figure 5.4: Seasonal and process annual consumption of company AAD22 
According to Figure 5.4, the company AAD22 has huge amount of seasonal natural gas consumption. Like company AAD22 all thirteen companies' seasonal and process energy consumption were calculated (shown in Appendix C).

Table 5.2 presents the seasonal NG consumption, process NG consumption, percent seasonal NG consumption and percent process NG consumption of all thirteen industries.

Table 5.2: Total calculated seasonal NG consumption, process consumption and percent seasonal and percent process NG consumption of all audited facilities

\begin{tabular}{|c|c|c|c|c|c|}
\hline Company & $\begin{array}{c}\text { Total NG } \\
\text { Consumption } \\
\left(\mathrm{m}^{3}\right)\end{array}$ & $\begin{array}{c}\text { Process } \\
\text { Consumption } \\
\left(\mathrm{m}^{3}\right)\end{array}$ & $\begin{array}{c}\text { Seasonal } \\
\text { Consumption } \\
\left(\mathrm{m}^{3}\right)\end{array}$ & $\begin{array}{c}\text { Process } \\
\text { Consumption } \\
(\%)\end{array}$ & $\begin{array}{c}\text { Seasonal } \\
\text { Consumption } \\
(\%)\end{array}$ \\
\hline AAD78 & 969,032 & 183,540 & 785,492 & 19 & 81 \\
\hline AAD22 & $1,232,860$ & 493,392 & 826,790 & 40 & 67 \\
\hline AASP & 373,975 & 85,198 & 291,617 & 23 & 78 \\
\hline AAMP & 517,909 & 323,640 & 194,269 & 62 & 38 \\
\hline AABN & 357,552 & 247,800 & 109,752 & 69 & 31 \\
\hline AAWI & 301,399 & 195,744 & 105,655 & 65 & 35 \\
\hline AAAL & 586763 & 464,270 & 123,401 & 79 & 21 \\
\hline AAWR & $1,064,841$ & 738,432 & 492,236 & 69 & 46 \\
\hline AASU & 674,445 & 585,984 & 88,461 & 87 & 13 \\
\hline AASN & 550,606 & 484,380 & 194,269 & 88 & 35 \\
\hline AAGF & $3,347,868$ & $2,782,068$ & 591,342 & 83 & 18 \\
\hline AAKK1 & $1,032,623$ & 577,620 & 455,003 & 56 & 44 \\
\hline AAKK2 & 639,812 & 441,060 & 208,398 & 69 & 33 \\
\hline
\end{tabular}

Figure 5.5 presents percent process energy consumption of plants. According to Figure 5.5 , the percentage of process related natural gas consumption of plants ranges between $19 \%$ to $88 \%$. This indicates that, most of the companies are using their major portion of natural gas consumption for production purposes. Only two powder coating industries are using a small amount of energy for process purposes. 


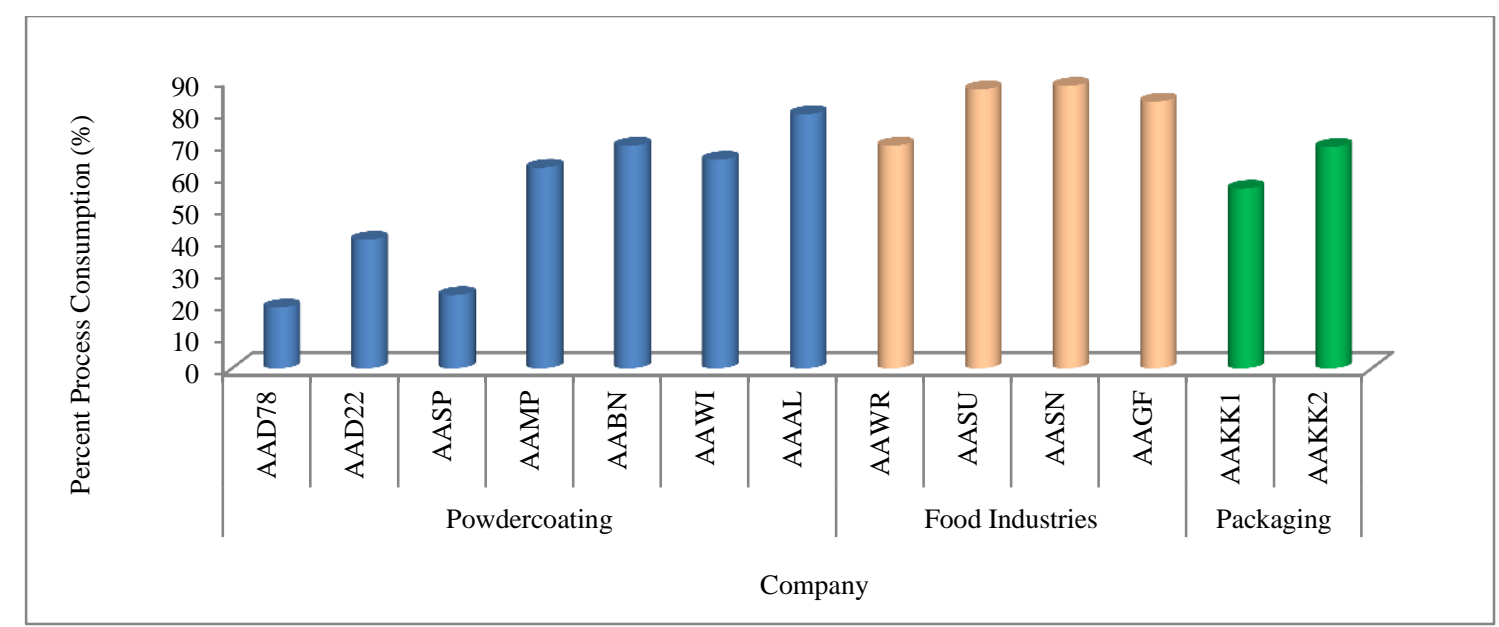

Figure 5.5: Percent process energy consumption of companies

Figure 5.6 presents the percent of seasonal related natural gas consumption of plants. According to Figure 5.6, companies are consuming 12\% - 81\% of their annual consumption for seasonal purpose. Most of companies are consuming less than $50 \%$ of their annual natural gas consumption for seasonal purposes but only powder coating industries have higher seasonal related natural gas consumption records. To get more reliable results, plants were categorized according to their production type.

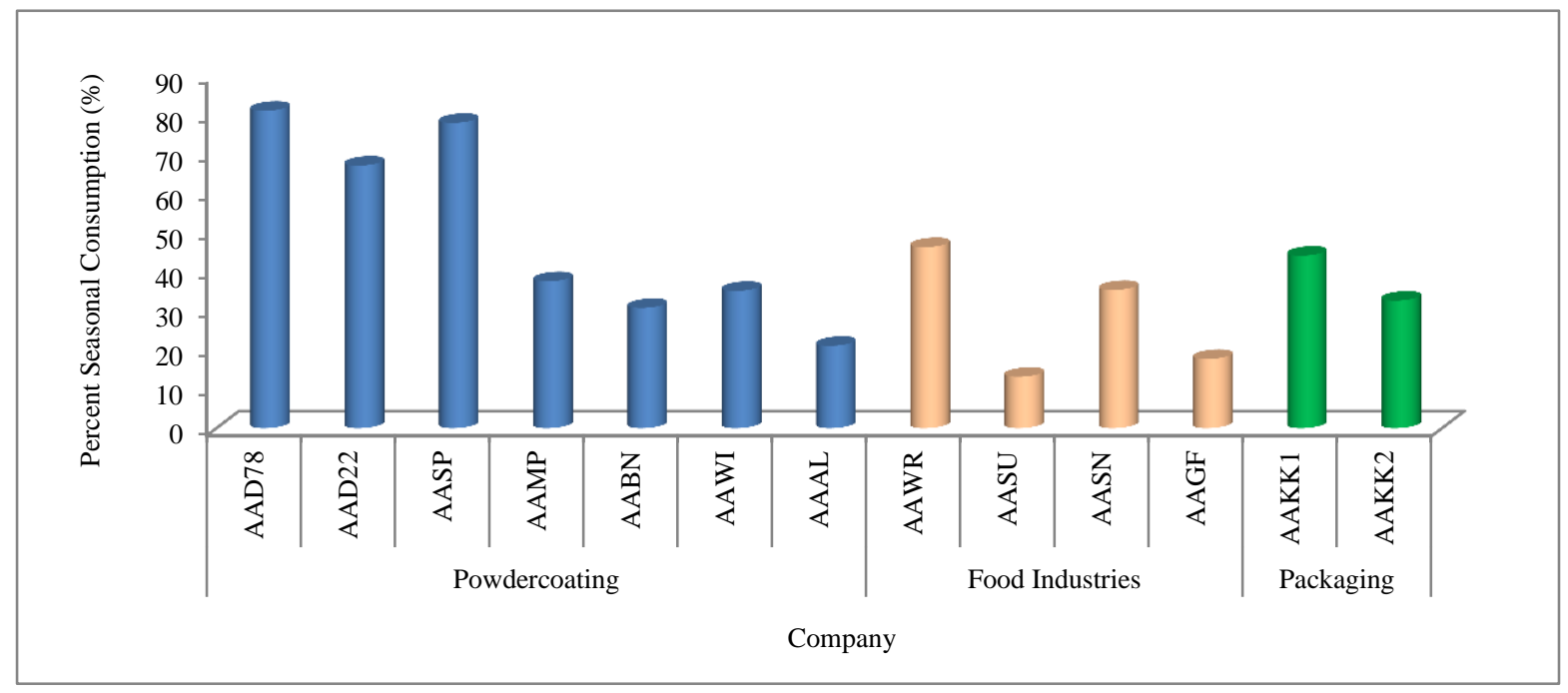

Figure 5.6: Percent seasonal energy consumption of companies

Table 5.3 presents the categorization of thirteen audited plants. 
Table 5.3: Plant categorization

\begin{tabular}{|c|c|}
\hline Company & Type \\
\hline AAD78 & Powder coating \\
\hline AAD22 & Powder coating \\
\hline AASP & Powder coating \\
\hline AAAL & Powder coating \\
\hline AAWI & Powder coating \\
\hline AAMP & Powder coating \\
\hline AABN & Powder coating \\
\hline AAKK1 & Packaging \\
\hline AAKK2 & Packaging \\
\hline AAGF & Food industry \\
\hline AASN & Food industry \\
\hline AASU & Food industry \\
\hline AAWR & Food industry \\
\hline
\end{tabular}

After categorizing plants according to their production type, total normalized natural gas consumption of plants in the same category was plotted against plant area to determine the statistical correlation $\left(\mathrm{R}^{2}\right)$. Figure 5.7 presents the statistical correlation between plant area and normalized natural gas consumption.

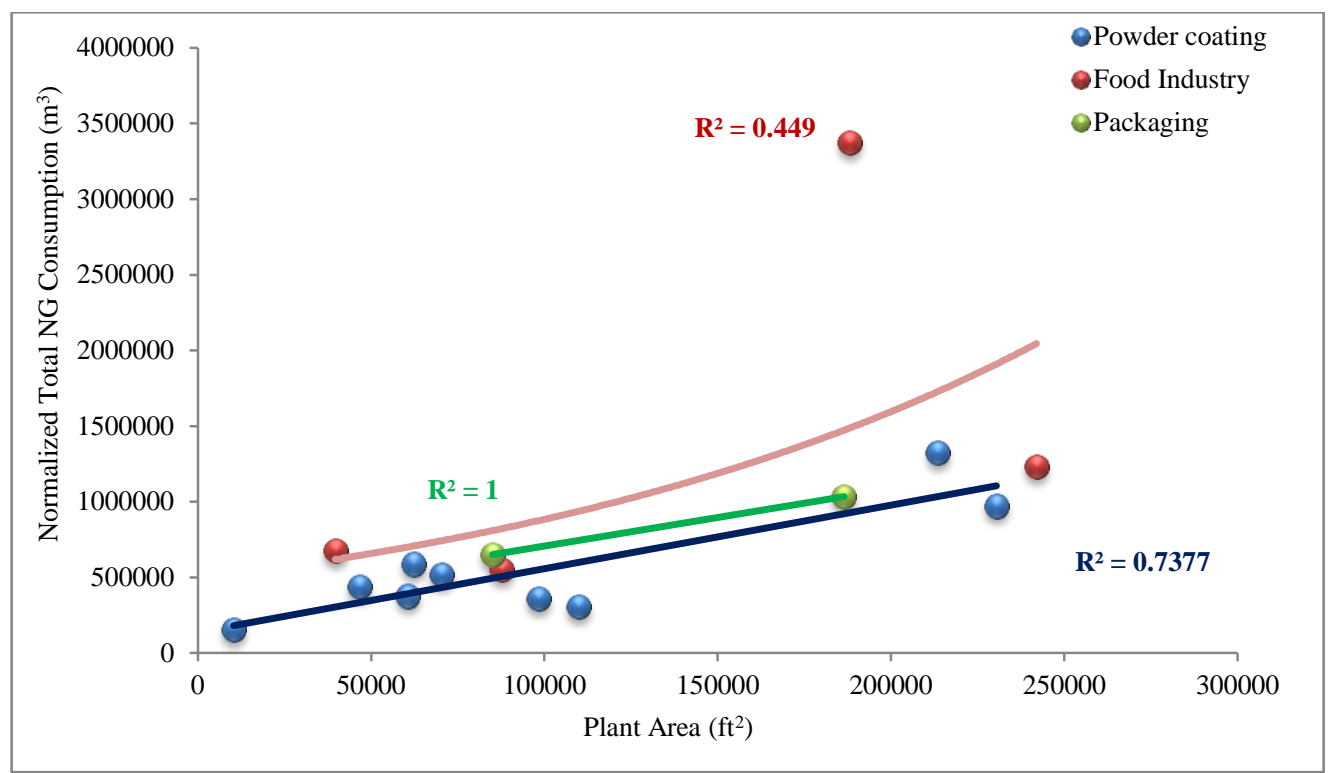

Figure 5.7: Statistical correlations between plant areas and normalized total natural gas consumption 
Figure 5.7 depicts that powder coating companies have large statistical correlation between plant normalized natural gas consumption and plant area (square footage). According to Cohen [73], if statistical correlation is 0.1 then it is small, if it is 0.3 then it is medium, and if it is 0.5 then it is large. In the dataset, there were only four food industries; the statistical correlation between food industries' normalized natural gas consumption and plant area was medium. On the other hand, there were only two packaging industries in the dataset. For this reason, it was found to have large statistical co-relation between plant area and normalized natural gas consumption. It is expected that, if more data will be added the results would be more sophisticated and reliable.

To determine the statistical correlation between plant seasonal related natural gas consumption and plant area, the seasonal related natural gas consumption was plotted against plant area. Figure 5.8 presents the statistical correlation between plant seasonal related natural gas consumption and plant area.

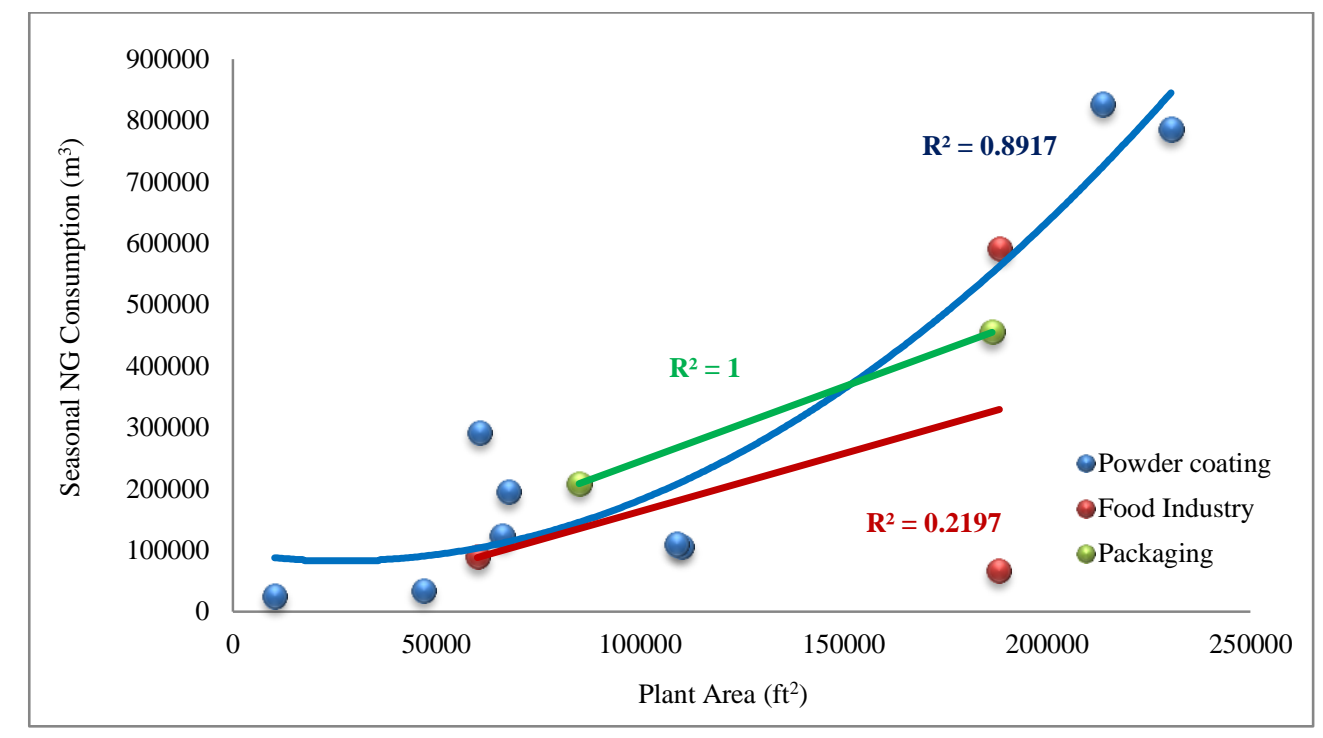

Figure 5.8: Statistical correlations between plant areas and normalized seasonal natural gas consumption

According to Figure 5.8, powder coating industries' seasonal related natural gas consumption shows large statistical correlation with plant area. The reason is that seasonal related natural gas consumption is responsible for ventilation consumption, space heating and infiltration loss that has direct relationship with plant area. The statistical correlation between food industries' seasonal related natural gas consumption and plant area was small. Again, for packaging industries the data was very limited and the statistical correlation was large. Similar to 
seasonal related natural gas consumption, process related natural gas consumption of plants was plotted against plant area.

Figure 5.9 presents statistical correlation between plant process related natural gas consumption and plant area. According to Figure 5.9, powder coating industries' process related natural gas consumption has very small statistical correlation with plant area. The reason is, process energy consumption do not depend on plant area. Due to very limited data of packaging industries, it shows large relation between process related natural gas consumption and plant area.

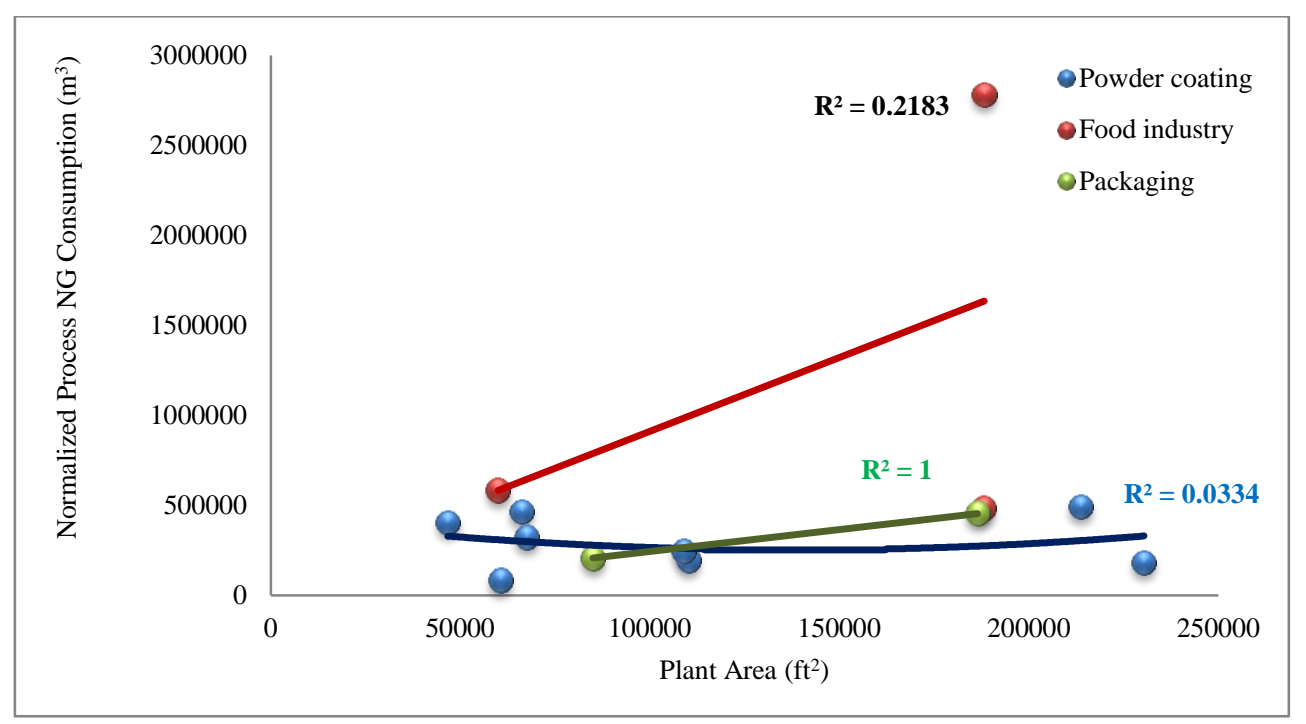

Figure 5.9: Statistical correlations between plant area and normalized process related natural gas consumption

Plant natural gas consumption does not only depend on plant area but also depending on plant operational hour. To obtain more reliable and realistic results, plant total normalized annual natural gas consumption was plotted against plant area multiplied with operational hour to determine the statistical correlation $\left(\mathrm{R}^{2}\right)$. Figure 5.10 presents the statistical relation between plant normalized natural gas consumption and plant area multiplied with operational hour. 


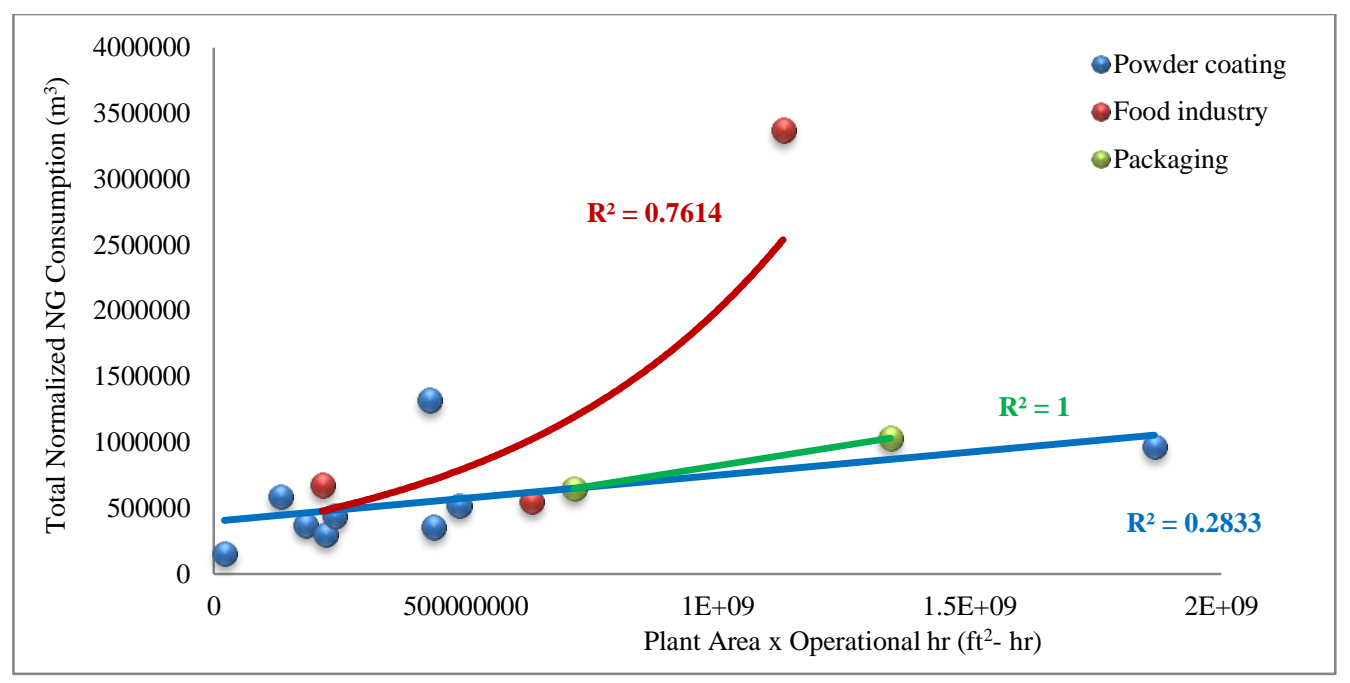

Figure 5.10: Statistical correlations between plant area multiplied with operational hour and normalized total natural gas consumption

According to Figure 5.10 powder coating companies' normalized natural gas consumption have small statistical relationship with plant area multiplied with plant operational hours. Food industries normalized natural gas consumption has large statistical relationship with plant area multiplied with plant operational hour. In case of packaging industries, there are only two companies in the dataset so there statistical relation $\mathrm{R}^{2}$ is large. If more data will be added, the relation will be changed. Similarly all companies seasonal related natural gas consumption was plotted with plant area multiplied with operational hour to determine the statistical relation.

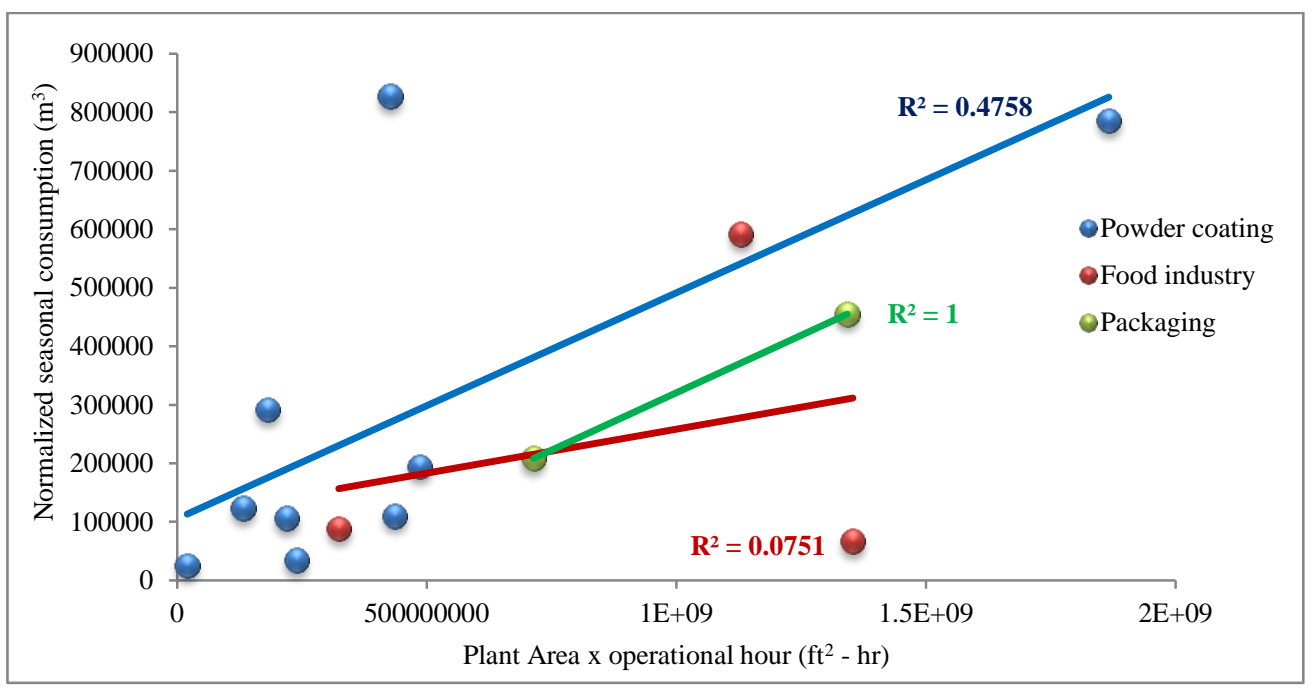

Figure 5.11: Statistical correlations between plant area multiplied with operational hour and normalized seasonal natural gas consumption 
According to Figure 5.11, powder coating industries' seasonal related normalized natural gas consumption has medium statistical relationship with plant area multiplied with plant operational hour. Food industries have statistical relation less than small effect size and due to limited number of packaging companies' data, the statistical relationship between normalized consumption, and area multiplied with operational hour was large.

\subsection{Ranking Distribution and Saving Analysis:}

\subsubsection{Ranking Distribution of Powder Coating Industries Based on Per Unit Area:}

Ranking based distribution of similar types of plants were conducted using Microsoft Excel Rank And Percentile Analysis. In this case, the plant that uses the least amount of energy per unit area was considered the most efficient plant and the plant that uses the highest amount of energy was considered the most inefficient. In this case, if a company falls in the $0^{\text {th }}$ to $25^{\text {th }}$ percentile, it was grouped into the efficient category. If a company falls in the $26^{\text {th }}$ to $50^{\text {th }}$ percentile it was grouped into the typical category. Lastly, if the company falls in the $50^{\text {th }}$ percentile or higher it was grouped into the inefficient category. This categorization was done based on Mahssa [58]. In that thesis, similar type rank and percentile analysis was done for 100 residential building in Toronto. After that, an energy saving analysis was conducted for each of the companies in in all three percentiles. Figure 5.12 depicts the ranking distribution of plants based on per unit area consumption. According to Figure 5.12, the most efficient plant consumes $4.85 \mathrm{~m}^{3} / \mathrm{ft}^{2}$ or less and the most inefficient plant consumes $5.86 \mathrm{~m}^{3} / \mathrm{ft}^{2}$ or more. 


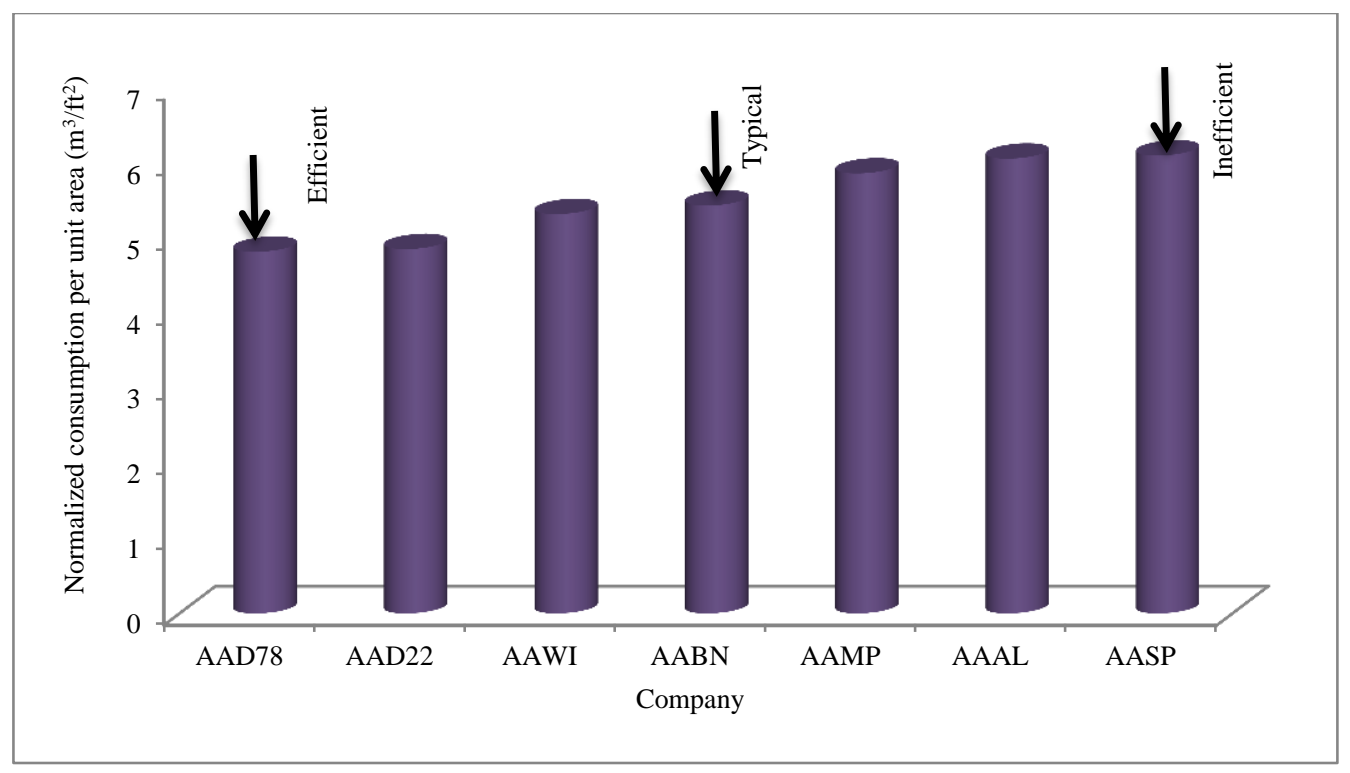

Figure 5.12: Annual normalized natural gas consumption benchmark per unit area of seven powder coating companies

Using Equation 4.5, 4.6 and 4.7 [58] potential savings of typical and inefficient companies were calculated. Table 5.4 presents the potential reductions of natural gas, cost and GHG emissions. According to Table 5.4 based on benchmark industry typical and inefficient companies can save 10 to 21 percent of their total energy consumption that contributes 55,270 to $77,881 \mathrm{~m}^{3} /$ year of natural gas consumption and a related cost of $\$ 13,818$ to $\$ 19,470$ per year.

Table 5.4: Potential reductions of natural gas, cost and GHG emission

\begin{tabular}{|c|c|c|c|c|}
\hline Benchmark & Saving Potential (\%) & $\begin{array}{c}\text { Natural Gas } \\
\text { Savings }\left(\mathrm{m}^{3}\right)\end{array}$ & Cost Savings (\$) & $\begin{array}{c}\text { GHG Emission } \\
\text { Reduction } \\
\text { (tonne) }\end{array}$ \\
\hline Efficient & $0-9$ & $0-55,270$ & $0-13,817$ & $0-3,973$ \\
\hline Typical & $10-18$ & $55,270-73,455$ & $13,818-18,364$ & $3,974-5,281$ \\
\hline Inefficient & $19-21$ & $73,455-77,881$ & $18,365-19,470$ & $5,281-5,599$ \\
\hline
\end{tabular}

\subsubsection{Ranking Distribution of Powder Coating Industries Based on Area x Operational Hr.}

A ranking based distribution of seven powder coating industries' consumption per unit area multiplied with operational hour was conducted. Figure 5.13 presents the ranking based distribution. According to Figure 5.13, the most efficient plant consumes $0.0005 \mathrm{~m}^{3} / \mathrm{ft}^{2}$-hr or less and the most inefficient plant consumes $0.0012 \mathrm{~m}^{3} / \mathrm{ft}^{2}$-hr or more. 


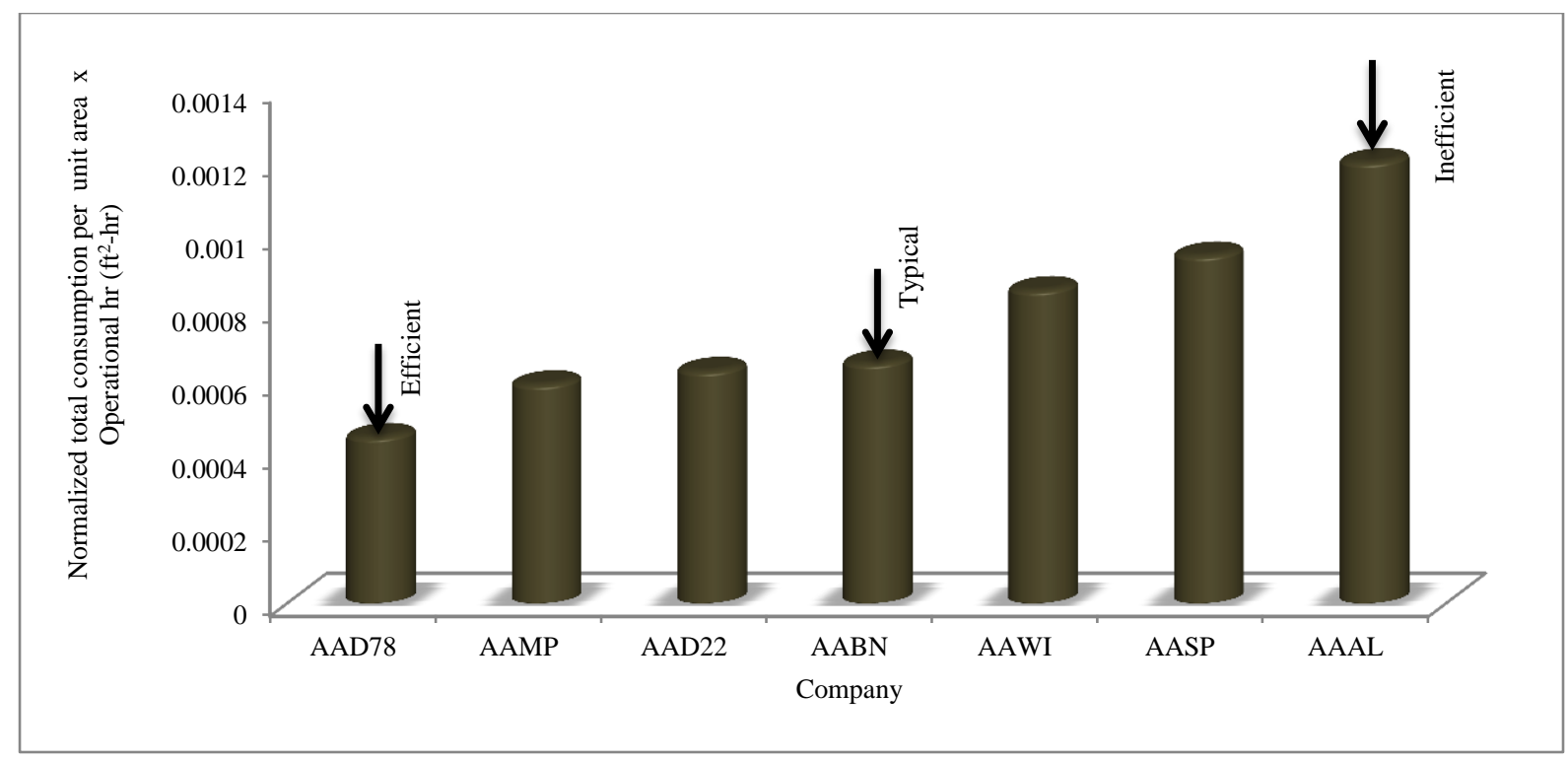

Figure 5.13: Annual normalized natural gas consumption benchmark per unit area multiplied with operational hour of seven powder coating companies

Using Equation 4.25, 4.26 and 4.27, potential savings of in typical and inefficient companies were calculated. Table 5.5 presents the potential reductions of natural gas, cost and GHG emission.

Table 5.5: Potential reductions of natural gas, cost and GHG emission

\begin{tabular}{|c|c|c|c|c|}
\hline Benchmark & $\begin{array}{c}\text { Saving potential } \\
(\%)\end{array}$ & $\begin{array}{c}\text { Natural Gas } \\
\text { Savings }\left(\mathrm{m}^{3}\right)\end{array}$ & Cost Savings (\$) & $\begin{array}{c}\text { GHG Emission } \\
\text { Reduction } \\
\text { (tonne) }\end{array}$ \\
\hline Efficient & $0-28$ & $0-76,997$ & $0-19,249$ & $0-5,535$ \\
\hline Typical & $29-47$ & $76,997-88,089$ & $19,249-22,022$ & $5,535-6,333$ \\
\hline Inefficient & $48-62$ & $88,089-93,202$ & $22,022-23,301$ & $6,333-6,700$ \\
\hline
\end{tabular}

According to Table 5.5, based on a benchmark industry, typical and inefficient plants can save 29 to 62 percent of their total energy consumption. Total natural gas savings was calculated for typical and inefficient companies was 76,997 to $93,202 \mathrm{~m}^{3} /$ year and related cost savings was calculated $\$ 19,249$ to $\$ 23,301$ per year that is a good amount of money and natural gas consumption that inefficient companies can save. The savings of natural gas will also reduce GHG emissions by 5535 to 6700 ton/year. 


\subsubsection{Ranking Distribution of Food Industries Based on Per Unit Plant Area:}

A ranking based distribution of four food industries' consumption per unit area was conducted. Figure 5.14 presents the ranking based distribution.

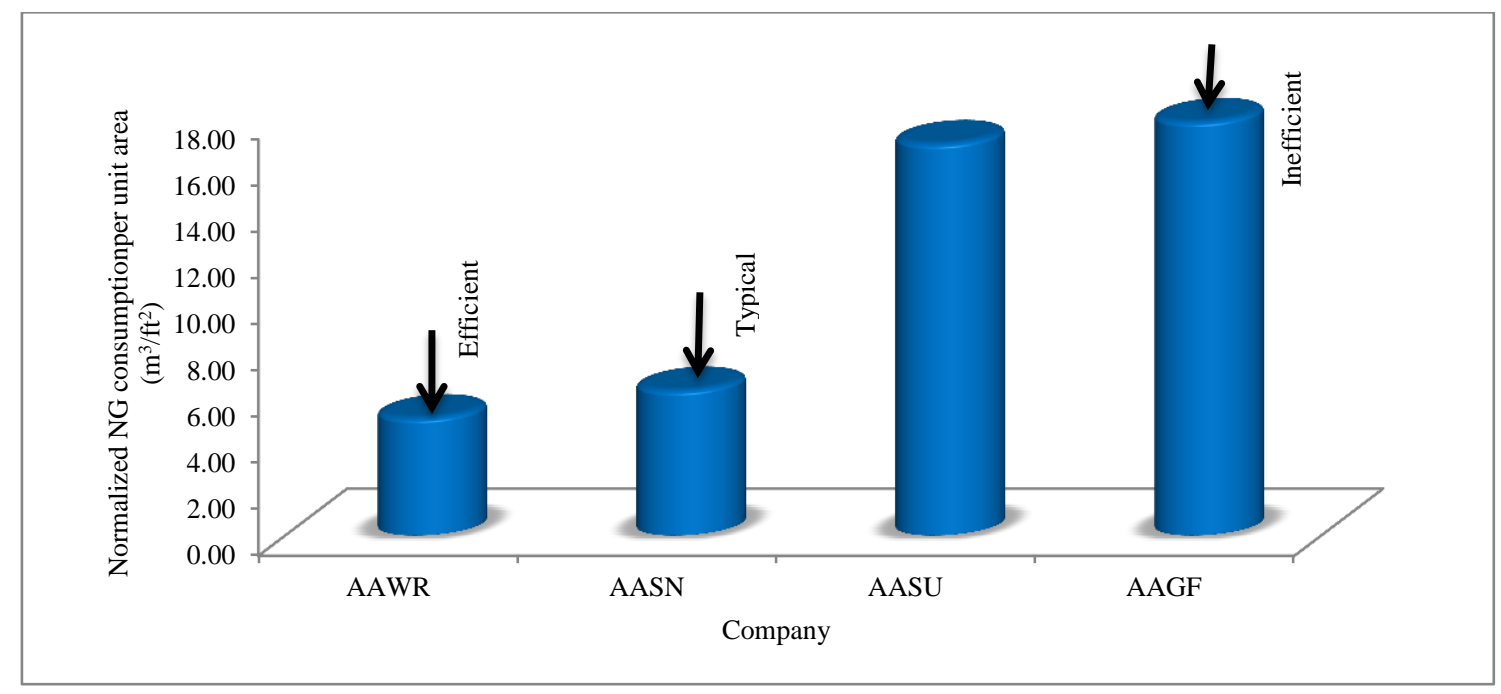

Figure 5.14: Annual normalized natural gas consumption benchmark per unit area of four food companies

According to Figure 5.14 the most efficient plant consumes $5.09 \mathrm{~m}^{3} / \mathrm{ft}^{2}$ or less and the most inefficient plant consumes $17.92 \mathrm{~m}^{3} / \mathrm{ft}^{2}$ or more which is $72 \%$ more than the most efficient plant. Using Equation 4.5, 4.6 and 4.7, potential savings of typical and inefficient companies were calculated. Table 5.6 presents the potential reductions of natural gas, cost and GHG emission.

Table 5.6: Potential reductions of natural gas, cost and GHG emission

\begin{tabular}{|c|c|c|c|c|}
\hline Benchmark & $\begin{array}{c}\text { Saving Potential } \\
(\%)\end{array}$ & $\begin{array}{c}\text { Natural Gas Savings } \\
\left(\mathrm{m}^{3}\right)\end{array}$ & Cost Savings (\$) & $\begin{array}{c}\text { GHG Emission } \\
\text { Reduction } \\
\text { (tonne) }\end{array}$ \\
\hline Efficient & $0-19$ & $0-104,971$ & $0-26,243$ & $0-7,546$ \\
\hline Typical & $20-70$ & $104,971-472,238$ & $26,244-118,060$ & $7,546-33,949$ \\
\hline Inefficient & $71-72$ & $472,239-2,415,899$ & $118,060-603,975$ & $33,950-173,680$ \\
\hline
\end{tabular}

According to Table 5.6 based on a benchmark company typical and inefficient plants can save 20 to 72 percent of their energy consumption. Total natural gas savings were calculated $104,971 \mathrm{~m}^{3} / \mathrm{yr}$. to $2,415,899 \mathrm{~m}^{3} / \mathrm{yr}$. and related cost $\$ 26,244$ to $\$ 603,975$ per year. The reduction 
of natural gas consumption will also reduce GHG emissions by 7,546 ton to 173,680 ton per year.

\subsubsection{Ranking Distribution of Food Companies Based on Plant Area x Operational Hour}

A ranking based distribution of four food industries' consumption per unit area multiplied with operational hour was conducted. Figure 5.15 presents the ranking based distribution.

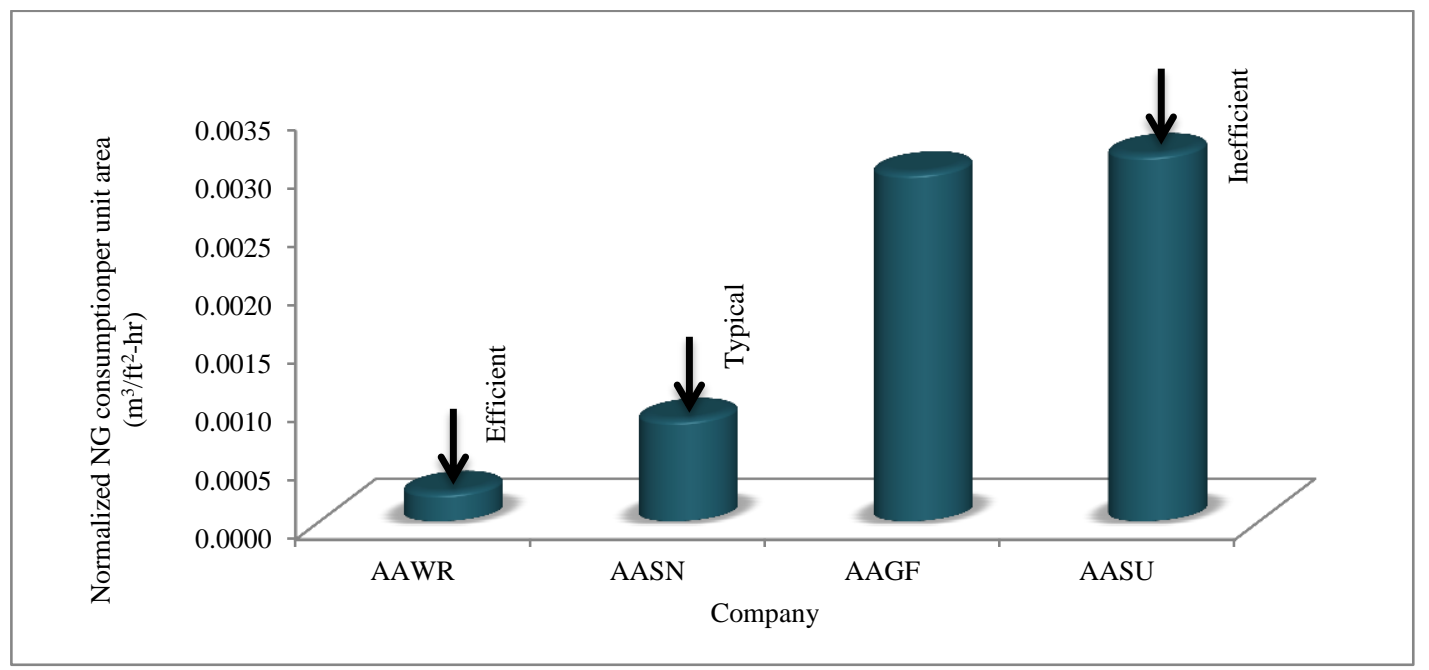

Figure 5.15: Annual normalized natural gas consumption benchmark per unit area multiplied with operational hours of four food companies

According to Figure 5.15, the most efficient plant consumes $0.0003 \mathrm{~m}^{3} / \mathrm{ft}^{2}-\mathrm{hr}$ or less natural gas and the most inefficient plant consumes $0.0031 \mathrm{~m}^{3} / \mathrm{ft}^{2}-\mathrm{hr}$ or more which is $92 \%$ more than the most efficient one. Microsoft EXCEL Rank and Percentile Analysis was conducted to rank plants. Using Equation 4.25, 4.26 and 4.27, potential savings of typical and inefficient companies were calculated. Table 5.7 presents the potential reductions of natural gas, cost and GHG emission.

Table 5.7: Potential reductions of natural gas, cost and GHG emission

\begin{tabular}{|c|c|c|c|c|}
\hline Benchmark & $\begin{array}{c}\text { Saving Potential } \\
(\%)\end{array}$ & $\begin{array}{c}\text { Natural Gas Savings } \\
\left(\mathrm{m}^{3}\right)\end{array}$ & Cost Savings (\$) & $\begin{array}{c}\text { GHG Emission } \\
\text { Reduction } \\
\text { (tonne) }\end{array}$ \\
\hline Efficient & 0 & 0 & 0 & 0 \\
\hline Typical & $1-71$ & $1-392,868$ & $1-98,217$ & $1-28,243$ \\
\hline
\end{tabular}




\begin{tabular}{|l|c|c|c|c|}
\hline Inefficient & $72-92$ & $392,869-3,090,975$ & $98,218-772,744$ & $28,244-222,212$ \\
\hline
\end{tabular}

According to Table 5.7, based on a benchmark industry typical and inefficient plants can save 71 to 92 percent of their natural gas consumption which indicates natural gas consumption reduction $392,868 \mathrm{~m}^{3}$ to $3,090,975 \mathrm{~m}^{3}$ and related cost $\$ 98,217$ to $\$ 772,744$ per year. The reduction of GHG emissions were calculated 28,243 ton to 222,212 ton per year.

\subsection{Ventilation Analysis}

As described in chapter 4, the seasonal natural gas consumption of plants was separated into transmission heat loss and ventilation related consumption. Multivariable regression analysis was used to estimate the heat transfer coefficient (U-value) of transmission heat loss and CFM of total ventilation consumption of plants. Equations 4.14, 4.15 and 4.16 were used to estimate the value of $x_{11}, x_{12}, x_{21}$, and $x_{22}$ for $1^{\text {st }}$ level multivariable regression analysis. Due to variation in the data, a large bias was created in the multivariable regression analysis. To solve the issue, infiltration loss and ventilation consumption were considered together as a single term with two unknown parameters; CFM for ventilation and Air Change per Hour (ACH) for infiltration loss, respectively and together considered $x_{2}$ in this analysis. Table 5.8 was presents one company AAAL's estimated $x_{1}$ and $x_{2}$ values.

Table 5.8: Values of $x_{1}$ and $x_{2}$ for plant AAAL in winter months

\begin{tabular}{|c|c|c|}
\hline $\begin{array}{c}\text { Normalized Seasonal } \\
\text { Consumption (Btu), Y }\end{array}$ & $\begin{array}{c}\text { Transmission Heat Loss, } x_{1} \\
=\left(x_{11}+x_{12}\right),(\mathrm{Btu})\end{array}$ & $\begin{array}{c}\text { Total Ventilation }, x_{2}=\left(x_{21}+x_{22}\right), \\
(\mathrm{Btu})\end{array}$ \\
\hline $793,664,892$ & $3,335,935,246$ & $1,070,604,208$ \\
\hline $697,933,344$ & $2,941,130,682$ & $942,282,351$ \\
\hline $615,999,809$ & $2,603,643,514$ & $819,133,342$ \\
\hline $388,475,020$ & $1,666,472,151$ & $499,723,144$ \\
\hline $197,974,709$ & $881,305,874$ & $227,675,313$ \\
\hline $101,861,466$ & $485,044,820$ & $94,016,257$ \\
\hline $320,185,680$ & $1,384,579,899$ & $400,501,719$ \\
\hline $484,696,506$ & $2,062,453,502$ & $635,704,381$ \\
\hline $686,465,384$ & $2,893,978,410$ & $918,835,052$ \\
\hline
\end{tabular}


The calculated $x_{1}$ and $x_{2}$ values were used to conduct a $1^{\text {st }}$ level multivariable regression analysis to determine wall and roof insulations and ventilation CFM. Equation 4.12 was used to conduct the multivariable regression analysis in Microsoft Excel. Figure 5.16 presents the $1^{\text {st }}$ level multivariable regression analysis of plant AAAL. Similarly remaining 12 companies' multivariable regression analyses are presented in Appendix D.

\begin{tabular}{|c|c|c|c|c|c|c|c|c|}
\hline \multicolumn{9}{|l|}{ SUMMARY OUTPUT } \\
\hline \multicolumn{9}{|c|}{ Regression Statistics } \\
\hline Multiple R & 0.99 & & & & & & & \\
\hline R Square & 0.99 & & & & & & & \\
\hline Adjusted R Square & 0.85 & & & & & & & \\
\hline Standard Error & 539989.33 & & & & & & & \\
\hline Observations & 9 & & & & & & & \\
\hline \multicolumn{9}{|l|}{ ANOVA } \\
\hline & $d f$ & $S S$ & $M S$ & $F$ & Significance $F$ & & & \\
\hline Regression & 2 & $2.50564 \mathrm{E}+18$ & $1.2528 \mathrm{E}+18$ & 4296526.91 & $3.4042 \mathrm{E}-19$ & & & \\
\hline Residual & 7 & $2.04112 \mathrm{E}+12$ & $2.9159 \mathrm{E}+11$ & & & & & \\
\hline \multirow[t]{2}{*}{ Total } & 9 & $2.50564 \mathrm{E}+18$ & & & & & & \\
\hline & Coefficients, & tandard Error & $t$ Stat & $P$-value & Lower 95\% & Upper $95 \%$ & ower 95.0' & per $95.0 \%$ \\
\hline Intercept & 0.00 & \#N/A & \#N/A & \#N/A & \#N/A & \#N/A & \#N/A & \#N/A \\
\hline TRANSMISSION, $\beta_{1}$ & 0.17 & 0.00 & 92.89 & 0.00 & 0.16 & 0.17 & 0.16 & 0.17 \\
\hline VENTILATION, $\beta_{2}$ & 0.21 & 0.01 & 36.82 & 0.00 & 0.20 & 0.23 & 0.20 & 0.23 \\
\hline
\end{tabular}

Figure 5.16: $1^{\text {st }}$ Level multivariable regression analysis of plant AAAL

Figure 5.16 presents the Microsoft Excel multiple regression analysis. The result of multivariable regression shows that the intercept is 0 , the coefficient of ventilation $\left(\beta_{1}\right)$ is 0.17 , and the coefficient for transmission heat loss $\left(\beta_{2}\right)$ is 0.21 . Using these coefficients ventilation and transmission heat losses of all audited plants were calculated using Equation 4.12 and then compared with respect to the seasonal consumption. 
Table 5.9: Percent consumption for total ventilation and transmission heat loss

\begin{tabular}{|c|c|c|c|c|c|}
\hline Facility & $\begin{array}{c}\text { Total Seasonal } \\
\text { Consumption } \\
\left(\mathrm{m}^{3}\right)\end{array}$ & $\begin{array}{c}\text { Total } \\
\text { Ventilation } \\
\left(\mathrm{m}^{3}\right)\end{array}$ & $\begin{array}{c}\text { Total } \\
\text { Transmission } \\
\left(\mathrm{m}^{3}\right)\end{array}$ & $\begin{array}{c}\text { Total } \\
\text { Ventilation } \\
(\%)\end{array}$ & $\begin{array}{c}\text { Transmission } \\
\text { Heat Loss }(\%)\end{array}$ \\
\hline AAD78 & 785,492 & 238,896 & 548,446 & 30 & 70 \\
\hline AAD22 & 826,790 & 157,196 & 673,706 & 19 & 81 \\
\hline AASP & 291,617 & 802,77 & 208,512 & 28 & 72 \\
\hline AAMP & 194,269 & 101,214 & 93,055 & 52 & 48 \\
\hline AABN & 109,752 & 36,722 & 74,178 & 33 & 68 \\
\hline AAWI & 105,655 & 5,356 & 100,386 & 5 & 95 \\
\hline AAAL & 123,401 & 34,238 & 88,259 & 28 & 72 \\
\hline AAWR & 492,236 & 164,696 & 332,686 & 33 & 68 \\
\hline AASU & 88,461 & 45,351 & 44,594 & 51 & 50 \\
\hline AASN & 194,269 & 174,183 & 20,297 & 90 & 10 \\
\hline AAGF & 591,342 & 98,567 & 493,390 & 17 & 83 \\
\hline AAKK1 & 455,003 & 75,842 & 379,635 & 17 & 83 \\
\hline AAKK2 & 208,398 & 18,489 & 190,152 & 9 & 91 \\
\hline
\end{tabular}

Table 5.9 depicts that, facilities are using most of their seasonal energy consumption for space heating purposes.

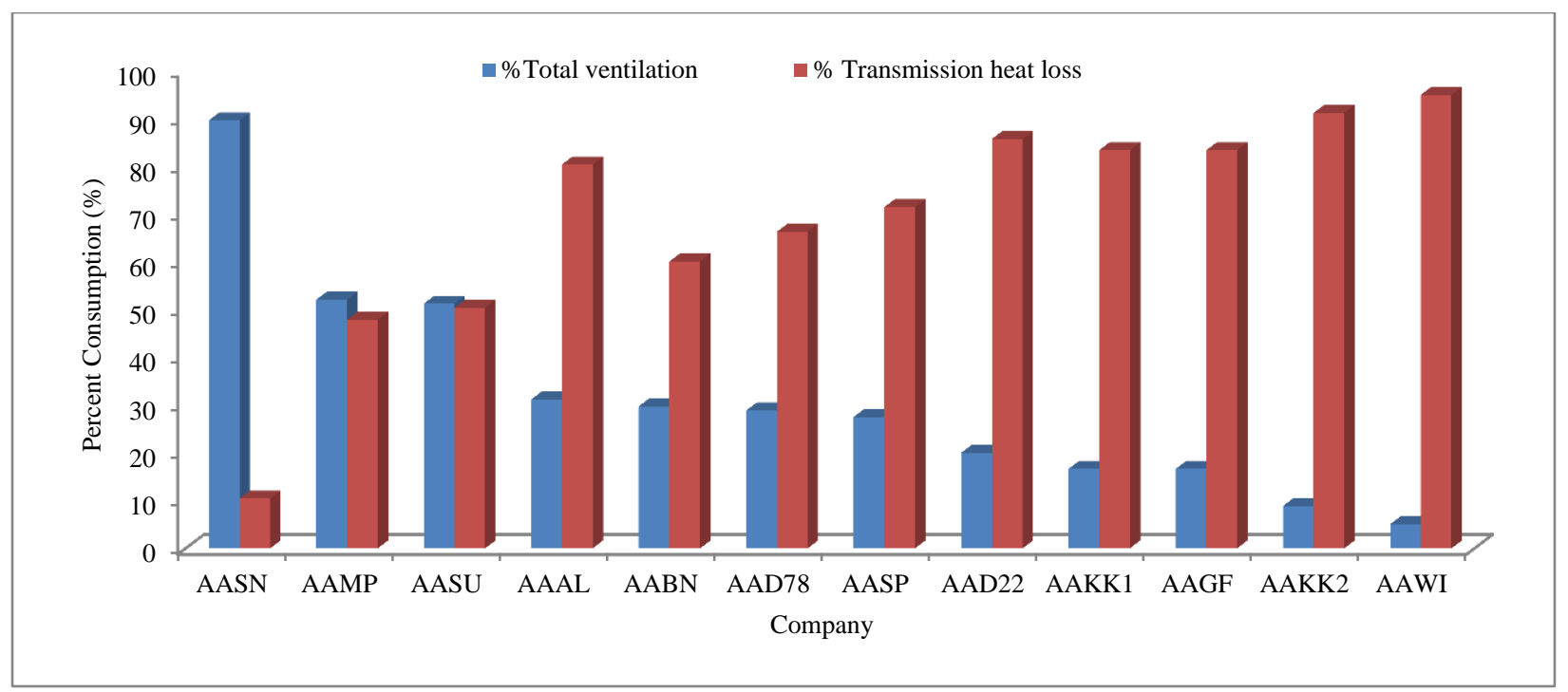

Figure 5.17: Percent consumption of plant total ventilation and transmission heat loss

According to Figure 5.17 the all plants consume an average of $69 \%$ of seasonal consumption for transmission heat loss purpose which indicates $249,792 \mathrm{~m}^{3}$ natural gas consumption per year and $32 \%$ for ventilation purposes which indicates $94,694 \mathrm{~m}^{3} /$ year. That means companies are using most of their seasonal natural gas consumption for space heating 
purpose. Enbridge Gas Distribution Inc. considers standard $1 \mathrm{~m}^{3} / \mathrm{ft}^{2} /$ year consumption for plant space heating purpose. To evaluate the validation of this standard, the plants have calculated the space heating using multivariable regression and space heating calculated using Enbridge standard was compared.

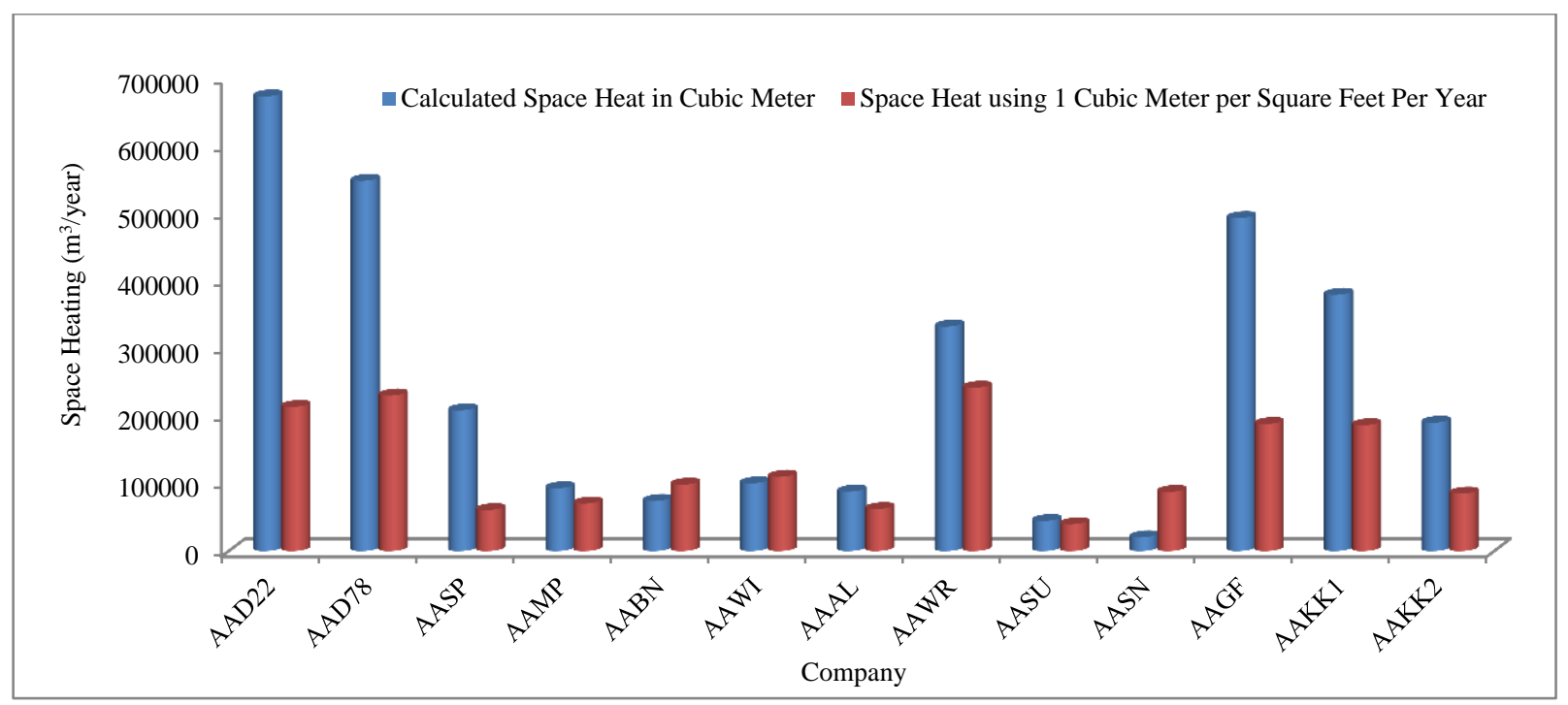

Figure 5.18: Comparison between plants calculated total transmission heat loss and Enbridge standard

According to Figure 5.18 there are differences between calculated space heating and space heating using the Enbridge standard. Therefore, the assumption for the Enbridge standard was too strict and unreliable. In multivariable regression analysis, the plant wall and roof insulation were calculated. In this case, equipment efficiency was unknown, so in the multivariable regression equation, U-values (heat transfer coefficient) were embedded with equipment efficiency. Figure 5.19 presents the calculated $\mathrm{U}$ values including equipment efficiency. 


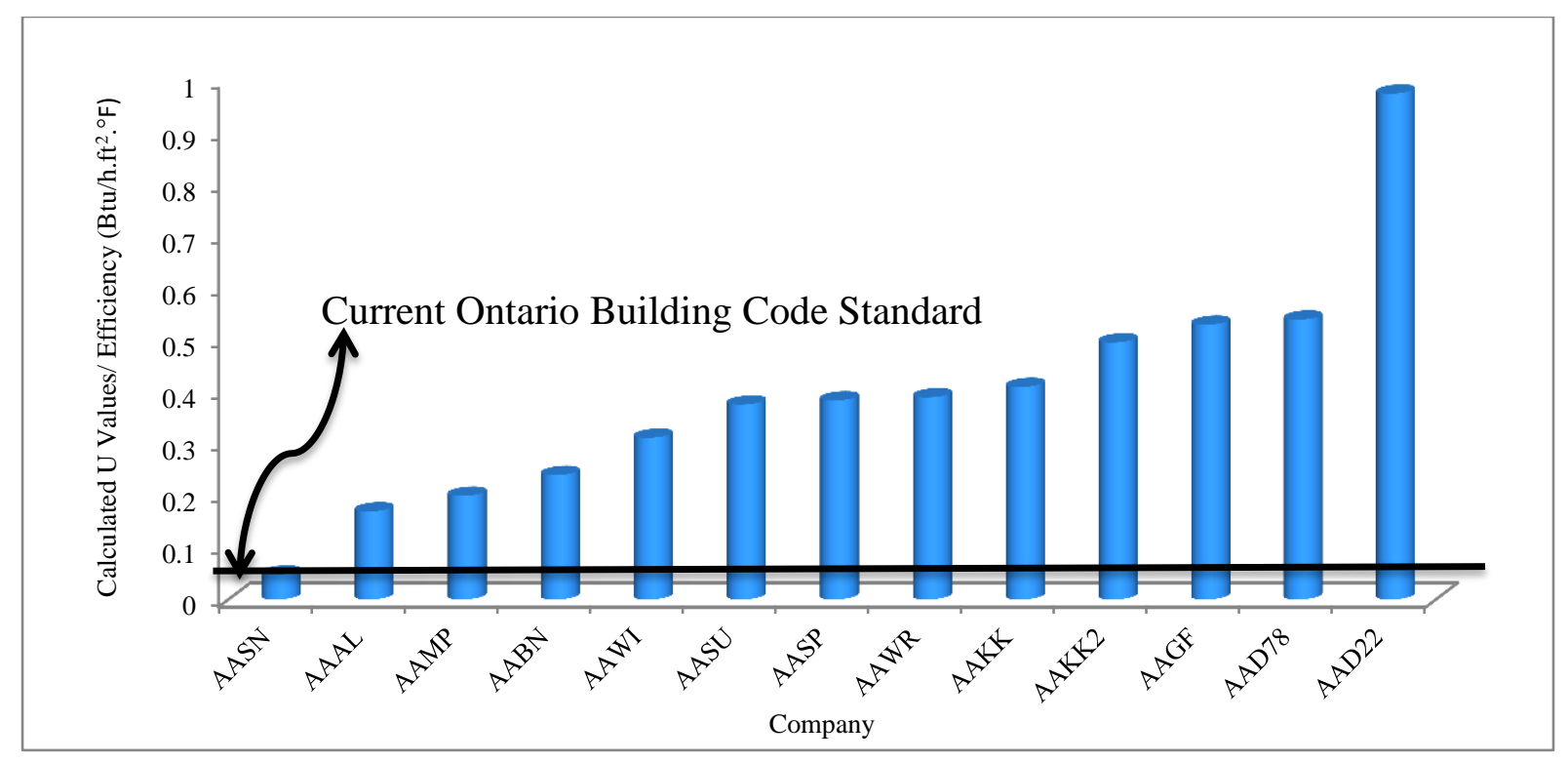

Figure 5.19: Plant calculated U Values/ equipment efficiency

According to Figure 5.20 plants' U-Values/Efficiency were calculated; these values were determined to range from 0.048 to $0.97 \mathrm{Btu} / \mathrm{h} . \mathrm{ft}^{2}{ }^{\circ} \mathrm{F}$. The average U-Value/efficiency was calculated $0.39 \mathrm{Btu} / \mathrm{h} . \mathrm{ft}^{2}{ }^{\circ} \mathrm{F}$. A sensitivity analysis was conducted to find the equipment efficiency and plant actual U-Values for wall and roof insulation. Figure 5.20 presents the sensitivity analysis of plant equipment's efficiency from $30 \%$ to $95 \%$.

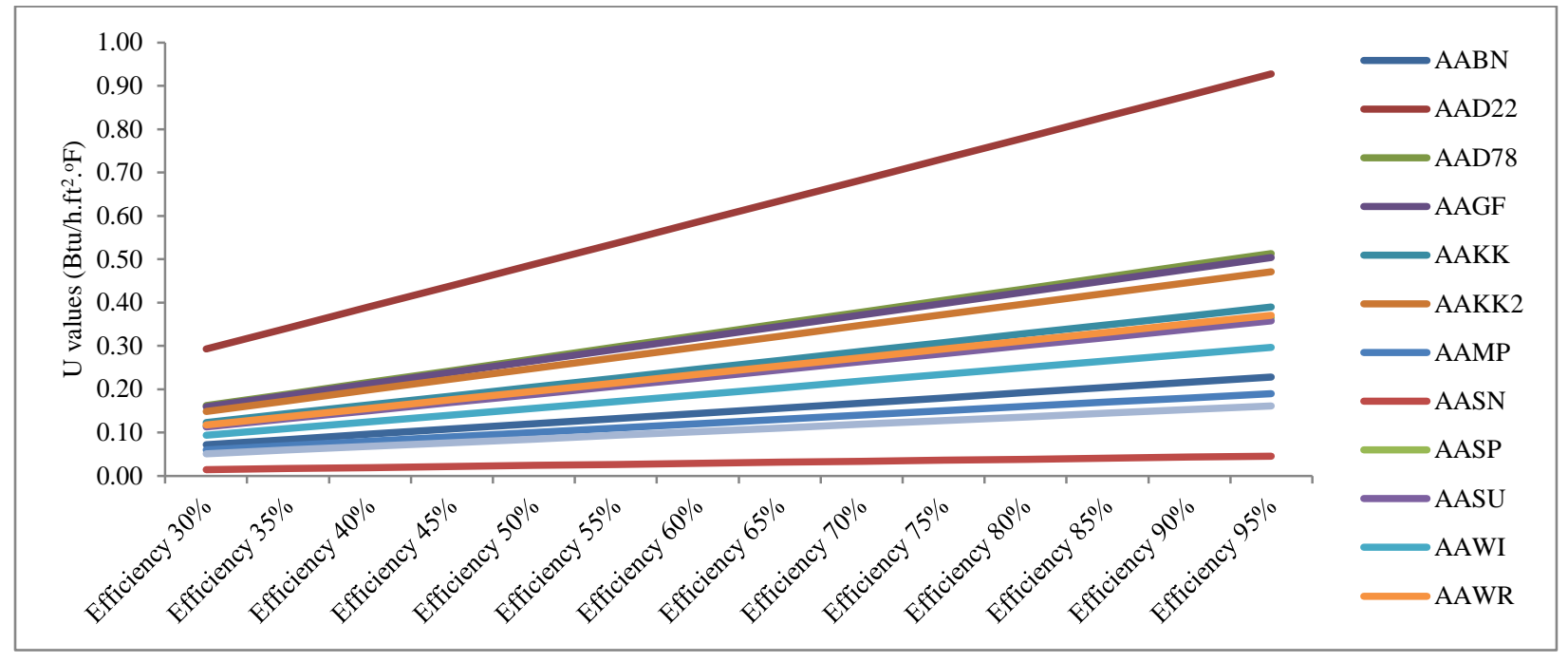

Figure 5.20: Sensitivity analysis for plant's equipment efficiency 
After calculating U-values for different equipment efficiency, these were compared with the Ontario Building Code'. Figure 5.21 presents the Ontario building Codes for wall insulation from 1975 to 2006 [50].

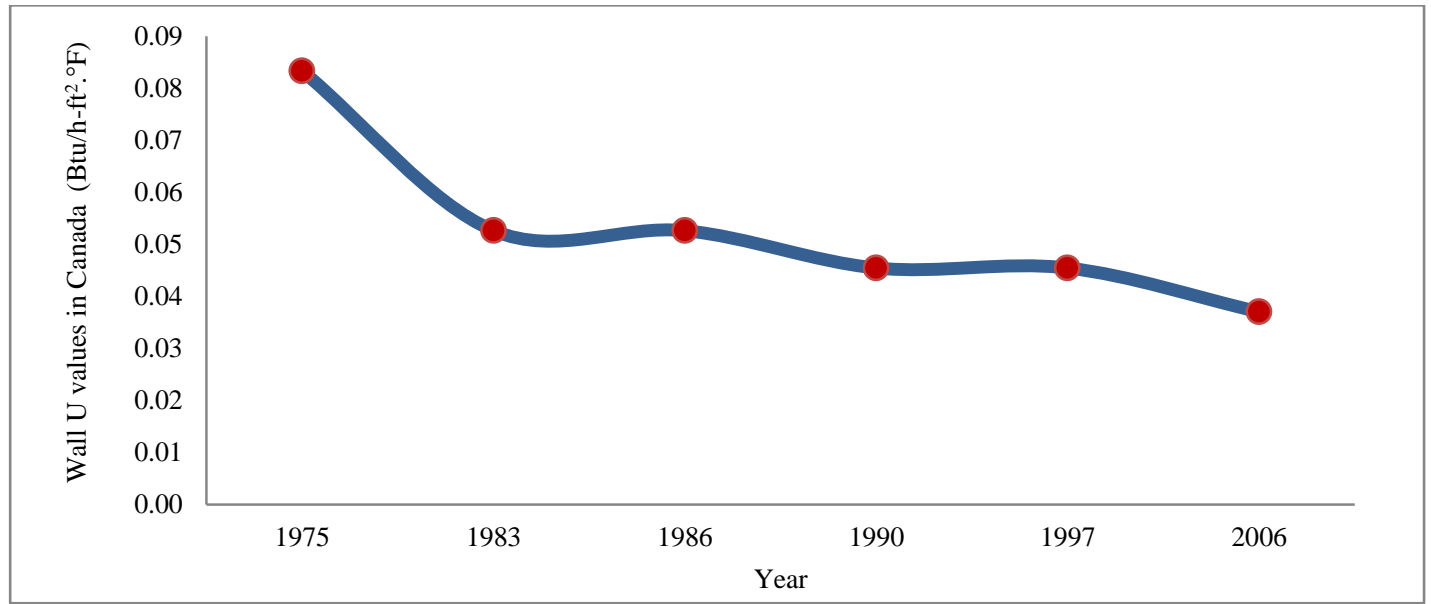

Figure 5.21: Ontario building code for wall insulation of plants from 1975 to 2006

According to Figure 5.21 plants' U-values range between 0.05 to $0.08 \mathrm{Btu} / \mathrm{h}-\mathrm{ft}^{2 \circ} \mathrm{F}$. Then, calculated $U$ values were compared to the Ontario Building code. Figure 5.22 presents the comparison.

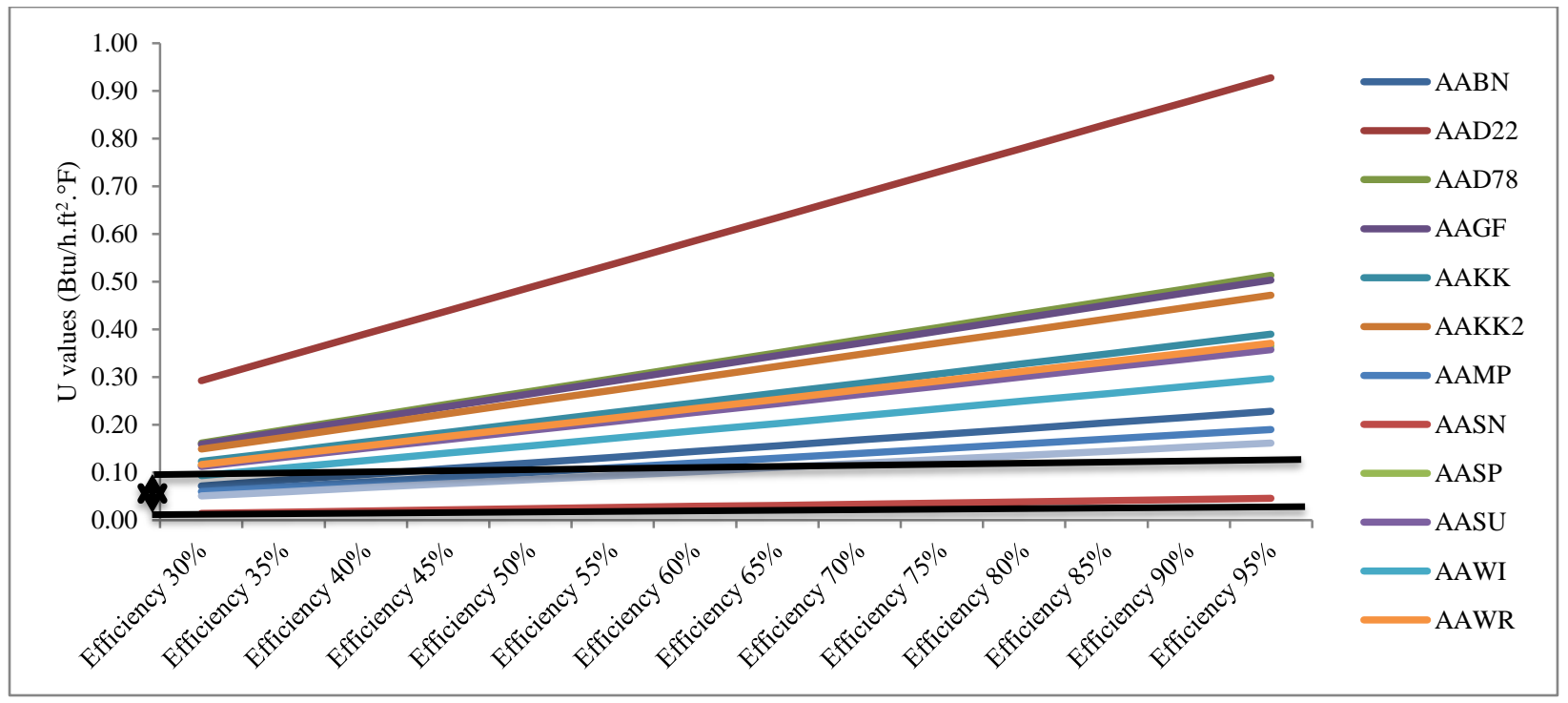

Figure 5.22: Comparison of calculated u values with Ontario Building Code

According to Figure 5.22 some plants have really good wall insulation, some plants have moderate, but one plants has poor wall insulation. 
In the $2^{\text {nd }}$ level multivariable regression analysis, a decision was made to separate the building ventilation CFM and Air change per hour for infiltration heat loss (shown in Appendix E). In the second layer, Equation 4.13 was used for conducting multivariable regression analysis. Table 5.10 presents the calculated value for ventilation CFM and ACH for infiltration loss.

Table 5.10: Value of ventilation CFM/efficiency and ACH/efficiency

\begin{tabular}{|c|c|c|c|}
\hline Type & Company & $\begin{array}{c}\text { Ventilation } \\
\text { CFM/Efficiency }\end{array}$ & $\begin{array}{c}\text { Infiltration } \\
\text { ACH/Efficiency }\end{array}$ \\
\hline Powder coating & AABN & 200 & 0.13 \\
\hline & AAD22 & 547 & 0.28 \\
\hline & AAD78 & 419 & 0.40 \\
\hline & AASP & 95 & 0.51 \\
\hline & AAMP & 8 & 0.55 \\
\hline Food industry & AAGF & 136 & 0.20 \\
\hline & AASN & 46 & 0.77 \\
\hline & AASU & 96 & 0.44 \\
\hline Packaging & AAKK & 374 & 0.15 \\
\hline & AAKK2 & 46 & 0.08 \\
\hline
\end{tabular}

Air change per hour was also estimated by Younes [43] in the USA and building envelop condition was standardized. Calculated air change per hour was compared with Younes standardization [43]. According to the standard, in winter time if ACH ranges between $0.2-0.6$ the envelope is tight, if $0.6-1.0$ then envelope is medium and $1.0-2.0$ then the envelope is loose. Calculated $\mathrm{ACH}$ for audited building was compared with the standard and building envelope condition was determined. Table 5.11 presents the plant envelope condition.

Table 5.11: Plant envelopes condition based on calculated ACH

\begin{tabular}{|c|c|c|}
\hline Company & Infiltration ACH & Envelope Condition \\
\hline AABN & 0.16 & Tight \\
\hline AAD22 & 0.35 & Tight \\
\hline AAD78 & 0.49 & Tight \\
\hline AAGF & 0.25 & Tight \\
\hline AAKK & 0.19 & Tight \\
\hline AAKK2 & 0.10 & Tight \\
\hline AAWR & 0.32 & Tight \\
\hline AASU & 0.55 & Tight \\
\hline AAMP & 0.69 & Medium \\
\hline AASN & 0.96 & Medium \\
\hline AASP & 0.63 & Medium \\
\hline
\end{tabular}




\subsection{Saving Analysis}

\subsubsection{Transmission Heat Loss per Unit Area}

Annual total transmission heat loss includes heat loss from plant walls and roofs. Due to plant transmission heat losses, space heating is required. The total annual transmission heat loss was calculated using the $1^{\text {st }}$ level multivariable regression analysis. The annual transmission heat loss of the plant was plotted against the plant area because there are strong statistical relationships between transmission heat loss and plant area. In this case, thirteen audited industries in the Greater Toronto Area were considered. Figure 5.23 presents the scatter plot of plant annual transmission heat loss $\left(\mathrm{m}^{3} /\right.$ year) with respect to plant area $\left(\mathrm{ft}^{2}\right)$

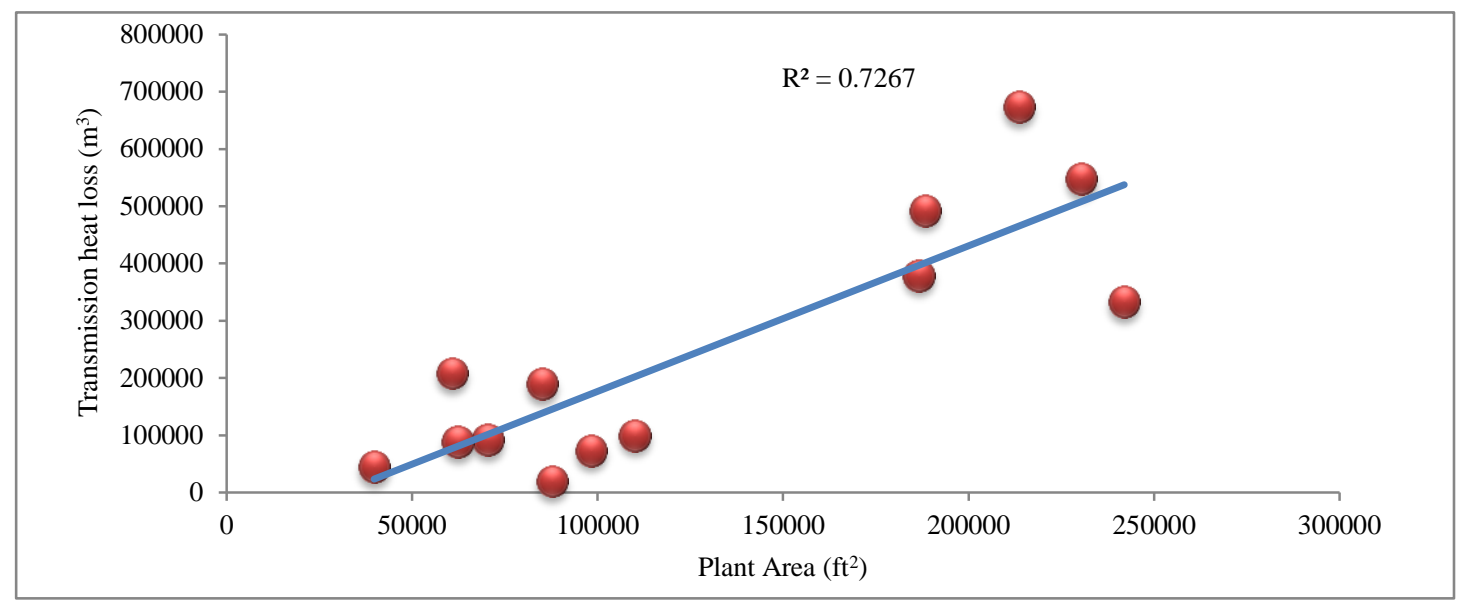

Figure 5.23: Scatter plot of transmission heat loss with plant area

According to Figure 5.23, there are large statistical relationships between the plant area and the transmission heat loss. After that, annual transmission heat losses per unit area between thirteen audited industries were compared. Here, the plants that used the least amount of energy per unit area was considered the most efficient plant and the ones who used the greatest amount of energy per unit area was considered the most inefficient plant. Microsoft EXCEL Rank and Percentile Analysis was conducted to rank plants. The benchmarking range for transmission heat loss per unit area are presented in Table 5.12

Table 5.12: Transmission heat loss benchmark range $\left(\mathrm{m}^{3} / \mathrm{ft}^{2}\right)$ for thirteen industries

\begin{tabular}{|c|c|}
\hline Consumption Benchmark & $\begin{array}{c}\text { Normalized Annual Transmission Heat Loss } \\
\left(\mathrm{m}^{3} / \mathrm{ft}^{2}\right)\end{array}$ \\
\hline Efficient & $0.23-0.91$ \\
\hline
\end{tabular}




\begin{tabular}{|c|c|}
\hline Typical & $0.92-1.42$ \\
\hline Inefficient & $1.43-3.43$ \\
\hline
\end{tabular}

According to Table 5.12, if companies consume $0.23 \mathrm{~m}^{3} / \mathrm{ft}^{2}$ to $0.91 \mathrm{~m}^{3} / \mathrm{ft}^{2}$ or less they were considered efficient plants. If companies consume 0.92 to $1.42 \mathrm{~m}^{3} / \mathrm{ft}^{2}$ they were considered the typical one and if companies consume 1.43 to $3.43 \mathrm{~m}^{3} / \mathrm{ft}^{2}$ or above they were considered inefficient plants. Figure 5.24 presents the dataset $\left(\mathrm{m}^{3} / \mathrm{ft}^{2}\right)$ for thirteen different industries in GTA.

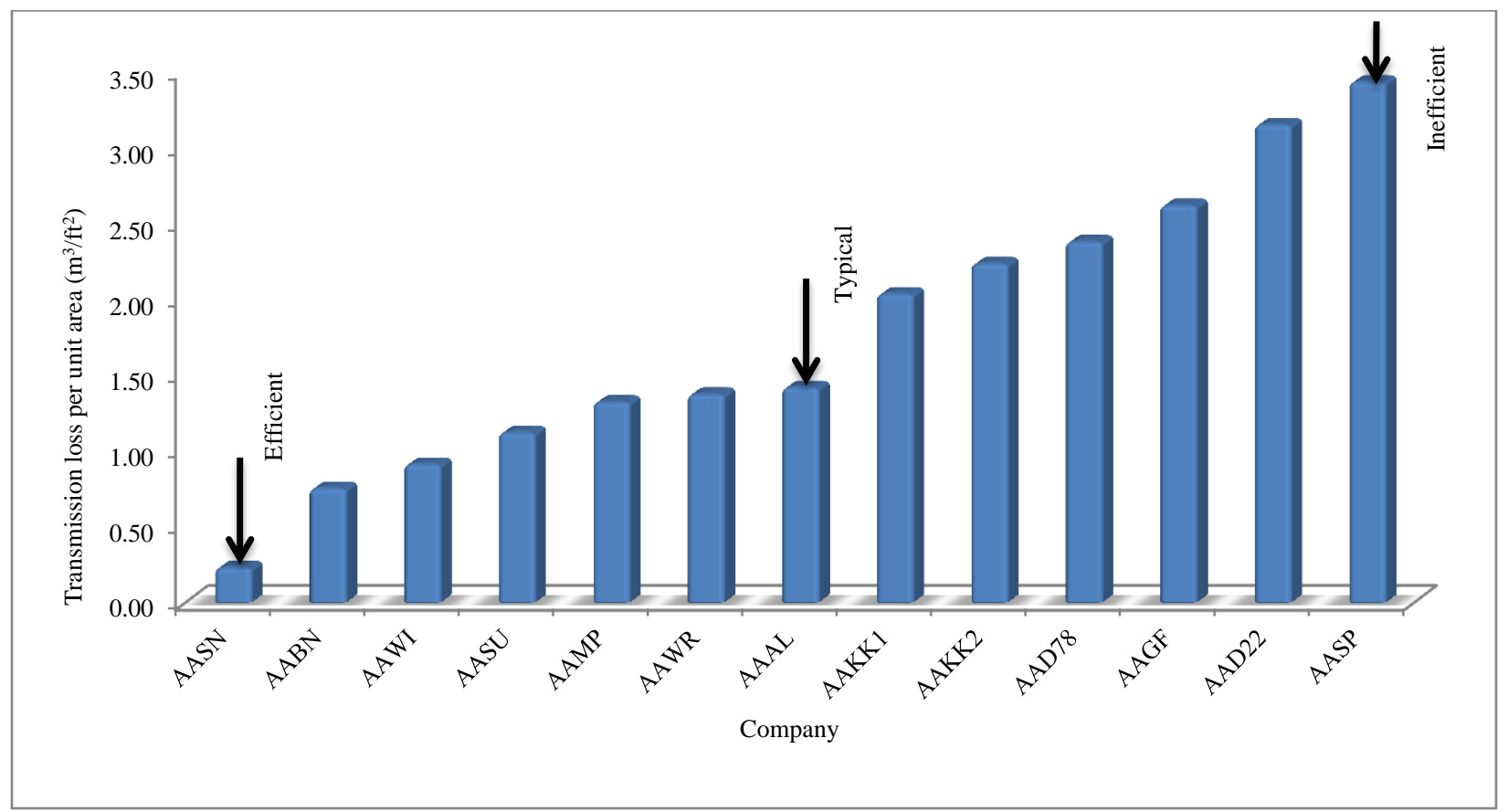

Figure 5.24: Annual transmission heat loss benchmark per unit area of thirteen audited industries

According to Figure 5.24, the most inefficient plant consumes fourteen times more than the most efficient plant. Using Equations 4.5, 4.6 and 4.7, potential savings of typical and inefficient companies were calculated. Table 5.13 presents the potential reductions of natural gas, cost and GHG emissions.

Table 5.13: Potential reductions of natural gas, cost and GHG emission

\begin{tabular}{|c|c|c|c|c|}
\hline Benchmark & Saving Potential (\%) & $\begin{array}{c}\text { Natural Gas } \\
\text { Savings }\left(\mathrm{m}^{3}\right)\end{array}$ & Cost Savings (\$) & $\begin{array}{c}\text { GHG Emission } \\
\text { Reduction } \\
\left.\text { (tonne } \mathrm{CO}_{2} \mathrm{eq}\right)\end{array}$ \\
\hline Efficient & $0-75$ & $0-74,909$ & $0-18,727$ & $0-5,385$ \\
\hline Typical & $76-84$ & $74,910-76,758$ & $18,728-19,190$ & $5,385-5,518$ \\
\hline
\end{tabular}




\begin{tabular}{|l|c|c|c|c|}
\hline Inefficient & $85-93$ & $76,758-624,216$ & $19,190-156,054$ & $5,518-44,875$ \\
\hline
\end{tabular}

According to Table 5.13, inefficient plants can save 76 to 93 percent of their annual transmission heat loss which indicates 5 to 50 percent of total natural gas reduction. The amount of natural gas consumption reduction was $74,910 \mathrm{~m}^{3}$ to $624,216 \mathrm{~m}^{3}$ and related cost $\$ 18,728$ to $\$ 156,054$ per year. Reductions of GHG emissions were calculated to be 5,385 ton to 44,875 ton per year.

\subsubsection{Transmission Heat Loss per Unit Area Multiplied With Operational Hour}

Transmission heat losses of plants were plotted with respect to plant area multiplied with operational hour. Figure 5.25 presents the scatter plot of plant annual transmission heat loss $\left(\mathrm{m}^{3} /\right.$ year) with respect to plant area multiplied by operational hour (hr).

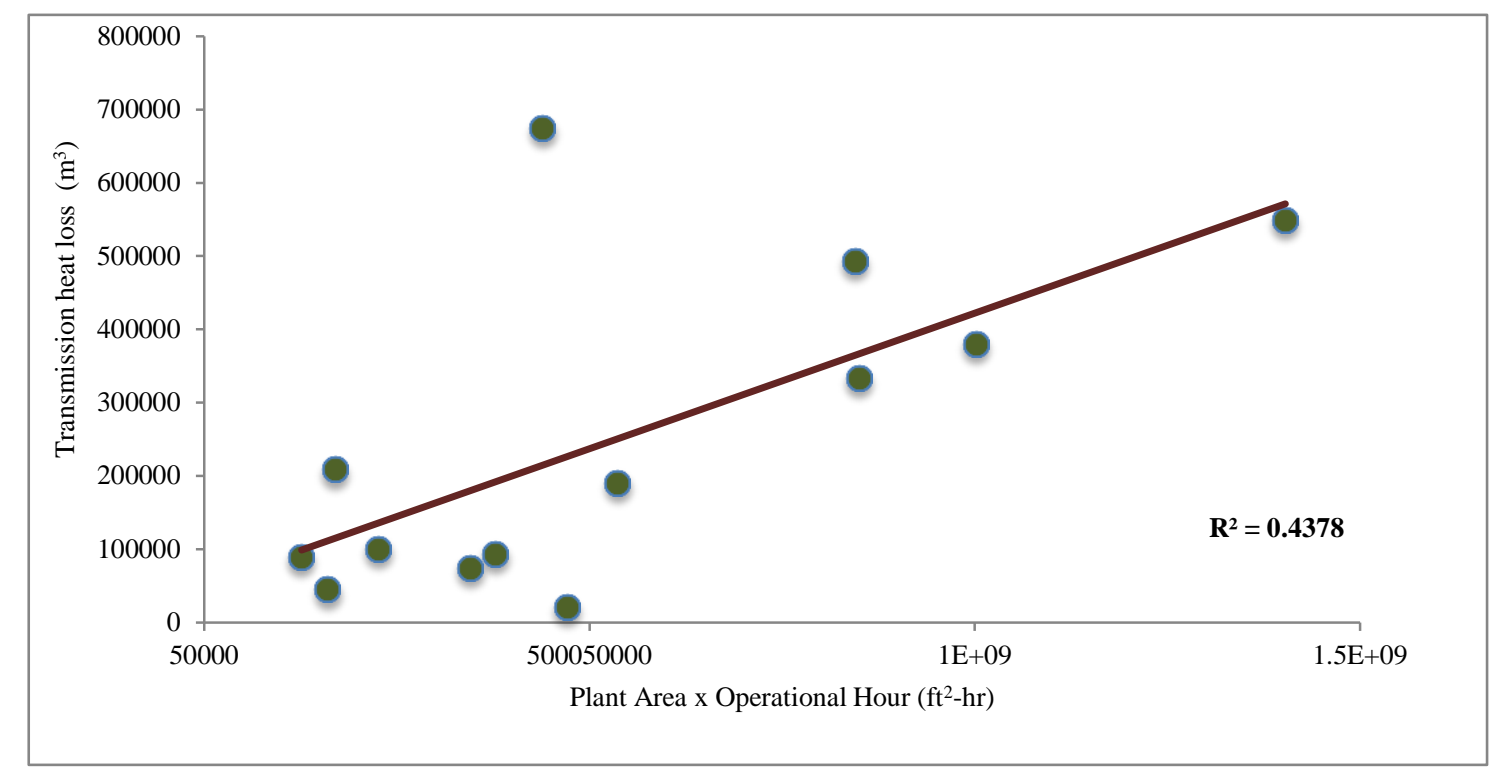

Figure 5.25: Scatter plot of transmission heat loss with area multiplied with operational hour

According to Figure 5.25, there is medium statistical relationship between plant area and transmission heat loss. Then, annual transmission heat loss per unit area multiplied with operational hour was compared between thirteen audited industries data. Similarly, the plant that uses the least amount of energy per unit area times operational hour was considered the most efficient plant and who uses the highest amount of energy per unit area times operational hour was considered the most inefficient plant. Microsoft Excel Rank and Percentile Analysis was 
conducted to rank plants. The benchmarking ranges for transmission heat loss per unit area are presented in Table 5.14.

Table 5.14: Transmission heat loss benchmark range $\left(\mathrm{m}^{3} / \mathrm{ft}^{2}-\mathrm{hr}\right)$ for thirteen industries

\begin{tabular}{|c|c|}
\hline $\begin{array}{c}\text { Consumption Benchmark } \\
\text { Efficient }\end{array}$ & $\begin{array}{c}\text { Normalized Annual Transmission Heat Loss } \\
\left(\mathrm{m}^{3} / \mathrm{ft}^{2}-\mathrm{hr}\right)\end{array}$ \\
\hline Typical & $0.00004-0.00027$ \\
\hline Inefficient & $0.00028-0.00039$ \\
\hline
\end{tabular}

According to Table 5.14, if the company consumes $0.00004 \mathrm{~m}^{3} / \mathrm{ft}^{2}-\mathrm{hr}$ to $0.00027 \mathrm{~m}^{3} / \mathrm{ft}^{2}$-hr or less was considered the efficient plant. If the company consumes 0.00028 to $0.00039 \mathrm{~m}^{3} / \mathrm{ft}^{2}-\mathrm{hr}$ was considered the typical one and if the company consumes 0.0004 to $0.0015 \mathrm{~m}^{3} / \mathrm{ft}^{2}-\mathrm{hr}$ or above was considered the inefficient plant. Figure 5.26 presents the dataset $\left(\mathrm{m}^{3} / \mathrm{ft}^{2}-\mathrm{hr}\right)$ for thirteen different industries in GTA.

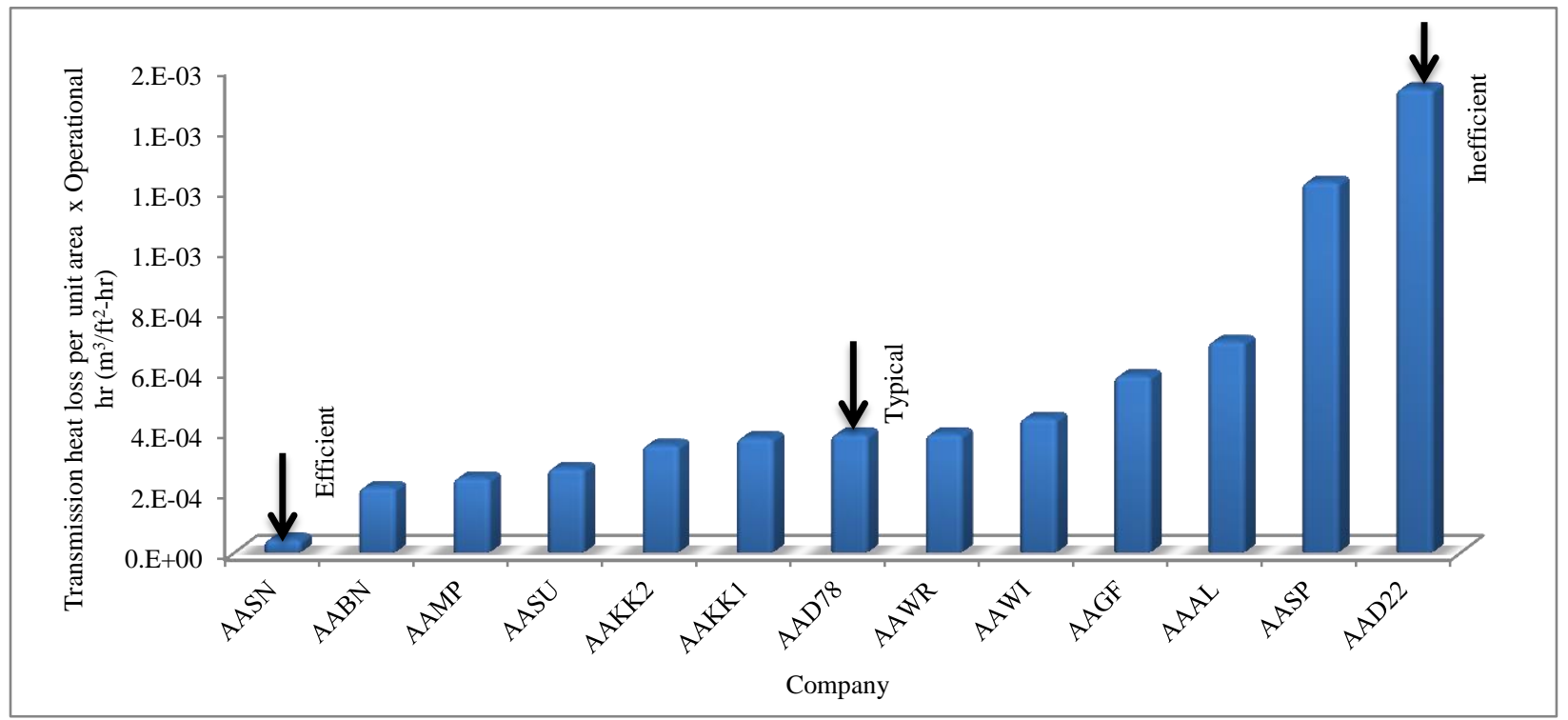

Figure 5.26: Annual transmission heat loss benchmark per unit area multiplied with operational hour of thirteen audited industries

According to Figure 5.26, the most inefficient plant consumes thirty seven times more than the most efficient plant. Using Equations 4.25, 4.26 and 4.27, potential savings of typical and inefficient companies were calculated. Table 5.15 presents the potential reductions of natural gas, cost and GHG emissions.

Table 5.15: Potential reductions of natural gas, cost and GHG emission 


\begin{tabular}{|c|c|c|c|c|}
\hline Benchmark & Saving Potential (\%) & $\begin{array}{c}\text { Natural Gas } \\
\text { Savings }\left(\mathrm{m}^{3}\right)\end{array}$ & Cost Savings (\$) & $\begin{array}{c}\text { GHG Emission } \\
\text { Reduction } \\
\left.\text { (tonne } \mathrm{CO}_{2} \mathrm{eq}\right)\end{array}$ \\
\hline Efficient & $0-85$ & $0-37,687$ & $0-9,422$ & $0-2,709$ \\
\hline Typical & $86-89$ & $37,688-296,037$ & $9,423-74,009$ & $2,710-5,953$ \\
\hline Inefficient & $90-97$ & $296,038-654,770$ & $74,010-163,692$ & $5,954-47,072$ \\
\hline
\end{tabular}

According to Table 5.15, based on a benchmark plant, typical and inefficient plants can save 86 to 97 percent of their annual transmission heat loss which indicates 6 to 50 percent of total natural gas reduction. The amount of natural gas consumption reduction was calculated to be $37,688 \mathrm{~m}^{3}$ to $654,770 \mathrm{~m}^{3}$ and related cost of $\$ 9,423$ to $\$ 163,692$ per year. The reduction of GHG emissions was calculated to be 2,710 ton to 47,072 ton per year.

\subsubsection{Total Ventilation Consumption per Unit Area}

Total ventilation related natural gas consumption of plants include infiltration loss and mechanical ventilation consumption. In first level of multiple variable regression analysis, total ventilation consumption of the plant was calculated.

Annual total ventilation related natural gas consumption of plants was plotted with respect to plant area. Total ventilation related natural gas consumption depends on plant area. So ventilation consumption and plant area should have good statistical relationship. Figure 5.27 presents the scatter plot of plant annual total ventilation consumption with respect to plant area. 


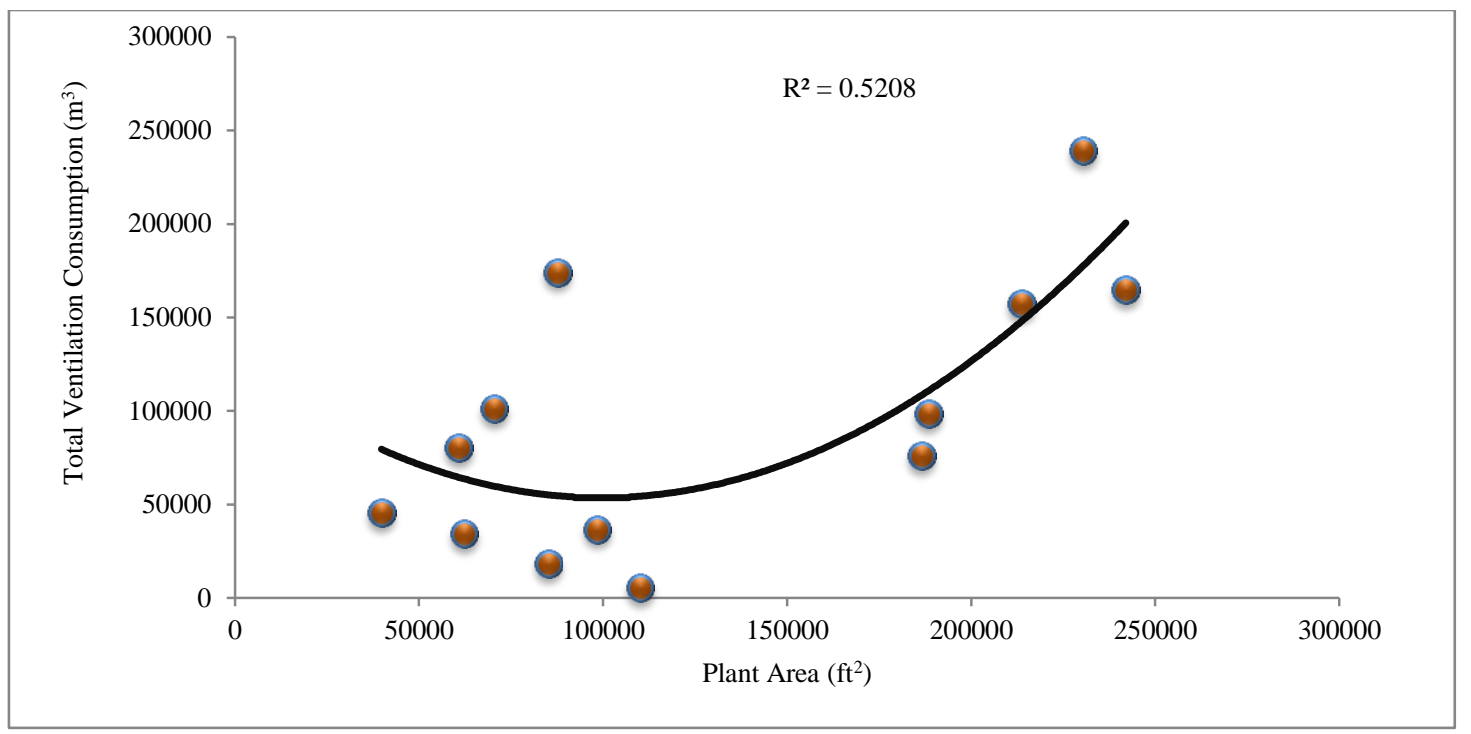

Figure 5.27: Scatter plot of total ventilation related natural gas consumption per unit area

According to Figure 5.27, there are large statistical relationships between plant area and total ventilation related natural gas consumption. Then, total ventilation consumption per unit area was compared between thirteen audited industries. Similarly, the plant that uses the least amount of energy per unit area was considered the most efficient plants and who uses the highest amount of energy per unit area was considered the most inefficient plants. Microsoft Excel Rank and Percentile Analysis was conducted to rank the plants. The benchmarking ranges for total ventilation consumption per unit area are presented in Table 5.16.

Table 5.16: Total ventilation consumption benchmark range $\left(\mathrm{m}^{3} / \mathrm{ft}^{2}\right)$ for thirteen industries

\begin{tabular}{|c|c|}
\hline Consumption Benchmark & $\begin{array}{c}\text { Normalized Annual Total Ventilation } \\
\text { Consumption }\left(\mathrm{m}^{3} / \mathrm{ft}^{2}\right)\end{array}$ \\
\hline Efficient & $0.05-0.37$ \\
\hline Typical & $0.38-0.68$ \\
\hline Inefficient & $0.69-1.99$ \\
\hline
\end{tabular}

According to Table 5.16, if the company consumes $0.05 \mathrm{~m}^{3} / \mathrm{ft}^{2}$ to $0.37 \mathrm{~m}^{3} / \mathrm{ft}^{2}$ or less was considered the efficient plant. If the company consumes 0.38 to $0.68 \mathrm{~m}^{3} / \mathrm{ft}^{2}$ was considered the typical one and if the company consumes 0.69 to $1.99 \mathrm{~m}^{3} / \mathrm{ft}^{2}$ or above was considered the inefficient plant. Figure 5.28 presents the dataset $\left(\mathrm{m}^{3} / \mathrm{ft}^{2}\right)$ for thirteen different industries in GTA. 


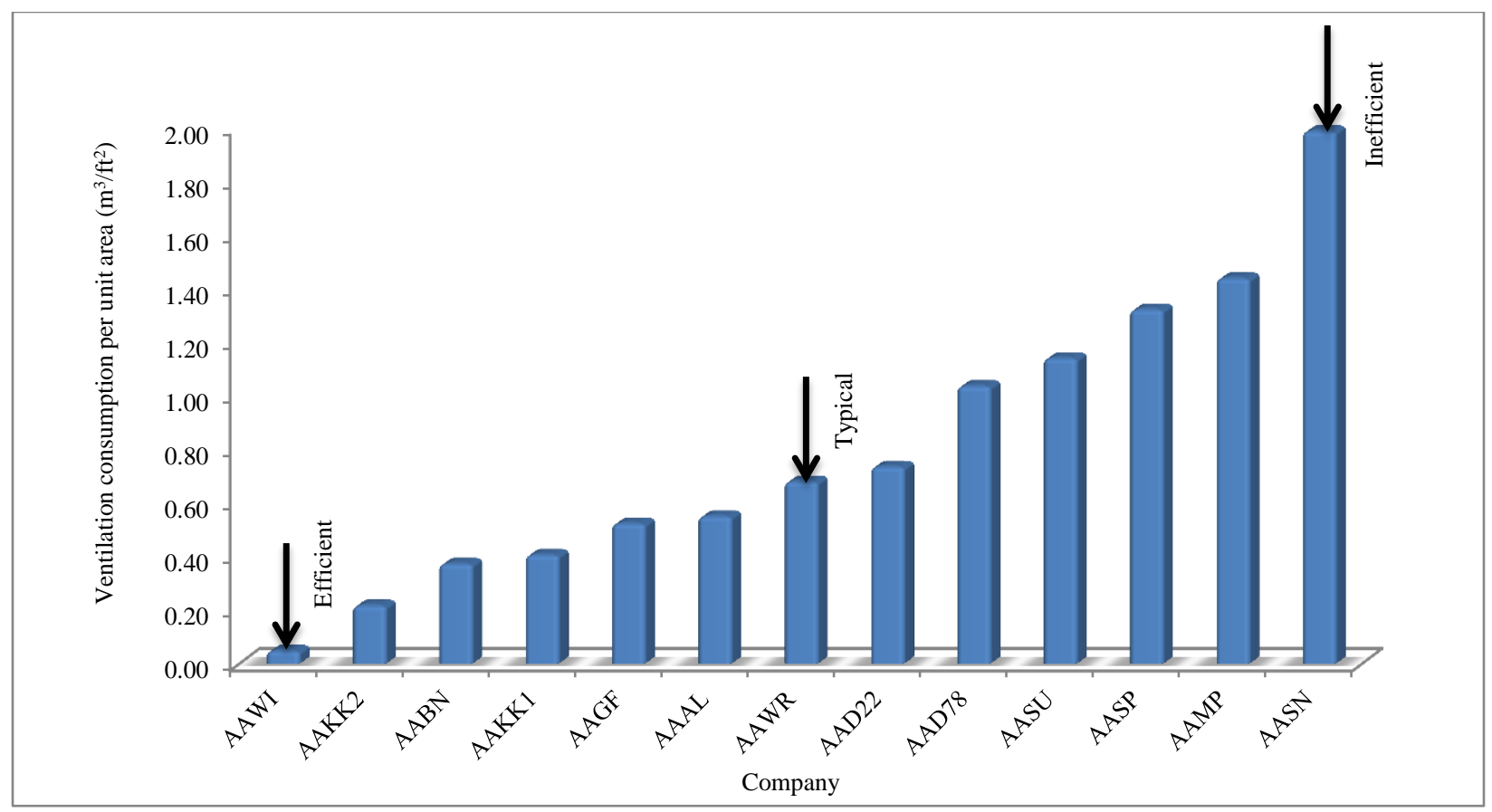

Figure 5.28: Total ventilation related natural gas consumption benchmark per unit area of thirteen audited industries

According to Figure 5.28, the most inefficient plants consume thirty nine times more than the most efficient plants. Using Equation 4.5, 4.6 and 4.7, potential savings of typical and inefficient companies were calculated. Table 5.17 presents the potential reductions of natural gas, cost and GHG emissions.

Table 5.17: Potential reductions of natural gas, cost and GHG emission

\begin{tabular}{|c|c|c|c|c|}
\hline Benchmark & $\begin{array}{c}\text { Saving Potential } \\
(\%)\end{array}$ & $\begin{array}{c}\text { Natural Gas Savings } \\
\left(\mathrm{m}^{3}\right)\end{array}$ & Cost Savings (\$) & $\begin{array}{c}\text { GHG Emission } \\
\text { Reduction }\end{array}$ \\
\hline Efficient & $0-87$ & $0-31,932$ & $0-7,983$ & $0-2,296$ \\
\hline Typical & $88-93$ & $31,933-152,913$ & $7,983-38,228$ & $2,296-10,993$ \\
\hline Inefficient & $94-98$ & $152,914-169,916$ & $38,229-42,479$ & $10,994-12,215$ \\
\hline
\end{tabular}

According to Table 5.17, based on a benchmark plant, typical and inefficient plants can save 88 to 98 percent of their annual total ventilation consumption which indicates 2 to 20 percent of total natural gas consumption. The amount of natural gas consumption reduction was 
calculated to be $31,933 \mathrm{~m}^{3}$ to $169,916 \mathrm{~m}^{3}$ and related cost of $\$ 7,983$ to $\$ 42,479$ per year. The reduction of GHG emissions was calculated to be 2,296 ton to 12,215 ton per year.

\subsubsection{Ventilation Consumption per Unit Operational Hour}

Annual ventilation related natural gas consumption of plants was plotted with respect to plant operational hours. As mentioned before, total ventilation consumption of the plant has two parts. One is mechanical ventilation and another is infiltration loss. Among them mechanical ventilation consumption depends on plant operational hour but infiltration loss happens 24/7. The purpose of plotting total ventilation consumption with plant operational hour was to find the statistical relationship between total ventilation related natural gas consumption and plant operational hour. Figure 5.29 presents the scatter plot of plant total ventilation consumption $\left(\mathrm{m}^{3}\right)$ with respect to plant operational hour.

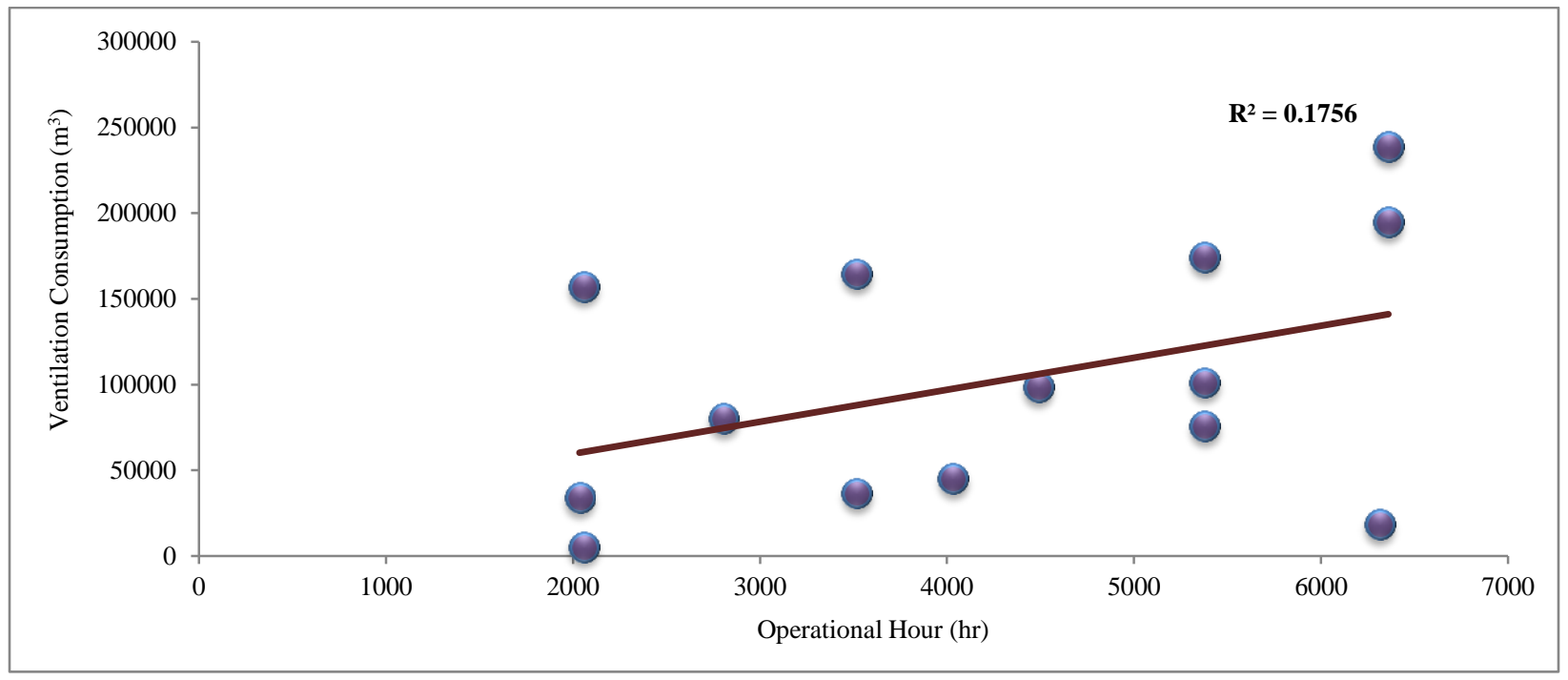

Figure 5.29: Scatter plot of total ventilation consumption with operational hour

According to Figure 5.29, it was found that there are small statistical relationship between total ventilation consumption and plant operational hour. Then, Microsoft Excel Rank and Percentile Analysis was conducted to rank plants. The benchmarking ranges are presented in Table 5.18.

Table 5.18: Total ventilation consumption benchmark range $\left(\mathrm{m}^{3} / \mathrm{hr}\right)$ for thirteen industries

\begin{tabular}{|c|c|}
\hline Consumption Benchmark & $\begin{array}{c}\text { Normalized Annual Total Ventilation } \\
\text { Consumption }\left(\mathrm{m}^{3} / \mathrm{hr} .\right)\end{array}$ \\
\hline Efficient & $2.6-10.44$ \\
\hline Typical & $10.45-18.82$ \\
\hline
\end{tabular}


According to Table 5.18, if the company consumes $2.6 \mathrm{~m}^{3} / \mathrm{hr}$ to $10.44 \mathrm{~m}^{3} / \mathrm{hr}$ or less was considered the efficient plant. If the company consumes 10.45 to $18.82 \mathrm{~m}^{3} / \mathrm{hr}$ was considered the typical one and if the company consumes 18.83 to $76.4 \mathrm{~m}^{3} / \mathrm{hr}$ or above was considered the inefficient plant. Figure 5.30 presents the dataset $\left(\mathrm{m}^{3} / \mathrm{hr}\right)$ for thirteen different industries in GTA.

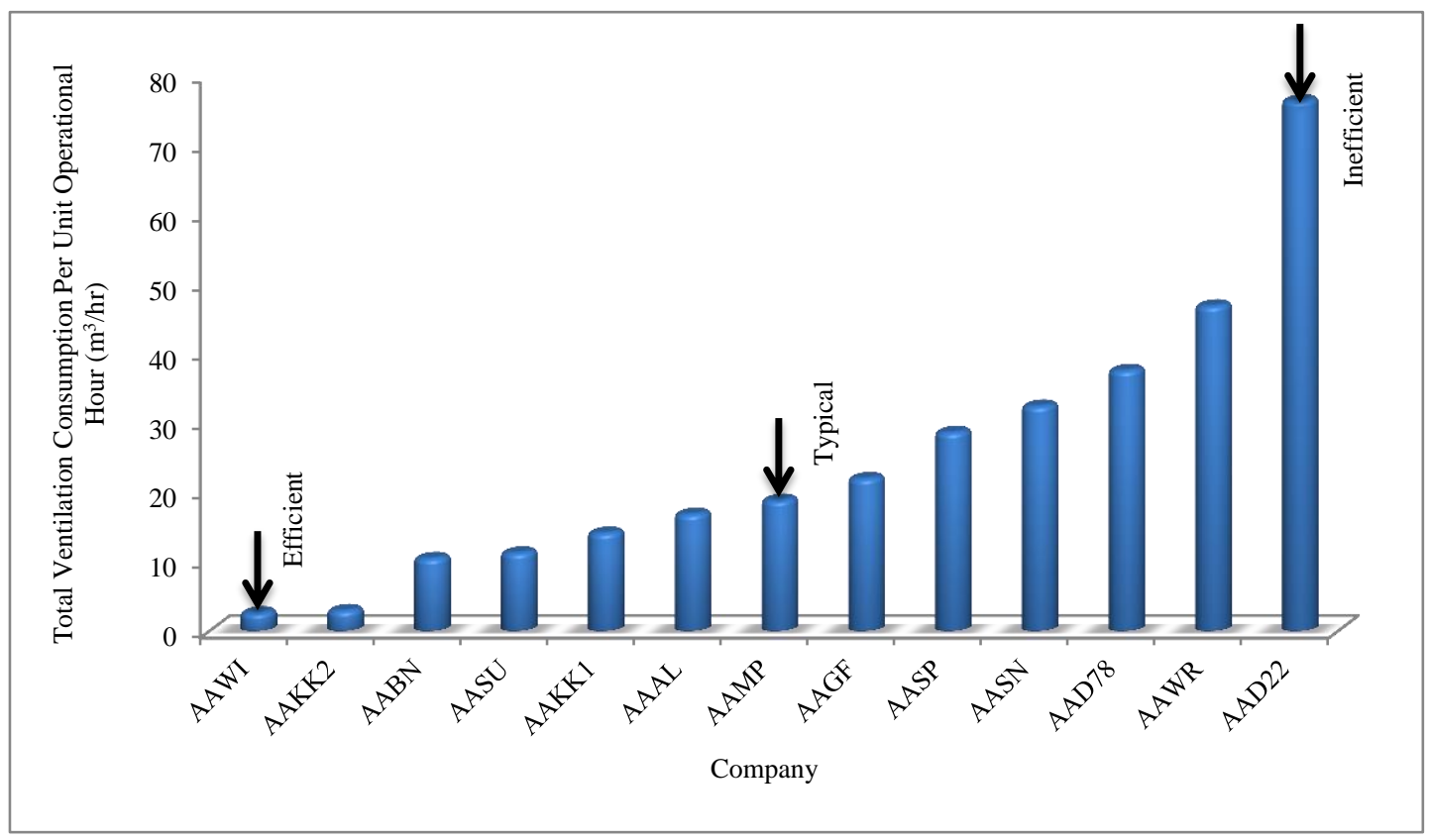

Figure 5.30: Total ventilation related natural gas consumption benchmark per unit operational hour of thirteen audited industries

According to Figure 5.30, the most inefficient plant consume twenty nine times more than the most efficient plant. Using Equations 4.21, 4.22 and 4.23, potential savings of typical and inefficient companies were calculated. Table 5.19 presents the potential reductions of natural gas, cost and GHG emission

Table 5.19: Potential reductions of natural gas, cost and GHG emission

\begin{tabular}{|c|c|c|c|c|}
\hline Benchmark & $\begin{array}{c}\text { Saving Potential } \\
(\%)\end{array}$ & $\begin{array}{c}\text { Natural Gas Savings } \\
\left(\mathrm{m}^{3}\right)\end{array}$ & Cost Savings (\$) & $\begin{array}{c}\text { GHG Emission } \\
\text { Reduction } \\
\left.\text { (tonne } \mathrm{CO}_{2} \mathrm{eq}\right)\end{array}$ \\
\hline Efficient & $0-75$ & $0-27,570$ & $0-6,893$ & $0-1,982$ \\
\hline Typical & $76-86$ & $27,571-87,217$ & $6,894-21,804$ & $1,982-6,270$ \\
\hline
\end{tabular}




\begin{tabular}{|l|c|c|c|c|}
\hline Inefficient & $87-97$ & $87,217-151,840$ & $21,804-37,960$ & $6,270-10,916$ \\
\hline
\end{tabular}

According to Table 5.19, based on the most efficient plant, typical and inefficient plants can save 76 to 97 percent of their total ventilation consumption which indicates 6 to 20 percent of total natural gas consumption. The amount of natural gas consumption reduction was calculated to be $27,571 \mathrm{~m}^{3}$ to $151,840 \mathrm{~m}^{3}$ and related cost of $\$ 6,894$ to $\$ 37,960$ per year. The reduction of GHG emissions was calculated to be 1,982 ton to 10,916 ton per year.

\subsubsection{Total Ventilation Consumption per unit Area Multiplied with Operational Hour}

Annual total ventilation related natural gas consumption of plants was plotted with respect to plant area $\mathrm{x}$ operational hr. Plant total ventilation related natural gas consumption depends on both operational hour and area. Figure 5.31 presents the scatter plot of plant annual total ventilation related natural gas consumption $\left(\mathrm{m}^{3}\right)$ with respect to plant area $\mathrm{x}$ operational hour.

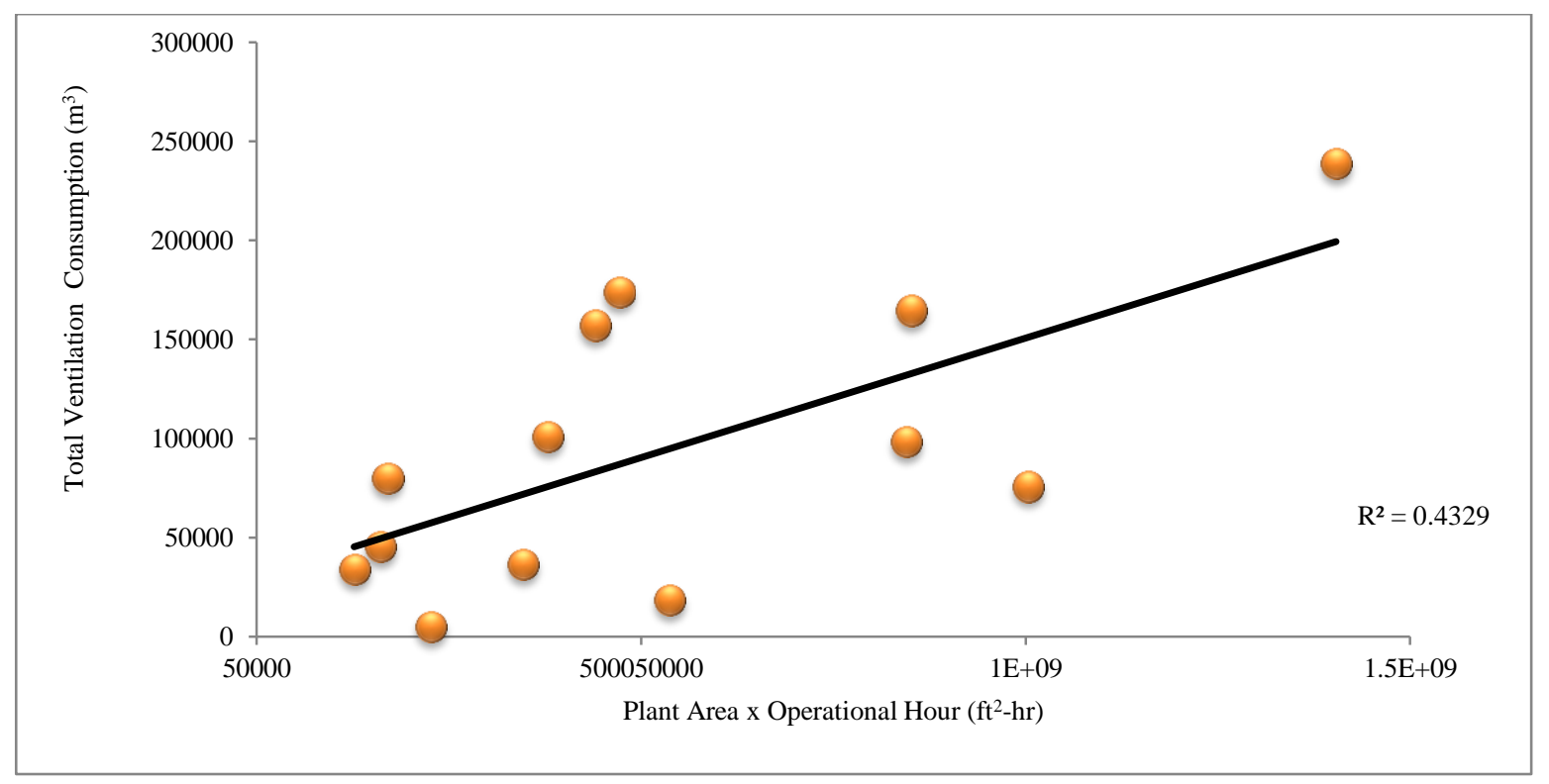

Figure 5.31: Scatter plot of total ventilation related natural gas consumption with area $x$ operational hour

Figure 5.31 presents medium statistical relationship between total ventilation related natural gas consumption and plant area x operational hour. Microsoft Excel Rank and Percentile Analysis was conducted to rank plants. The benchmarking ranges are presented in Table 5.20.

Table 5.20: Total ventilation related natural gas consumption benchmark range $\left(\mathrm{m}^{3} / \mathrm{ft}^{2}-\mathrm{hr}\right)$

\begin{tabular}{|c|c|}
\hline Consumption Benchmark & $\begin{array}{c}\text { Predicted Annual Ventilation Consumption } \\
\left(\mathrm{m}^{3} / \mathrm{ft}^{2}-\mathrm{hr}\right)\end{array}$ \\
\hline
\end{tabular}




\begin{tabular}{|c|c|}
\hline Efficient & $2.36 \mathrm{E}-05-3.44 \mathrm{E}-05$ \\
\hline Typical & $3.45 \mathrm{E}-05-0.00019$ \\
\hline Inefficient & $0.00020-0.00047$ \\
\hline
\end{tabular}

According to Table 5.20, if the company consumes $2.36 \mathrm{E}-05 \mathrm{~m}^{3} / \mathrm{ft}^{2}$-hr to $3.44 \mathrm{E}-05 \mathrm{~m}^{3} / \mathrm{ft}^{2}-\mathrm{hr}$ or less was considered the efficient plant. If the company consumes $3.45 \mathrm{E}-05$ to $0.00019 \mathrm{~m}^{3} / \mathrm{ft}^{2}-\mathrm{hr}$ was considered the typical one and if the company consumes 0.00020 to $0.00047 \mathrm{~m}^{3} / \mathrm{ft}^{2}-\mathrm{hr}$ or above was considered the inefficient plant. Figure 5.32 presents the dataset $\left(\mathrm{m}^{3} / \mathrm{ft}^{2}-\mathrm{hr}\right)$ for thirteen different industries in GTA.

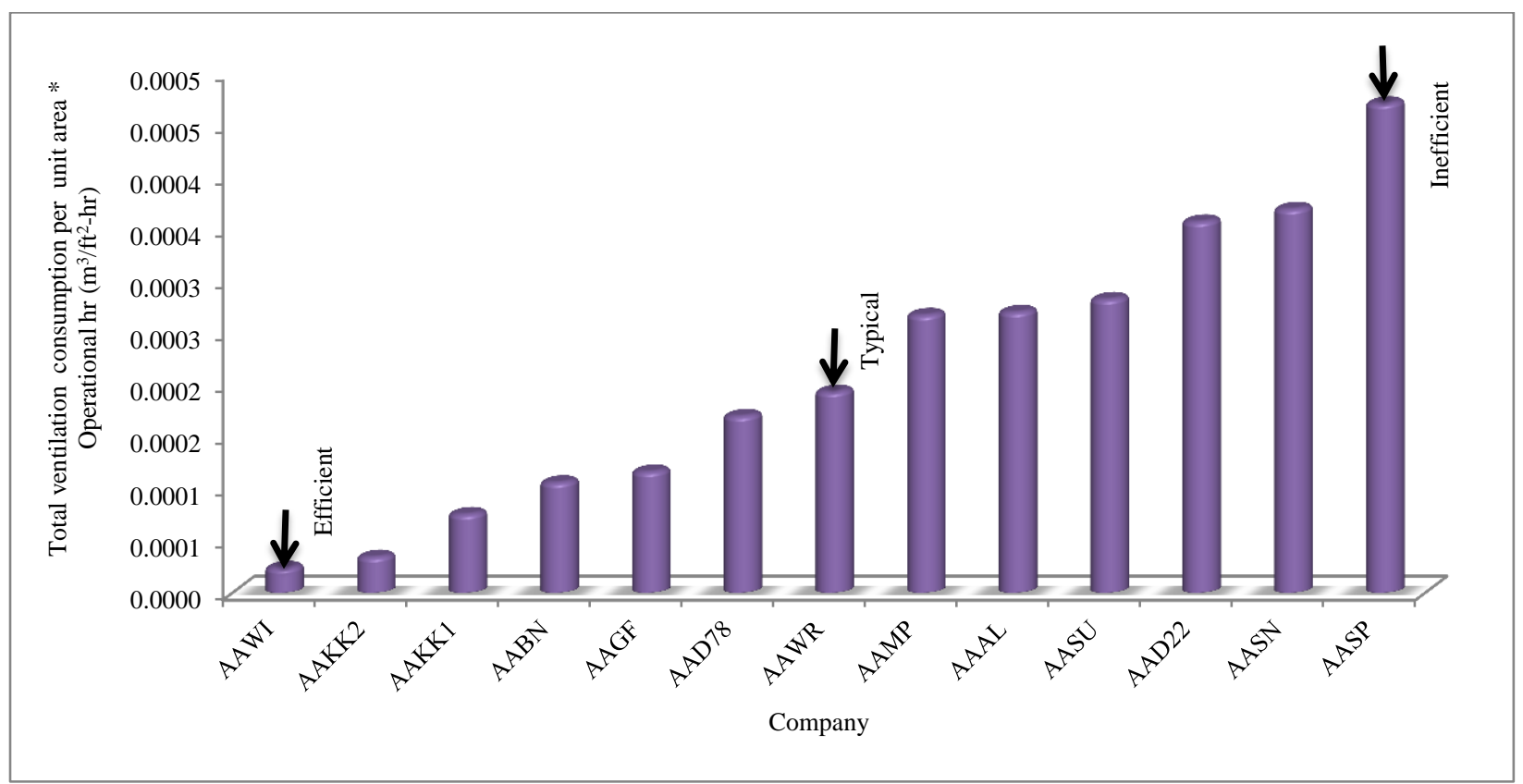

Figure 5.32: Total ventilation related natural gas consumption benchmark per unit area $x$ operational hour of thirteen audited industries

According to Figure 5.32, the most inefficient plant consumes twenty nineteen times more than the most efficient plant. Using Equations 4.24, 4.25 and 4.26, potential savings of typical and inefficient companies were calculated. Table 5.21 presents the potential reductions of natural gas, cost and GHG emissions.

Table 5.21: Potential reductions of natural gas, cost and GHG emission

\begin{tabular}{|c|c|c|c|c|}
\hline Benchmark & $\begin{array}{c}\text { Saving Potential } \\
(\%)\end{array}$ & $\begin{array}{c}\text { Natural Gas Savings } \\
\left(\mathrm{m}^{3}\right)\end{array}$ & $\begin{array}{c}\text { Cost Savings (\$) } \\
\text { GHG Emission }\end{array}$ & \begin{tabular}{c} 
Reduction (tonne \\
\hline
\end{tabular}
\end{tabular}




\begin{tabular}{|c|c|c|c|c|}
\hline & & & & $\mathrm{CO}_{2}$ eq $)$ \\
\hline Efficient & $0-31$ & $0-5,780$ & $0-1,445$ & $0-416$ \\
\hline Typical & $32-88$ & $5,781-144,561$ & $1,446-36,140$ & $417-10,393$ \\
\hline Inefficient & $89-94$ & $144,562-163,032$ & $36,140-40,758$ & $10,393-11,720$ \\
\hline
\end{tabular}

According to Table 5.21, typical and inefficient plants can save 32 to 94 percent of their annual ventilation consumption which indicates 1 to 20 percent of total natural gas consumption. The amount of natural gas consumption reduction was calculated to be $5,781 \mathrm{~m}^{3}$ to $163,032 \mathrm{~m}^{3}$ and related cost $\$ 1,446$ to $\$ 40,758$ per year. The reduction of GHG emission was calculated 417 ton to 11,720 ton per year.

\subsubsection{Mechanical Ventilation Related Natural Gas Consumption per Unit Area}

In second layer of multivariable regression analysis, total ventilation consumption of the plant was further divided into infiltration loss and mechanical ventilation consumption.

Annual mechanical ventilation related natural gas consumption of the plant was plotted with respect to the plant area. The purpose of this analysis was to verify the statistical correlation between plant area and mechanical ventilation related natural gas consumption. Figure 5.33 presents the scatter plot of plant annual mechanical ventilation consumption $\left(\mathrm{m}^{3}\right)$ with respect to plant area.

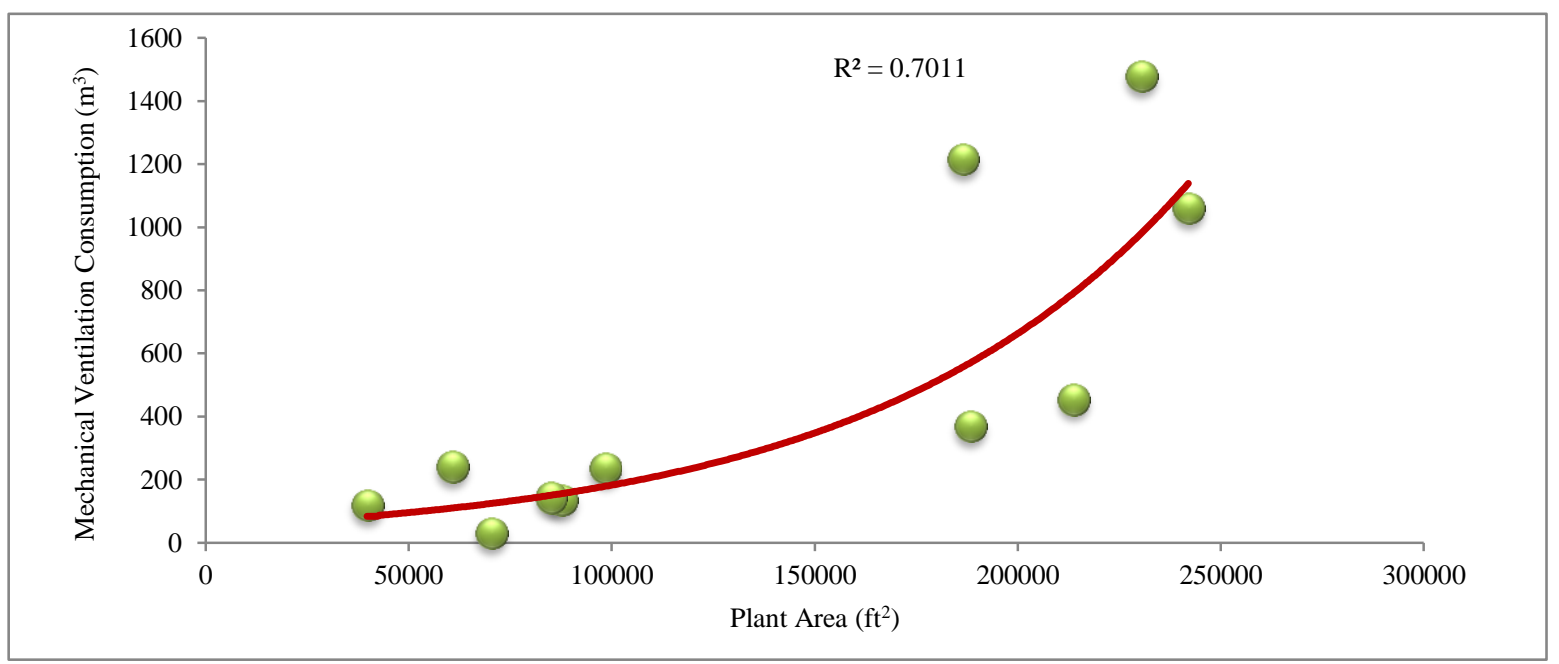

Figure 5.33: Scatter plot of mechanical ventilation related natural gas consumption with plant area 
Figure 5.33 presents large statistical relationship between plant area and mechanical ventilation related natural gas consumption of plants. Microsoft EXCEL Rank and Percentile Analysis was conducted to rank plants. In this case, the plant that uses the least amount of natural gas per unit area for mechanical ventilation purpose was considered the most efficient plant and the plant that uses the highest amount of energy per unit area for mechanical ventilation purpose was considered the most inefficient one. The benchmarking ranges for mechanical ventilation related natural gas consumption per unit area are presented in Table 5.22.

Table 5.22: Mechanical ventilation related natural gas consumption per unit area benchmark range $\left(\mathrm{m}^{3} / \mathrm{ft}^{2}\right)$

\begin{tabular}{|c|c|}
\hline $\begin{array}{c}\text { Consumption Benchmark } \\
\text { Efficient }\end{array}$ & $\begin{array}{c}\text { Annual Mechanical Ventilation Consumption } \\
\left(\mathrm{m}^{3} / \mathrm{ft}^{2}\right)\end{array}$ \\
\hline Typical & $0.0004-0.0016$ \\
\hline Inefficient & $0.0017-0.0024$ \\
\hline
\end{tabular}

According to Table 5.22, if the company consumes $0.0004 \mathrm{~m}^{3} / \mathrm{ft}^{2}$ to $.0016 \mathrm{~m}^{3} / \mathrm{ft}^{2}$ or less was considered the efficient plant. If the company consumes .0017 to $0.0024 \mathrm{~m}^{3} / \mathrm{ft}^{2}$ was considered the typical one and if the company consumes 0.0025 to $0.0065 \mathrm{~m}^{3} / \mathrm{ft}^{2}$ or above was considered the inefficient plant. Figure 5.34 presents the dataset $\left(\mathrm{m}^{3} / \mathrm{ft}^{2}\right)$ for eleven different industries in GTA.

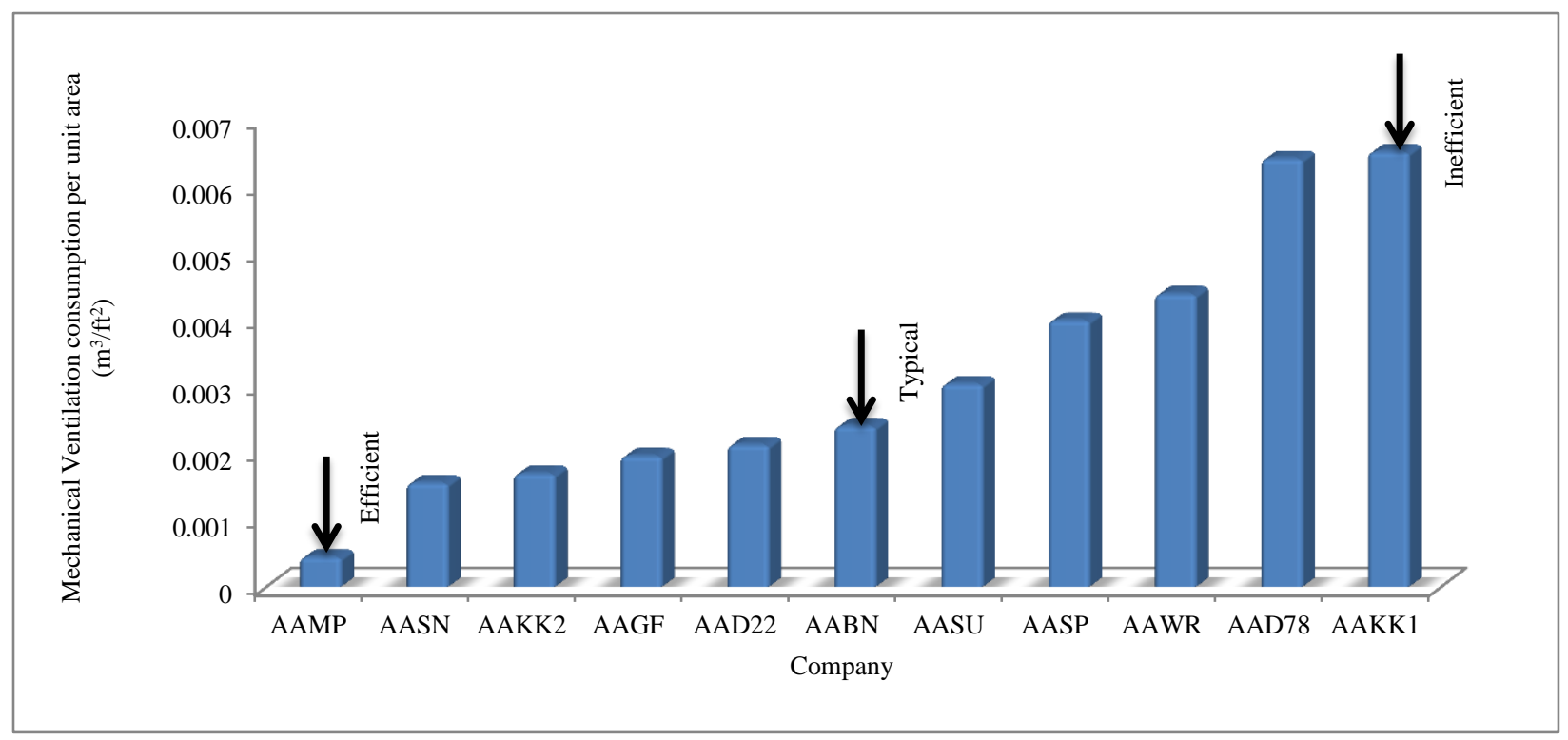


Figure 5.34: Annual mechanical ventilation related natural gas consumption benchmark per unit area

According to Figure 5.34, the most inefficient plant consumes fourteen times more than the most efficient plant. Using Equations 4.5, 4.6 and 4.7, potential savings of typical and inefficient companies were calculated. Table 5.23 presents the potential reductions of natural gas, cost and GHG emissions.

Table 5.23: The potential savings of natural gas, cost and GHG emissions

\begin{tabular}{|c|c|c|c|c|}
\hline Benchmark & Saving Potential (\%) & $\begin{array}{c}\text { Natural Gas Saving } \\
\left(\mathrm{m}^{3}\right)\end{array}$ & Cost Saving (\$) & $\begin{array}{c}\text { GHG Emissions } \\
\text { Reduction } \\
\left.\text { (tonne } \mathrm{CO}_{2} \mathrm{eq}\right)\end{array}$ \\
\hline Efficient & $0-71$ & $0-98$ & $0-24$ & $0-7$ \\
\hline Typical & $72-81$ & $99-193$ & $25-48$ & $8-14$ \\
\hline Inefficient & $82-93$ & $194-1,133$ & $49-283$ & $15-81$ \\
\hline
\end{tabular}

According to Table 5.23, based on a benchmark plant, typical and inefficient plants can save 71 to 93 percent of their annual ventilation consumption which indicates 0.05 to 0.14 percent of total natural gas consumption. The amount of natural gas consumption reduction was calculated to be $98 \mathrm{~m}^{3}$ to $1,133 \mathrm{~m}^{3}$ and related cost of $\$ 24$ to $\$ 283$ per year. The reduction of GHG emissions was calculated to be 7 ton to 81 ton per year.

\subsubsection{Mechanical Ventilation Related NG Consumption per Unit Area X Operation Hr.}

Annual mechanical ventilation related natural gas consumption of plants was plotted with respect to the plant area multiplied with operational hour. The purpose was to verify the statistical relationship between plant area multiplied with operational hour and mechanical ventilation related natural gas consumption. Figure 5.35 presents the scatter plot of plant annual mechanical ventilation consumption $\left(\mathrm{m}^{3}\right)$ with respect to plant area $\mathrm{x}$ operational hour. 


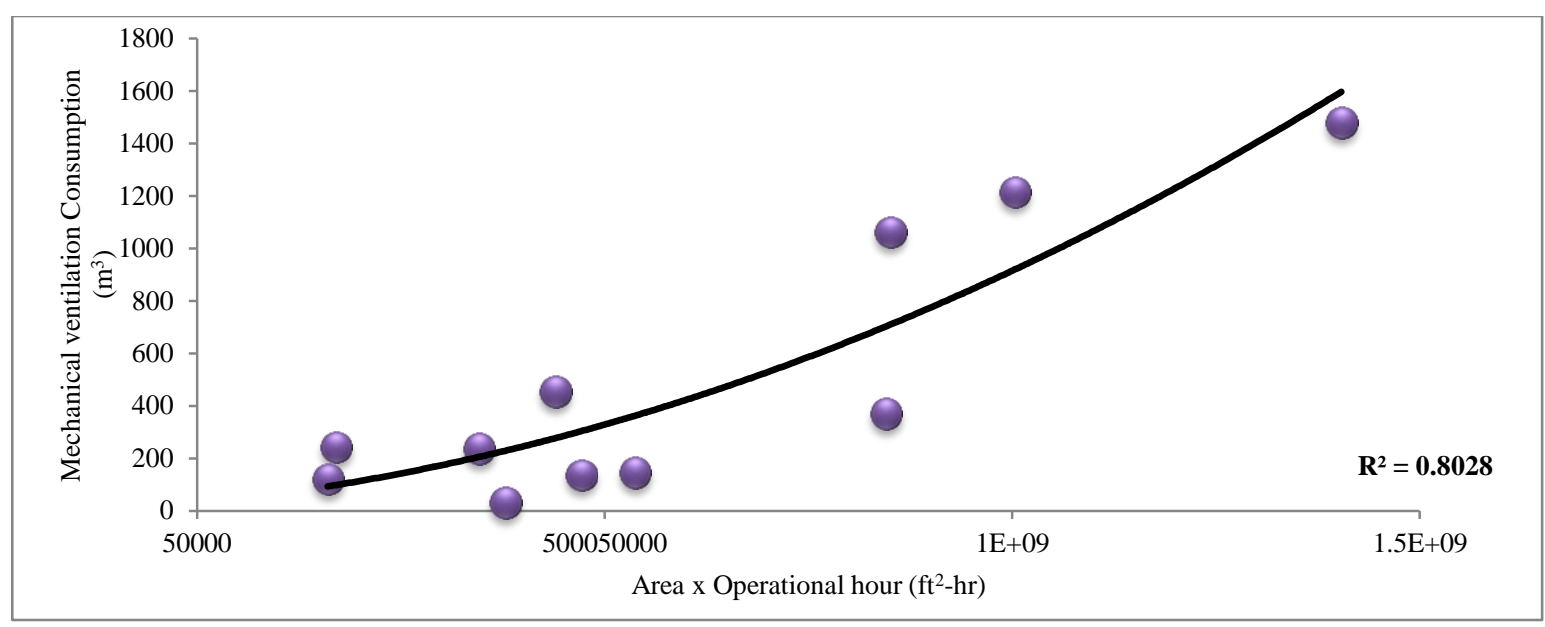

Figure 5.35: Scatter plot of mechanical ventilation related natural gas consumption with plant area $x$ operational hour

Figure 5.35 presents large statistical relationship between plant area multiplied with operational hour and mechanical ventilation related natural gas consumption of plants. Microsoft EXCEL Rank and Percentile Analysis was conducted to rank plants. In this case, the plant that uses the least amount of natural gas per unit area $\mathrm{x}$ operational hour for mechanical ventilation purpose was considered the most efficient plant and the plant that uses the highest amount of energy per unit area $\mathrm{x}$ operational hour for mechanical ventilation purpose was considered the most inefficient one. The benchmarking ranges for mechanical ventilation related natural gas consumption per unit area are presented in Table 5.24.

Table 5.24: Mechanical ventilation related natural gas consumption per unit area $x$ operational hour benchmark range $\left(\mathrm{m}^{3} / \mathrm{ft}^{2}-\mathrm{hr}\right)$

\begin{tabular}{|c|c|}
\hline $\begin{array}{c}\text { Consumption Benchmark } \\
\text { Efficient }\end{array}$ & $\begin{array}{c}\text { Annual Mechanical Ventilation Consumption } \\
\left(\mathrm{m}^{3} / \mathrm{ft}^{2}-\mathrm{hr}\right)\end{array}$ \\
\hline Typical & $8.30 \mathrm{E}-08-2.89 \mathrm{E}-07$ \\
\hline Inefficient & $4.37 \mathrm{E}-07-7.54 \mathrm{E}-07$ \\
\hline
\end{tabular}

According to Table 5.23, if the company consumes $8.30 \mathrm{E}-08 \mathrm{~m}^{3} / \mathrm{ft}^{2}-\mathrm{hr}$ to $2.89 \mathrm{E}-07 \mathrm{~m}^{3} / \mathrm{ft}^{2}-\mathrm{hr}$ or less was considered the efficient plant. If the company consumes $4.37 \mathrm{E}-07$ to $7.54 \mathrm{E}-07 \mathrm{~m}^{3} / \mathrm{ft}^{2}-\mathrm{hr}$ was considered the typical one and if the company consumes $1.03 \mathrm{E}-06$ to $1.42 \mathrm{E}-06 \mathrm{~m}^{3} / \mathrm{ft}^{2}-\mathrm{hr}$ or above was considered the inefficient plant. Figure 5.36 presents the dataset $\left(\mathrm{m}^{3} / \mathrm{ft}^{2}-\mathrm{hr}\right)$ for twelve different industries in GTA. 


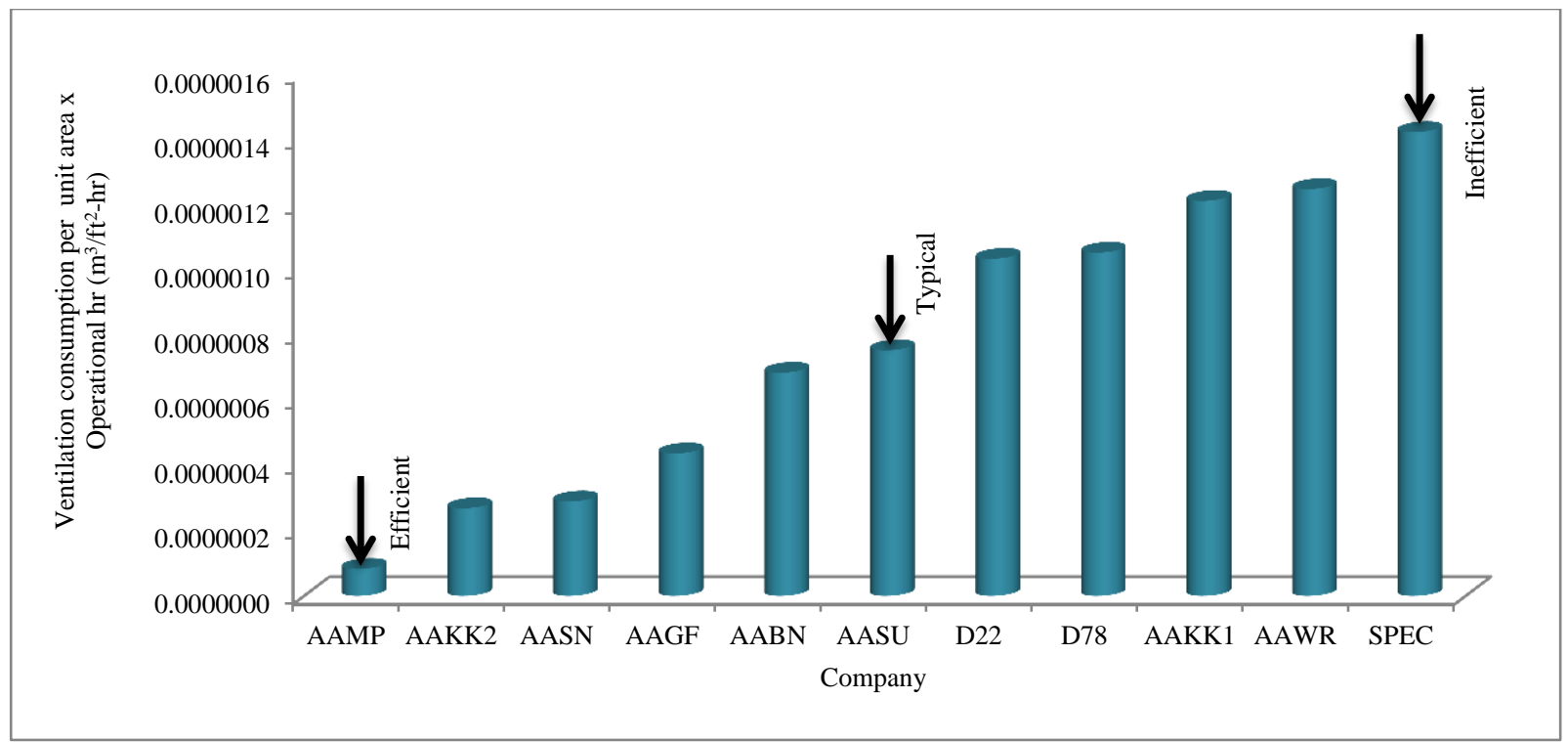

Figure 5.36: Annual mechanical ventilation related natural gas consumption benchmark per unit area

According to Figure 5.36, the most inefficient plant consumes seventeen times more than the most efficient plant. Using Equations 4.25, 4.26 and 4.27, potential savings of in typical and inefficient companies were calculated. Table 5.25 presents the potential reductions of natural gas, cost and GHG emissions.

Table 5.25: The potential savings of natural gas, cost and GHG emissions

\begin{tabular}{|c|c|c|c|c|}
\hline Benchmark & Saving potential (\%) & $\begin{array}{c}\text { Natural Gas Saving } \\
\left(\mathrm{m}^{3}\right)\end{array}$ & Cost Saving (\$) & $\begin{array}{c}\text { GHG Emissions } \\
\text { Reduction } \\
\left.\text { (tonne } \mathrm{CO}_{2} \mathrm{eq}\right)\end{array}$ \\
\hline Efficient & $0-71$ & $0-98$ & $0-24$ & $0-7$ \\
\hline Typical & $72-89$ & $99-108$ & $25-27$ & $8-9$ \\
\hline Inefficient & $90-92$ & $109-418$ & $28-105$ & $10-30$ \\
\hline
\end{tabular}

According to Table 5.25, based on a benchmark plant, typical and inefficient plants can save 72 to 92 percent of their annual ventilation consumption which indicates 0.05 to 0.14 percent of total natural gas consumption. The amount of natural gas consumption reduction was calculated to be $99 \mathrm{~m}^{3}$ to $418 \mathrm{~m}^{3}$ and related cost of $\$ 25$ to $\$ 105$ per year. The reduction of GHG emissions was calculated to be 8 ton to 30 ton per year. 


\subsubsection{Infiltration Loss per Unit Area}

Annual infiltration losses of plants were plotted with respect to the plant area. The purpose this was to verify the statistical relationship between plant area and infiltration loss. Figure 5.37 presents the scatter plot of plant annual infiltration loss $\left(\mathrm{m}^{3}\right)$ with respect to plant area.

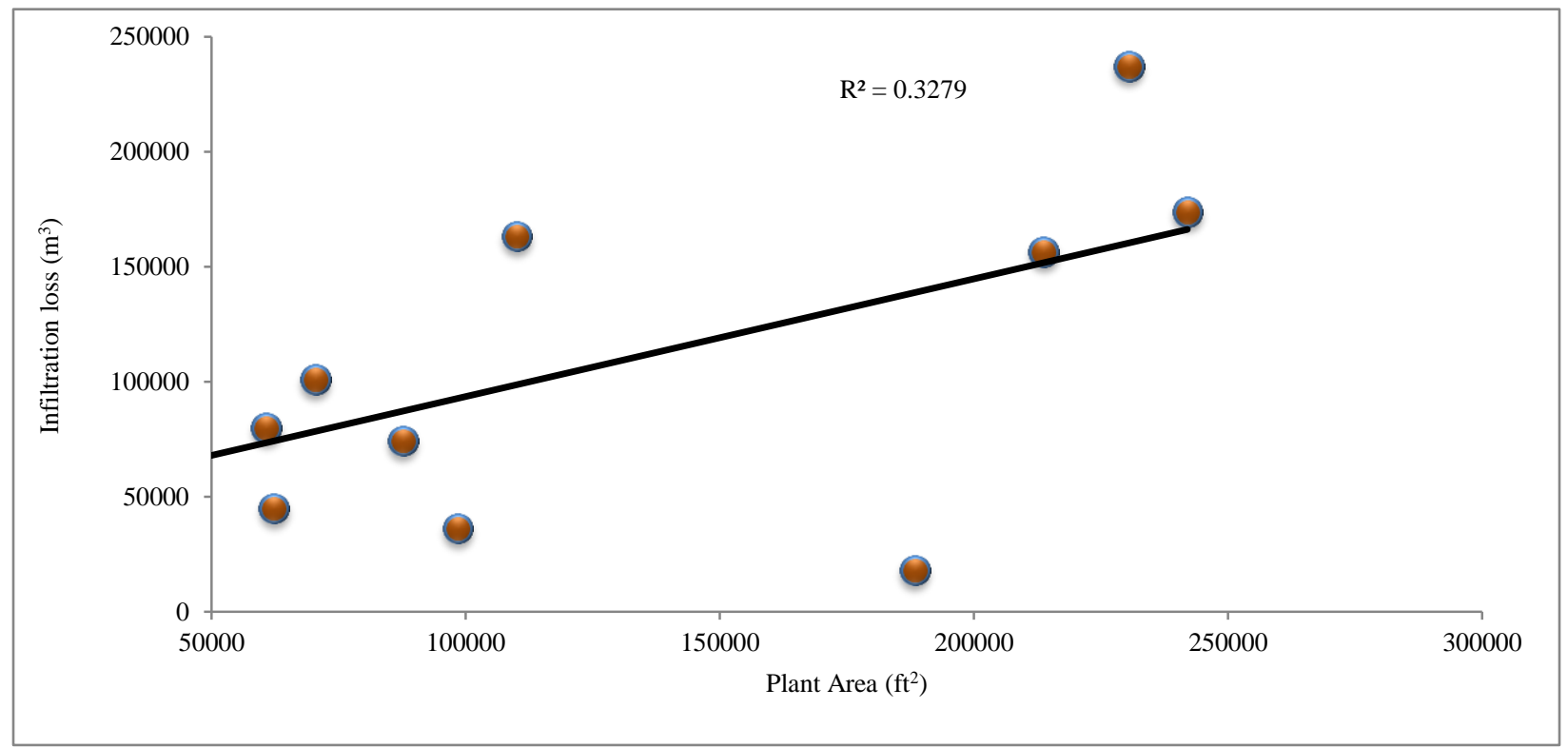

Figure 5.37: Scatter plot of infiltration loss with plant area

Figure 5.37 presents medium statistical relationship between plant area and infiltration loss related natural gas consumption of the plant. Microsoft Excel Rank and Percentile Analysis was conducted to rank plants. In this case, the plant that uses the least amount of natural gas per unit area for infiltration loss purpose was considered the most efficient plant and the plant that uses the highest amount of energy per unit area for infiltration loss purpose was considered the most inefficient one. The benchmarking ranges for infiltration loss related natural gas consumption per unit area are presented in Table 5.26.

Table 5.26: Infiltration loss related natural gas consumption per unit area benchmark range $\left(\mathrm{m}^{3} / \mathrm{ft}^{2}\right)$

\begin{tabular}{|c|c|}
\hline Consumption Benchmark & Annual Infiltration Loss $\left(\mathrm{m}^{3} / \mathrm{ft}^{2}\right)$ \\
\hline Efficient & $0.18-0.39$ \\
\hline Typical & $0.73-1.02$ \\
\hline
\end{tabular}


According to Table 5.26, if the company consumes $0.18 \mathrm{~m}^{3} / \mathrm{ft}^{2}$ to $0.39 \mathrm{~m}^{3} / \mathrm{ft}^{2}$ or less was considered the efficient plant. If the company consumes 0.73 to $1.02 \mathrm{~m}^{3} / \mathrm{ft}^{2}$ was considered the typical one and if the company consumes 1.12 to $4.37 \mathrm{~m}^{3} / \mathrm{ft}^{2}$ or above was considered the inefficient plant. Figure 5.38 presents the dataset $\left(\mathrm{m}^{3} / \mathrm{ft}^{2}\right)$ for eleven different industries in GTA.

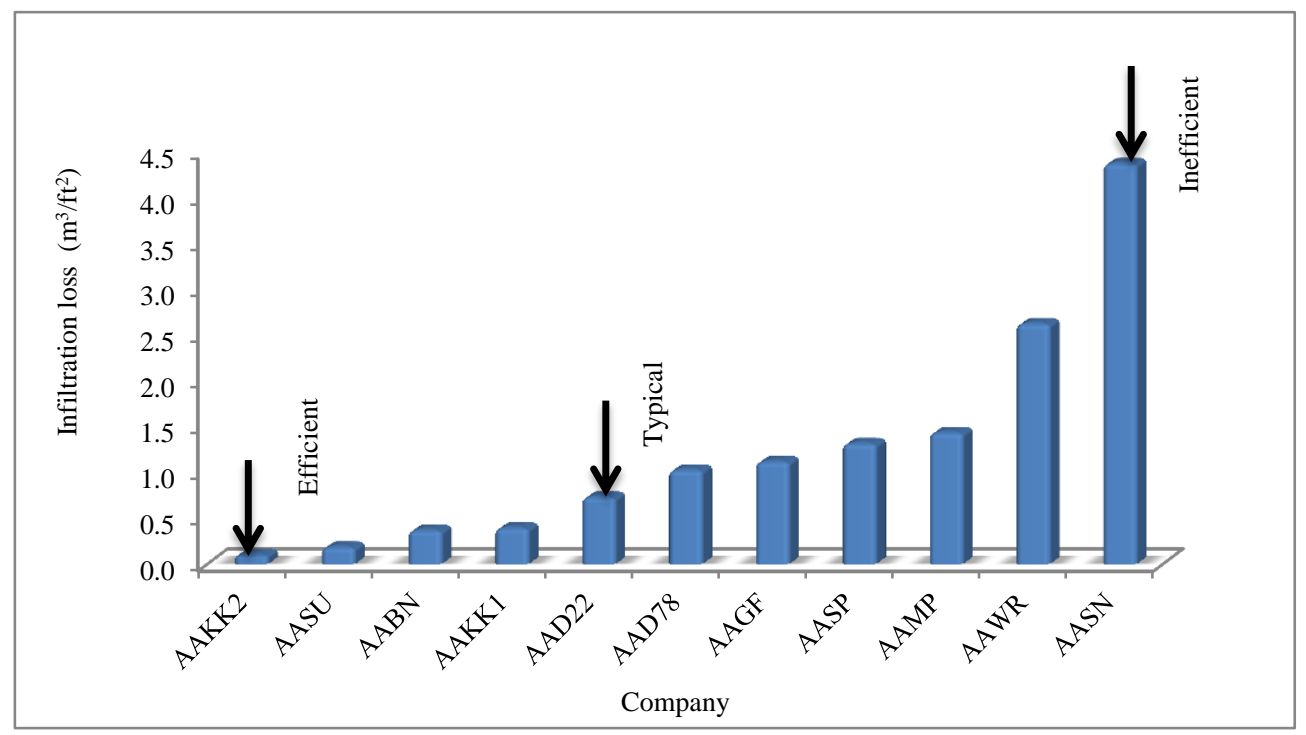

Figure 5.38: Annual infiltration loss benchmark per unit area

According to Figure 5.38, the most inefficient plant consumes thirteen times more than the most efficient plant. Using Equations 4.5, 4.6 and 4.7, potential savings of typical and inefficient companies were calculated. Table 5.27 presents the potential reductions of natural gas, cost, and GHG emissions.

Table 5.27: The potential savings of natural gas, cost and GHG emissions

\begin{tabular}{|c|c|c|c|c|}
\hline Benchmark & Saving potential (\%) & $\begin{array}{c}\text { Natural Gas Saving } \\
\left(\mathrm{m}^{3}\right)\end{array}$ & Cost Saving (\$) & $\begin{array}{c}\text { GHG Emission } \\
\text { Reduction } \\
\left.\text { (tonne } \mathrm{CO}_{2} \mathrm{eq}\right)\end{array}$ \\
\hline Efficient & $0-53$ & $0-39,389$ & $0-9,847$ & $0-2,832$ \\
\hline Typical & $54-75$ & $39,390-116,769$ & $9,848-29,192$ & $2,833-8,395$ \\
\hline Inefficient & $76-96$ & $116,770-166,608$ & $29,193-41,652$ & $8,396-11,978$ \\
\hline
\end{tabular}


According to Table 5.27, based on a benchmark plant, typical and inefficient plants can save 54 to 96 percent of their annual infiltration loss which indicates 5 to 20 percent of total natural gas consumption. The amount of natural gas consumption reduction was calculated to be $39,390 \mathrm{~m}^{3}$ to $166,608 \mathrm{~m}^{3}$ and related cost of $\$ 9,848$ to $\$ 41,652$ per year. The reduction of GHG emissions was calculated to be 2,833 ton to 11,978 ton per year.

\subsection{Energy and Cost Reduction by Improving Plant Wall and Roof Insulation}

Based on transmission heat loss analysis it was found that most of the plant were not well insulated and considerable amount of energy saving potentials could be available. For this reason a decision was made to estimate the reduction of plant transmission heat loss by improving plant envelope (wall and roof) insulation. In this case all plants' wall and roof target insulation R value was considered 20 according to 2012 Ontario Building Code [50] and transmission heat losses of plants were calculated using Equation 4.14. From the analysis it was found that, plants could save minimum 70 percent and maximum 91 percent of their transmission heat loss by improving their current $\mathrm{R}$ value to the current building code standard of 20. According to 13 plants' analysis, total $2846835 \mathrm{~m}^{3}$ natural gas could be saved per year in resulting in cost savings of $\$ 711,709$ per year and reduction of GHG emission of 204,660 ton per year. Figure 5.39 presents the reduction of natural gas consumption in cubic meter.

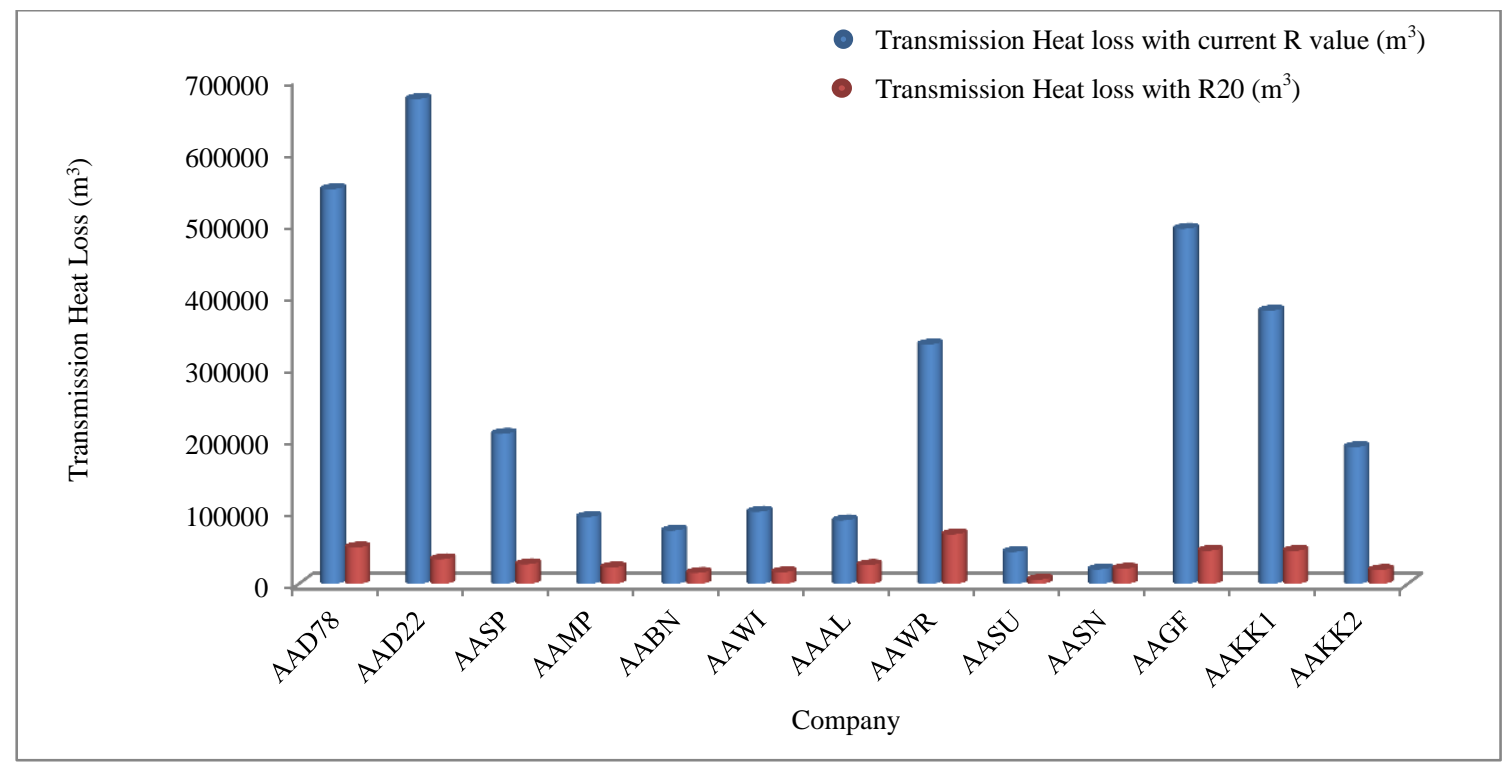

Figure 5.39: Natural gas reduction by improving building insulation $R$ value 
According to Figure 5.39, Plant AAD22 can save the highest amount of natural gas by improving insulation value and plant AASN cannot save natural gas because this plant already have insulation R20. The savings of natural gas will also reduce the cost. Figure 5.40 presents the savings of cost $(\$ /$ year $)$

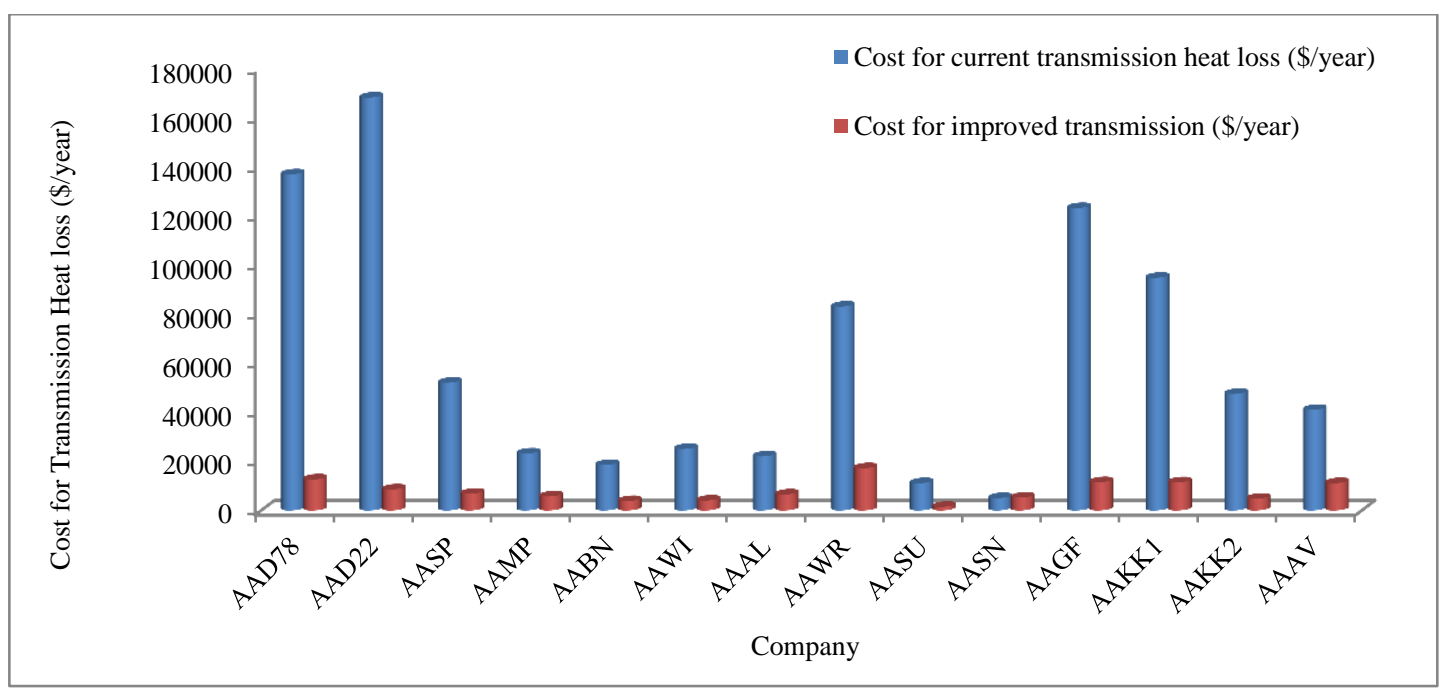

Figure 5.40: Cost reduction by improving building wall insulation

According to analysis, plants can save average 25 percent of their total natural gas cost which indicates $\$ 54,747$ per year by improving building insulation R-value. Figure 5.41 presents the percent savings of natural gas of audited industries by improving R-value.

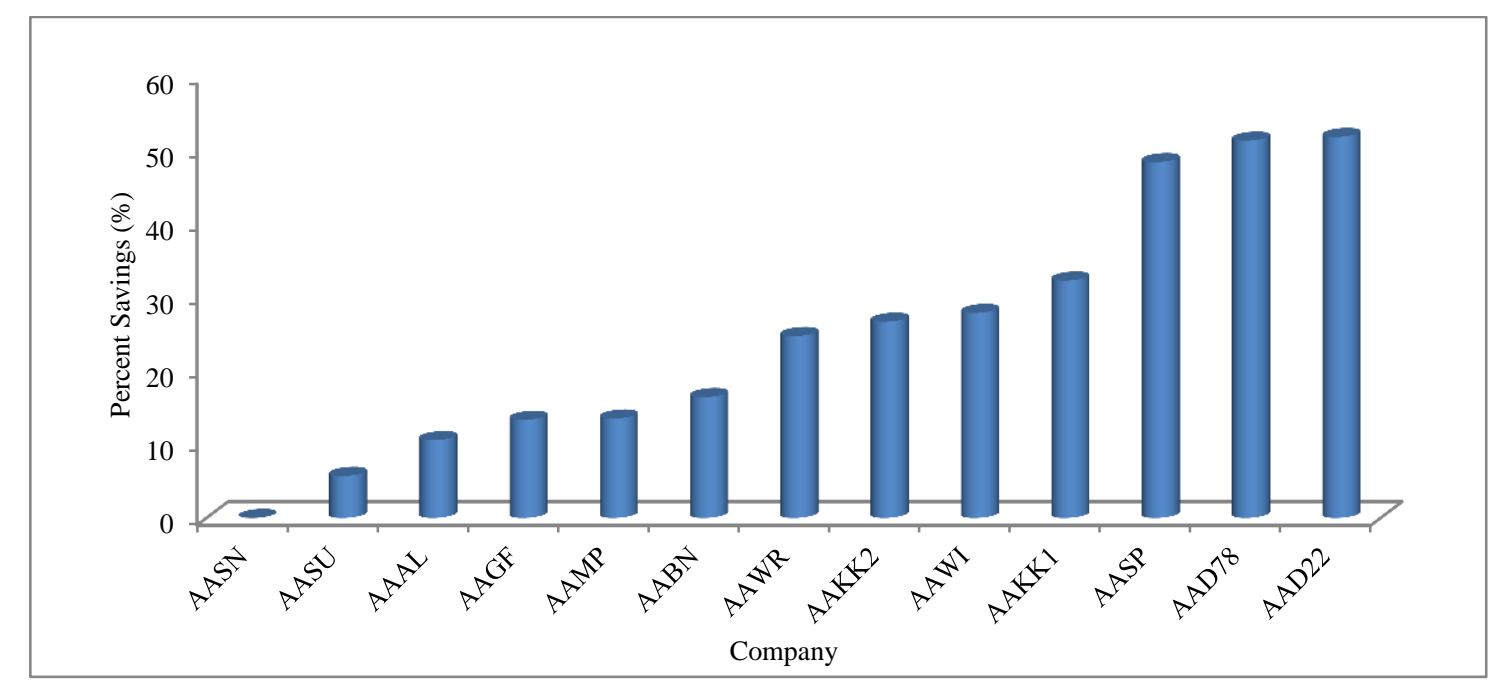

Figure 5.41: Percent total natural gas reduction of audited plants

According to Figure 5.41, Plant AAD22 can save the highest amount of natural gas per year that indicates 52 percent of total natural gas savings and the amount is $639,409 \mathrm{~m}^{3}$ per year 
and the plant AASN had saving 0\% because this plant already has R20 insulation. After that, insulation upgrade cost and payback period was also calculated based on required insulation $\mathrm{R}$ value and plant area using Equation 5.1 [74].

Incentive $(\$)=($ Required R Value - Existing R Value $) \times$ Area x Enbridge Gas Rate

Incentive $\left(\$ / \mathrm{ft}^{2}\right)=$ Incentive $(\$) /$ Area $\left(\mathrm{ft}^{2}\right)$

Table 5.28 presents the amount of natural gas reduction percent and calculated payback period of audited plants

Table 5.28: Amount of natural gas, cost reduction and payback period of all audited plants

\begin{tabular}{|c|c|c|c|c|c|c|}
\hline Facility & $\begin{array}{c}\text { Transmission } \\
\text { Heat Loss } \\
\text { With Current } \\
\text { R Value }\left(\mathrm{m}^{3}\right)\end{array}$ & $\begin{array}{c}\text { Transmission } \\
\text { Heat Loss } \\
\text { With R 20 } \\
\left(\mathrm{m}^{3}\right)\end{array}$ & $\begin{array}{c}\text { Reduction of } \\
\text { NG } \\
\text { Consumption } \\
\left(\mathrm{m}^{3}\right)\end{array}$ & $\begin{array}{c}\text { Cost } \\
\text { Reduction } \\
(\$)\end{array}$ & $\begin{array}{c}\text { NG } \\
\text { Consumption } \\
\text { Reduction } \\
(\%)\end{array}$ & $\begin{array}{c}\text { Payback } \\
\text { (yr.) }\end{array}$ \\
\hline AAD78 & 548,446 & 50,718 & 497,728 & 124,432 & 51 & 8 \\
\hline AAD22 & 673,706 & 34,297 & 639,409 & 159,852 & 52 & 6 \\
\hline AASP & 208,512 & 27,361 & 181,150 & 45,288 & 48 & 6 \\
\hline AAMP & 93,055 & 22,971 & 70,084 & 17,521 & 14 & 15 \\
\hline AABN & 74,178 & 15,344 & 58,834 & 14,708 & 16 & 26 \\
\hline AAWI & 100,386 & 16,271 & 84,114 & 21,029 & 28 & 22 \\
\hline AAAL & 88,259 & 26,078 & 62,181 & 15,545 & 11 & 14 \\
\hline AAWR & 332,686 & 68,920 & 263,767 & 65,942 & 25 & 16 \\
\hline AASU & 44,594 & 5,952 & 38,643 & 9,661 & 6 & 18 \\
\hline AASN & 20,297 & 20,297 & 0 & 0 & 0 & 0 \\
\hline AAGF & 493,390 & 46,237 & 447,153 & 111,788 & 13 & 8 \\
\hline AAKK1 & 379,635 & 45,946 & 333,689 & 83,422 & 32 & 10 \\
\hline AAKK2 & 190,152 & 19,257 & 170,895 & 42,724 & 27 & 9 \\
\hline
\end{tabular}

According to table 5.28 average pay back period of plants were calculated 12 years. Plant AASN already has building insulation R20. For this reason, this company does not have any natural gas and cost reduction. 


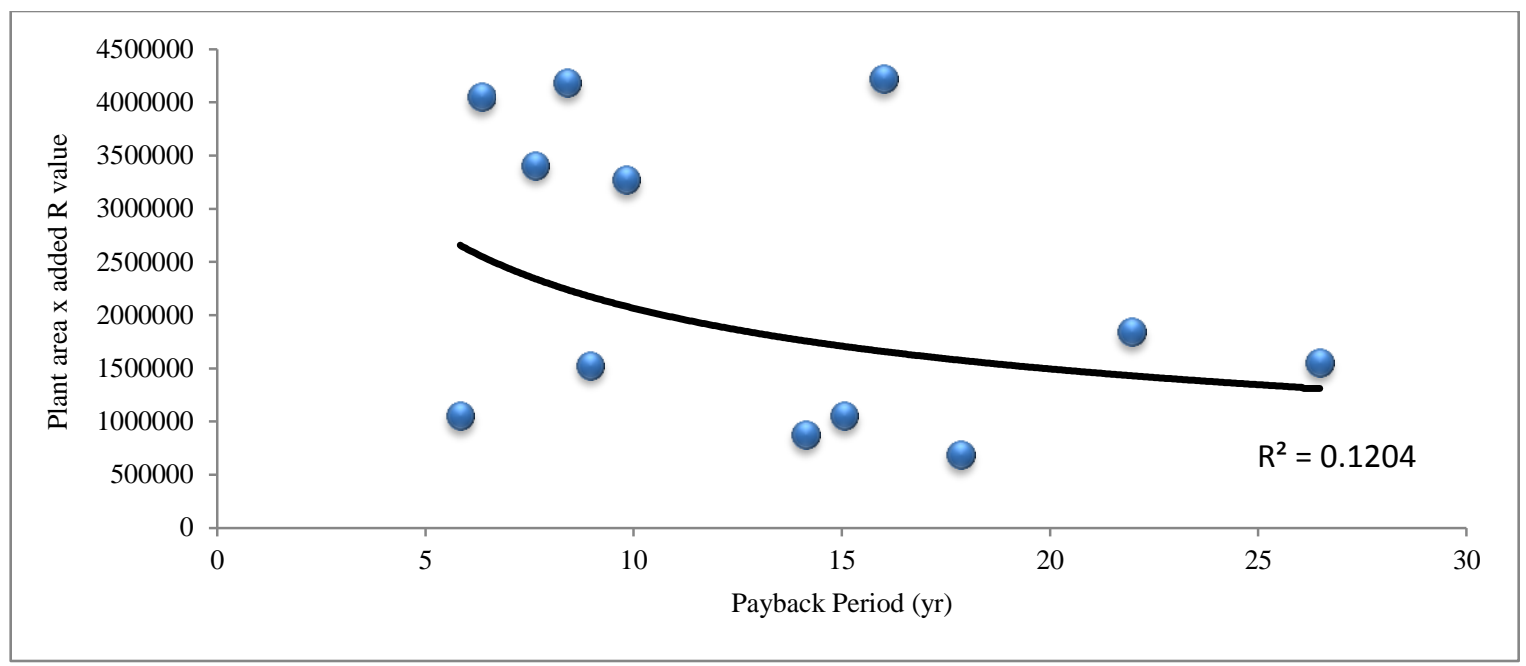

Figure 5.39: Payback period for improving insulation $R$ Value.

According to Figure 5.39 six to twenty six years payback period was estimated for selected audited plants. 


\section{Chapter 6}

\section{Summary and Conclusion}

\subsection{Summary of the Thesis}

In this paper, natural gas consumption of different small and medium sized industries in GTA and related potential energy and cost savings were analyzed. Detailed energy audits were conducted and in-depth natural gas consumption analyses were performed. The procedure consisted of four major phases: data collection, weather normalization, ventilation analysis and development of calculating tool to automate the analysis.

During the assessments, virtual and on-site energy audits were conducted. Three different types of SMEs were audited; powder coating, food industries and packaging. Due to the limited number of plants in each category, the ventilation benchmarking was conducted together. The study delivers detailed analysis of transmission heat loss, total ventilation energy consumption, mechanical ventilation energy consumption and infiltration loss. After that, the energy consumption trend and saving potentials were calculated. In addition to natural gas savings, cost savings and reduction of GHG emission were also calculated. Table 6.1 presents the summary of overall natural gas consumption, GHG emission, and cost by 1different audited industries dataset.

Table 6.1: Summary of overall NG consumption, GHG emission and cost by different audited industries' dataset

\begin{tabular}{|c|c|c|}
\hline & $\begin{array}{c}\text { Energy Consumption - Range } \\
\left(\mathrm{m}^{3} / \text { year }\right)\end{array}$ & $\begin{array}{c}\text { Energy Consumption } \\
\left(\mathrm{m}^{3} / \text { year }\right) \text { - Median }\end{array}$ \\
\hline $\begin{array}{c}\text { Total Normalized NG } \\
\text { Consumption }\end{array}$ & $267,303-3,347,868$ & 613,288 \\
\hline Seasonal Consumption & $34,419-826,790$ & 194,269 \\
\hline Process Consumption & $85,198-2,782,068$ & 441,060 \\
\hline Transmission Heat Loss & $20,297-673,706$ & 177,140 \\
\hline $\begin{array}{l}\text { Total Ventilation } \\
\text { Consumption }\end{array}$ & $5,356-238,896$ & 80,277 \\
\hline $\begin{array}{l}\text { Mechanical Ventilation } \\
\text { Consumption }\end{array}$ & $31-1,479$ & 243 \\
\hline \multirow[t]{2}{*}{ Infiltration Loss } & $18,331-237,328$ & 98,178 \\
\hline & $\begin{array}{c}\text { Energy Cost - Range } \\
(\$ / \text { year })\end{array}$ & $\begin{array}{c}\text { Energy Cost } \\
\text { (\$/year) - Median }\end{array}$ \\
\hline
\end{tabular}




\begin{tabular}{|c|c|c|}
\hline $\begin{array}{c}\text { Total Normalized NG } \\
\text { Consumption }\end{array}$ & $66,826-836,967$ & 153,322 \\
\hline Seasonal Consumption & $8,605-206,698$ & 48,567 \\
\hline Process Consumption & $21,299-695,517$ & 110,265 \\
\hline Transmission Heat Loss & $5,074-168,426$ & 44,285 \\
\hline $\begin{array}{c}\text { Total Ventilation } \\
\text { Consumption }\end{array}$ & $1,339-59,724$ & 20,069 \\
\hline $\begin{array}{c}\text { Mechanical Ventilation } \\
\text { Consumption }\end{array}$ & $8-370$ & 61 \\
\hline Infiltration Loss & $4,583-59,332$ & 24,545 \\
\hline $\begin{array}{c}\text { Range } \\
\text { Total Normalized NG } \\
\text { Consumption }\end{array}$ & $31,485-242,516$ & Median \\
\hline Seasonal Consumption & $2,474-59,438$ & 39,583 \\
\hline Process Consumption & $6,125-200,004$ & 13,966 \\
\hline Transmission Heat Loss & $1,405-46,648$ & 31,708 \\
\hline $\begin{array}{c}\text { Total Ventilation } \\
\text { Consumption }\end{array}$ & $371-16,541$ & 12,265 \\
\hline $\begin{array}{c}\text { Mechanical Ventilation } \\
\text { Consumption }\end{array}$ & $1-27$ & 5,558 \\
\hline Infiltration Loss & $1,318-17,062$ & 4 \\
\hline
\end{tabular}

After calculating overall natural gas consumption, a savings analysis was conducted. Table 6.2 presents the savings of normalized natural gas consumption of powder coating and food industries in GTA.

Table 6.2: Summary result of normalized natural gas, cost and GHG emission savings of food and powder coating industries

\begin{tabular}{|c|c|c|c|c|c|}
\hline Type & & $\begin{array}{c}\text { Energy Saving - } \\
\text { Range } \\
\left(\mathrm{m}^{3} / \text { year }\right)\end{array}$ & $\begin{array}{c}\text { Total Saving } \\
\text { from all } \\
\text { plants }\end{array}$ & $\begin{array}{c}\text { Total NG } \\
\text { savings } \\
(\%)\end{array}$ & $\begin{array}{c}\text { Energy Saving } \\
- \text { Median } \\
\left(\mathrm{m}^{3} / \text { year }\right)\end{array}$ \\
\hline $\begin{array}{c}\text { Powder } \\
\text { Coating }\end{array}$ & $\begin{array}{c}\text { Consumption Per } \\
\text { Unit Area }\end{array}$ & $7,701-77,881$ & 352,107 & 8 & 60,603 \\
\cline { 2 - 6 } & $\begin{array}{c}\text { Consumption Per } \\
\text { Unit Operational } \\
\text { hour }\end{array}$ & $2,896-460,692$ & 911,041 & 72 & 50,992 \\
\cline { 2 - 6 } & $\begin{array}{c}\text { Consumption per } \\
\text { unit Area x } \\
\text { Operational hour }\end{array}$ & $72,757-93,202$ & 499,967 & 23 & 78,808 \\
\hline $\begin{array}{c}\text { Food } \\
\text { Industries }\end{array}$ & $\begin{array}{c}\text { Consumption Per } \\
\text { Unit Area }\end{array}$ & $104,971-$ & $2,993,108$ & 51 & 288,605 \\
\hline & Consumption per & $39,415,899$ & & & 506,817 \\
\hline
\end{tabular}




\begin{tabular}{|c|c|c|c|c|c|}
\hline & $\begin{array}{c}\text { unit Area } \mathrm{x} \\
\text { Operational hour }\end{array}$ & $3,090,975$ & & & \\
\hline Type & & $\begin{array}{l}\text { Energy Cost } \\
\text { Saving - Range } \\
\text { (\$/year) }\end{array}$ & $\begin{array}{l}\text { Total Cost } \\
\text { Saving from } \\
\text { all plants }\end{array}$ & $\begin{array}{c}\text { Total } \\
\text { Cost } \\
\text { savings } \\
(\%)\end{array}$ & $\begin{array}{l}\text { Cost Saving - } \\
\text { Median } \\
\text { (\$/year) }\end{array}$ \\
\hline \multirow[t]{3}{*}{$\begin{array}{l}\text { Powder } \\
\text { Coating }\end{array}$} & $\begin{array}{l}\text { Consumption Per } \\
\text { Unit Area }\end{array}$ & $1,925-19,470$ & 88,027 & 8 & 15,151 \\
\hline & $\begin{array}{c}\text { Consumption Per } \\
\text { Unit Operational } \\
\text { hour }\end{array}$ & $724-115,173$ & 227,760 & 72 & 12,748 \\
\hline & $\begin{array}{l}\text { Consumption per } \\
\text { unit Area x } \\
\text { Operational hour }\end{array}$ & $18,189-23,301$ & 124,992 & 23 & 19,702 \\
\hline \multirow[t]{2}{*}{$\begin{array}{c}\text { Food } \\
\text { Industries }\end{array}$} & $\begin{array}{l}\text { Consumption Per } \\
\text { Unit Area }\end{array}$ & $\begin{array}{c}26,243- \\
603,975\end{array}$ & 748,277 & 51 & 72,151 \\
\hline & $\begin{array}{l}\text { Consumption per } \\
\text { unit Area x } \\
\text { Operational hour }\end{array}$ & $\begin{array}{l}98,217- \\
772,744\end{array}$ & $1,026,152$ & 85 & 126,704 \\
\hline Type & & $\begin{array}{c}\text { GHG Saving - } \\
\text { Range } \\
\text { (tonne/year) }\end{array}$ & $\begin{array}{l}\text { Total GHG } \\
\text { Saving from } \\
\text { all plants } \\
\text { (tonne/year) }\end{array}$ & $\begin{array}{c}\text { Total } \\
\text { GHG } \\
\text { savings } \\
(\%)\end{array}$ & $\begin{array}{l}\text { GHG Saving - } \\
\text { Median } \\
\text { (tonne/year) }\end{array}$ \\
\hline \multirow[t]{3}{*}{$\begin{array}{l}\text { Powder } \\
\text { Coating }\end{array}$} & $\begin{array}{l}\text { Consumption Per } \\
\text { Unit Area }\end{array}$ & $554-5,599$ & 25,313 & 8 & 4,357 \\
\hline & $\begin{array}{c}\text { Consumption Per } \\
\text { Unit Operational } \\
\text { hour }\end{array}$ & $208-33,119$ & 65,495 & 72 & 3,666 \\
\hline & $\begin{array}{l}\text { Consumption per } \\
\text { unit Area x } \\
\text { Operational hour }\end{array}$ & $5,231-6,700$ & 35,943 & 23 & 5,666 \\
\hline \multirow[t]{2}{*}{$\begin{array}{c}\text { Food } \\
\text { Industries }\end{array}$} & $\begin{array}{l}\text { Consumption Per } \\
\text { Unit Area }\end{array}$ & $7,546-173,680$ & 215,176 & 51 & 20,748 \\
\hline & $\begin{array}{l}\text { Consumption per } \\
\text { unit Area x } \\
\text { Operational hour }\end{array}$ & $\begin{array}{l}28,243- \\
222,212\end{array}$ & 295,082 & 85 & 36,435 \\
\hline
\end{tabular}

After calculating normalized natural gas consumption, ventilation analysis was performed. Then, again natural gas, cost and GHG emissions saving analysis were performed by ranking based distribution and improving building insulation $\mathrm{R}$ Value. Table 6.3 presents the summary of natural gas, cost, and GHG emission savings of 13 audited plants. 
Table 6.3: Summary result of overall natural gas, cost and GHG emission savings

\begin{tabular}{|c|c|c|c|c|}
\hline & $\begin{array}{c}\text { Energy Saving - } \\
\text { Range } \\
\left(\mathrm{m}^{3} / \text { year }\right)\end{array}$ & $\begin{array}{c}\text { Total } \\
\text { Saving } \\
\text { from all } \\
\text { plants } \\
\left(\mathrm{m}^{3} / \text { year }\right)\end{array}$ & $\begin{array}{l}\text { Total NG } \\
\text { savings } \\
(\%)\end{array}$ & $\begin{array}{c}\text { Energy Saving - } \\
\text { Median } \\
\left(\mathrm{m}^{3} / \text { year }\right)\end{array}$ \\
\hline $\begin{array}{c}\text { Transmission Heat Loss per } \\
\text { unit Area }\end{array}$ & $35,384-624,216$ & $2,859,328$ & 25 & 170,450 \\
\hline $\begin{array}{l}\text { Transmission Heat Loss per } \\
\text { unit Area x Operational hour }\end{array}$ & $37,687-654,770$ & $2,947,568$ & 25 & 167020 \\
\hline $\begin{array}{c}\text { Total Ventilation } \\
\text { Consumption per unit Area }\end{array}$ & $14,347-227,676$ & 1149470 & 10 & 77,321 \\
\hline $\begin{array}{l}\text { Total Ventilation } \\
\text { Consumption per unit } \\
\text { Operational Hour }\end{array}$ & $2,055-222,265$ & 1092173 & 9 & 72,974 \\
\hline $\begin{array}{c}\text { Total Ventilation } \\
\text { Consumption per unit Area x } \\
\text { Operational Hour }\end{array}$ & $5,780-205,676$ & $1,066,357$ & 9 & 76,246 \\
\hline $\begin{array}{c}\text { Mechanical Ventilation } \\
\text { Consumption Per Unit Area }\end{array}$ & $98-1,377$ & 4825 & 0.04 & 215 \\
\hline $\begin{array}{c}\text { Mechanical Ventilation } \\
\text { Consumption Per Unit Area } \\
\text { x Operational Hour }\end{array}$ & $98-1,363$ & 4,948 & 0.04 & 228 \\
\hline $\begin{array}{c}\text { Infiltration Loss per Unit } \\
\text { area }\end{array}$ & $18,073-194,275$ & 925,515 & 10 & 84922 \\
\hline \multirow[t]{2}{*}{ Improving R Value } & $38,643-639,409$ & $2,966,264$ & 25 & 145,162 \\
\hline & $\begin{array}{l}\text { Cost Saving - } \\
\text { Range } \\
\text { (\$/year) }\end{array}$ & $\begin{array}{l}\text { Total Cost } \\
\text { Savings } \\
\text { (\$/year) }\end{array}$ & $\begin{array}{l}\text { Cost } \\
\text { Savings } \\
(\%)\end{array}$ & $\begin{array}{l}\text { Cost Savings - } \\
\text { Median } \\
\text { (\$/year) }\end{array}$ \\
\hline $\begin{array}{c}\text { Transmission Heat Loss per } \\
\text { unit Area }\end{array}$ & $8,846-156,054$ & 714,832 & 24 & 42,613 \\
\hline $\begin{array}{l}\text { Transmission Heat Loss per } \\
\text { unit Area x Operational hour }\end{array}$ & $9,422-163,692$ & 736,892 & 25 & 41,755 \\
\hline $\begin{array}{c}\text { Total Ventilation } \\
\text { Consumption per unit Area }\end{array}$ & $3,587-56,919$ & 287,367 & 10 & 19,330 \\
\hline $\begin{array}{c}\text { Total Ventilation } \\
\text { Consumption per unit } \\
\text { Operational Hour }\end{array}$ & $514-55,566$ & 273,043 & 9 & 18,243 \\
\hline $\begin{array}{c}\text { Total Ventilation } \\
\text { Consumption per unit Area x } \\
\text { Operational Hour }\end{array}$ & $1,445-51,419$ & 266,589 & 9 & 19,061 \\
\hline
\end{tabular}




\begin{tabular}{|c|c|c|c|c|}
\hline $\begin{array}{c}\text { Mechanical Ventilation } \\
\text { Consumption Per Unit Area }\end{array}$ & $24-344$ & 1,206 & 0.04 & 54 \\
\hline $\begin{array}{c}\text { Mechanical Ventilation } \\
\text { Consumption Per Unit Area } \\
\text { x Operational Hour }\end{array}$ & $24-341$ & 1,237 & 0.04 & 57 \\
\hline $\begin{array}{c}\text { Infiltration Loss per Unit } \\
\text { area }\end{array}$ & $4518-48,569$ & 231,379 & 10 & 21,231 \\
\hline Improving R Value & $9,661-159,852$ & 741,566 & 25 & 36,291 \\
\hline & $\begin{array}{l}\text { GHG Emission } \\
\text { Reduction- Range } \\
\text { (tonne/year) }\end{array}$ & $\begin{array}{l}\text { Total GHG } \\
\text { Emission } \\
\text { Reduction } \\
\text { (tonne/year) }\end{array}$ & $\begin{array}{c}\text { GHG } \\
\text { Emission } \\
\text { Reduction } \\
(\%)\end{array}$ & $\begin{array}{l}\text { GHG Emission } \\
\text { Reduction- } \\
\text { Median } \\
\text { (tonne/year) }\end{array}$ \\
\hline $\begin{array}{c}\text { Transmission Heat Loss per } \\
\text { unit Area }\end{array}$ & $2,544-44,875$ & 205,558 & 25 & 12,254 \\
\hline $\begin{array}{l}\text { Transmission Heat Loss per } \\
\text { unit Area x Operational hour }\end{array}$ & $2,709-47,072$ & 211,902 & 25 & 12,007 \\
\hline $\begin{array}{c}\text { Total Ventilation } \\
\text { Consumption per unit Area }\end{array}$ & $1,031-16,368$ & 82,636 & 10 & 5,559 \\
\hline $\begin{array}{c}\text { Total Ventilation } \\
\text { Consumption per unit } \\
\text { Operational Hour }\end{array}$ & $148-15,979$ & 78,517 & 9 & 5,246 \\
\hline $\begin{array}{c}\text { Total Ventilation } \\
\text { Consumption per unit Area x } \\
\text { Operational Hour }\end{array}$ & $416-14,786$ & 76,661 & 9 & 5,481 \\
\hline $\begin{array}{c}\text { Mechanical Ventilation } \\
\text { Consumption Per Unit Area }\end{array}$ & $7-99$ & 347 & 0.04 & 15 \\
\hline $\begin{array}{c}\text { Mechanical Ventilation } \\
\text { Consumption Per Unit Area } \\
\text { x Operational Hour }\end{array}$ & $7-98$ & 356 & 0.04 & 16 \\
\hline $\begin{array}{c}\text { Infiltration Loss per Unit } \\
\text { area }\end{array}$ & $1,299-13,966$ & 66,536 & 10 & 6,105 \\
\hline Improving R Value & $2,778-45,967$ & 213,246 & 25 & 10,436 \\
\hline
\end{tabular}

According to Table 6.2 and 6.3 plants can save natural gas from different categories. Based on these analyses, a plant manager can easily determine the current energy consuming trend for his company and take initiative to reduce energy consumption and related cost. The developed calculating tool contains the dataset for all 13 companies and when a new company will enter their utility bill in the tool all energy benchmarking analysis and saving potential analysis will be conducted within a second and the energy consumption trend will depicts the 
energy consumption condition of the plant compared to other plants in the dataset. The possible analysis, resulting from the calculating tool was demonstrated in Appendix F. A report template was also developed for the tool analysis demonstrated in Appendix F. This developed calculating tool will provide an initial picture of energy consumption and saving opportunity of the plant so that the plant manager can take further steps to save natural gas and utility cost. Thus Enbridge Gas Distribution will also be able to achieve Ontario Energy Board mandate to reduce natural gas consumption.

The results from this study suggest that energy benchmarking is an excellent tool to identify energy saving opportunities in industrial plants especially in the ventilation system. This will allow better energy management practice in industrial sector for the potential reduction of considerable amount of energy and cost.

\subsection{Author's Contribution}

Ryerson Enbridge partnership project gives opportunity to students to gather hand on experience in energy auditing and analyzing data to find energy saving opportunities. In this project, author has contributed following tasks:

According to the analysis it was found that, if all 13 audited companies will bring to the best condition, the GTA can save total $13,016,448 \mathrm{~m}^{3} /$ year which is $13 \%$ of their total natural gas consumption.

$>$ Development of Microsoft Excel based calculating tool using Visual Basic coding to automate ventilation analysis.

$>$ Conducted detailed analysis for building insulation improvement and energy and cost savings including payback period.

$>$ Prepared an energy audit report template

$>$ Entered heat recovery wheel system in the automated tool to calculate energy and cost savings including the installation cost and payback period.

$>$ Conducted detailed analysis of ventilation related natural gas consumption using multivariable regression analysis. 
Developed ranking distribution of natural gas consumption of plants based on normalized natural gas consumption and ventilation related natural gas consumption. This study is the first of this kind of benchmarking for small and medium enterprises in GTA

$>$ Calculated normalized natural gas consumption using Microsoft Excel and developed automated tool using Microsoft Visual Basic Coding.

Analysis of potential savings of natural gas, cost and GHG emission of typical and inefficient plants.

\subsection{Limitations}

The study is a part of Enbridge's Demand Side Management program. All data were collected by energy audit conducted by energy consultant of Enbridge gas distribution Inc. and a group of Ryerson University students. Due to limited number of energy audits, the types of industries were limited and numbers of plants were limited. The author did not have much control over this aspect. For this reason benchmarking analysis based on plant ventilation energy consumption was conducted combining all types of industries.

Another limitation was on the data that industries were interested to share. For example, there was no data for plant equipment efficiency, building height, building wall and roof insulation. For this reason, multivariable regression analysis was conducted to determine the missing variables in the dataset. For most of companies considerable result was calculated but for two companies, mechanical ventilation consumption was calculated negative due to misallocation in regression model. 


\section{Appendices}

\section{Appendix A: HDD Calculation}

\section{Calculated Monthly HDD of Plants:}

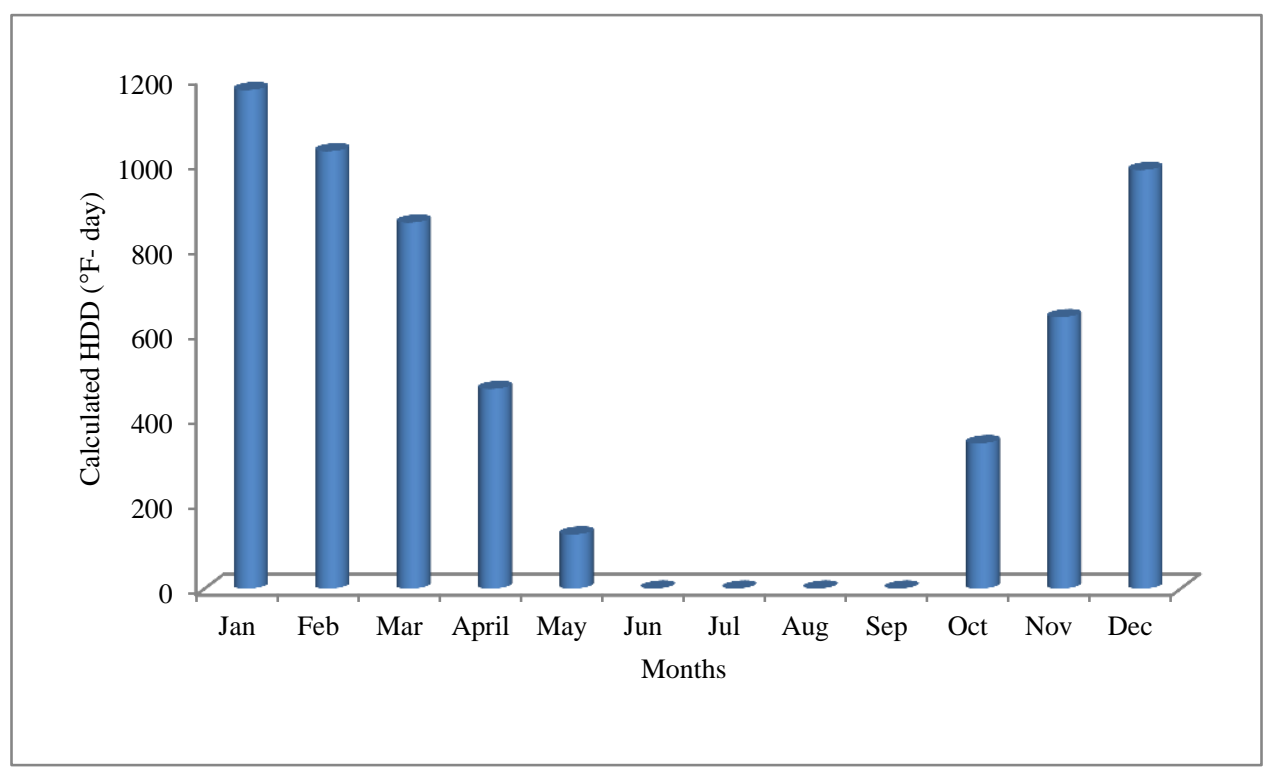

Figure A.1: Monthly heating degree days of plant AAD78

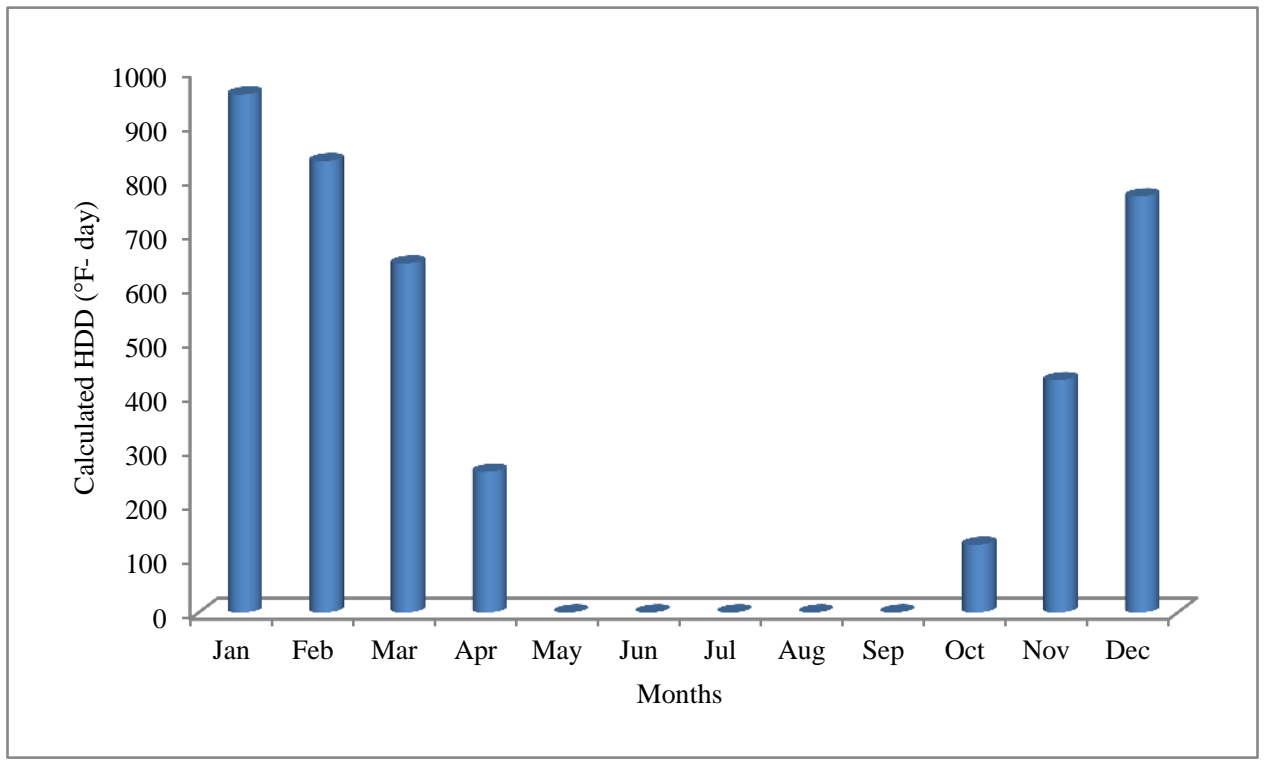

Figure A.2: Monthly heating degree days of plant AAD22 


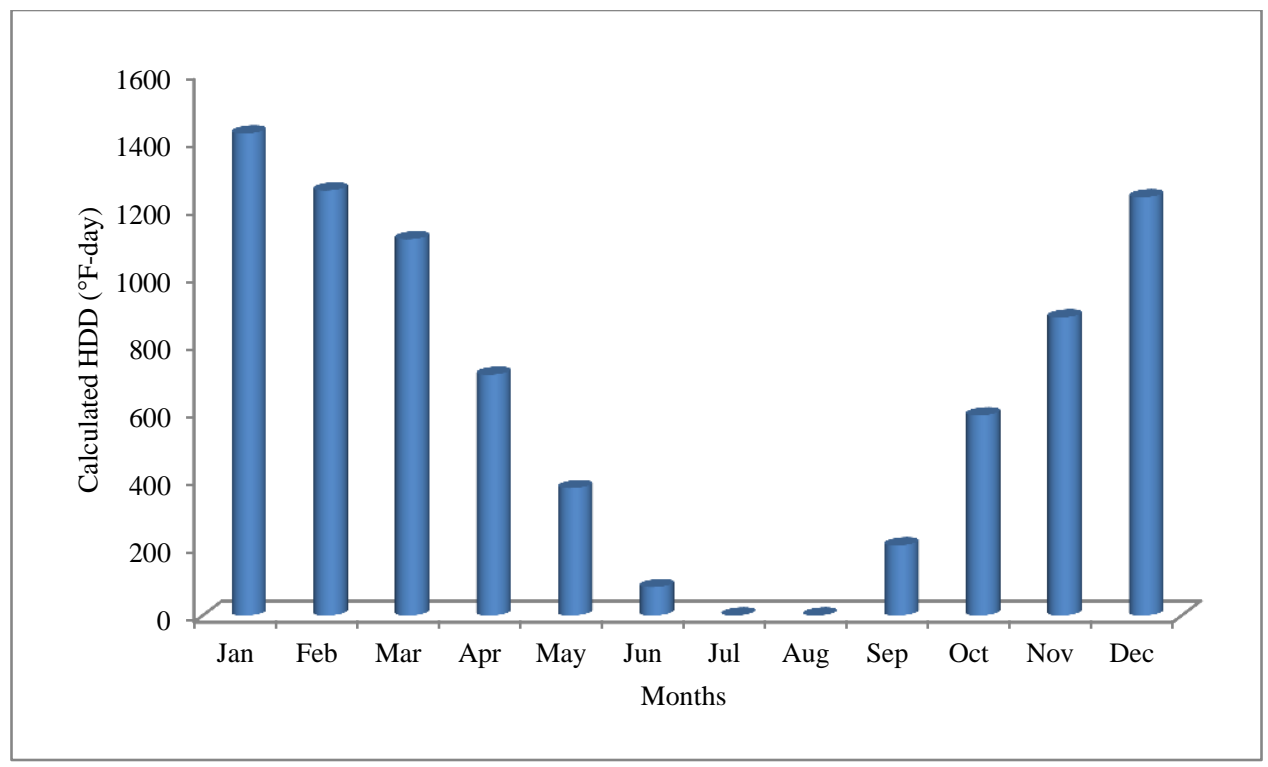

Figure A.3: Monthly heating degree days of plant AAAL

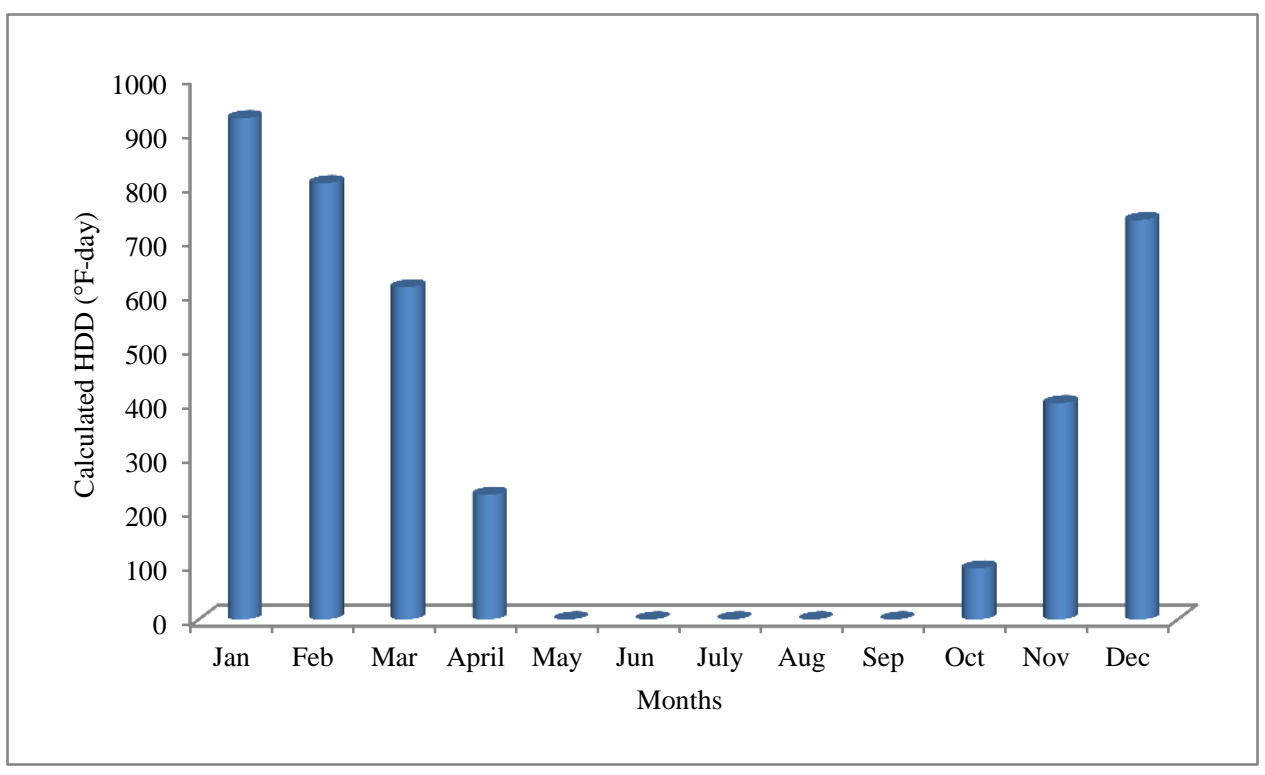

Figure A.4: Monthly heating degree days of plant AABN 


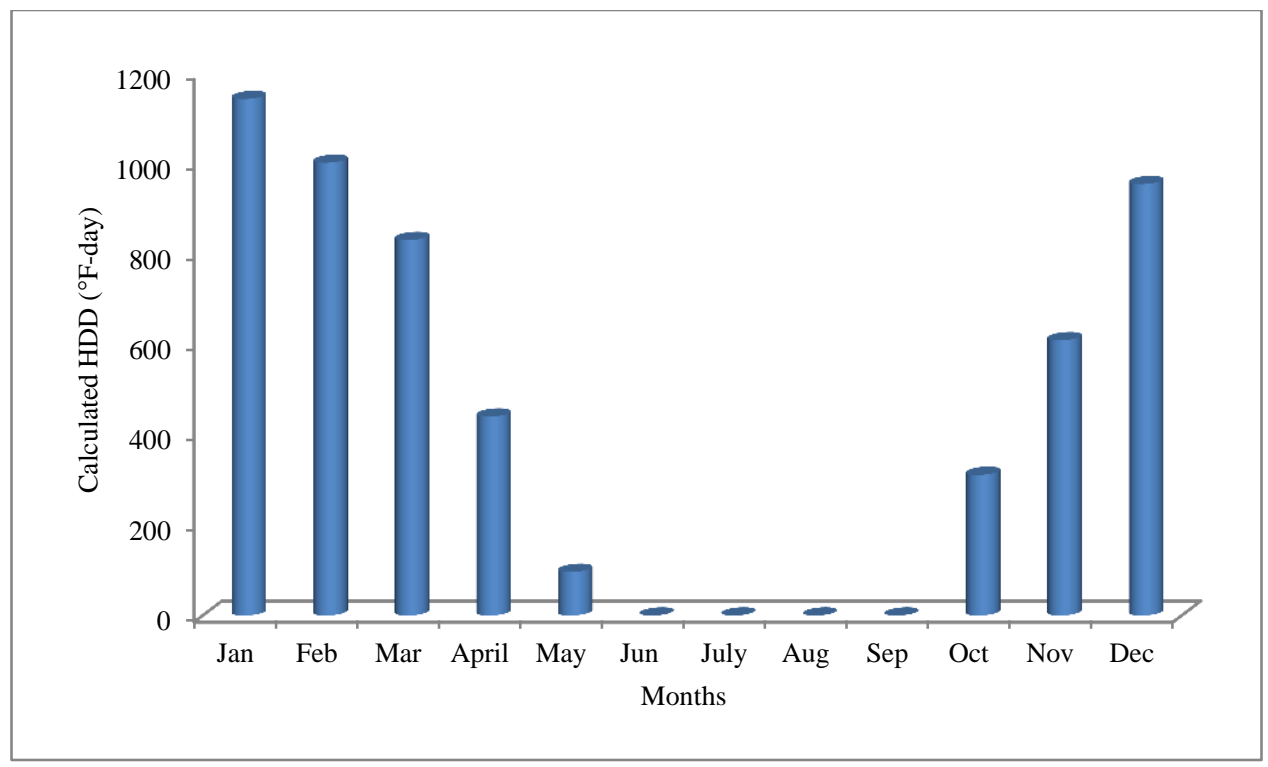

Figure A.5: Monthly heating degree days of plant AAGF

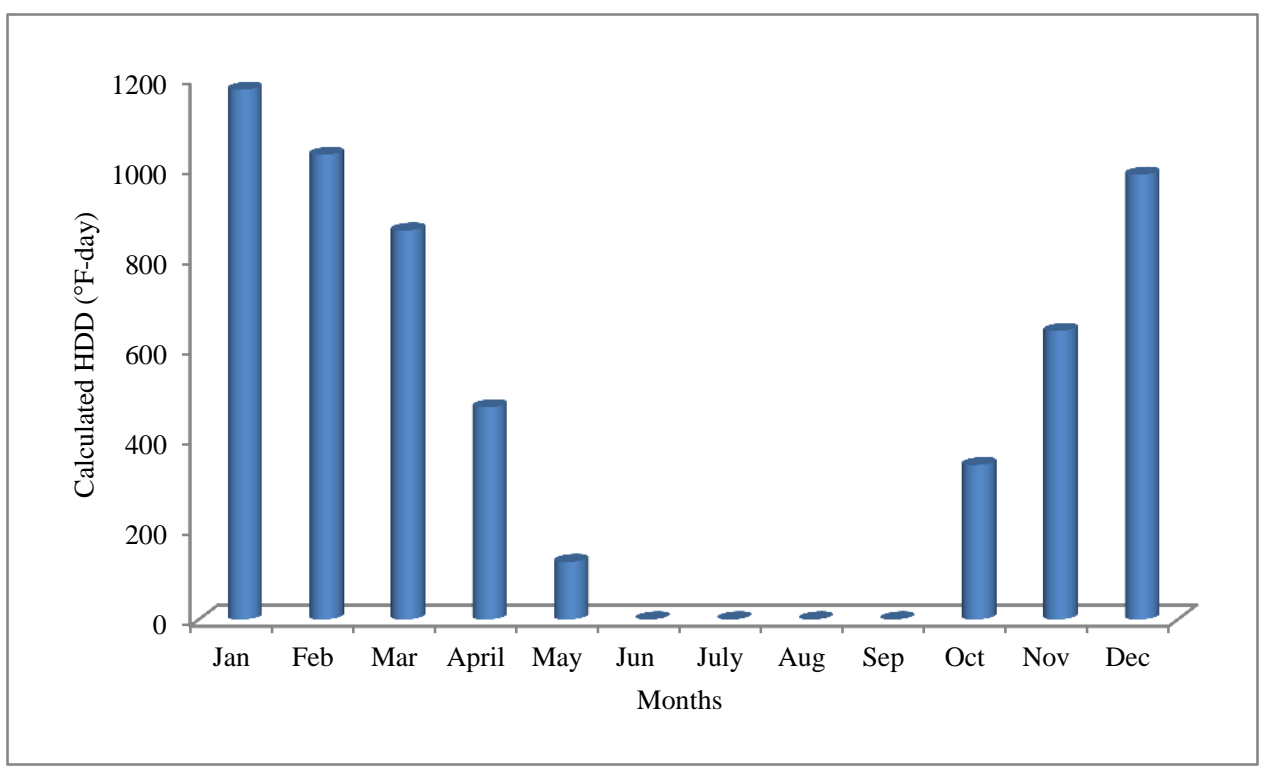

Figure A.6: Monthly heating degree days of plant AAKK 


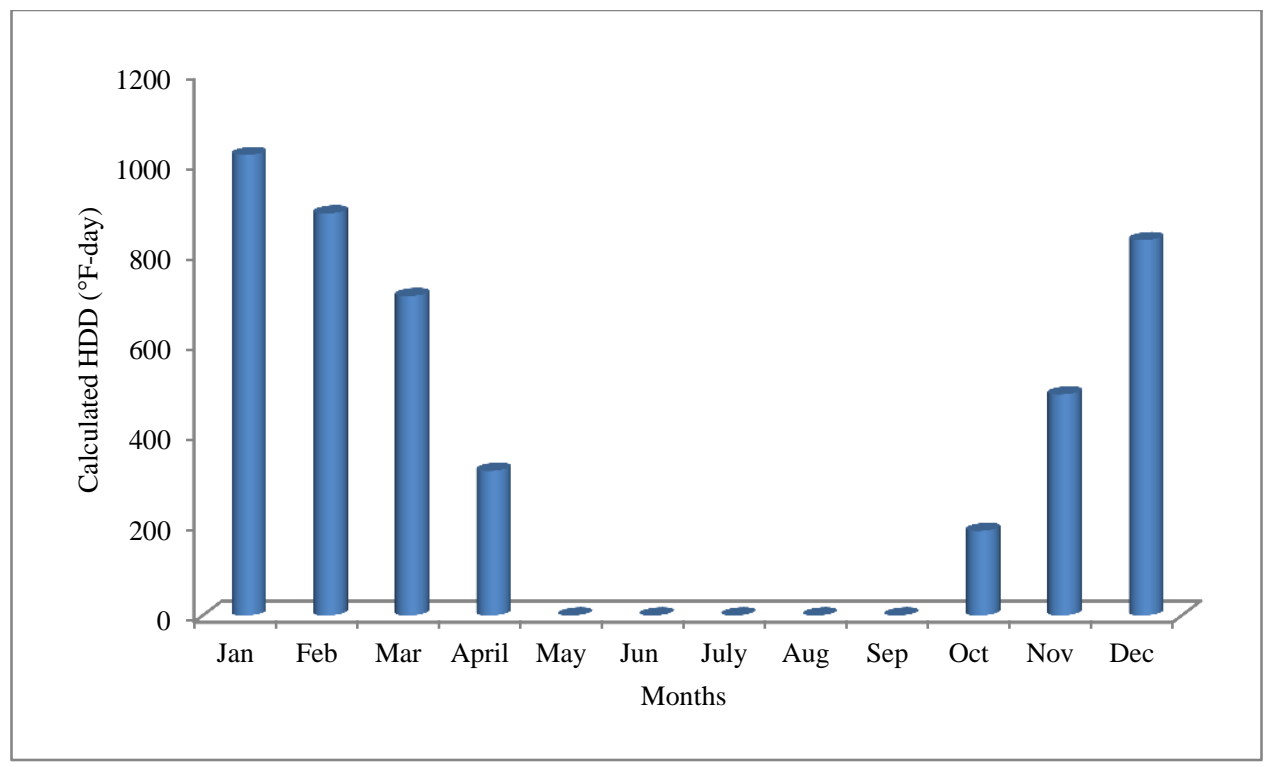

Figure A.7: Monthly heating degree days of plant AAKK2

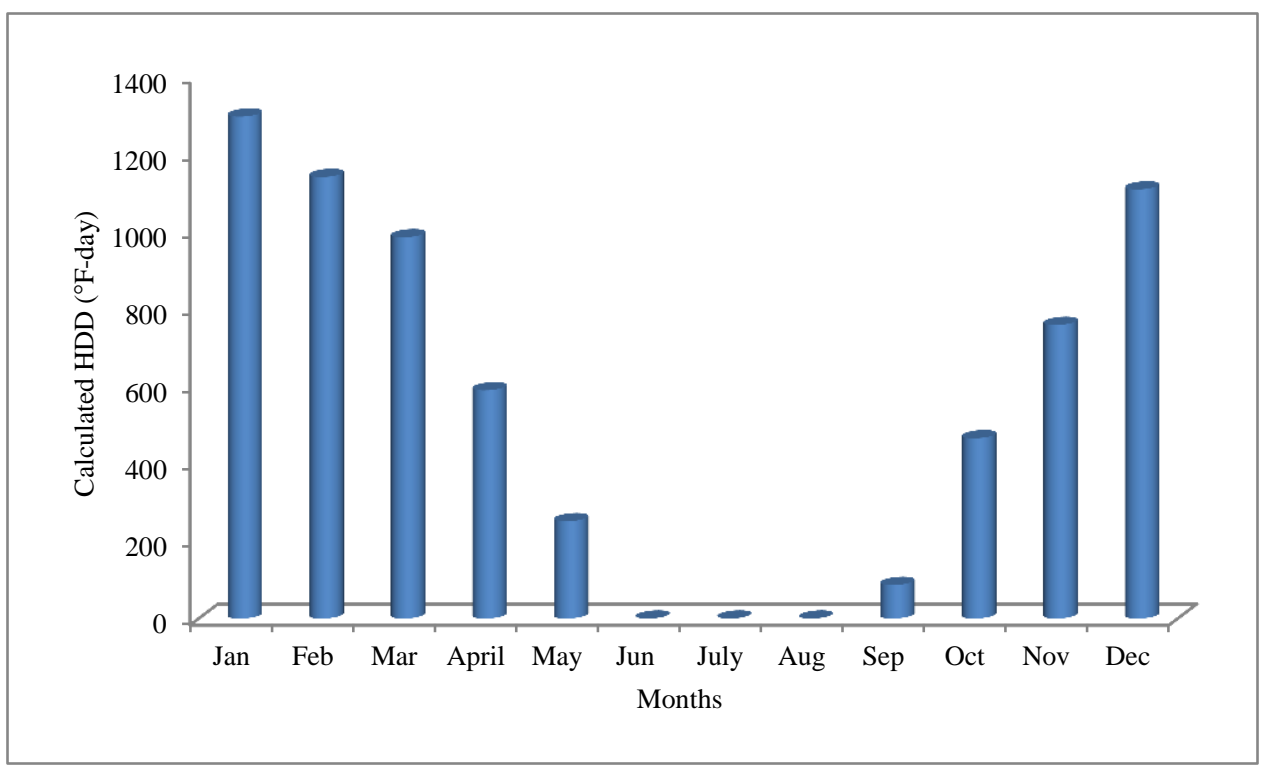

Figure A.8: Monthly heating degree days of plant AAMP 


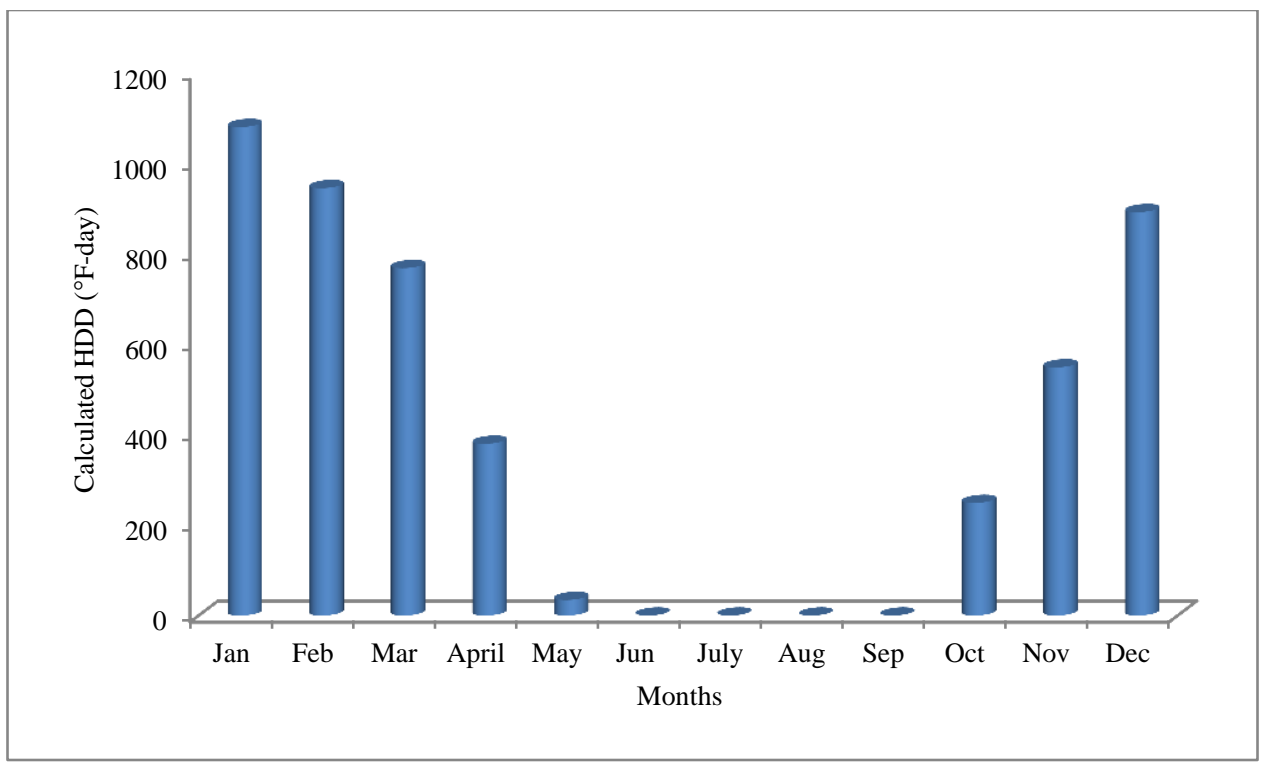

Figure A.9: Monthly heating degree days of plant AASN

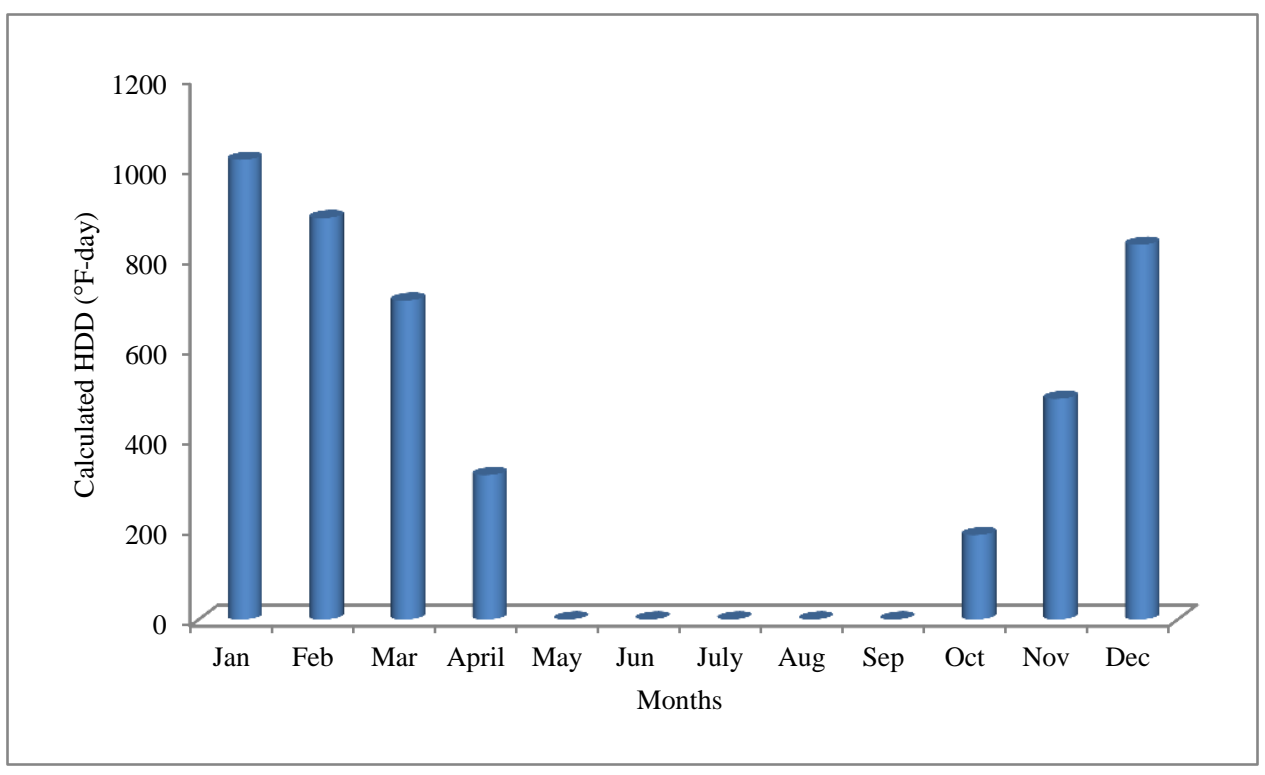

Figure A.10: Monthly heating degree days of plant AAWI 


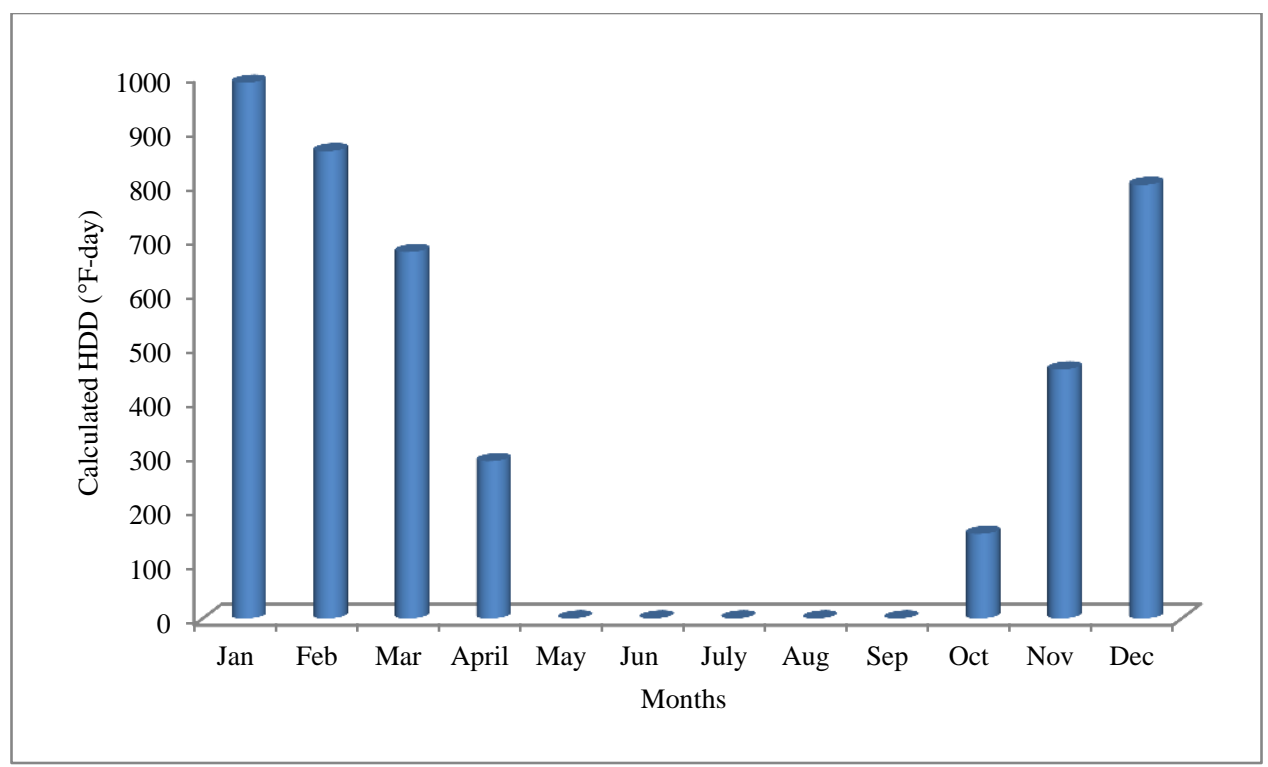

Figure A.11: Monthly heating degree days of plant AASU

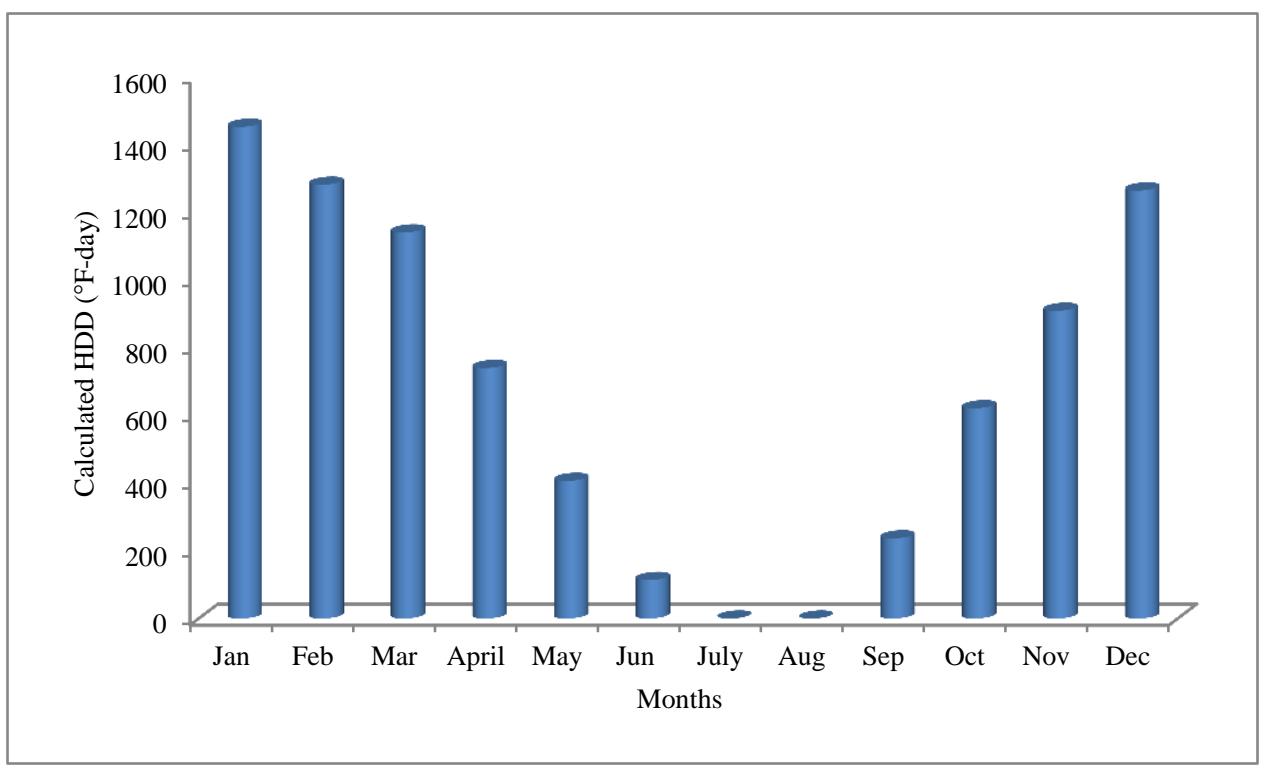

Figure A.12: Monthly heating degree days of plant AASP 


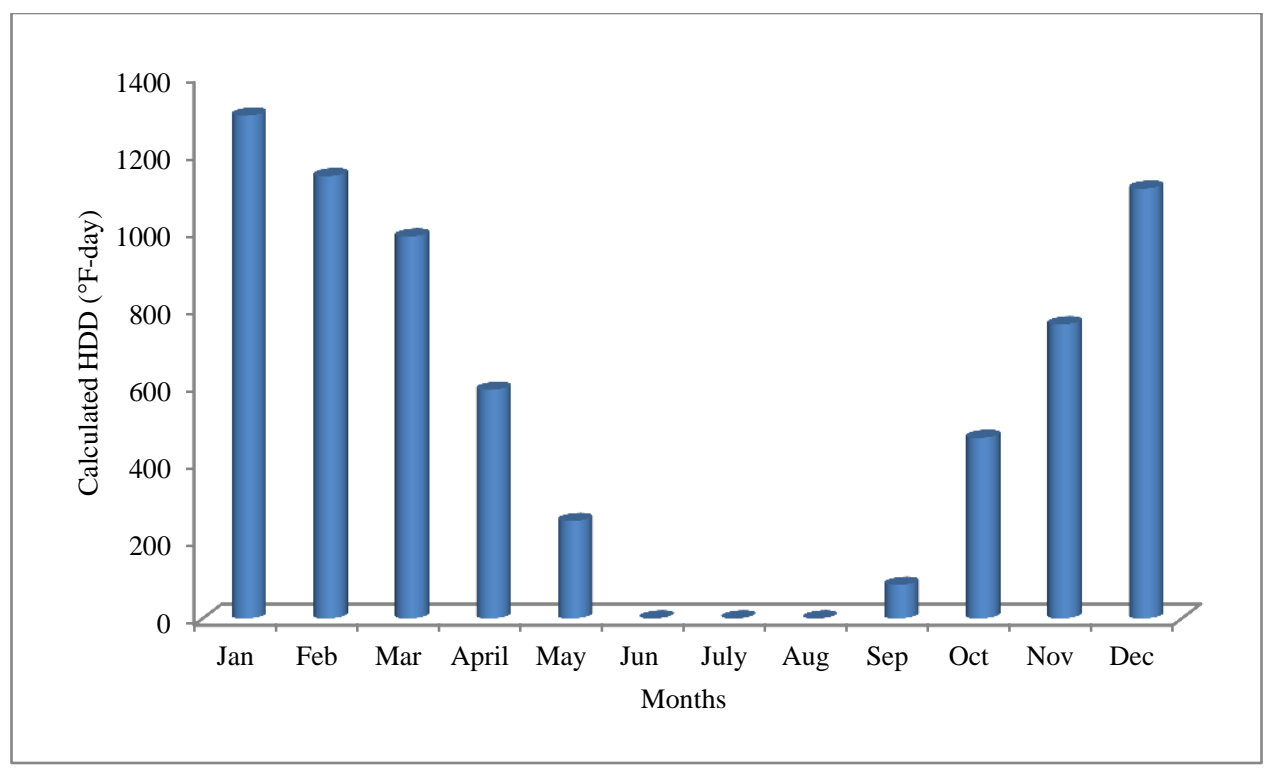

Figure A.13: Monthly heating degree days of plant AAWR 


\section{Appendix B: NAC Calculation}

Normalized Monthly Natural Gas Consumption of Plants:

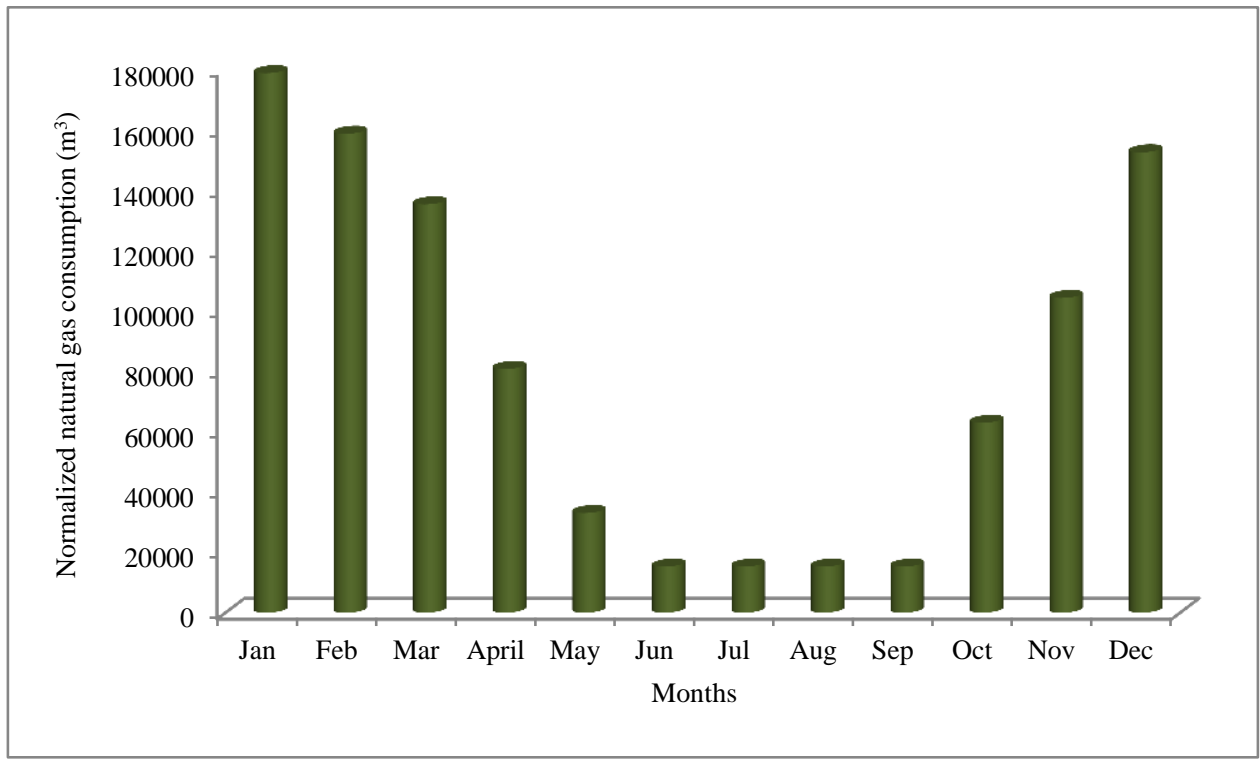

Figure B.1: Normalized monthly natural gas consumption of plant AAD78

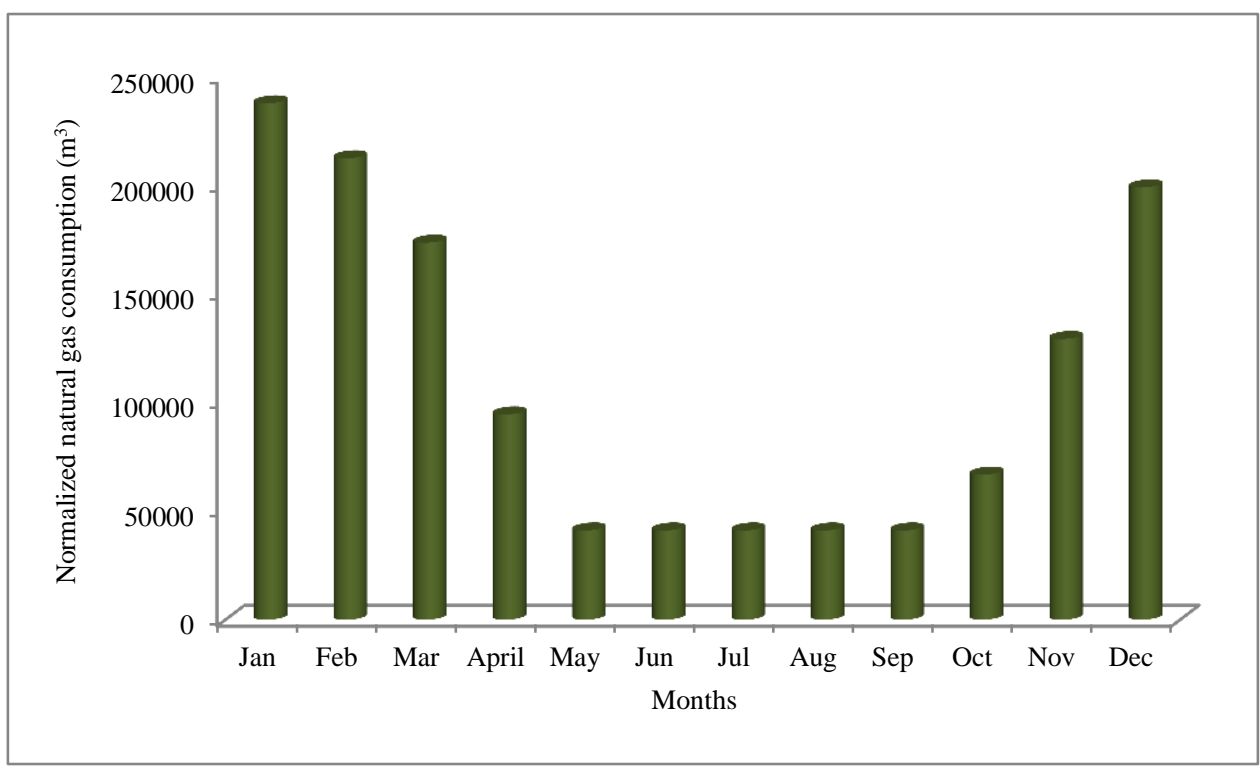

Figure B.2: Normalized monthly natural gas consumption of plant AAD22 


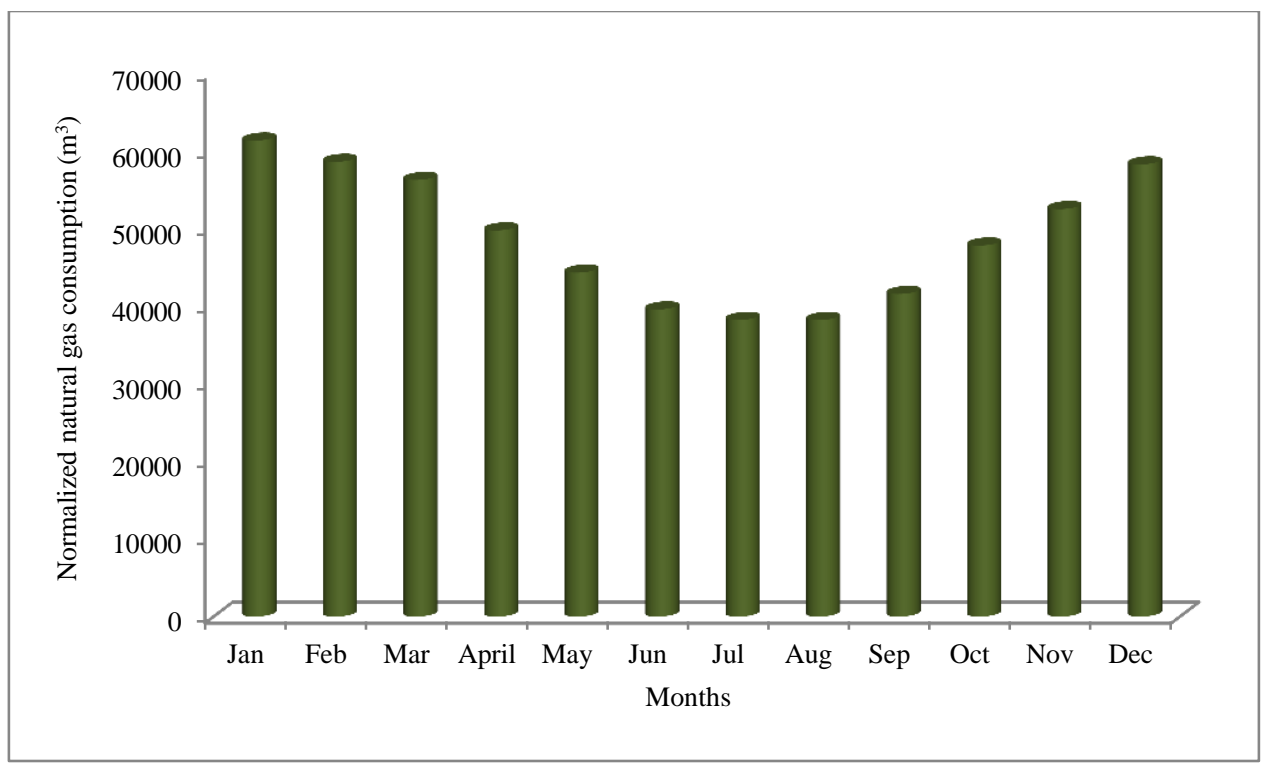

Figure B.3: Normalized monthly natural gas consumption of plant AAAL

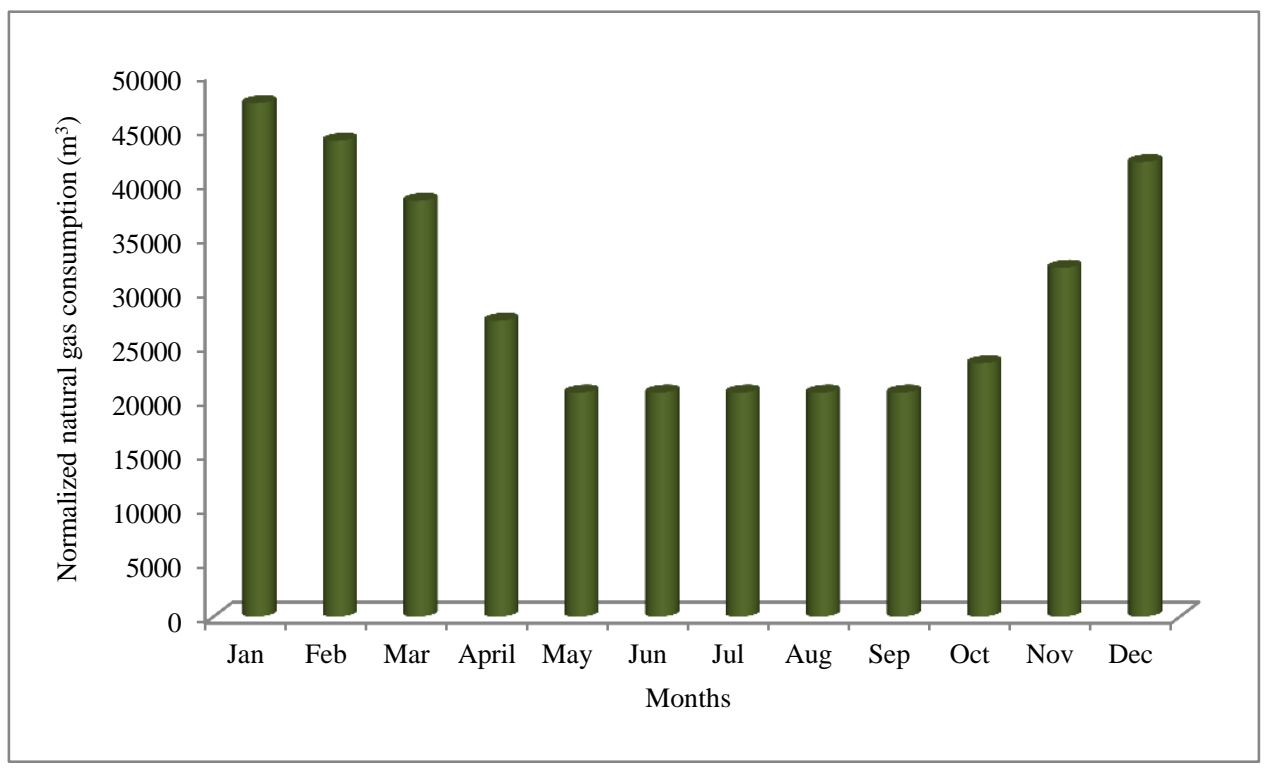

Figure B.4: Normalized monthly natural gas consumption of plant AABN 


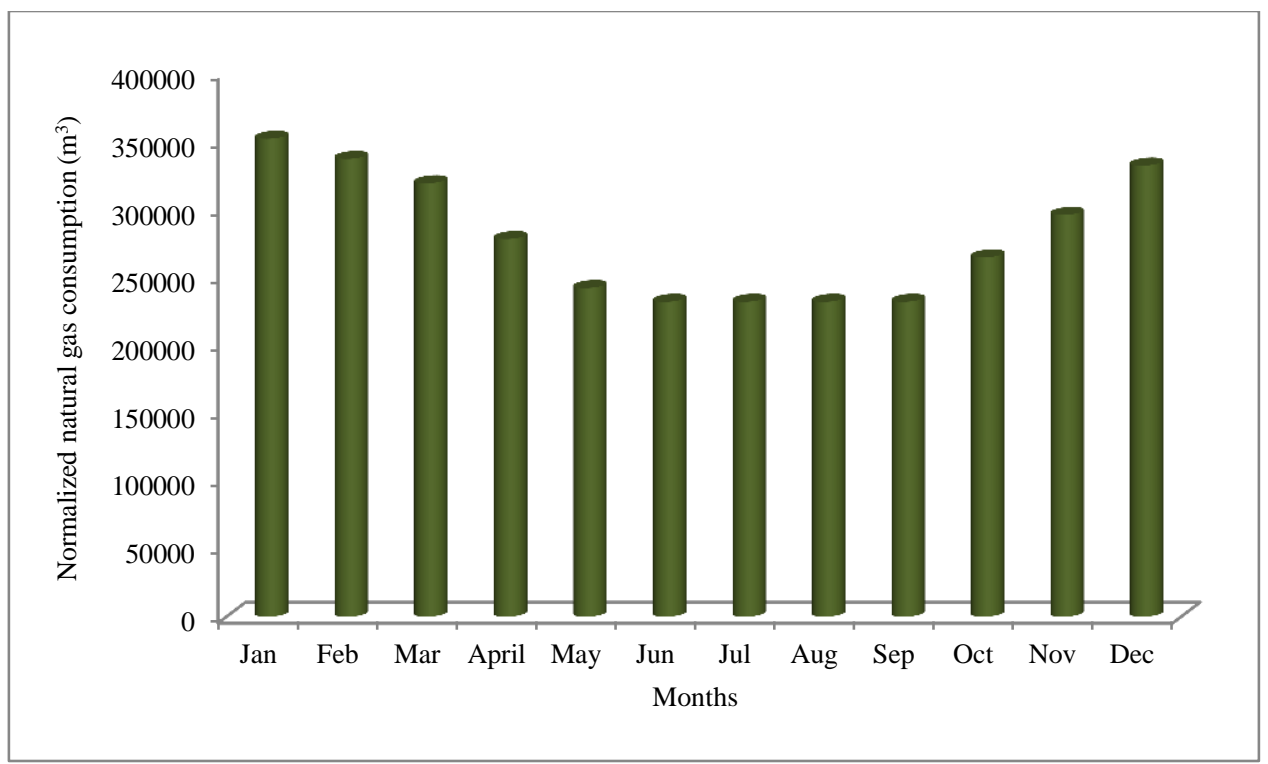

Figure B.5: Normalized monthly natural gas consumption of plant AAGF

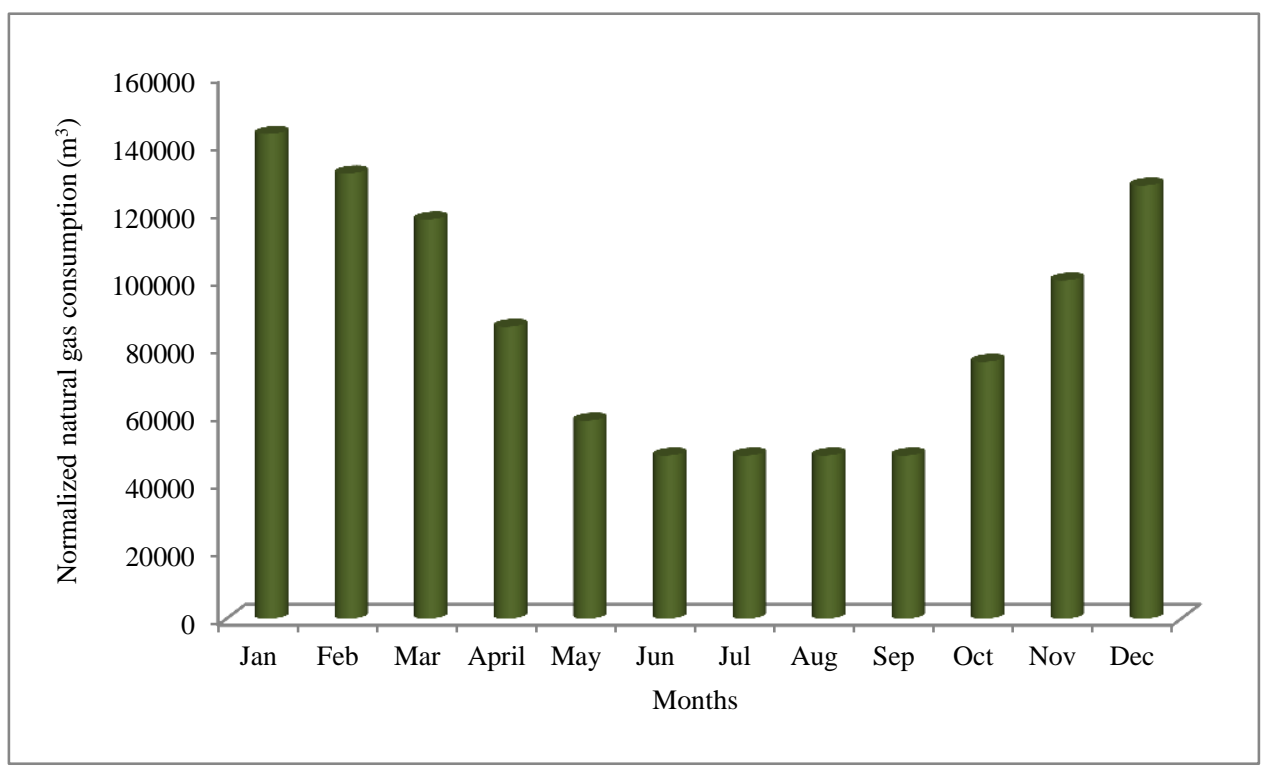

Figure B.6: Normalized monthly natural gas consumption of plant AAKK 


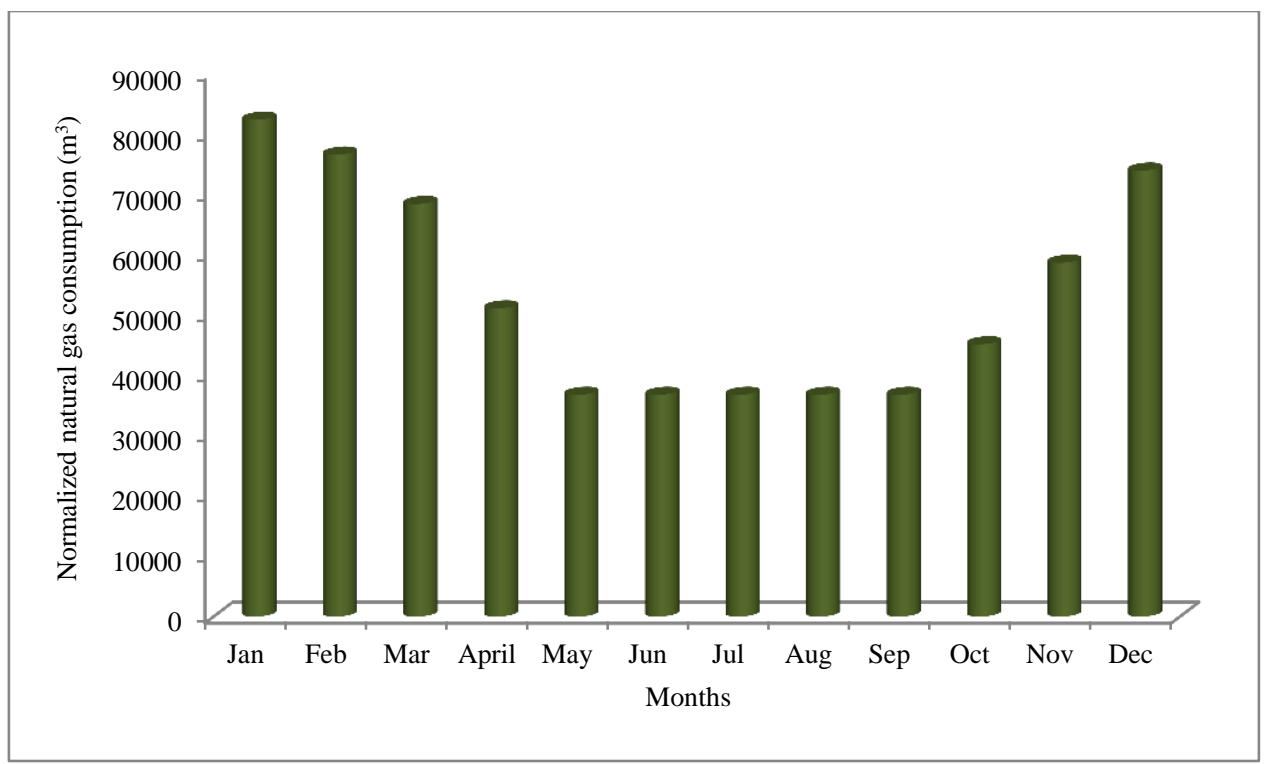

Figure B.7: Normalized monthly natural gas consumption of plant AAKK2

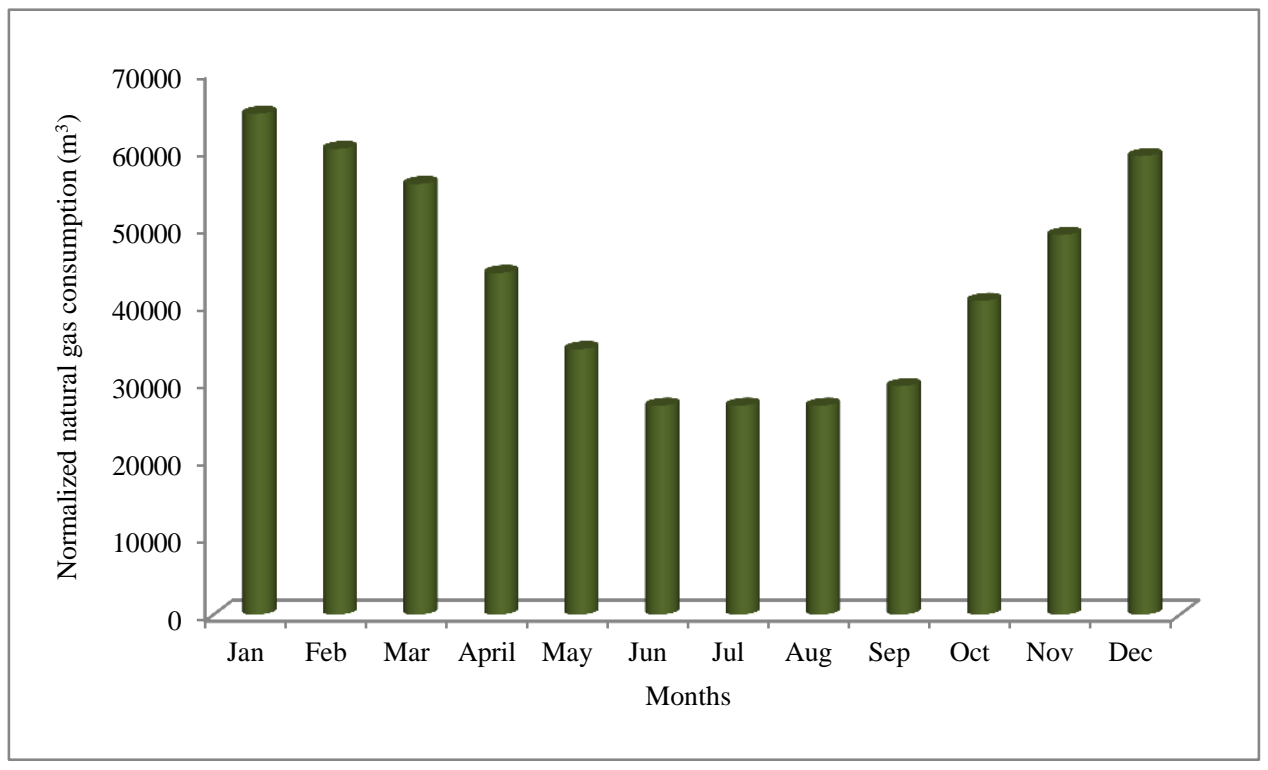

Figure B.8: Normalized monthly natural gas consumption of plant AAMP 


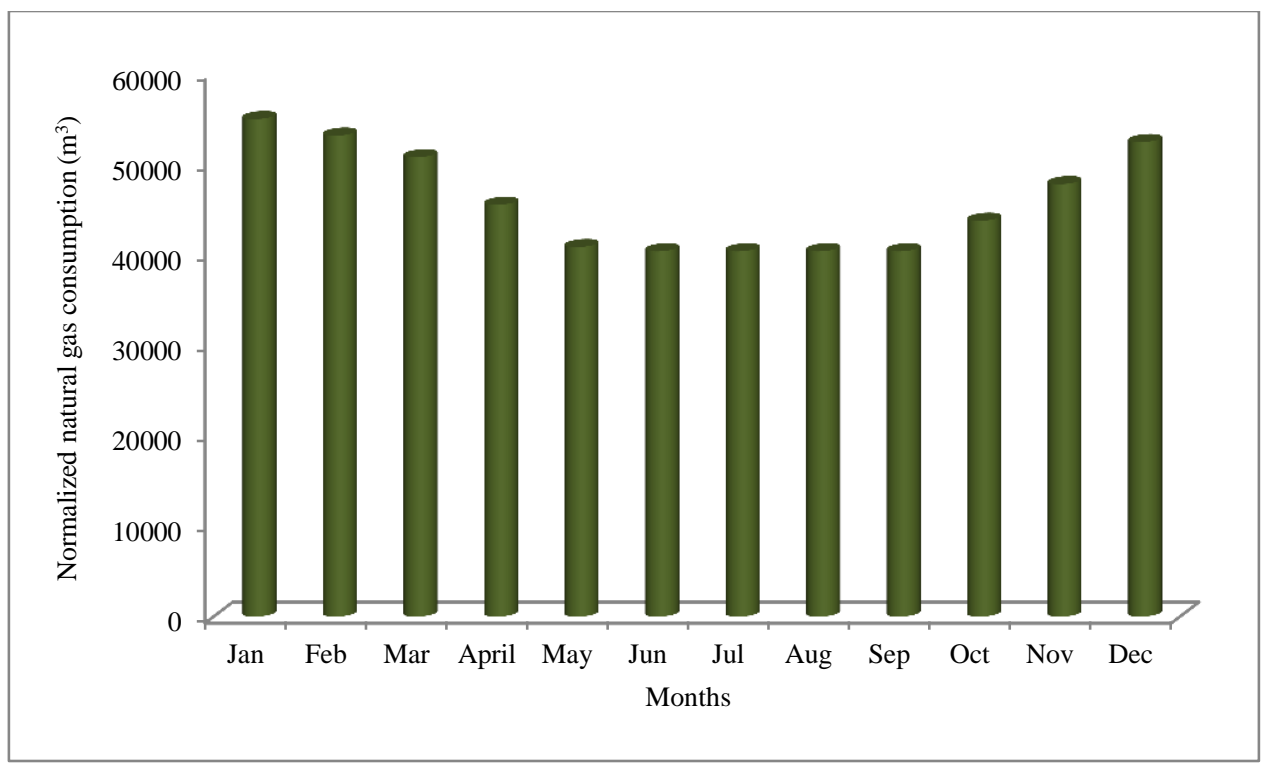

Figure B.9: Normalized monthly natural gas consumption of plant AASN

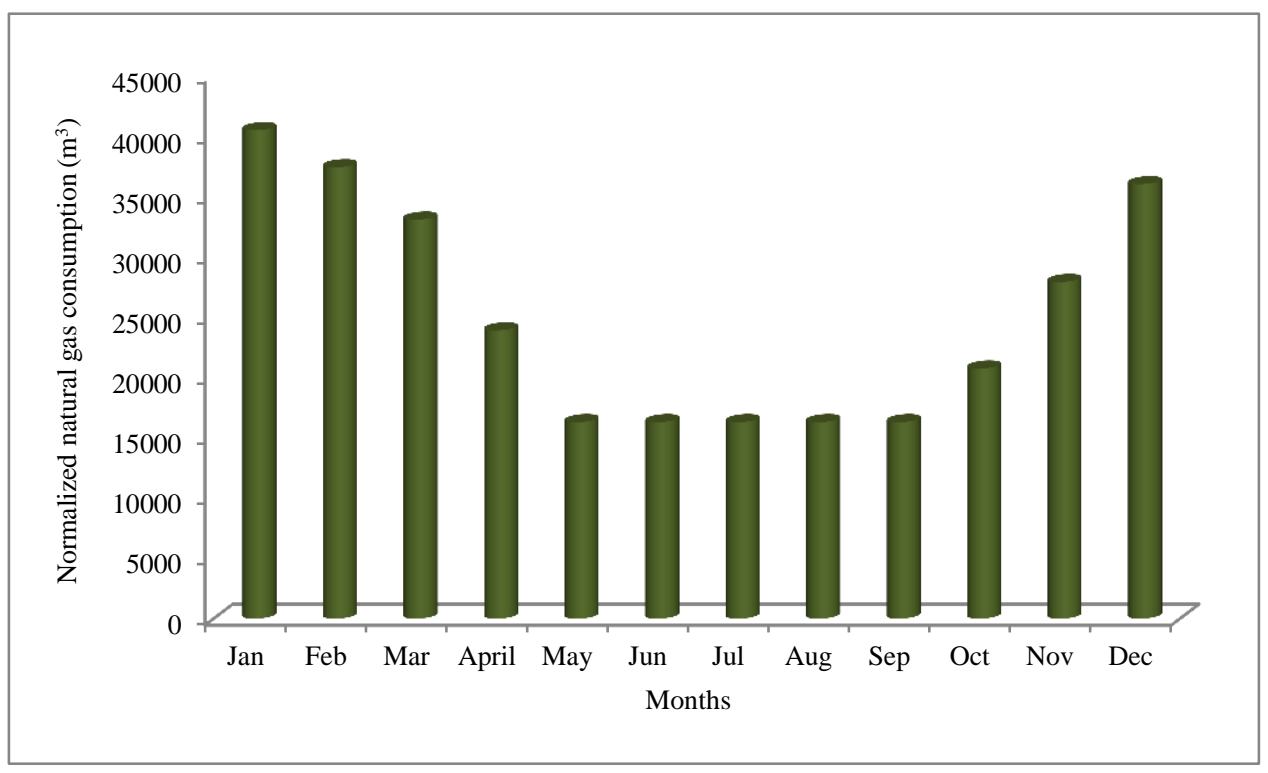

Figure B.10: Normalized monthly natural gas consumption of plant AAWI 


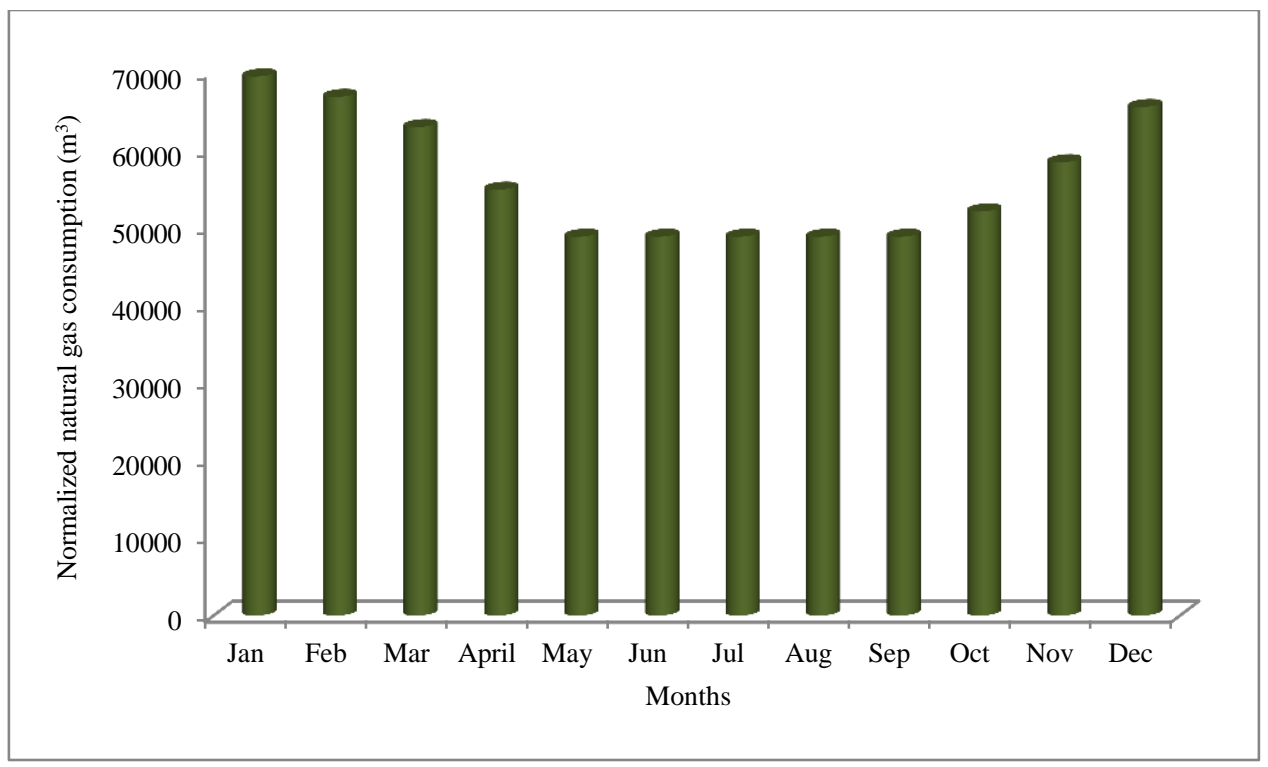

Figure B.11: Normalized monthly natural gas consumption of plant AASU

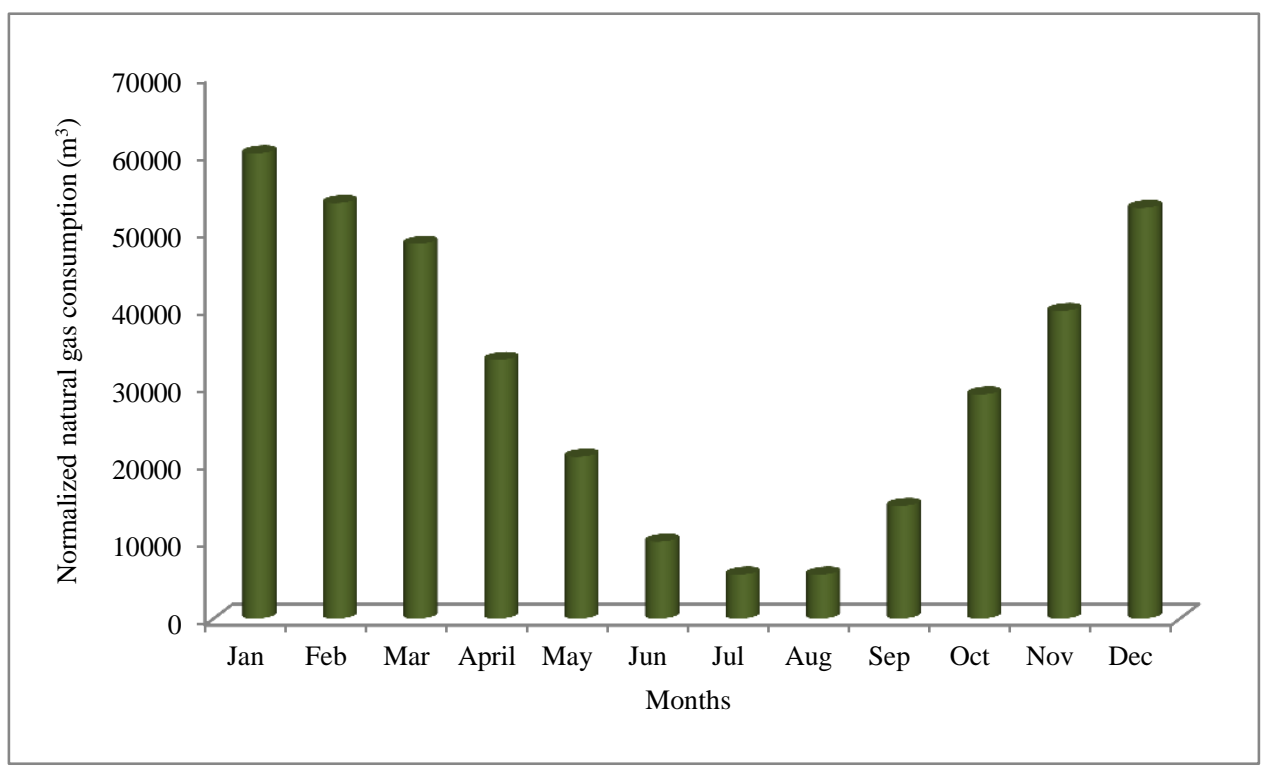

Figure B.12: Normalized monthly natural gas consumption of plant AASP 


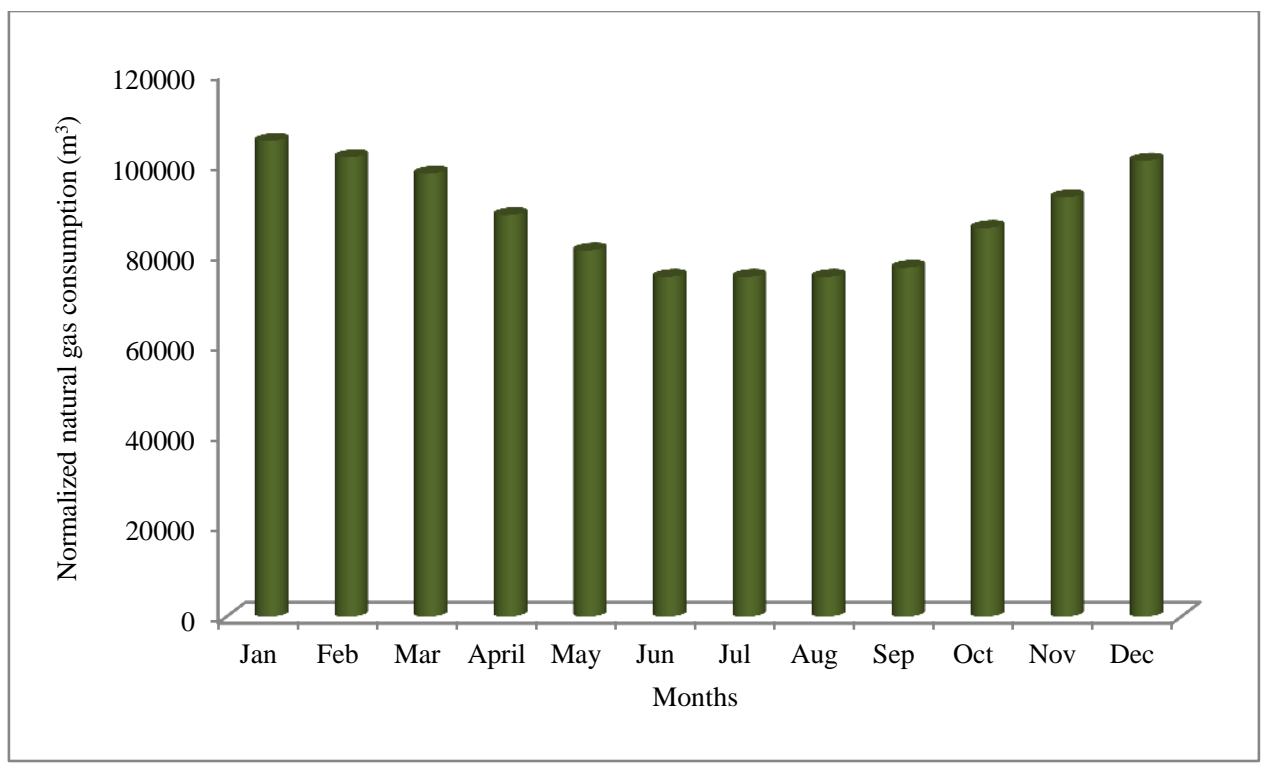

Figure B.13: Normalized monthly natural gas consumption of plant AAWR 
Appendix C: Seasonal and Process Load Analysis

Seasonal and Process Energy Consumption of Plants:

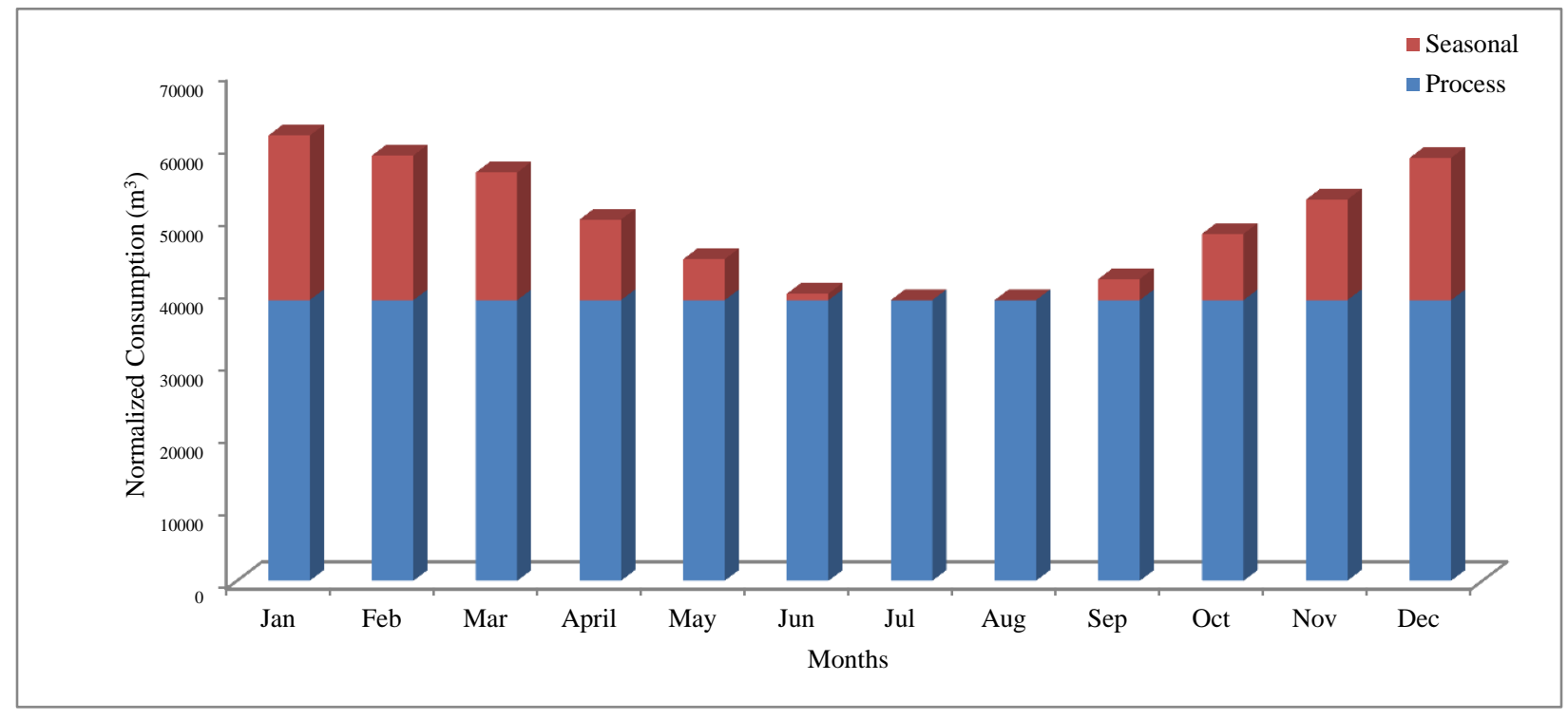

Figure C.1: Process and seasonal energy consumption of plant AAAL

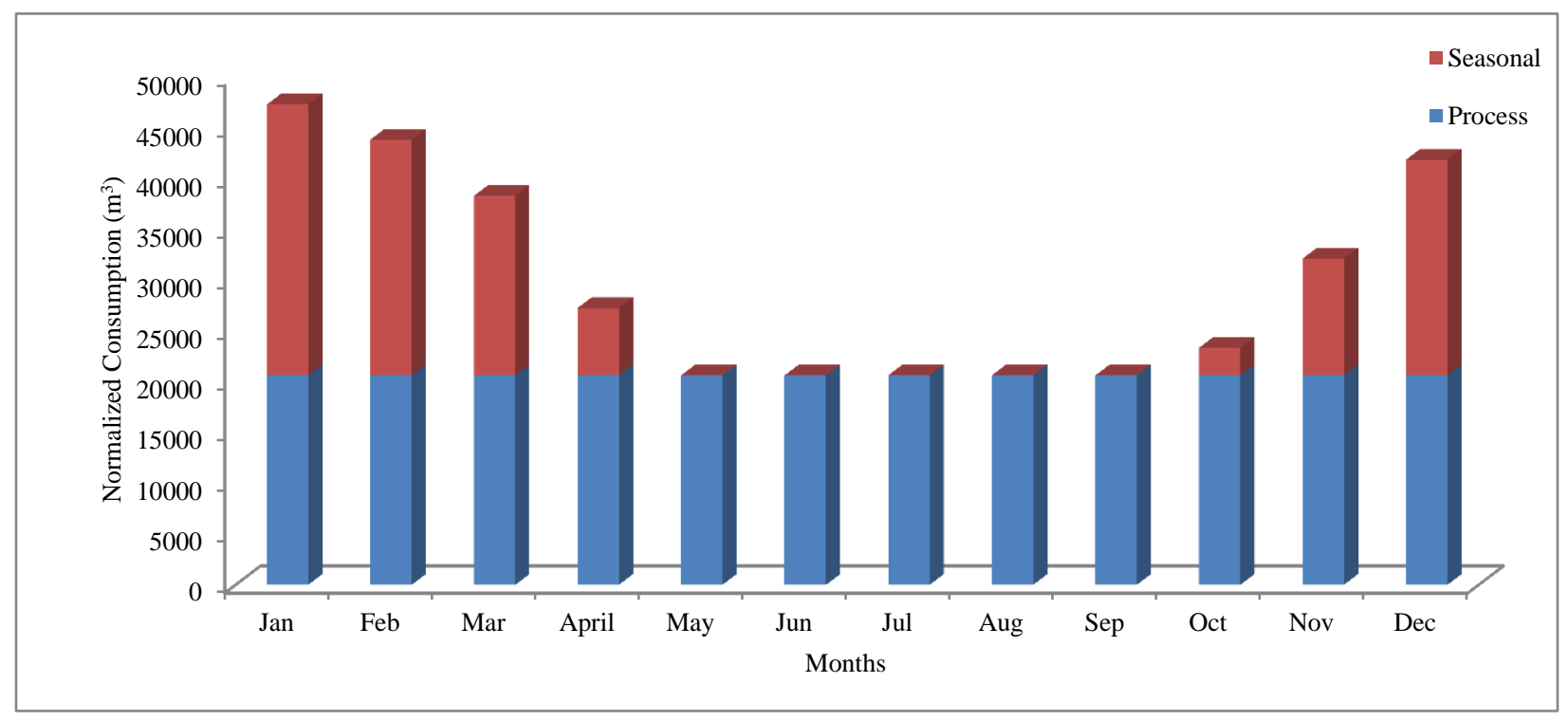

Figure C.2: Process and seasonal energy consumption of plant AABN 


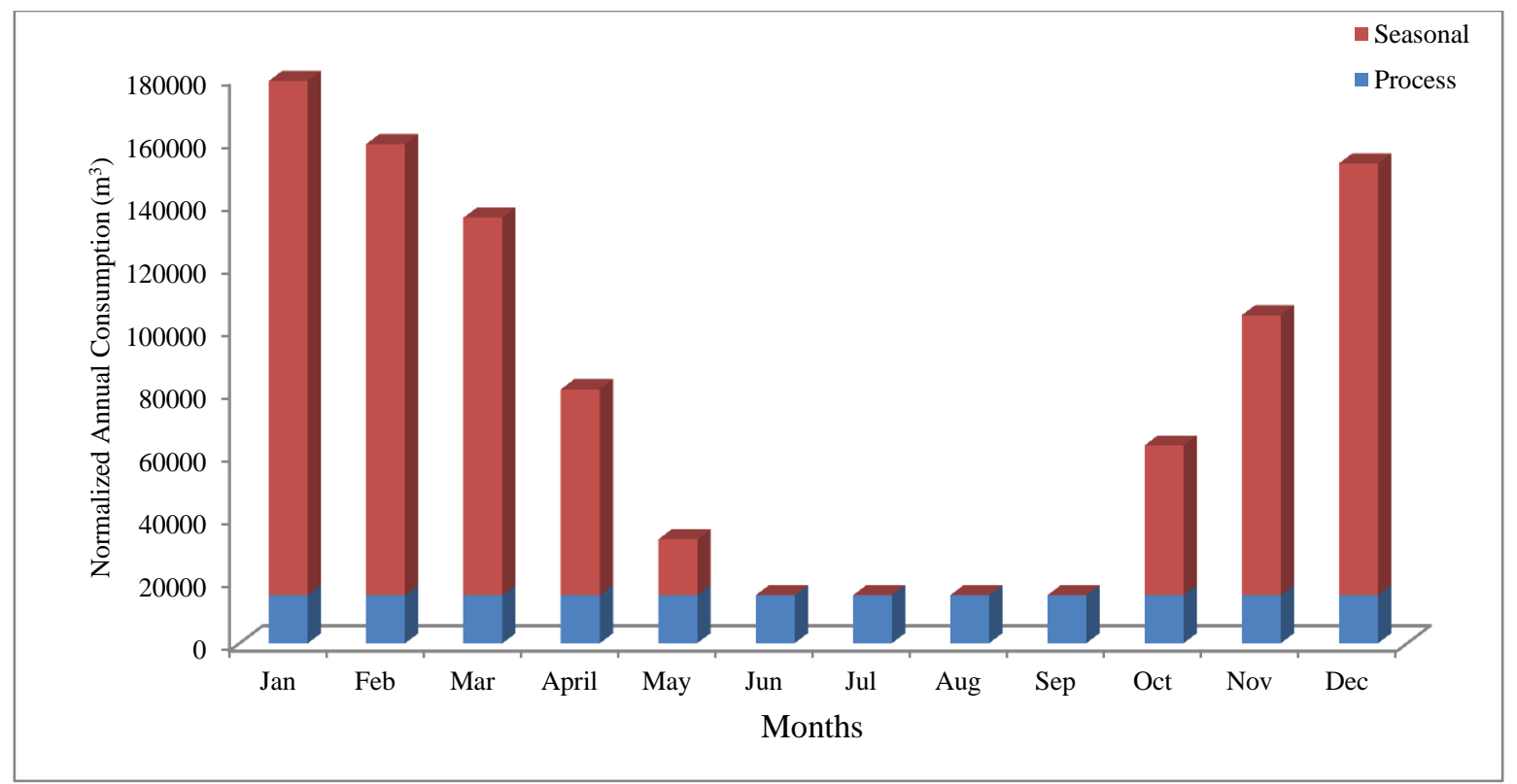

Figure C.3: Process and seasonal energy consumption of plant AAD78

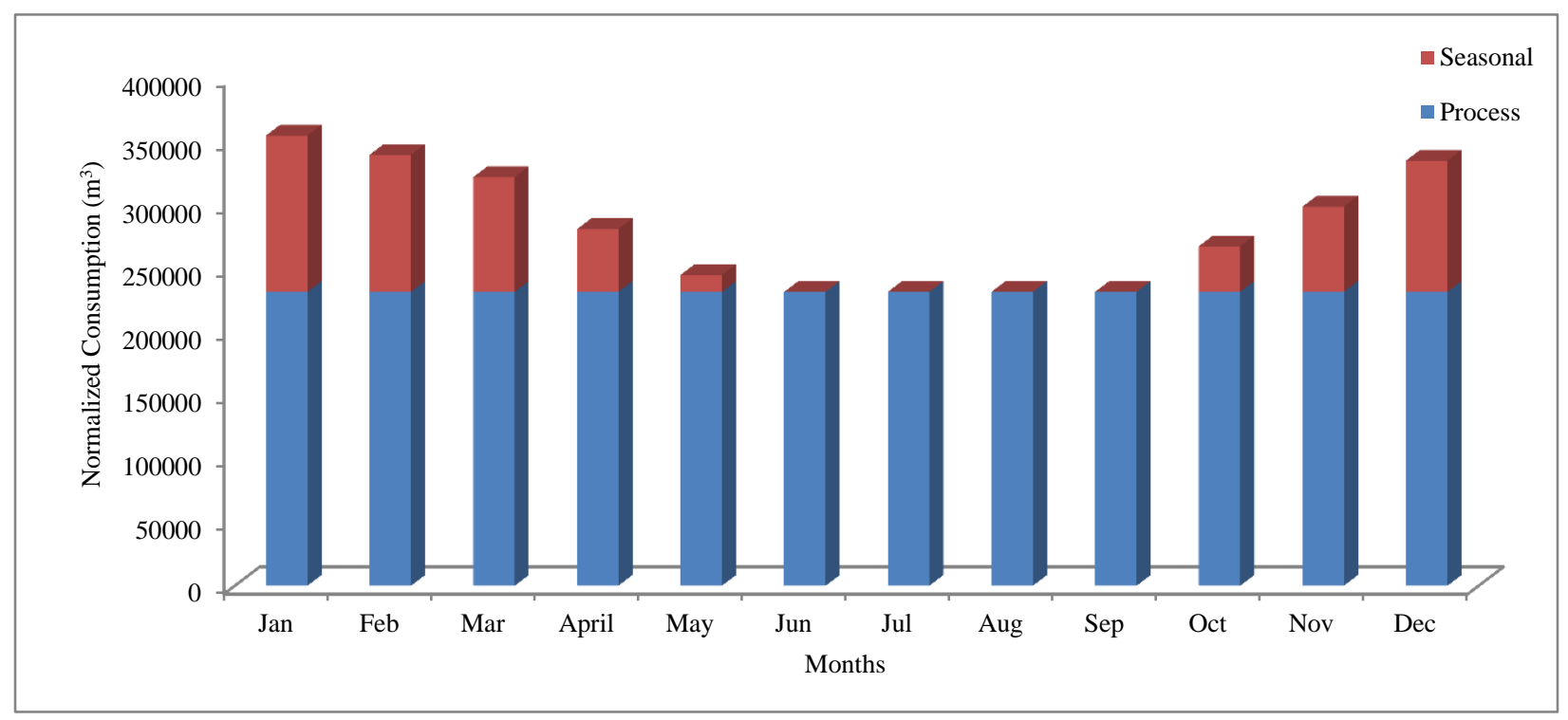

Figure C.4: Process and seasonal energy consumption of plant AAGF 


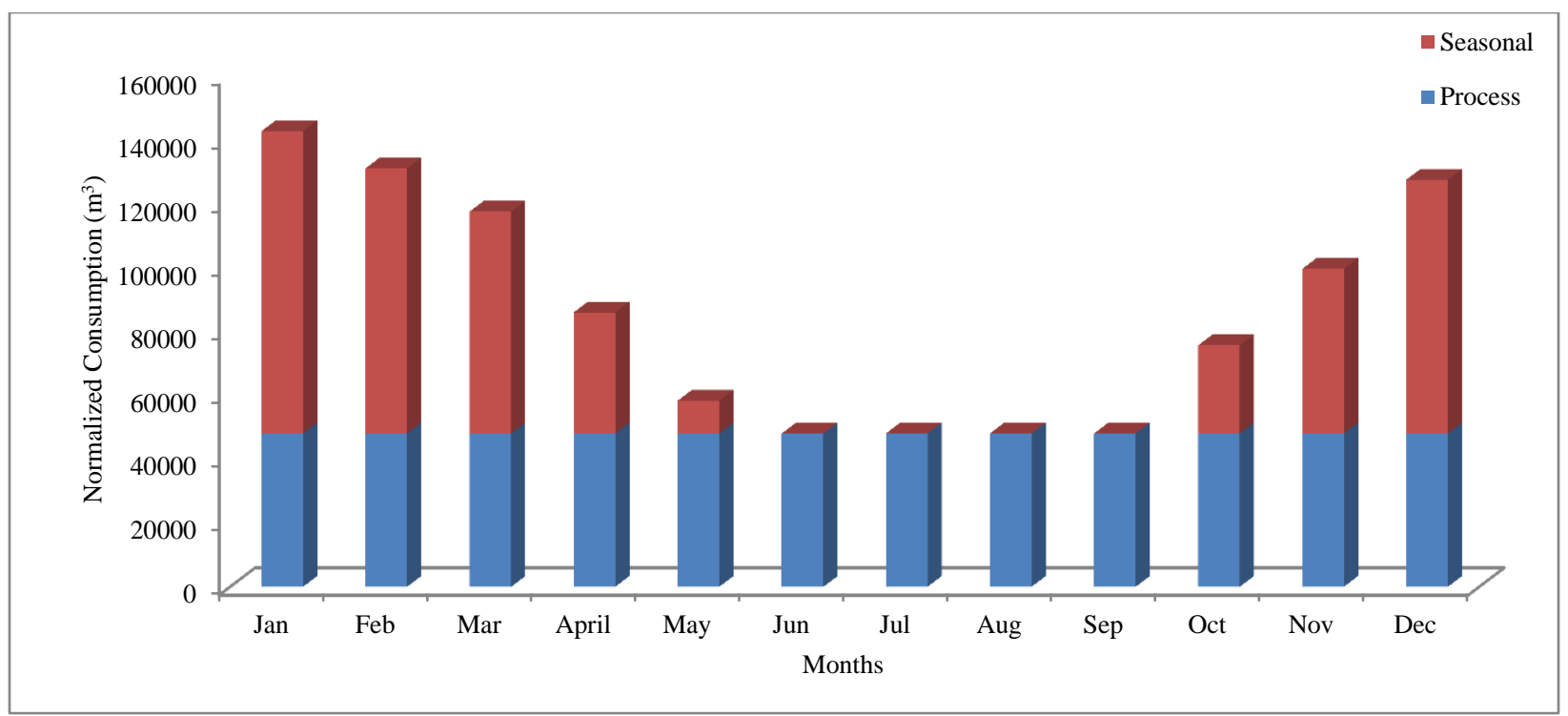

Figure C.5: Process and seasonal energy consumption of plant AAKK1

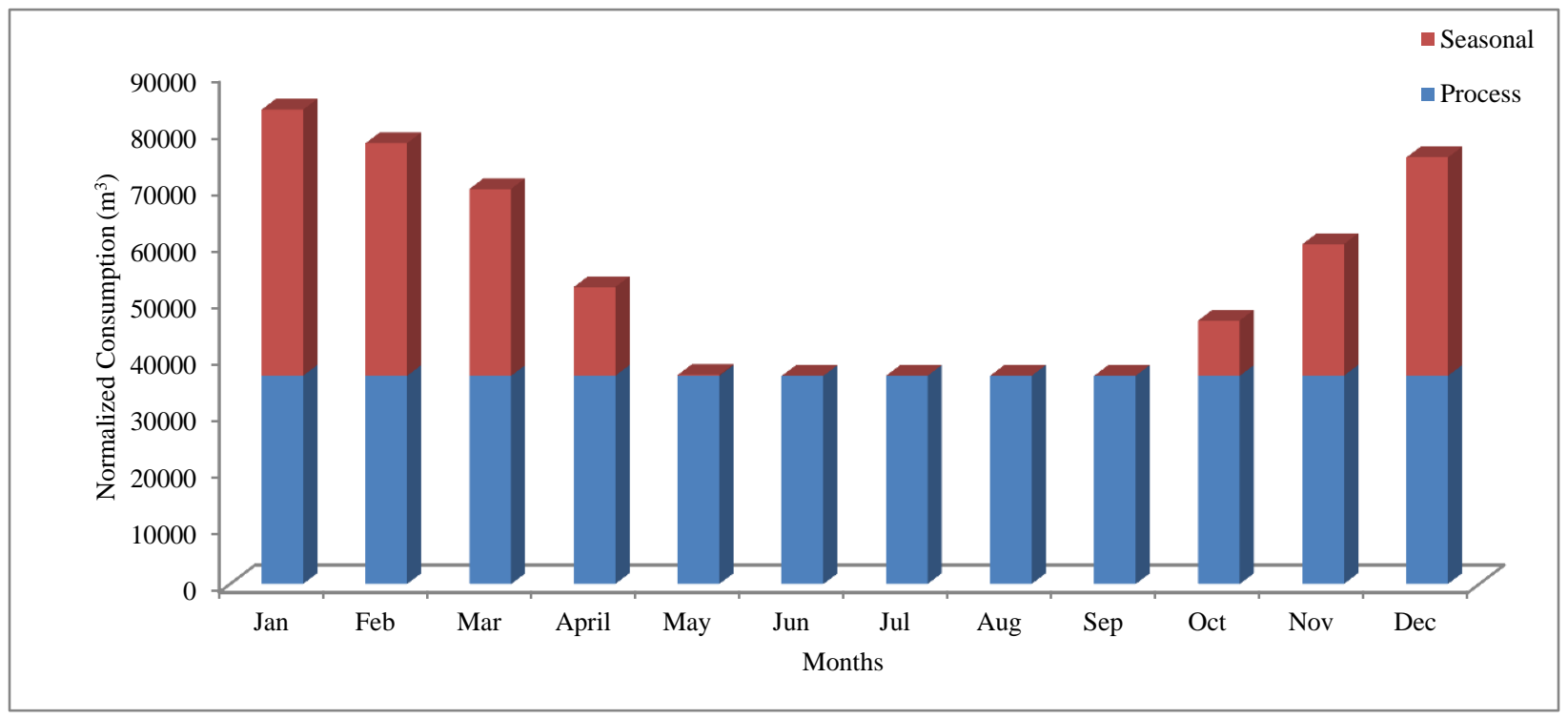

Figure C.6: Process and seasonal energy consumption of plant AAKK2 


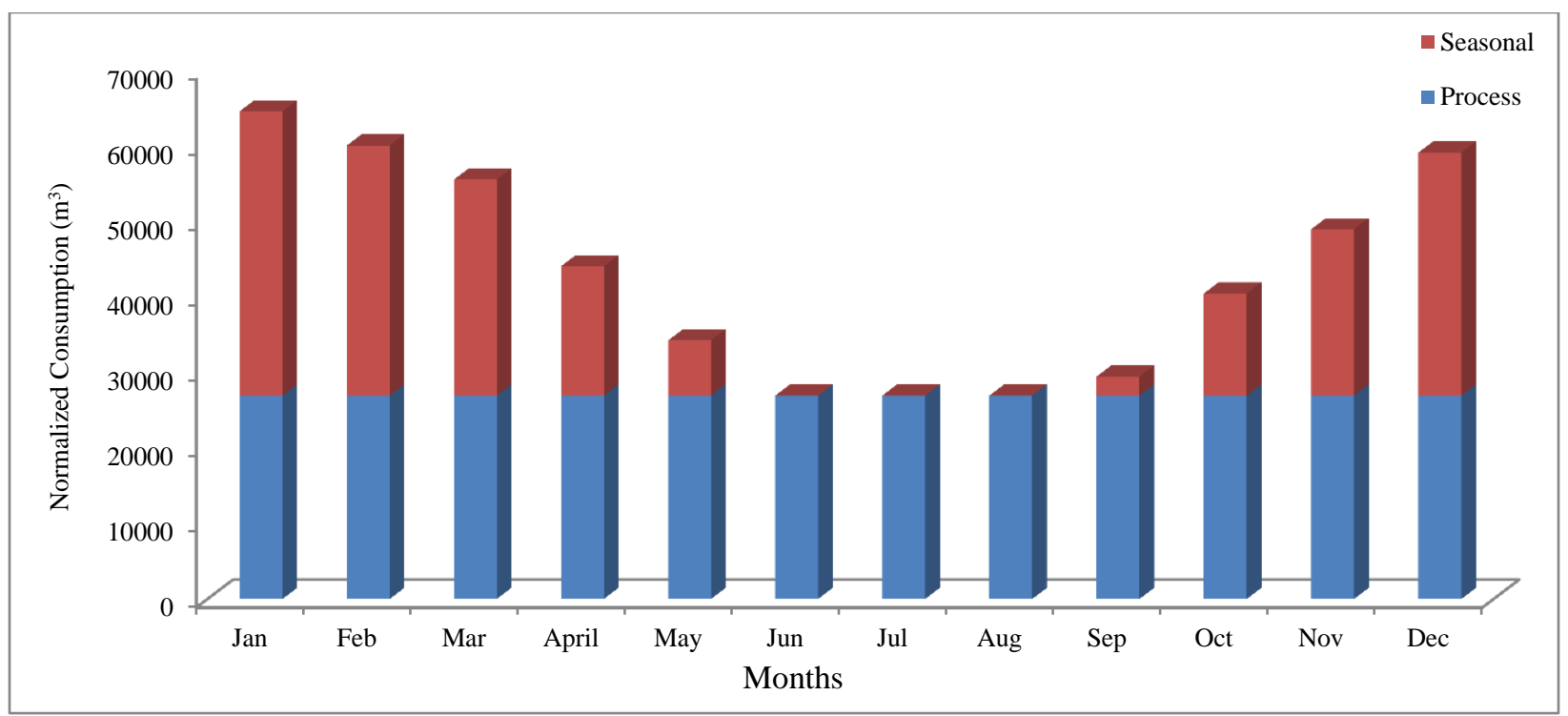

Figure C.7: Process and seasonal energy consumption of plant AAMP

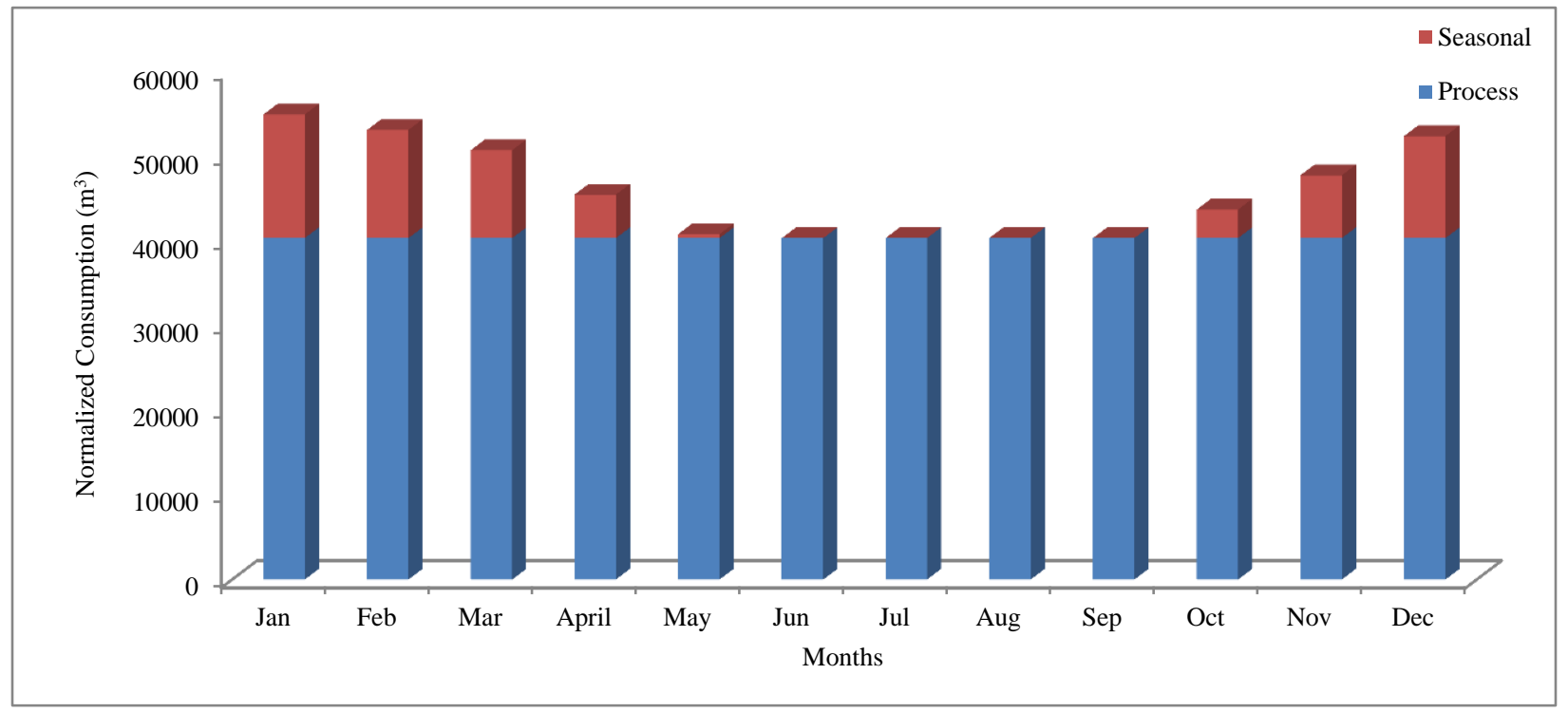

Figure C.8: Process and seasonal energy consumption of plant AASN 


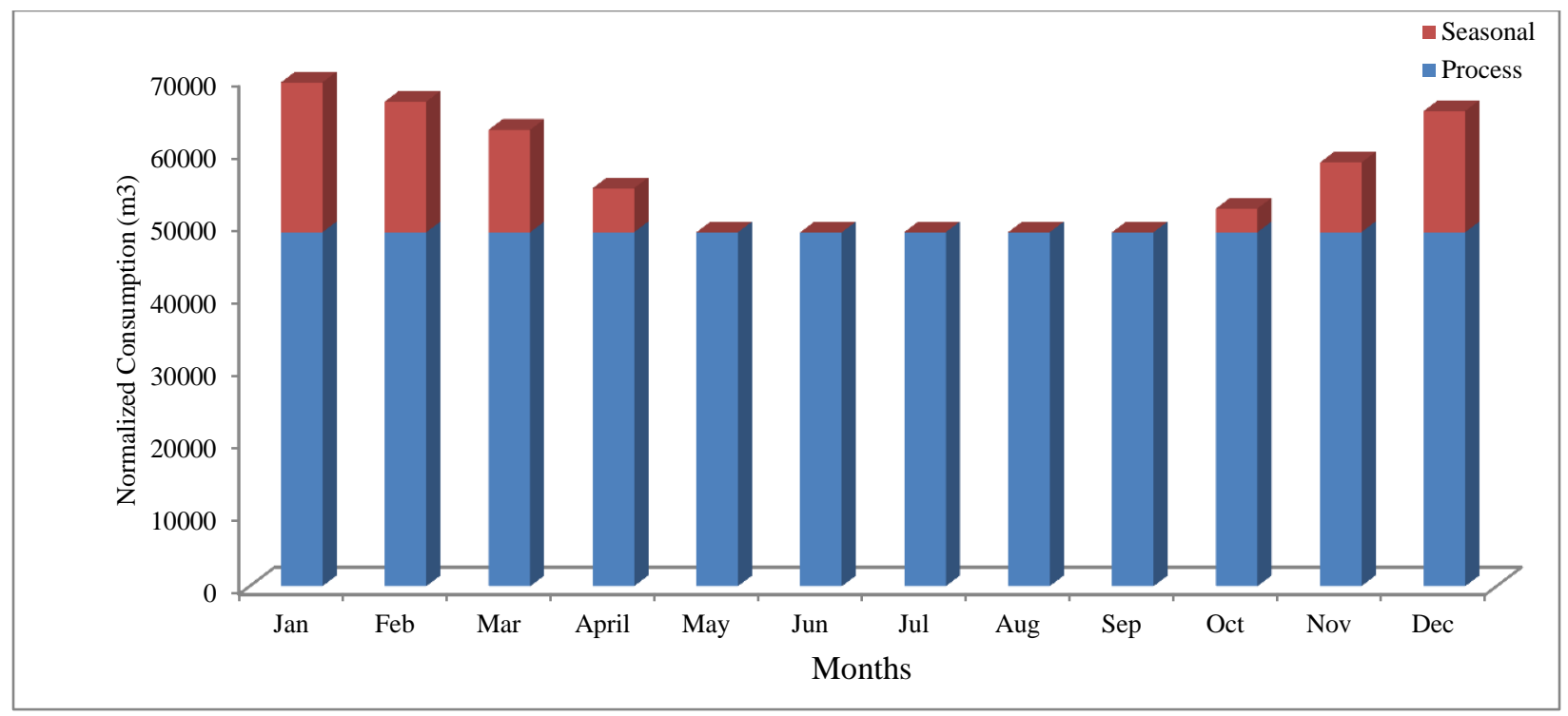

Figure C.8: Process and seasonal energy consumption of plant AASU

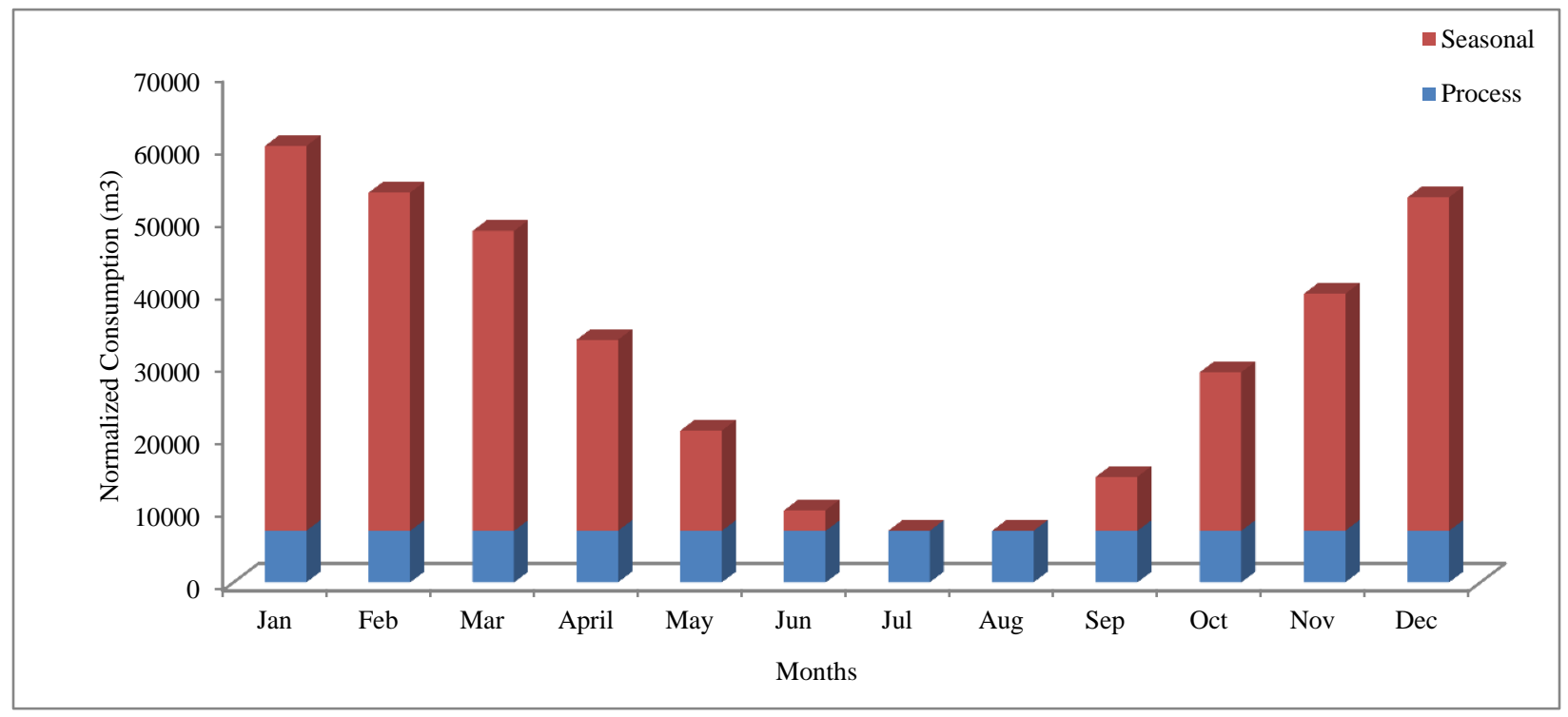

Figure C.9: Process and seasonal energy consumption of plant AASP 


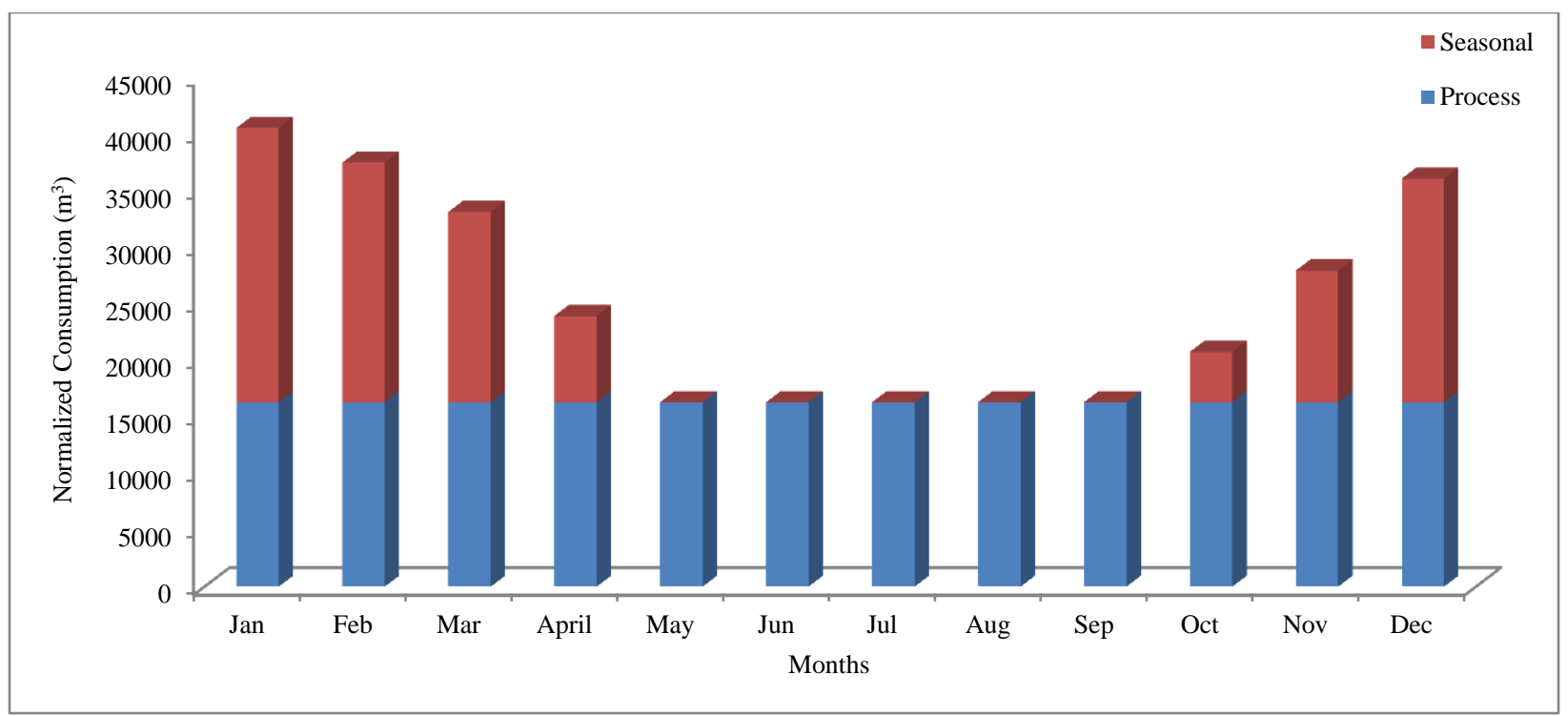

Figure C.10: Process and seasonal energy consumption of plant AAWI

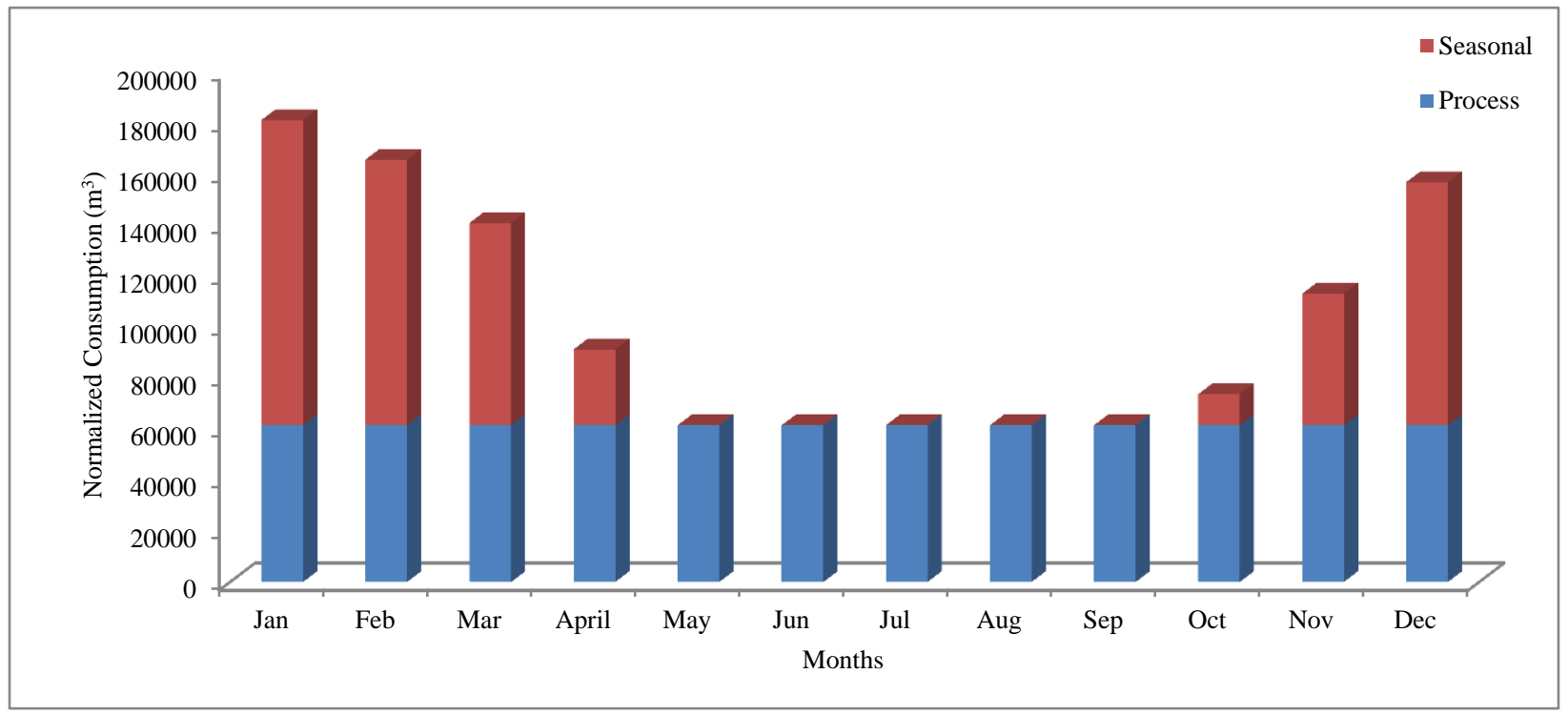

Figure C.11: Process and seasonal energy consumption of plant AAWR 


\section{Appendix D: $\mathbf{1}^{\text {st }}$ Level Multivariable Regression Analysis}

\section{First Level Multivariable Regression Analysis}

\begin{tabular}{|c|c|c|c|c|c|c|c|c|}
\hline SUMMARY OUTPUT & & & & & & & & \\
\hline \multicolumn{9}{|c|}{ Regression Statistics } \\
\hline Multiple R & 0.99 & & & & & & & \\
\hline R Square & 0.99 & & & & & & & \\
\hline Adjusted R Square & 0.85 & & & & & & & \\
\hline Standard Error & 539989.33 & & & & & & & \\
\hline Observations & 9 & & & & & & & \\
\hline \multicolumn{9}{|l|}{ ANOVA } \\
\hline & $d f$ & $S S$ & $M S$ & $F$ & Significance F & & & \\
\hline Regression & 2 & $2.50564 \mathrm{E}+18$ & $1.2528 \mathrm{E}+18$ & 4296526.91 & 3.4042E-19 & & & \\
\hline Residual & 7 & $2.04112 \mathrm{E}+12$ & $2.9159 \mathrm{E}+11$ & & & & & \\
\hline \multirow[t]{2}{*}{ Total } & 9 & $2.50564 \mathrm{E}+18$ & & & & & & \\
\hline & Coefficients, & tandard Error & $t$ Stat & $P$-value & Lower 95\% & Upper $95 \%$ & ower $95.0^{\circ}$ & per $95.0 \%$ \\
\hline Intercept & 0.00 & \#N/A & \#N/A & \#N/A & \#N/A & \#N/A & \#N/A & \#N/A \\
\hline TRANSMISSION, $\beta_{1}$ & 0.17 & 0.00 & 92.89 & 0.00 & 0.16 & 0.17 & 0.16 & 0.17 \\
\hline VENTILATION, $\beta_{2}$ & 0.21 & 0.01 & 36.82 & 0.00 & 0.20 & 0.23 & 0.20 & 0.23 \\
\hline
\end{tabular}

Figure D.1: Separation of seasonal consumption into total ventilation and transmission heat loss of company AAAL

SUMMARY OUTPUT

\begin{tabular}{lr}
\hline \multicolumn{2}{c}{ Regression Statistics } \\
\hline Multiple R & 1.00 \\
\hline RSquare & 1.00 \\
\hline Adjusted R Square & 0.86 \\
\hline Standard Error & 23985252.27 \\
\hline Observations & 9.00 \\
\hline
\end{tabular}

ANOVA

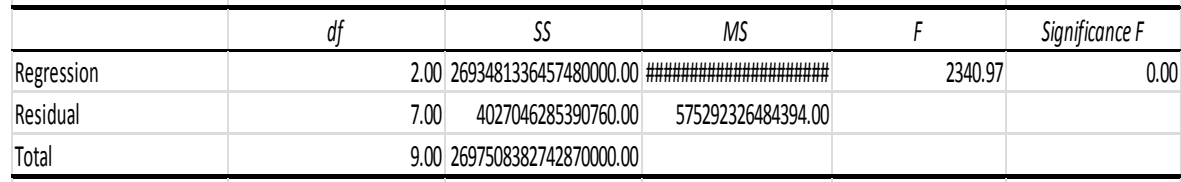

\begin{tabular}{|c|c|c|c|c|c|c|c|c|}
\hline & Coefficients & Standard Error & tStat & P-value & Lower 95\% & Upper 95\% & Lower $95.0 \%$ & Upper $95.0 \%$ \\
\hline Intercept & 0.00 & \#N/A & \#N/A & \#N/A & \#N/A & \#N/A & \#N/A & \#N/A \\
\hline VENTILATION & 0.13 & 0.02 & 6.15 & 0.00 & 0.08 & 0.18 & 0.08 & 0.18 \\
\hline total transmission (btu) & 0.24 & 0.02 & 14.99 & 0.00 & 0.20 & 0.28 & 0.20 & 0.28 \\
\hline
\end{tabular}

Figure D.2: Separation of seasonal consumption into total ventilation and transmission heat loss of company AABN 


\begin{tabular}{|c|c|c|c|c|c|c|c|c|}
\hline SUMMARY OUTPUT & & & & & & & & \\
\hline \multicolumn{9}{|c|}{ Regression Statistics } \\
\hline Multiple R & 1.00 & & & & & & & \\
\hline R Square & 1.00 & & & & & & & \\
\hline Adjusted R Square & 0.86 & & & & & & & \\
\hline Standard Error & 104255889.88 & & & & & & & \\
\hline Observations & 9.00 & & & & & & & \\
\hline \multicolumn{9}{|l|}{ ANOVA } \\
\hline & $d f$ & SS & MS & $F$ & Significance $F$ & & & \\
\hline Regression & 2.00 & $1.49533 \mathrm{E}+20$ & $7.47666 \mathrm{E}+19$ & 6878.70508 & $8.28468 \mathrm{E}-11$ & & & \\
\hline Residual & 7.00 & $7.6085 \mathrm{E}+16$ & $1.08693 \mathrm{E}+16$ & & & & & \\
\hline \multirow[t]{2}{*}{ Total } & 9.00 & $1.49609 \mathrm{E}+20$ & & & & & & \\
\hline & Coefficients & Standard Error & tStat & $P$-value & Lower 95\% & Upper 95\% & \multicolumn{2}{|c|}{ ower 95.0\% pper 95.0\% } \\
\hline Intercept & 0.00 & $\# N / A$ & $\# N / A$ & $\# N / A$ & \#N/A & \#N/A & \#N/A & $\# N / A$ \\
\hline VENTILATION (X3+X4) & 0.29 & 0.059417619 & 4.806214814 & 0.001952234 & 0.145073498 & 0.426074183 & 0.145073 & 0.426074 \\
\hline TRANSMISSION (X1+X2) & 0.98 & 0.041272982 & 23.79693882 & $5.88202 \mathrm{E}-08$ & 0.88457554 & 1.07976573 & 0.884576 & 1.079766 \\
\hline
\end{tabular}

Figure D.3: Separation of seasonal consumption into total ventilation and transmission heat loss of company AAD22

\begin{tabular}{|c|c|c|c|c|c|c|c|c|}
\hline SUMMARY OUTPUT & & & & & & & & \\
\hline \multicolumn{9}{|c|}{ Regression Statistics } \\
\hline Multiple R & 1.00 & & & & & & & \\
\hline RSquare & 1.00 & & & & & & & \\
\hline Adjusted R Square & 0.86 & & & & & & & \\
\hline Standard Error & 57106491.56 & & & & & & & \\
\hline Observations & 9.00 & & & & & & & \\
\hline \multicolumn{9}{|l|}{ ANOVA } \\
\hline & $d f$ & SS & MS & $F$ & Significance $F$ & & & \\
\hline Regression & 2.00 & $1.17186 E+20$ & $5.85928 \mathrm{E}+19$ & 17966.91968 & 4.65292E-12 & & & \\
\hline Residual & 7.00 & $2.28281 E+16$ & $3.26115 E+15$ & & & & & \\
\hline \multirow[t]{2}{*}{ Total } & 9.00 & 1.17209E+20 & & & & & & \\
\hline & Coefficients & Standard Error & tStat & P-value & Lower 95\% & Upper 95\% & ower 95.0\% & ipper 95.0\% \\
\hline Intercept & 0.00 & \#N/A & \#N/A & \#N/A & \#N/A & \#N/A & $\# N / A$ & \#N/A \\
\hline VENTILATION, X3+X4 & 0.40 & 0.061206859 & 6.574192207 & 0.000311707 & 0.25765443 & 0.547116874 & 0.257654 & 0.547117 \\
\hline TRANSMISSION (X1+X2) & 0.54 & 0.033469687 & 16.15428045 & $8.47202 E-07$ & 0.46153548 & 0.619821948 & 80.461535 & 0.619822 \\
\hline
\end{tabular}

Figure D.4: Separation of seasonal consumption into total ventilation and transmission heat loss of company AAD78 
SUMMARY OUTPUT

\begin{tabular}{lr}
\hline \multicolumn{2}{c}{ Regression Statistics } \\
\hline Multiple R & 1.00 \\
\hline RSquare & 1.00 \\
\hline Adjusted R Square & 0.86 \\
\hline Standard Error & 24311216.13 \\
\hline Observations & 9.00 \\
\hline
\end{tabular}

ANOVA

\begin{tabular}{|c|c|c|c|c|c|}
\hline & $d f$ & SS & MS & $F$ & Significance F \\
\hline Regression & 2.00 & $6.6424 E+19$ & $3.3212 E+19$ & 56192.91545 & $1.52142 E-13$ \\
\hline Residual & 7.00 & $4.13725 E+15$ & $5.91035 E+14$ & & \\
\hline Total & 9.00 & $6.64281 E+19$ & & & \\
\hline
\end{tabular}

\begin{tabular}{|c|c|c|c|c|c|c|c|c|}
\hline & Coefficients & Standard Error & tStat & P-value & Lower 95\% & Upper 95\% & Lower $95.0 \%$ & Upper $95.0 \%$ \\
\hline Intercept & 0.00 & \#N/A & \#N/A & \#N/A & \#N/A & \#N/A & \#N/A & \#N/A \\
\hline VENTILATION (X3+X4) & 0.20 & 0.037385551 & 5.435232507 & 0.000971175 & 0.114796381 & 0.291601941 & 0.114796381 & 0.291601941 \\
\hline total transmission (btu) & 0.53 & 0.018508756 & 28.82636424 & $1.55565 E-08$ & 0.48977389 & 0.577306397 & 0.48977389 & 0.577306397 \\
\hline
\end{tabular}

Figure D.5: Separation of seasonal consumption into total ventilation and transmission heat loss of company AAGF

\begin{tabular}{|c|c|c|c|c|c|c|c|c|}
\hline SUMMARY OUTPUT & & & & & & & & \\
\hline \multicolumn{9}{|c|}{ Regression Statistics } \\
\hline Multiple R & 1.00 & & & & & & & \\
\hline RSquare & 1.00 & & & & & & & \\
\hline Adjusted RSquare & 0.86 & & & & & & & \\
\hline Standard Error & 18706052.42 & & & & & & & \\
\hline Observations & 9.00 & & & & & & & \\
\hline \multicolumn{9}{|l|}{ ANOVA } \\
\hline & $d f$ & SS & MS & $F$ & Significance F & & & \\
\hline Regression & 2.00 & $3.93257 E+19$ & $1.96628 E+19$ & 56192.9581 & 1.52142E-13 & & & \\
\hline Residual & 7.00 & $2.44941 E+15$ & $3.49916 E+14$ & & & & & \\
\hline \multirow[t]{2}{*}{ Total } & 9.00 & $3.93281 \mathrm{E}+19$ & & & & & & \\
\hline & Coefficients & Standard Error & tStat & P-value & Lower $95 \%$ & Upper 95\% & Lower $95.0 \%$ & Upper $95.0 \%$ \\
\hline Intercept & 0.00 & $\# N / A$ & \#N/A & \#N/A & \#N/A & \#N/A & $\# N / A$ & \#N/A \\
\hline VENTILATION, (X3+X4) & 0.16 & 0.029042066 & 5.435235059 & 0.000971173 & 0.089176881 & 0.226524028 & 0.089176881 & 0.226524028 \\
\hline TRANSMISSION (X1+X2) & 0.41 & 0.014331794 & 28.82634634 & $1.55565 \mathrm{E}-08$ & 0.379243945 & 0.447022559 & 0.379243945 & 0.447022559 \\
\hline
\end{tabular}

Figure D.6: Separation of seasonal consumption into total ventilation and transmission heat loss of company AAKK 


\begin{tabular}{|c|c|c|c|c|c|c|c|c|}
\hline SUMMARY OUTPUT & & & & & & & & \\
\hline \multicolumn{9}{|c|}{ Regression Statistics } \\
\hline Multiple R & 1.00 & & & & & & & \\
\hline RSquare & 1.00 & & & & & & & \\
\hline Adjusted R Square & 0.86 & & & & & & & \\
\hline Standard Error & 12037471.71 & & & & & & & \\
\hline Observations & 9.00 & & & & & & & \\
\hline \multicolumn{9}{|l|}{ ANOVA } \\
\hline & $d f$ & SS & MS & $F$ & Significance $F$ & & & \\
\hline Regression & 2.00 & $9.00096 E+18$ & $4.50048 E+18$ & 31059.04224 & 9.00894E-13 & & & \\
\hline Residual & 7.00 & $1.01431 E+15$ & 1.44901E+14 & & & & & \\
\hline \multirow[t]{2}{*}{ Total } & 9.00 & $9.00197 \mathrm{E}+18$ & & & & & & \\
\hline & Coefficients & Standard Error & tStat & P-value & Lower 95\% & Upper 95\% & Lower $95.0 \%$ & Upper $95.0 \%$ \\
\hline Intercept & 0.00 & $\# N / A$ & \#N/A & $\# N / A$ & \#N/A & $\# N / A$ & $\# N / A$ & \#N/A \\
\hline VENTILATION & 0.08 & 0.024082557 & 3.503394443 & 0.009947453 & 0.027424498 & 0.141316897 & 0.027424498 & 0.141316897 \\
\hline total transmission (btu) & 0.49 & 0.012387763 & 39.85530457 & $1.63091 \mathrm{E}-09$ & 0.464425675 & 0.523010486 & 0.464425675 & 0.523010486 \\
\hline
\end{tabular}

Figure D.7: Separation of seasonal consumption into total ventilation and transmission heat loss of company AAKK2

\begin{tabular}{|c|c|}
\hline SUMMARY OUTPUT & \\
\hline \multicolumn{2}{|c|}{ Regression Statistics } \\
\hline Multiple R & 0.999999996 \\
\hline RSquare & 0.999999993 \\
\hline Adjusted R Square & 0.857142849 \\
\hline Standard Error & 83025.97907 \\
\hline Observations & \\
\hline
\end{tabular}

ANOVA

\begin{tabular}{|c|c|c|c|c|c|}
\hline & $d f$ & SS & MS & $F$ & Significance F \\
\hline Regression & 2 & $6.61718 E++18$ & $3.30859 E+18$ & 479971171 & $2.44185 E-25$ \\
\hline Residual & 7 & 48253192409 & 6893313201 & & \\
\hline Total & 9 & $6.61718 E+18$ & & & \\
\hline
\end{tabular}

\begin{tabular}{|c|c|c|c|c|c|c|c|c|}
\hline & Coefficients & Standard Error & tStat & P-value & Lower 95\% & Upper $95 \%$ & Lower $95.0 \%$ & Upper $95.0 \%$ \\
\hline Intercept & 0 & \#N/A & \#N/A & $\mathbb{\# N / A}$ & \#N/A & \#N/A & \#N/A & \#N/A \\
\hline ventilation(X3+X4) & 0.558379042 & 0.001015266 & 549.9828941 & 1.735E-17 & 0.555978319 & 0.560779765 & 0.555978319 & 0.560779765 \\
\hline Total Transmission hea & 0.202550359 & 0.000393256 & 515.0599983 & $2.74622 E-17$ & 0.201620457 & 0.203480262 & 0.201620457 & 0.203480262 \\
\hline
\end{tabular}

Figure D.8: Separation of seasonal consumption into total ventilation and transmission heat loss of company AAMP 


\begin{tabular}{|c|c|c|c|c|c|c|c|c|}
\hline SUMMARY OUTPUT & & & & & & & & \\
\hline \multicolumn{9}{|c|}{ Regression Statistics } \\
\hline Multiple R & 1.00 & & & & & & & \\
\hline RSquare & 1.00 & & & & & & & \\
\hline Adjusted R Square & 0.86 & & & & & & & \\
\hline Standard Error & 5590338.02 & & & & & & & \\
\hline Observations & 9.00 & & & & & & & \\
\hline \multicolumn{9}{|l|}{ ANOVA } \\
\hline & $d f$ & SS & MS & $F$ & Significance F & & & \\
\hline Regression & 2.00 & $6.61696 E+18$ & $3.30848 \mathrm{E}+18$ & 105865.066 & 2.27546E-14 & & & \\
\hline Residual & 7.00 & 2.18763E+14 & $3.12519 E+13$ & & & & & \\
\hline \multirow[t]{2}{*}{ Total } & 9.00 & $6.61718 \mathrm{E}+18$ & & & & & & \\
\hline & Coefficients & Standard Error & tStat & P-value & Lower 95\% & Upper 95\% & Lower $95.0 \%$ & Upper $95.0 \%$ \\
\hline Intercept & 0.00 & \#N/A & \#N/A & $\# N / A$ & \#N/A & \#N/A & $\# N / A$ & \#N/A \\
\hline X1 (ventilation) & 0.77 & 0.013562735 & 56.88633575 & $1.36082 E-10$ & 0.739463527 & 0.803605071 & 0.739463527 & 0.803605071 \\
\hline X2, Total Transmission & 0.05 & 0.006698954 & 7.176935464 & 0.000181054 & 0.03223745 & 0.063918467 & 0.03223745 & 0.063918467 \\
\hline
\end{tabular}

Figure D.9: Separation of seasonal consumption into total ventilation and transmission heat loss of company AASN

\begin{tabular}{lr}
\hline \multicolumn{2}{l|}{ SUMMARY OUTPUT } \\
\hline & \\
\hline \multicolumn{2}{|c|}{ Regression Statistics } \\
\hline Multiple R & 1.00 \\
\hline RSquare & 1.00 \\
\hline Adjusted RSquare & 0.86 \\
\hline Standard Error & 1696369.95 \\
\hline Observations & 9.00 \\
\hline
\end{tabular}

ANOVA

\begin{tabular}{|c|c|c|c|c|c|}
\hline & $d f$ & SS & MS & $F$ & Significance F \\
\hline Regression & 2.00 & $1.38037 E+19$ & $6.90186 E+18$ & 2398417.054 & $1.95699 \mathrm{E}-18$ \\
\hline Residual & 7.00 & $2.01437 E+13$ & $2.87767 E+12$ & & \\
\hline Total & 9.00 & $1.38037 E+19$ & & & \\
\hline
\end{tabular}

\begin{tabular}{|c|c|c|c|c|c|c|c|c|}
\hline & Coefficients & Standard Error & tStat & P-value & Lower 95\% & Upper 95\% & Lower $95.0 \%$ & Upper $95.0 \%$ \\
\hline Intercept & 0.00 & \#N/A & \#N/A & \#N/A & $\mathbb{\# N / A}$ & $\# N / A$ & \#N/A & $\# N / A$ \\
\hline X3+X4(ventilation) & 0.51 & 0.01441348 & 35.60833121 & $3.57664 E-09$ & 0.47915751 & 0.547322439 & 0.47915751 & 0.547322439 \\
\hline X1+X2, Total Transmissi & 0.38 & 0.004234493 & 89.98340497 & $5.51405 E-12$ & 0.371021084 & 0.391047052 & 0.371021084 & 0.391047052 \\
\hline
\end{tabular}

Figure D.10: Separation of seasonal consumption into total ventilation and transmission heat loss of company AASP 


\begin{tabular}{|c|c|c|c|c|c|c|c|c|}
\hline SUMMARY OUTPUT & & & & & & & & \\
\hline \multicolumn{9}{|c|}{ Regression Statistics } \\
\hline Multiple R & 1.00 & & & & & & & \\
\hline RSquare & 1.00 & & & & & & & \\
\hline Adjusted R Square & 0.85 & & & & & & & \\
\hline Standard Error & 29383538.75 & & & & & & & \\
\hline Observations & 9.00 & & & & & & & \\
\hline \multicolumn{9}{|l|}{ ANOVA } \\
\hline & $d f$ & SS & MS & $F$ & Significance F & & & \\
\hline Regression & 2.00 & $1.67271 E+18$ & $8.363565+17$ & 968.6862885 & $2.94297 \mathrm{E}-08$ & & & \\
\hline Residual & 7.00 & $6.04775++15$ & $8.63392 E+14$ & & & & & \\
\hline \multirow[t]{2}{*}{ Total } & 9.00 & $1.67876 E+18$ & & & & & & \\
\hline & Coefficients & Standard Error & tStat & P-value & Lower $95 \%$ & Upper 95\% & Lower $95.0 \%$ & Upper $95.0 \%$ \\
\hline Intercept & 0.00 & \#N/A & \#N/A & $\# N / A$ & \#N/A & \#N/A & \#N/A & \#N/A \\
\hline X1 (ventilation) & 0.44 & 0.06775944 & 6.533538695 & 0.000323779 & 0.282483307 & 0.602934536 & 0.282483307 & 0.602934536 \\
\hline X2, Total Transmissio & 0.37 & 0.047705168 & 7.853145886 & 0.000102576 & 0.261830844 & 0.487440436 & 0.261830844 & 0.487440436 \\
\hline
\end{tabular}

Figure D.11: Separation of seasonal consumption into total ventilation and transmission heat loss of company AASU

\begin{tabular}{|c|c|c|c|c|c|c|c|c|c|}
\hline SUMMARY OUTPUT & & & & & & & & & \\
\hline \multicolumn{10}{|c|}{ Regression Statistics } \\
\hline Multiple R & 1.00 & & & & & & & & \\
\hline RSquare & 1.00 & & & & & & & & \\
\hline Adjusted RSquare & 0.86 & & & & & & & & \\
\hline Standard Error & 4068214.48 & & & & & & & & \\
\hline Observations & 9.00 & & & & & & & & \\
\hline \multicolumn{10}{|l|}{ ANOVA } \\
\hline & $d f$ & SS & MS & $F$ & Significance F & & & & \\
\hline Regression & 2.00 & $2.35306 E+18$ & $1.17653 E+18$ & 71087.78479 & 7.51491E-14 & & & & \\
\hline Residual & 7.00 & 1.15853E+14 & $1.65504 E+13$ & & & & & & \\
\hline \multirow[t]{2}{*}{ Total } & 9.00 & $2.35317 E+18$ & & & & & & & \\
\hline & Coefficients & Standard Error & tStat & P-value & Lower 95\% & Upper $95 \%$ & Lower $95.0 \%$ & Upper $95.0 \%$ & Upper $95.0 \%$ \\
\hline Intercept & 0.00 & \#N/A & \#N/A & \#N/A & \#N/A & $\# N / A$ & \#N/A & \#N/A & \#N/A \\
\hline X3+X4 (ventilation) & 0.02 & 0.00601556 & 3.141777581 & 0.016338566 & 0.004675013 & 0.033124091 & 0.004675013 & 0.033124091 & 0.033124091 \\
\hline x1+X2, Total Transmissi & 0.31 & 0.004712083 & 65.46459939 & $5.09946 E-11$ & 0.297332225 & 0.319616904 & 0.297332225 & 0.319616904 & 0.319616904 \\
\hline
\end{tabular}

Figure D.12: Separation of seasonal consumption into total ventilation and transmission heat loss of company AAWI 
Appendix E: $2^{\text {nd }}$ Level Multivariable Regression Analysis

\section{Second Level Multivariable Regression Analysis}

\begin{tabular}{|c|c|c|c|c|c|c|c|c|}
\hline SUMMARY OUTPUT & & & & & & & & \\
\hline \multicolumn{9}{|c|}{ Regression Statistics } \\
\hline Multiple R & 0.991447601 & & & & & & & \\
\hline R Square & 0.982968345 & & & & & & & \\
\hline Adjusted R Square & 0.837678109 & & & & & & & \\
\hline Standard Error & 23981518.26 & & & & & & & \\
\hline Observations & 9 & & & & & & & \\
\hline \multicolumn{9}{|l|}{ ANOVA } \\
\hline & $d f$ & SS & $M S$ & $F$ & gnificance & & & \\
\hline Regression & 2 & $2.32 \mathrm{E}+17$ & $1.16 \mathrm{E}+17$ & 201.9997 & $3.13 E-06$ & & & \\
\hline Residual & 7 & $4.03 E+15$ & $5.75 E+14$ & & & & & \\
\hline \multirow[t]{2}{*}{ Total } & 9 & $2.36 \mathrm{E}+17$ & & & & & & \\
\hline & Coefficients & andard Err & t Stat & P-value & Lower 95\%L & Upper 95\% & ower 95.0\% & pper 95.0\% \\
\hline Intercept & 0 & $\# N / A$ & $\# N / A$ & $\# N / A$ & $\# N / A$ & $\# N / A$ & $\# \mathrm{~N} / \mathrm{A}$ & $\# N / A$ \\
\hline Ventilation $\beta_{21}$ & 200.9396978 & 4300.817 & 0.046721 & 0.96404 & -9968.88 & 10370.75 & -9968.88 & 10370.75 \\
\hline Infiltration loss $\beta_{22}$ & 0.130479924 & 0.021813 & 5.981666 & 0.000552 & 0.0789 & 0.18206 & 0.0789 & 0.18206 \\
\hline
\end{tabular}

Figure E.1: $2^{\text {nd }}$ level multivariable regression analysis of plant AABN

\begin{tabular}{|c|c|c|c|c|c|c|c|c|}
\hline SUMMARY OUTPUT & & & & & & & & \\
\hline \multicolumn{9}{|c|}{ Regression Statistics } \\
\hline Multiple R & 0.99118315 & & & & & & & \\
\hline R Square & 0.982444037 & & & & & & & \\
\hline Adjusted R Square & 0.837078899 & & & & & & & \\
\hline Standard Error & 104254005.5 & & & & & & & \\
\hline Observations & 9 & & & & & & & \\
\hline \multicolumn{9}{|l|}{ ANOVA } \\
\hline & $d f$ & SS & MS & $F$ & gnificance & & & \\
\hline Regression & 2 & $4.26 \mathrm{E}+18$ & $2.13 \mathrm{E}+18$ & 195.8625 & $3.43 \mathrm{E}-06$ & & & \\
\hline Residual & 7 & $7.61 \mathrm{E}+16$ & $1.09 \mathrm{E}+16$ & & & & & \\
\hline \multirow[t]{2}{*}{ Total } & 9 & $4.33 \mathrm{E}+18$ & & & & & & \\
\hline & Coefficients & andard Err & tStat & P-value & Lower 95\%L & Upper 95\%c & wer 95.0\% & pper 95.0\% \\
\hline Intercept & 0 & $\# N / A$ & $\# N / A$ & $\# N / A$ & \#N/A & \#N/A & $\# N / A$ & $\# N / A$ \\
\hline VENTILATION $\left(\beta_{21}\right)$ & 546.5871754 & 34341.8 & 0.015916 & 0.987745 & -80658.9 & 81752.03 & -80658.9 & 81752.03 \\
\hline INFILTRATION LOSS $\left(\beta_{22}\right)$ & 0.284648823 & 0.059912 & 4.751104 & 0.002081 & 0.142979 & 0.426319 & 0.142979 & 0.426319 \\
\hline
\end{tabular}

Figure E.2: $2^{\text {nd }}$ level multivariable regression analysis of plant AAD22 


\begin{tabular}{|c|c|c|c|c|c|c|c|c|}
\hline SUMMARY OUTPUT & & & & & & & & \\
\hline \multicolumn{9}{|c|}{ Regression Statistics } \\
\hline Multiple R & 0.998841577 & & & & & & & \\
\hline R Square & 0.997684496 & & & & & & & \\
\hline Adjusted R Square & 0.854496567 & & & & & & & \\
\hline Standard Error & 57099173.8 & & & & & & & \\
\hline Observations & 9 & & & & & & & \\
\hline \multicolumn{9}{|l|}{ ANOVA } \\
\hline & $d f$ & SS & $M S$ & $F$ & gnificance $F$ & & & \\
\hline Regression & 2 & $9.83 \mathrm{E}+18$ & $4.92 \mathrm{E}+18$ & 1508.05 & $7.83 E-09$ & & & \\
\hline Residual & 7 & $2.28 \mathrm{E}+16$ & $3.26 E+15$ & & & & & \\
\hline \multirow[t]{2}{*}{ Total } & 9 & $9.86 \mathrm{E}+18$ & & & & & & \\
\hline & Coefficients & andard Err & tStat & $P$-value & Lower 95\%U & Upper 95\%c & ower 95.0\% & pper 95.0\% \\
\hline Intercept & 0 & \#N/A & $\# N / A$ & $\# N / A$ & \#N/A & $\# N / A$ & $\# N / A$ & $\# N / A$ \\
\hline VENTILATION, $\beta_{21}$ & 419.473241 & 9893.166 & 0.0424 & 0.967364 & -22974.1 & 23813.09 & -22974.1 & 23813.09 \\
\hline INFILTRATION, $\beta_{22}$ & 0.399745903 & 0.062747 & 6.370776 & 0.000378 & 0.251373 & 0.548119 & 0.251373 & 0.548119 \\
\hline
\end{tabular}

Figure E.3: 2nd level multivariable regression analysis of plant AAD78

\begin{tabular}{|c|c|c|c|c|c|c|c|c|}
\hline \multicolumn{9}{|l|}{ SUMMARY OUTPUT } \\
\hline \multicolumn{9}{|c|}{ Regression Statistics } \\
\hline Multiple R & 0.998766623 & & & & & & & \\
\hline R Square & 0.997534767 & & & & & & & \\
\hline Adjusted R Square & 0.854325448 & & & & & & & \\
\hline Standard Error & 24310411.71 & & & & & & & \\
\hline Observations & 9 & & & & & & & \\
\hline \multicolumn{9}{|l|}{ ANOVA } \\
\hline & $d f$ & SS & $M S$ & $F$ & \multicolumn{2}{|c|}{ gnificance $F$} & & \\
\hline Regression & 2 & 1.67E+18 & 8.37E+17 & 1416.244 & $9.44 \mathrm{E}-09$ & & & \\
\hline Residual & 7 & $4.14 \mathrm{E}+15$ & $5.91 \mathrm{E}+14$ & & & & & \\
\hline \multirow[t]{2}{*}{ Total } & 9 & $1.68 \mathrm{E}+18$ & & & & & & \\
\hline & Coefficients & andard Err & tStat & P-value ! & \multicolumn{4}{|c|}{ Lower 95\% Upper 95\%ower 95.0\%pper 95.0\% } \\
\hline Intercept & 0 & $\# N / A$ & $\# N / A$ & $\# N / A$ & \#N/A & \#N/A & $\# N / A$ & $\# N / A$ \\
\hline VENTILATION $\left(\beta_{21}\right)$ & 135.7431041 & 6297.28 & 0.021556 & 0.983404 & -14755 & 15026.45 & -14755 & 15026.45 \\
\hline INFILTRATION LOSS $\beta_{22}$ & 0.202397624 & 0.037435 & 5.406616 & 0.001001 & 0.113877 & 0.290918 & 0.113877 & 0.290918 \\
\hline
\end{tabular}

Figure E.4: 2nd level multivariable regression analysis of plant AAGF 


\begin{tabular}{|c|c|c|c|c|c|c|c|c|}
\hline \multicolumn{9}{|l|}{ SUMMARY OUTPUT } \\
\hline \multicolumn{9}{|c|}{ Regression Statistics } \\
\hline Multiple R & 0.998767944 & & & & & & & \\
\hline R Square & 0.997537405 & & & & & & & \\
\hline Adjusted R Square & 0.854328463 & & & & & & & \\
\hline Standard Error & 18695444.79 & & & & & & & \\
\hline Observations & 9 & & & & & & & \\
\hline \multicolumn{9}{|l|}{ ANOVA } \\
\hline & $d f$ & SS & $M S$ & $F$ & gnificance $F$ & & & \\
\hline Regression & 2 & $9.91 \mathrm{E}+17$ & $4.96 \mathrm{E}+17$ & 1417.765 & $9.41 \mathrm{E}-09$ & & & \\
\hline Residual & 7 & $2.45 \mathrm{E}+15$ & $3.5 \mathrm{E}+14$ & & & & & \\
\hline \multirow[t]{2}{*}{ Total } & 9 & $9.94 \mathrm{E}+17$ & & & & & & \\
\hline & Coefficients & andard Err & tStat & P-value & Lower 95\% & Jpper 95\%o & wer 95.0\% & pper 95.0\% \\
\hline Intercept & 0 & $\# N / A$ & $\# N / A$ & $\# N / A$ & \#N/A & $\# N / A$ & $\# \mathrm{~N} / \mathrm{A}$ & $\# N / A$ \\
\hline VENTILATION $\left(\beta_{21}\right)$ & 373.9960283 & 4193.887 & 0.089176 & 0.931439 & -9542.97 & 10290.96 & -9542.97 & 10290.96 \\
\hline INFILTRATION LOSS, $\beta_{22}$ & 0.155193529 & 0.029954 & 5.181124 & 0.001279 & 0.084364 & 0.226023 & 0.084364 & 0.226023 \\
\hline
\end{tabular}

Figure E.5: 2nd level multivariable regression analysis of plant AAKK

\begin{tabular}{|c|c|c|c|c|c|c|c|c|}
\hline \multicolumn{9}{|l|}{ SUMMARY OUTPUT } \\
\hline \multicolumn{9}{|c|}{ Regression Statistics } \\
\hline Multiple R & 0.991499999 & & & & & & & \\
\hline R Square & 0.983072249 & & & & & & & \\
\hline Adjusted R Square & 0.837796856 & & & & & & & \\
\hline Standard Error & 12036681.7 & & & & & & & \\
\hline Observations & 9 & & & & & & & \\
\hline \multicolumn{9}{|l|}{ ANOVA } \\
\hline & $d f$ & SS & $M S$ & $F$ & gnificance & & & \\
\hline Regression & 2 & $5.89 E+16$ & $2.94 \mathrm{E}+16$ & 203.2611 & 3.08E-06 & & & \\
\hline Residual & 7 & $1.01 \mathrm{E}+15$ & $1.45 \mathrm{E}+14$ & & & & & \\
\hline \multirow[t]{2}{*}{ Total } & 9 & $5.99 \mathrm{E}+16$ & & & & & & \\
\hline & Coefficients & andard Err & tStat & P-value & Lower 95\%L & Upper 95\% & ower 95.0\% & pper 95.0\% \\
\hline Intercept & 0 & $\# N / A$ & $\# N / A$ & $\# N / A$ & $\# N / A$ & $\# N / A$ & $\# N / A$ & $\# N / A$ \\
\hline VENTILATION $\beta_{21}$ & 45.81166744 & 1508.485 & 0.030369 & 0.97662 & -3521.19 & 3612.812 & -3521.19 & 3612.812 \\
\hline INFILTRATION LOSS $\beta_{22}$ & 0.083654317 & 0.024 & 3.485583 & 0.010189 & 0.026903 & 0.140406 & 0.026903 & 0.140406 \\
\hline
\end{tabular}

Figure E.6: 2nd level multivariable regression analysis of plant AAKK2 


\begin{tabular}{|c|c|c|c|c|c|c|c|c|}
\hline SUMMARY OUTPUT & & & & & & & & \\
\hline \multicolumn{9}{|c|}{ Regression Statistics } \\
\hline Multiple R & 0.999999986 & & & & & & & \\
\hline R Square & 0.999999973 & & & & & & & \\
\hline Adjusted R Square & 0.857142826 & & & & & & & \\
\hline Standard Error & 82832.74769 & & & & & & & \\
\hline Observations & 9 & & & & & & & \\
\hline \multicolumn{9}{|l|}{ ANOVA } \\
\hline & $d f$ & SS & $M S$ & $F$ & gnificance & & & \\
\hline Regression & 2 & 1.77E+18 & $8.83 \mathrm{E}+17$ & $1.29 \mathrm{E}+08$ & $1.27 \mathrm{E}-23$ & & & \\
\hline Residual & 7 & $4.8 \mathrm{E}+10$ & $6.86 \mathrm{E}+09$ & & & & & \\
\hline \multirow[t]{2}{*}{ Total } & 9 & 1.77E+18 & & & & & & \\
\hline & Coefficients 0 & andard Err & tStat & P-value & Lower 95\%L & Upper $95 \%$ & ower 95.0\% & pper 95.0\% \\
\hline Intercept & 0 & $\# N / A$ & $\# N / A$ & $\# N / A$ & $\# N / A$ & $\# \mathrm{~N} / \mathrm{A}$ & \#N/A & $\# N / A$ \\
\hline Ventilation $\left(\beta_{21}\right)$ & 8.101826591 & 41.71718 & 0.194208 & 0.851529 & -90.5436 & 106.7473 & -90.5436 & 106.7473 \\
\hline INFILTRATION LOSS, $\beta_{22}$ & 0.558215461 & 0.000905 & 616.5998 & 7.79E-18 & 0.556075 & 0.560356 & 0.556075 & 0.560356 \\
\hline
\end{tabular}

Figure E.7: 2nd level multivariable regression analysis of plant AAMP

\begin{tabular}{|c|c|c|c|c|c|c|c|c|}
\hline SUMMARY OUTPUT & & & & & & & & \\
\hline \multicolumn{9}{|c|}{ Regression Statistics } \\
\hline Multiple R & 0.999979083 & & & & & & & \\
\hline R Square & 0.999958166 & & & & & & & \\
\hline Adjusted R Square & 0.857095047 & & & & & & & \\
\hline Standard Error & 5589496.743 & & & & & & & \\
\hline Observations & 9 & & & & & & & \\
\hline \multicolumn{9}{|l|}{ ANOVA } \\
\hline & $d f$ & SS & $M S$ & $F$ & gnificance & & & \\
\hline Regression & 2 & $5.23 \mathrm{E}+18$ & $2.61 \mathrm{E}+18$ & 83660.76 & $4.61 \mathrm{E}-14$ & & & \\
\hline Residual & 7 & $2.19 \mathrm{E}+14$ & $3.12 E+13$ & & & & & \\
\hline \multirow[t]{2}{*}{ Total } & 9 & $5.23 \mathrm{E}+18$ & & & & & & \\
\hline & Coefficients & andard Err & tStat & $P$-value $L$ & Lower 95\%L & Upper 95\%c & ower 95.0\% & 'pper 95.0\% \\
\hline Intercept & 0 & $\# N / A$ & $\# N / A$ & $\# N / A$ & $\# N / A$ & $\# N / A$ & $\# N / A$ & $\# N / A$ \\
\hline Ventilation $\left(\beta_{21}\right)$ & 46.21060605 & 989.8424 & 0.046685 & 0.964068 & -2294.39 & 2386.816 & -2294.39 & 2386.816 \\
\hline Infiltration loss $\beta_{22}$ & 0.770898507 & 0.013978 & 55.15127 & $1.69 \mathrm{E}-10$ & 0.737846 & 0.803951 & 0.737846 & 0.803951 \\
\hline
\end{tabular}

Figure E.8: 2nd level multivariable regression analysis of plant AASN 


\begin{tabular}{|c|c|c|c|c|c|c|c|c|}
\hline \multicolumn{9}{|l|}{ SUMMARY OUTPUT } \\
\hline \multicolumn{9}{|c|}{ Regression Statistics } \\
\hline Multiple R & 0.999991 & & & & & & & \\
\hline R Square & 0.999982 & & & & & & & \\
\hline Adjusted R Square & 0.857122 & & & & & & & \\
\hline Standard Error & 1694804 & & & & & & & \\
\hline Observations & 9 & & & & & & & \\
\hline \multicolumn{9}{|l|}{ ANOVA } \\
\hline & $d f$ & SS & $M S$ & $F$ & gnificance & & & \\
\hline Regression & 2 & $1.11 \mathrm{E}+18$ & $5.55 \mathrm{E}+17$ & 193285.1 & $3.74 \mathrm{E}-15$ & & & \\
\hline Residual & 7 & $2.01 \mathrm{E}+13$ & $2.87 E+12$ & & & & & \\
\hline \multirow[t]{2}{*}{ Total } & 9 & $1.11 \mathrm{E}+18$ & & & & & & \\
\hline & Coefficientsx & andard Err & t Stat & P-value & Lower 95\%L & Upper 95\% & ower $95.0 \%$ & 'pper 95.0\% \\
\hline Intercept & 0 & $\# N / A$ & $\# \mathrm{~N} / \mathrm{A}$ & $\# N / A$ & \#N/A & $\# \mathrm{~N} / \mathrm{A}$ & $\# N / A$ & $\# \mathrm{~N} / \mathrm{A}$ \\
\hline Ventilation $\left(\beta_{21}\right)$ & 95.21815 & 832.367 & 0.114394 & 0.912137 & -1873.02 & 2063.453 & -1873.02 & 2063.453 \\
\hline INFILTRATION LOSS, $\beta_{22}$ & 0.511744 & 0.013178 & 38.8319 & $1.96 \mathrm{E}-09$ & 0.480581 & 0.542906 & 0.480581 & 0.542906 \\
\hline
\end{tabular}

Figure E.9: 2nd level multivariable regression analysis of plant AASP

\begin{tabular}{|c|c|c|c|c|c|c|c|c|}
\hline SUMMARY OUTPUT & & & & & & & & \\
\hline \multicolumn{9}{|c|}{ Regression Statistics } \\
\hline Multiple R & 0.991580615 & & & & & & & \\
\hline R Square & 0.983232115 & & & & & & & \\
\hline Adjusted R Square & 0.83797956 & & & & & & & \\
\hline Standard Error & 29382618.51 & & & & & & & \\
\hline Observations & 9 & & & & & & & \\
\hline \multicolumn{9}{|l|}{ ANOVA } \\
\hline & $d f$ & SS & $M S$ & $F$ & gnificance & & & \\
\hline Regression & 2 & $3.54 \mathrm{E}+17$ & $1.77 \mathrm{E}+17$ & 205.2324 & $2.99 \mathrm{E}-06$ & & & \\
\hline Residual & 7 & $6.04 \mathrm{E}+15$ & $8.63 E+14$ & & & & & \\
\hline \multirow[t]{2}{*}{ Total } & 9 & $3.6 \mathrm{E}+17$ & & & & & & \\
\hline & Coefficients & andard Err & tStat & P-value & Lower 95\%L & Upper 95\%c & ower 95.0\% & 'pper 95.0\% \\
\hline Intercept & 0 & $\# N / A$ & $\# N / A$ & $\# N / A$ & $\# N / A$ & $\# N / A$ & $\# N / A$ & $\# N / A$ \\
\hline Ventilation $\left(\beta_{21}\right)$ & 95.67617459 & 4547.974 & 0.021037 & 0.983803 & -10658.6 & 10849.93 & -10658.6 & 10849.93 \\
\hline Infiltration loss $\beta_{21}$ & 0.441351876 & 0.068392 & 6.453281 & 0.000349 & 0.279631 & 0.603073 & 0.279631 & 0.603073 \\
\hline
\end{tabular}

Figure E.10: 2nd level multivariable regression analysis of plant AASU 


\begin{tabular}{|c|c|c|c|c|c|c|c|c|}
\hline \multicolumn{9}{|l|}{ SUMMARY OUTPUT } \\
\hline \multicolumn{9}{|c|}{ Regression Statistics } \\
\hline Multiple R & 0.986265395 & & & & & & & \\
\hline R Square & 0.972719429 & & & & & & & \\
\hline Adjusted R Square & 0.825965061 & & & & & & & \\
\hline Standard Error & 4439697.88 & & & & & & & \\
\hline Observations & 9 & & & & & & & \\
\hline \multicolumn{9}{|l|}{ ANOVA } \\
\hline & $d f$ & SS & $M S$ & $F$ & \multicolumn{2}{|l|}{ gnificance $F$} & & \\
\hline Regression & 2 & $4.92 \mathrm{E}+15$ & $2.46 \mathrm{E}+15$ & 124.7964 & $1.29 \mathrm{E}-05$ & & & \\
\hline Residual & 7 & $1.38 \mathrm{E}+14$ & $1.97 \mathrm{E}+13$ & & & & & \\
\hline \multirow[t]{2}{*}{ Total } & 9 & $5.06 \mathrm{E}+15$ & & & & & & \\
\hline & Coefficients & andard Err & t Stat & P-value & \multicolumn{4}{|c|}{ Lower 95\%Upper 95\%ower 95.0\%pper 95.0\% } \\
\hline Intercept & 0 & $\# N / A$ & $\# N / A$ & $\# N / A$ & $\# N / A$ & $\# N / A$ & $\# N / A$ & $\# N / A$ \\
\hline Ventilation $\left(\beta_{21}\right)$ & 2875.057482 & 742.5865 & 3.87168 & 0.006118 & 1119.119 & 4630.996 & 1119.119 & 4630.996 \\
\hline infiltration loss $\beta_{22}$ & $2.61478 \mathrm{E}-05$ & 0.000123 & 0.21278 & 0.837562 & -0.00026 & 0.000317 & -0.00026 & 0.000317 \\
\hline
\end{tabular}

Figure E.11: 2nd level multivariable regression analysis of plant AAWI

\begin{tabular}{|c|c|c|c|c|c|c|c|c|}
\hline SUMMARY OUTPUT & & & & & & & & \\
\hline \multicolumn{9}{|c|}{ Regression Statistics } \\
\hline Multiple R & 0.991447555 & & & & & & & \\
\hline R Square & 0.982968254 & & & & & & & \\
\hline Adjusted R Square & 0.837678004 & & & & & & & \\
\hline Standard Error & 107556660.3 & & & & & & & \\
\hline Observations & 9 & & & & & & & \\
\hline \multicolumn{9}{|l|}{ ANOVA } \\
\hline & $d f$ & SS & $M S$ & $F$ & gnificance $F$ & & & \\
\hline Regression & 2 & $4.67 \mathrm{E}+18$ & $2.34 \mathrm{E}+18$ & 201.9986 & 3.13E-06 & & & \\
\hline Residual & 7 & $8.1 \mathrm{E}+16$ & $1.16 \mathrm{E}+16$ & & & & & \\
\hline \multirow[t]{2}{*}{ Total } & 9 & $4.75 \mathrm{E}+18$ & & & & & & \\
\hline & Coefficients & andard Err & tStat & P-value 1 & Lower 95\% & Jpper 95\% & wer 95.0\% & pper 95.0\% \\
\hline Intercept & 0 & \#N/A & $\# N / A$ & $\# N / A$ & \#N/A & \#N/A & $\# N / A$ & $\# N / A$ \\
\hline VENTILATION $\beta_{21}$ & 900.8864251 & 19289.08 & 0.046704 & 0.964053 & -44710.5 & 46512.32 & -44710.5 & 46512.32 \\
\hline INFILTRATION LOSS $\beta_{22}$ & 0.262212534 & 0.043836 & 5.981665 & 0.000552 & 0.158557 & 0.365868 & 0.158557 & 0.365868 \\
\hline
\end{tabular}

Figure E.12: 2nd level multivariable regression analysis of plant AAWR 


\section{Appendix F: Audit Report Template}

Plant: AAAV

Area: $128,708 \mathrm{ft}^{2}$

Operational Hour: 18 hours per day 7 days per week and 6,372 hours per year

Summary Result:

Table F.1: Annual gas consumption of plant AAAV

\begin{tabular}{|c|c|c|c|}
\hline & $\begin{array}{c}\text { Normalized NG } \\
\text { Consumption }\left(\mathrm{m}^{3} / \text { year }\right)\end{array}$ & $\begin{array}{c}\text { Estimated Annual } \\
\text { Cost }(\$ / \text { year })\end{array}$ & $\begin{array}{c}\text { Percentage of } \\
\text { Total }(\%)\end{array}$ \\
\hline Process Consumption & 40,559 & 10,140 & 37 \\
\hline Seasonal Consumption & 227,849 & 56,962 & 63 \\
\hline Total & 267,303 & 66,826 & 100 \\
\hline
\end{tabular}

According to Table 1 Plant is using $63 \%$ of total consumption for its seasonal purposes and $37 \%$ for process purposes. That means huge amount of energy is consuming for space heating and ventilation purposes. Plant can save a huge amount of energy by improving wall and roof insulation. Table 2 presents the saving (\$) from improving wall and roof insulation.

Table F.2: Cost saving per year by improving building insulation

$$
\begin{aligned}
& \text { Cost reduction by improving building } \\
& \text { insulation R Value }
\end{aligned}
$$

$\$ 29,857$

\section{Weather Normalized Consumption Analysis:}

Weather normalization of plant was conducted with 30 years weather data using Microsoft Excel. Regression analysis was conducted using trial and error method to determine the best $\mathrm{R}^{2}$ value. Based on the best $\mathrm{R}^{2}$ value, reference temperature of plant was determined to be $67^{\circ} \mathrm{F}$. Then normalized annual natural gas consumption was calculated. Figure 1 presents the weather normalization of plant AAAV. 


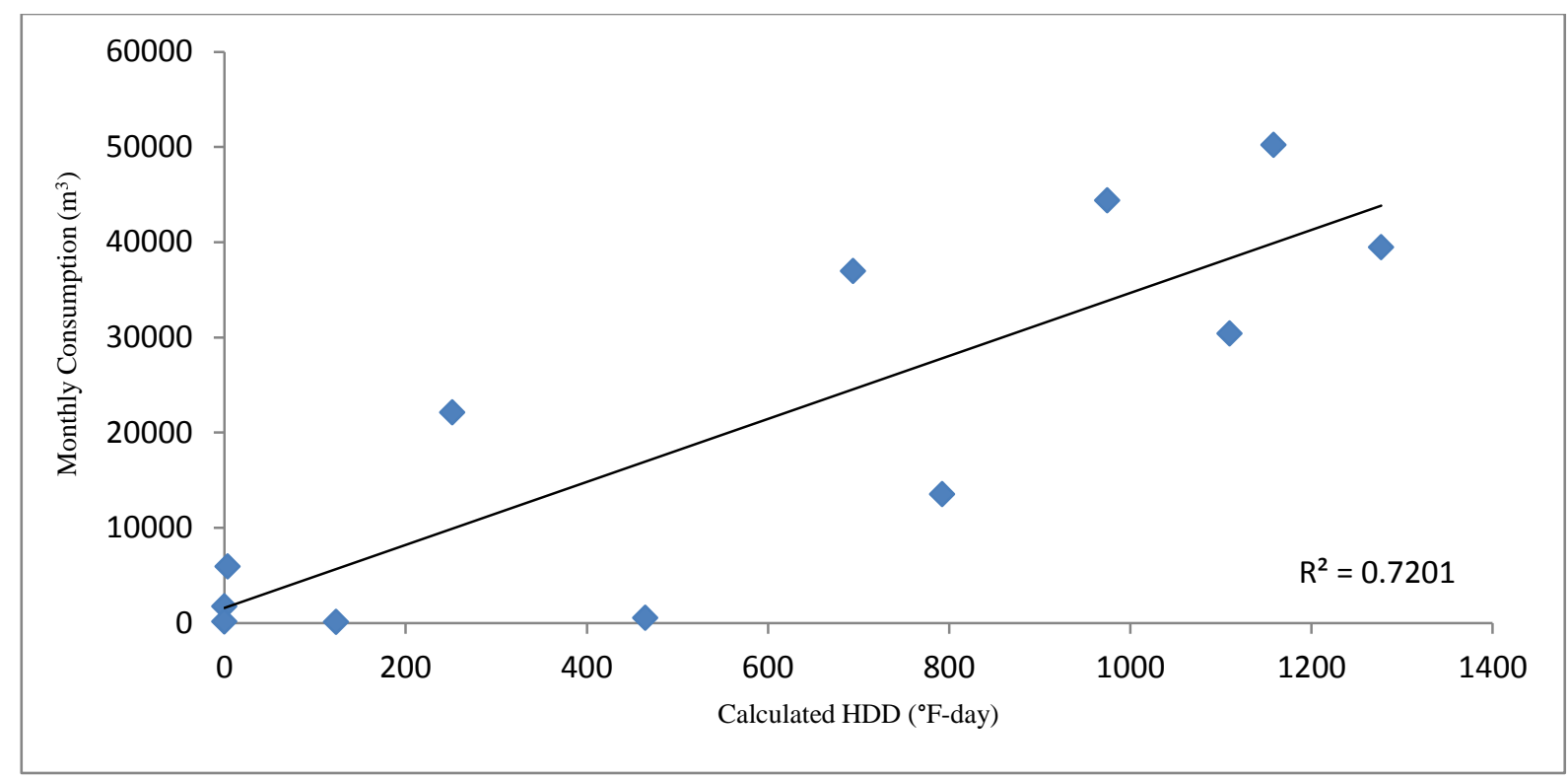

Figure F.1: Weather normalization of plant AAAV

After that seasonal and process natural gas consumption was separated. Average three summer months (June, July, and August) consumption was considered as process energy consumption. Subtracting the process energy consumption from monthly energy consumption seasonal natural gas consumption was calculated. Figure 2 presents the process and seasonal natural gas consumption of plant AAAV.

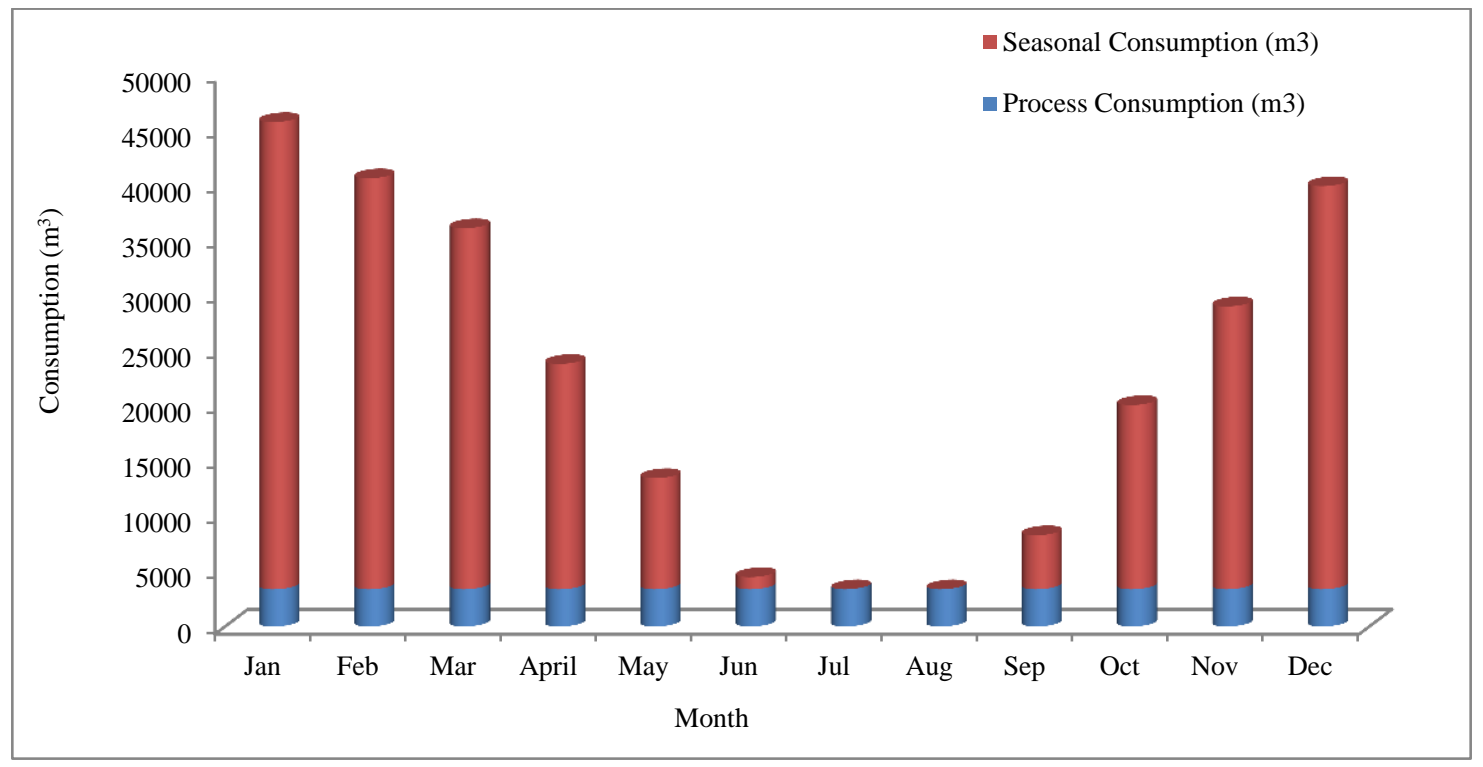

Figure F.2: Seasonal and process natural gas consumption of plant AAAV

According to Figure 2 plant AAAV consumes huge amount of natural gas for seasonal purposes. Figure 3 presents the percent of seasonal and process natural gas consumption. 


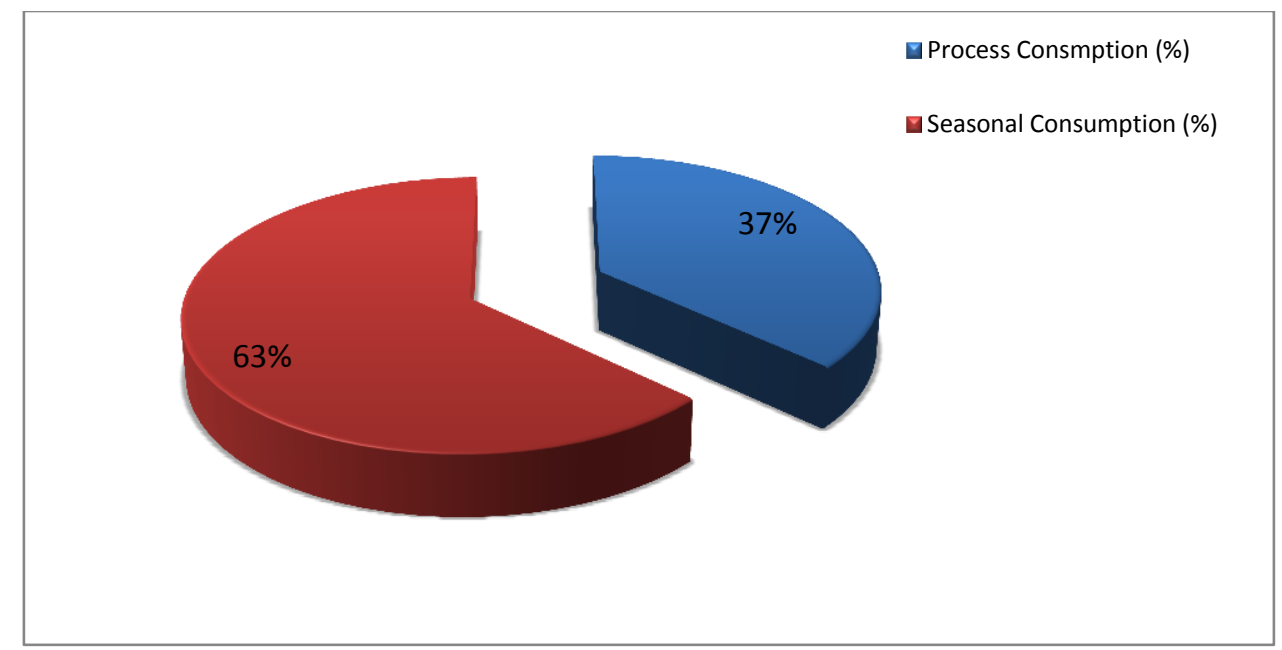

Figure F.3: Percent of seasonal and process natural gas consumption

According to Figure 3, Plant AAAV is consuming $63 \%$ of its total annual natural gas consumption for seasonally related purposes which indicate $227,849 \mathrm{~m}^{3} /$ year consumption and $37 \%$ for process purposes that indicates 405,59 $\mathrm{m}^{3} /$ year. Using first level multivariable regression analysis seasonal natural gas consumption was further divided into total ventilation consumption and transmission heat loss. Figure 4 presents the percent of transmission heat loss and total ventilation consumption of plant.

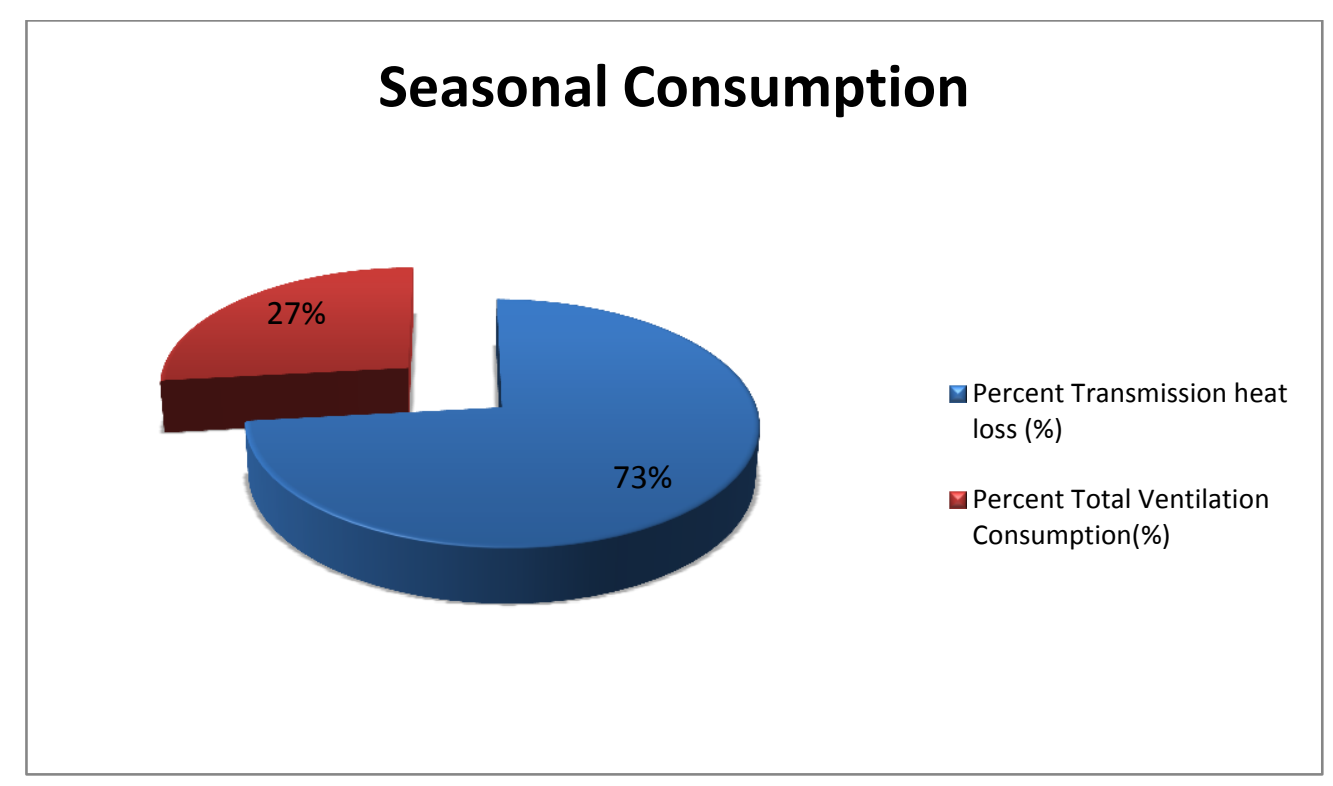

Figure F.4: Percent total transmission heat loss and total ventilation consumption of plant AAAV

According to Figure 4, Plant AAAV is consuming 73 percent of its seasonal natural gas consumption for space heating purposes that indicate $16,4126 \mathrm{~m}^{3} /$ year and $27 \%$ for ventilation 
purposes which indicates $62,621 \mathrm{~m}^{3} /$ year. After that using second level multivariable regression analysis, total ventilation consumption was further divided into mechanical ventilation and infiltration loss. Figure 5 presents the percent of infiltration loss and mechanical ventilation consumption of plant AAAV.

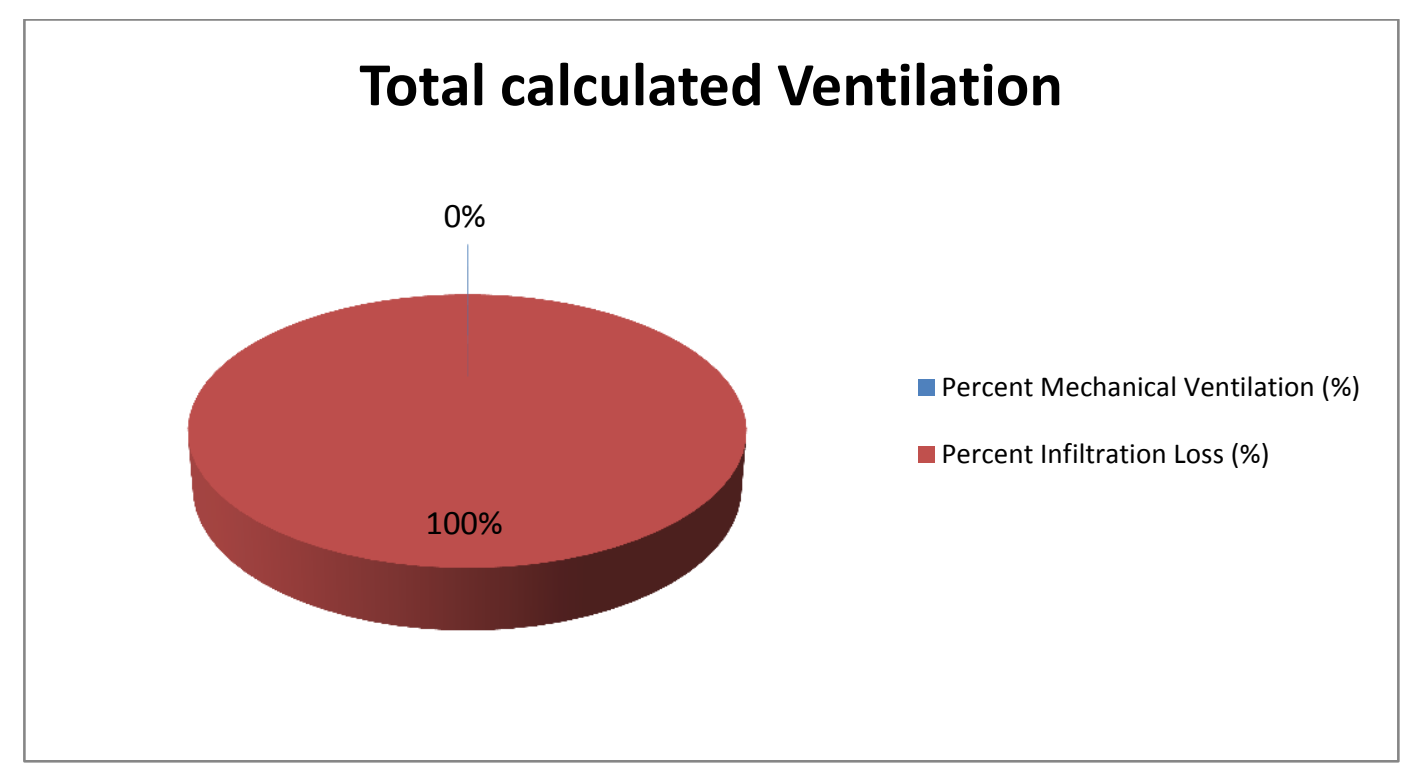

Figure F.5: Percent mechanical ventilation consumption and infiltration loss of plant AAAV

\section{Ranking Distribution of Plants:}

\section{Transmission Heat Loss per Unit Area}

Annual transmission heat loss per unit area was compared between nine audited powder coating industries. Here, the plant that uses the least amount of energy per unit area was considered the most efficient plant and who uses the highest amount of energy per unit area was considered the most inefficient plant. Microsoft Excel Rank and Percentile analysis was conducted to rank plants. Figure 6 presents the dataset $\left(\mathrm{m}^{3} / \mathrm{ft}^{2}\right)$ for thirteen different industries in GTA. 


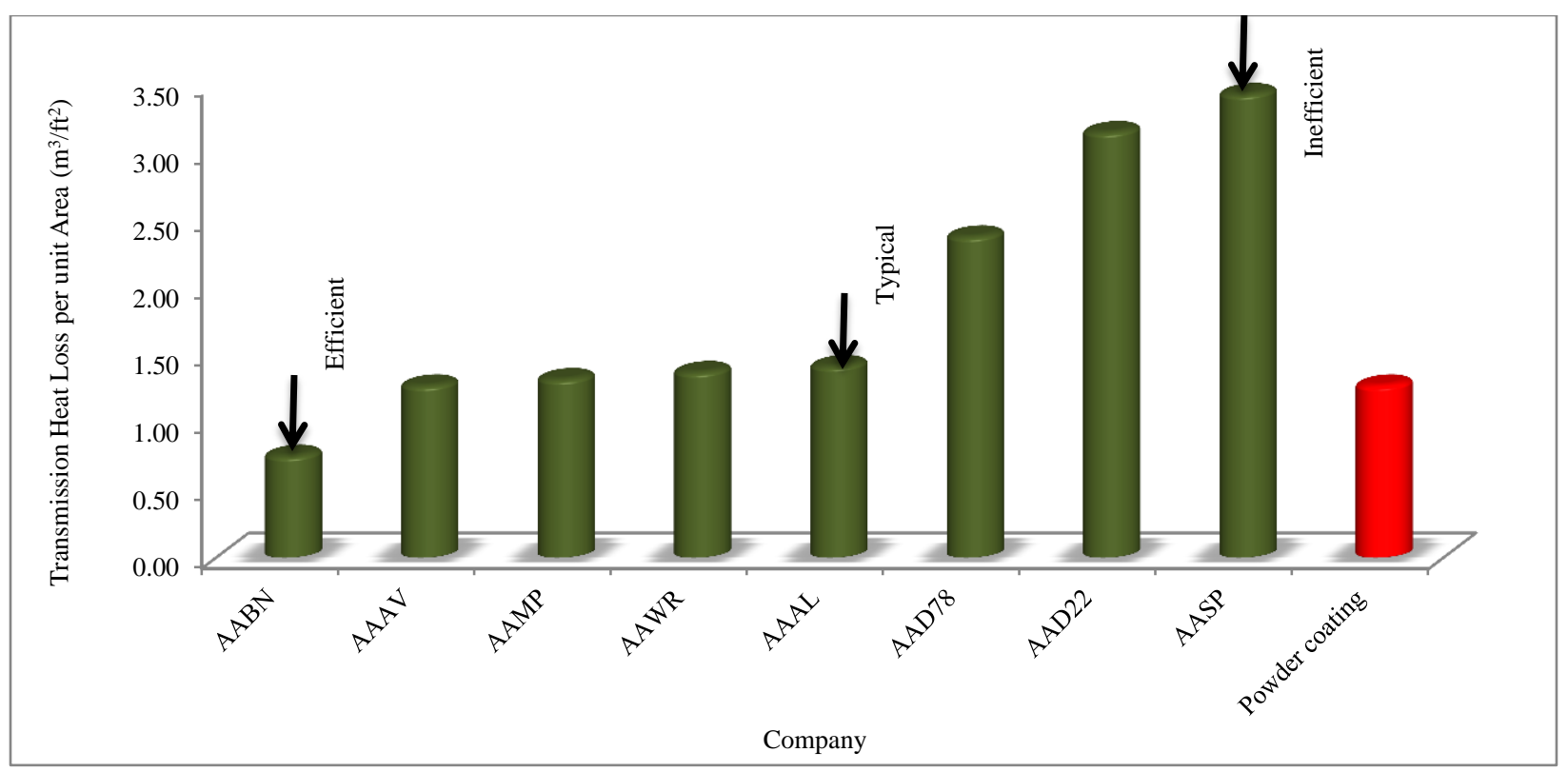

Figure F.6: Annual Transmission Heat Loss Benchmark per Unit Area

\section{Transmission Heat Loss per Unit Area Multiplied With Operational Hour}

Annual transmission heat loss per unit area multiplied with operational hour was compared between nine audited powder coating industries data. Similarly, the plant that uses the least amount of energy per unit area $\mathrm{x}$ operational hour was considered the most efficient plant and who uses the highest amount of energy per unit area $\mathrm{x}$ operational hour was considered the most inefficient plant. Microsoft Excel Rank and Percentile analysis was conducted to rank plants. Figure 7 presents the dataset $\left(\mathrm{m}^{3} / \mathrm{ft}^{2}\right.$-hr) for nine powder coating industries in GTA. 


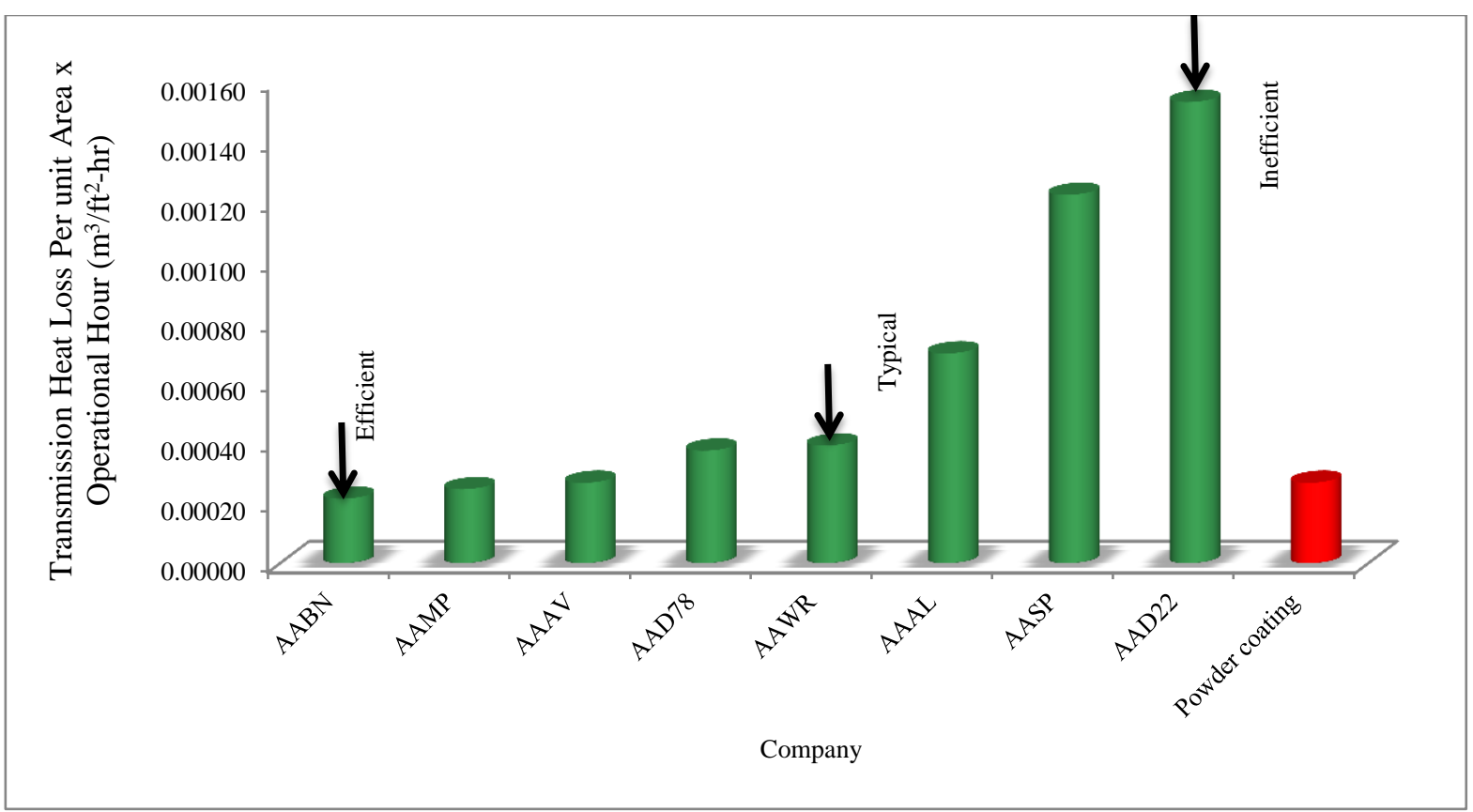

Figure F.7: Annual transmission heat loss benchmark per unit area multiplied with operational hour

\section{Total Ventilation Consumption per Unit Area}

Total ventilation consumption per unit area was compared between nine audited powder coating industries. Similarly, the plant that uses the least amount of energy per unit area was considered the most efficient plants and who uses the highest amount of energy per unit area was considered the most inefficient plants. Microsoft Excel Rank and Percentile Analysis was conducted to rank the plants. Figure 8 presents the dataset $\left(\mathrm{m}^{3} / \mathrm{ft}^{2}\right)$ for nine different powder coating industries in GTA. 


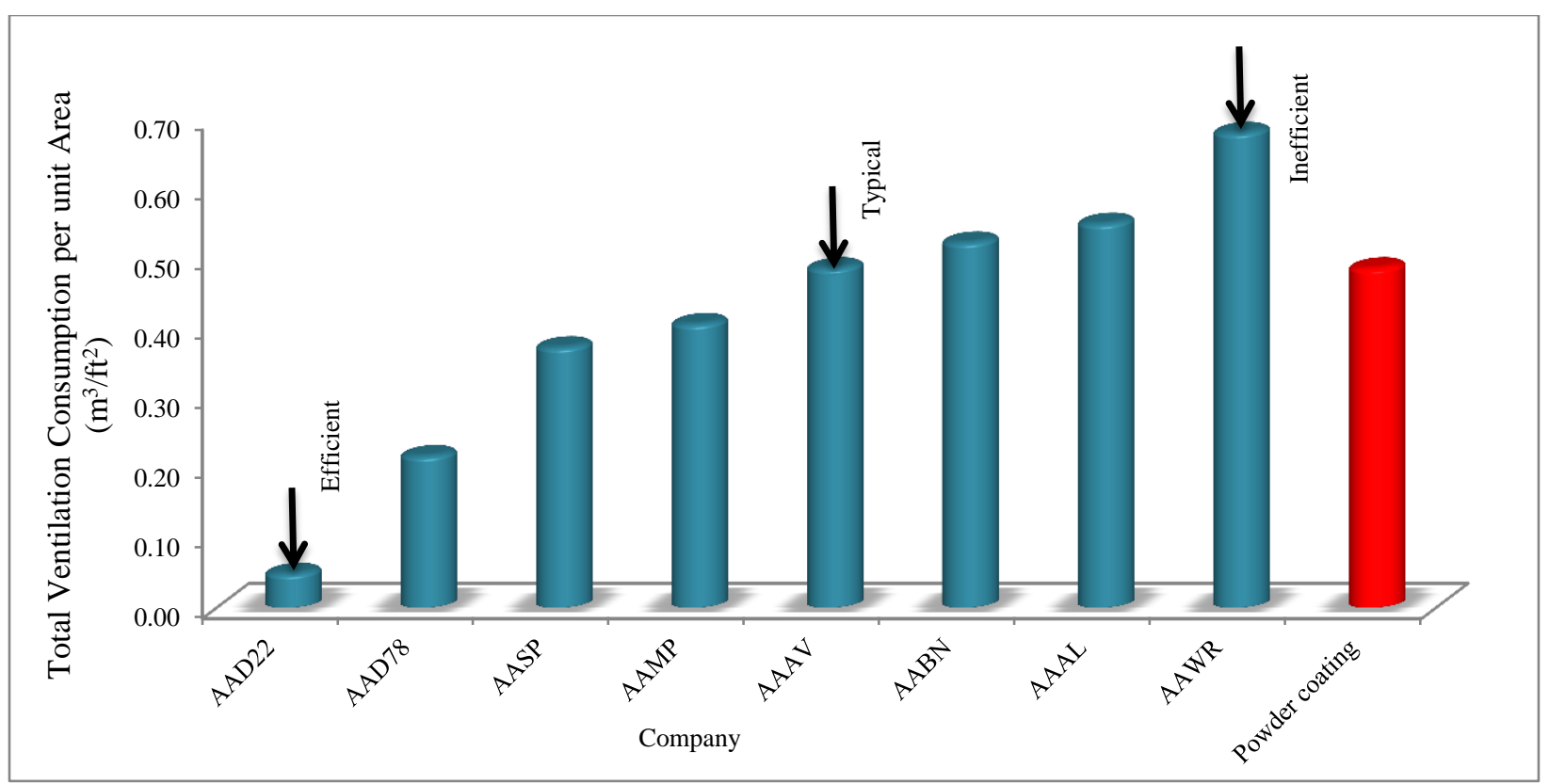

Figure F.8: Total ventilation related natural gas consumption benchmark per unit area

\section{Ventilation Consumption per unit Operational Hour}

Total ventilation consumption per unit operational hour was compared between nine audited powder coating industries. Similarly, the plant that uses the least amount of energy per unit area was considered the most efficient plants and who uses the highest amount of energy per unit operational hour was considered the most inefficient plants. Microsoft Excel Rank and Percentile Analysis was conducted to rank the plants. Figure 9 presents the dataset $\left(\mathrm{m}^{3} / \mathrm{hr}\right)$ for nine different powder coating industries in GTA. 


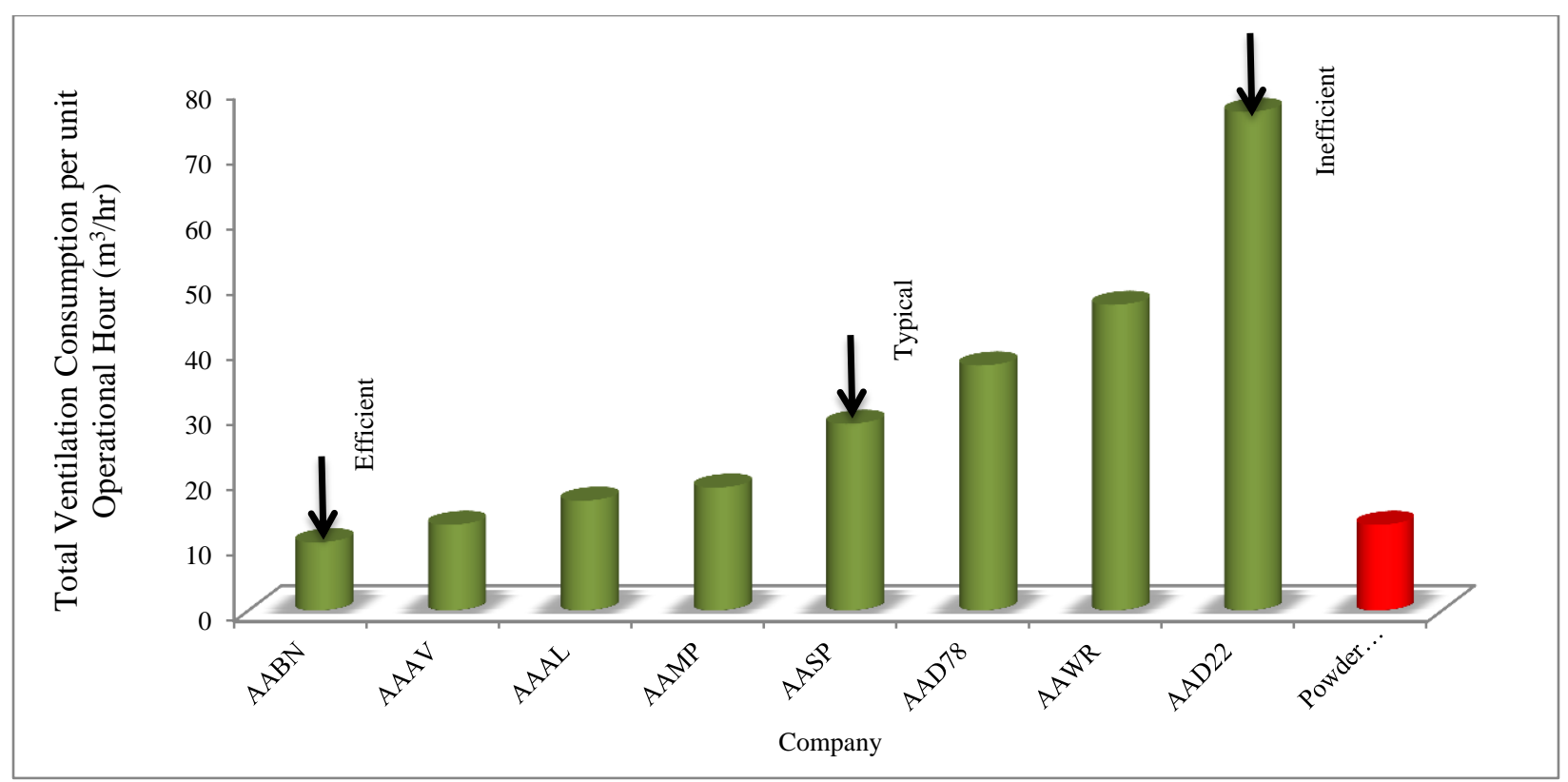

Figure F.9: Total ventilation related natural gas consumption benchmark per unit operational hour

\section{Total Ventilation Consumption per Unit Area Multiplied With Operational Hour}

Total ventilation consumption per unit area $\mathrm{x}$ operational hour was compared between nine audited powder coating industries. Similarly, the plant that uses the least amount of energy per unit area $\mathrm{x}$ operational hour was considered the most efficient plants and who uses the highest amount of energy per unit area x operational hour was considered the most inefficient plants. Microsoft Excel Rank and Percentile analysis was conducted to rank the plants. Figure 10 presents the dataset $\left(\mathrm{m}^{3} / \mathrm{ft}^{2}-\mathrm{hr}\right)$ for nine different powder coating industries in GTA. 


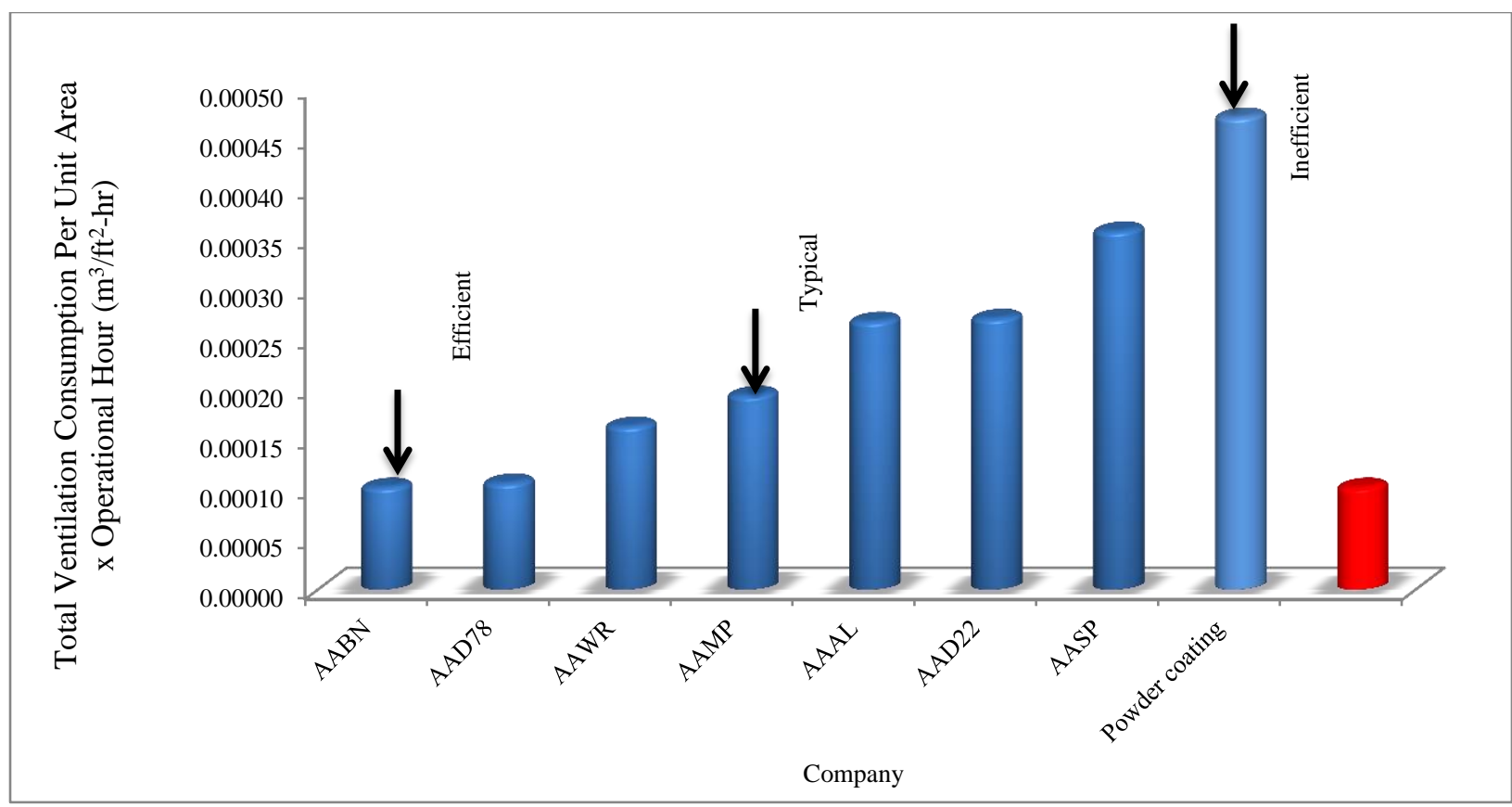

Figure F.10: Total ventilation related natural gas consumption benchmark per unit area $\mathrm{x}$ operational hour

\section{Mechanical Ventilation Related Natural Gas Consumption per Unit Area}

Mechanical ventilation consumption per unit area was compared between nine audited powder coating industries. The plant that uses the least amount of energy per unit area was considered the most efficient plants and who uses the highest amount of energy per unit area was considered the most inefficient plants. Microsoft Excel Rank and Percentile analysis was conducted to rank the plants. Figure 11 presents the dataset $\left(\mathrm{m}^{3} / \mathrm{ft}^{2}\right)$ for nine different powder coating industries in GTA.

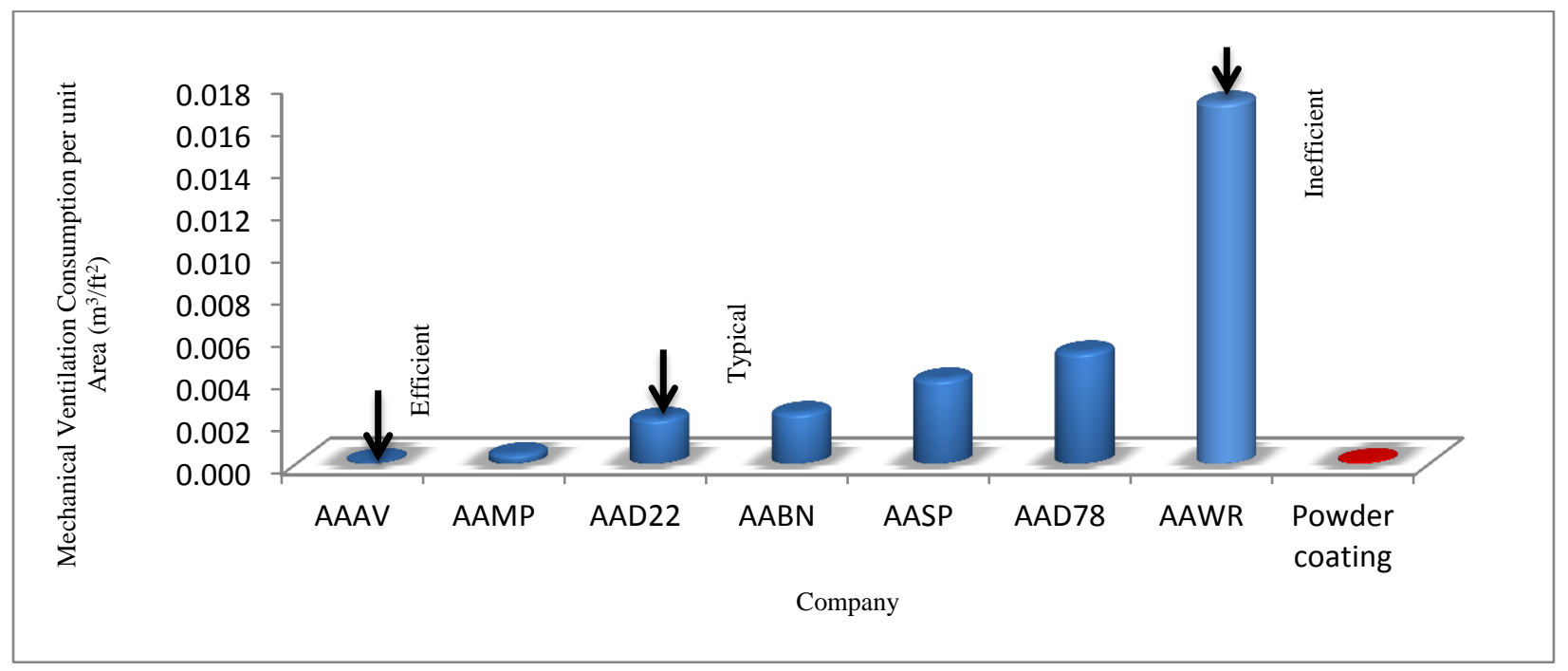

Figure F.11: Annual mechanical ventilation related natural gas consumption benchmark per unit area 


\section{Mechanical Ventilation Related Natural Gas Consumption per Unit Area X Operation}

Hour

Mechanical ventilation consumption per unit area $\mathrm{x}$ operational hour was compared between nine audited powder coating industries. Similarly, the plant that uses the least amount of energy per unit area $\mathrm{x}$ operational hour was considered the most efficient plants and who uses the highest amount of energy per unit area $\mathrm{x}$ operational hour was considered the most inefficient plants. Microsoft EXCEL Rank and Percentile analysis was conducted to rank the plants. Figure 12 presents the dataset $\left(\mathrm{m}^{3} / \mathrm{ft}^{2}-\mathrm{hr}\right)$ for nine different powder coating industries in GTA.

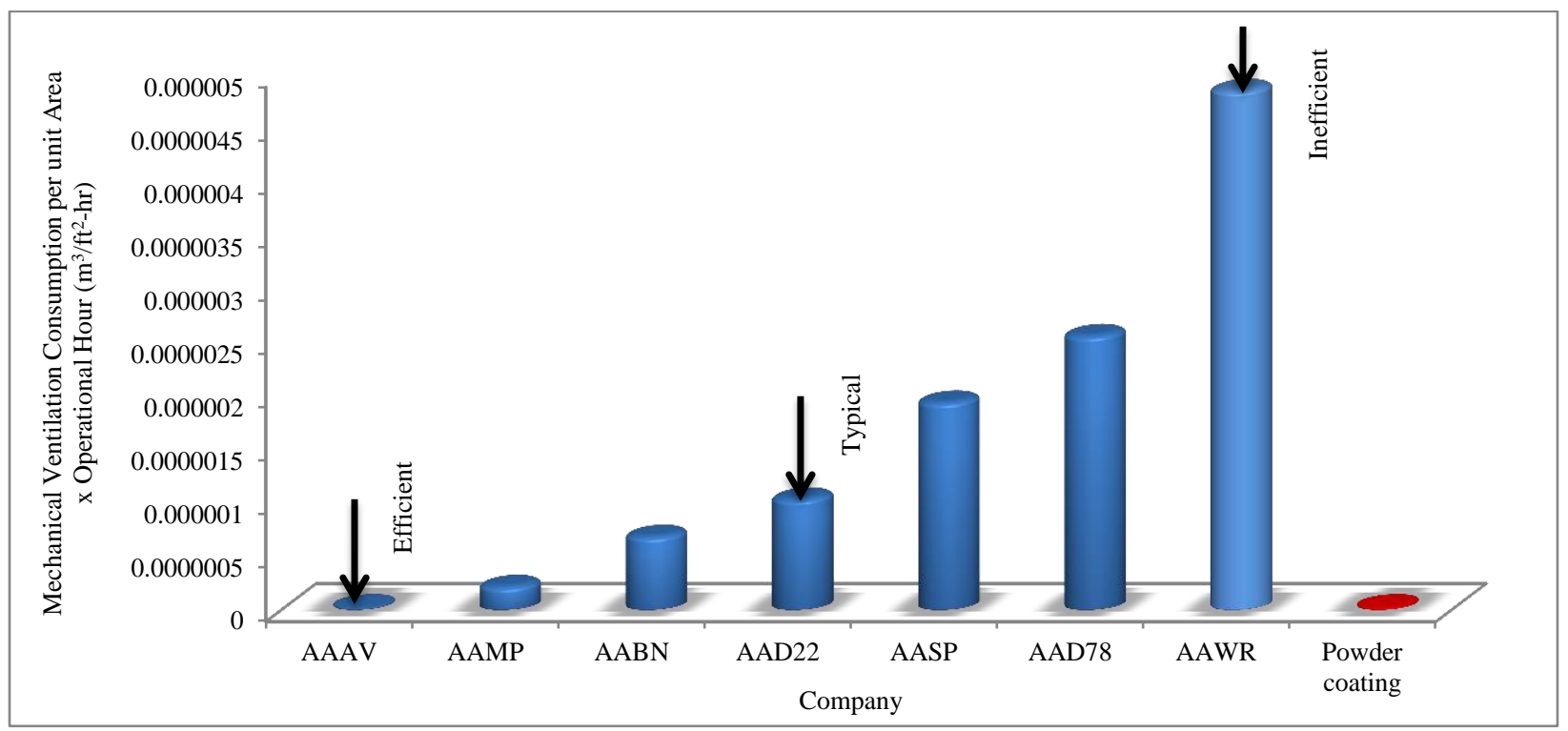

Figure F.12: Annual mechanical ventilation related natural gas consumption benchmark per unit area

\section{Infiltration Loss per Unit Area}

Infiltration loss per unit area was compared between audited powder coating industries. Microsoft EXCEL Rank and Percentile analysis was conducted to rank plants. In this case, the plant that uses the least amount of natural gas per unit area for infiltration loss purpose was considered the most efficient plant and the plant that uses the highest amount of energy per unit area for infiltration loss purpose was considered the most inefficient one. Figure 13 presents the dataset $\left(\mathrm{m}^{3} / \mathrm{ft}^{2}\right)$ for different powder coating industries in GTA. 


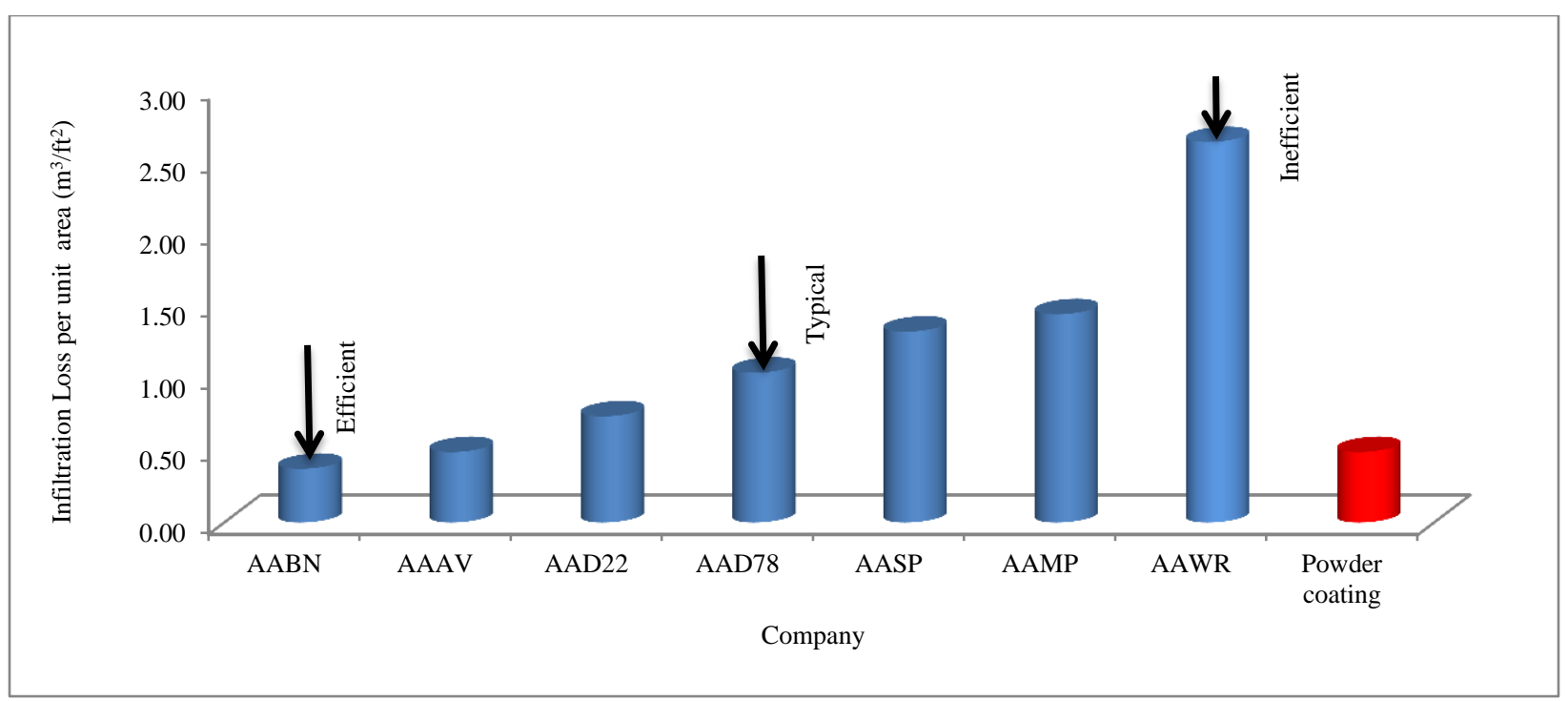

\section{Summary Result}

Figure F.13: Annual Infiltration Loss Benchmark per Unit Area

After conducting ranking based distribute on saving analysis was conducted in each category based on the most efficient plant in the dataset. Saving analysis was conducted for transmission heat loss, total ventilation consumption, mechanical ventilation and infiltration loss. In this case, if the saving result is 0 that means the plant is the most efficient plant in the dataset. In this analysis it was found that plant AAAV is the most efficient plant in terms of mechanical ventilation consumption and for this reason, savings for mechanical ventilation was calculated to be 0 . Table 2 presents the summary result for saving analysis. 
Table F.3: Summary results for saving analysis

\begin{tabular}{|c|c|c|c|c|c|c|c|c|c|c|c|c|}
\hline & 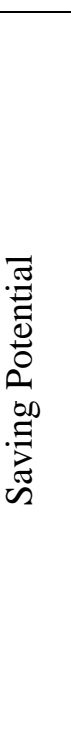 & & 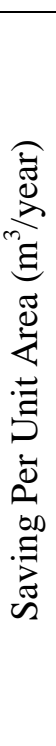 & 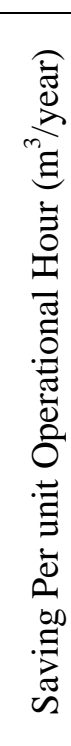 & 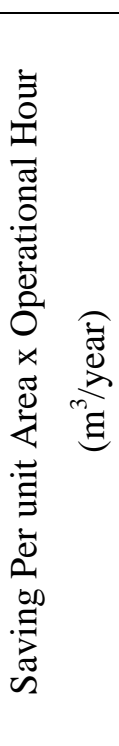 & 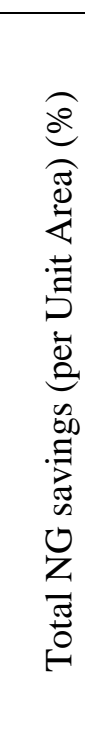 & 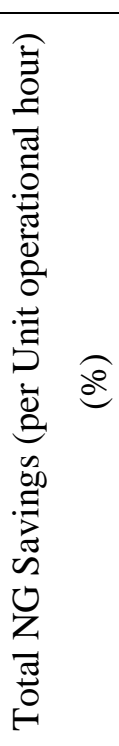 & 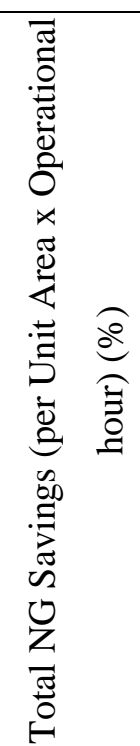 & 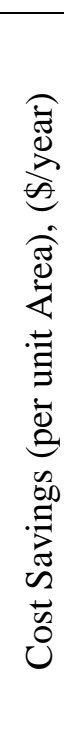 & 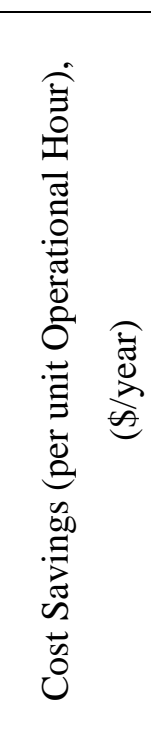 & 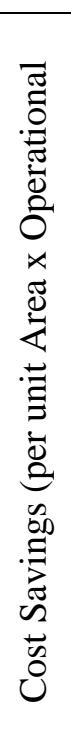 & 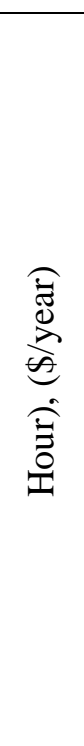 \\
\hline ‡ْ & 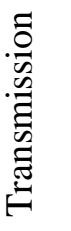 & 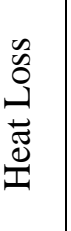 & $\begin{array}{l}n \\
m \\
\tilde{n} \\
\tilde{n}\end{array}$ & & $\begin{array}{l}0 \\
\sigma \\
\tilde{n}\end{array}$ & in & & in & 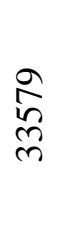 & & $\underset{m}{\stackrel{g}{f}}$ & \\
\hline 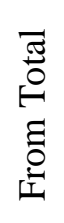 & 苛 & 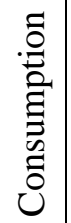 & 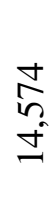 & 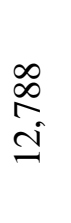 & $\begin{array}{l}2 \\
\infty \\
0 \\
\infty \\
+\end{array}$ & $n$ & $n$ & $n$ & $\begin{array}{l}\text { Ji } \\
\text { mi }\end{array}$ & $\frac{\hat{\sigma}}{\dot{m}}$ & $\begin{array}{l}\text { ป̂ } \\
\text { ป } \\
\text { I }\end{array}$ & \\
\hline 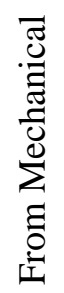 & 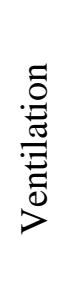 & 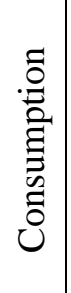 & 0 & 0 & 0 & 0 & 0 & 0 & 0 & 0 & 0 & \\
\hline 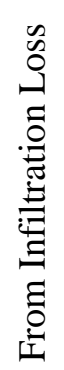 & & & $\frac{\infty}{\sigma}$ & & & 6 & & & $\frac{\curvearrowright}{\curvearrowright}$ & & & \\
\hline
\end{tabular}




\section{Improvement of Building Insulation Value to R20}

From transmission heat loss analysis it was found that most of the plant were not well insulated and considerable amount of energy saving potentials could available. For this reason a decision was made to estimate the reduction of plant transmission heat loss by improving plant envelope (wall and roof) insulation. In this case all plants' wall and roof target insulation R value was considered 20 according to 2012 Ontario Building Code [50] and transmission heat losses of plant AAAV was calculated. Table 3 presents the natural gas, cost reduction and payback period to improve plant insulation $\mathrm{R}$ Value.

Table F.4: Summary result to improve building insulation $R$ Value

\begin{tabular}{|c|c|c|c|c|c|c|c|c|}
\hline 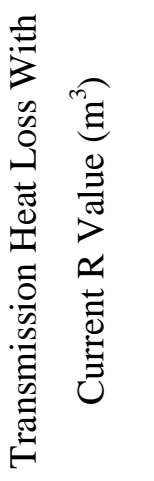 & 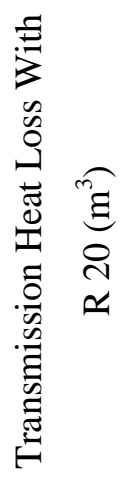 & 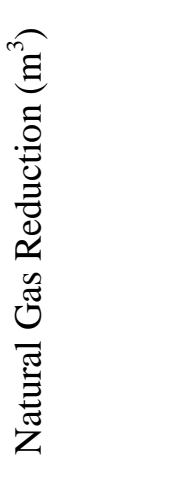 & 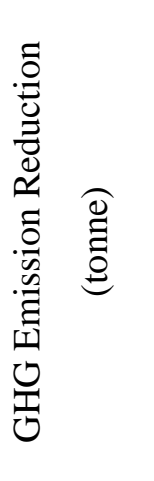 & 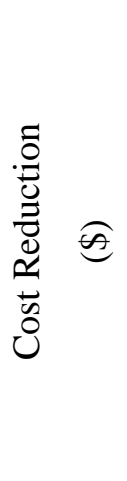 & 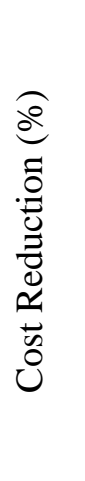 & 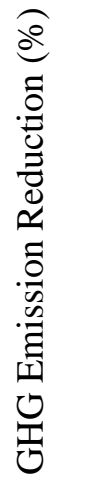 & 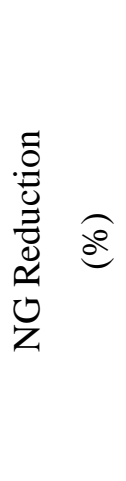 & 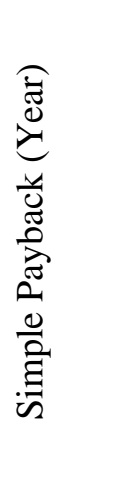 \\
\hline 164,127 & 44,697 & 119,430 & 204,660 & 29,857 & 24 & 24 & 25 & 16 \\
\hline
\end{tabular}




\section{References}

[1] Teaser, R., (1991), "Climate and building energy management", Energy and Buildings, Vol. 15, No. 16, pp. 599 - 608.

[2] Phylipsen, G.J.M. , Blok, K., Worrell, E., (1997), "International comparisons of energyefficiency methodologies for the manufacturing industry", Energy Policy, Vol. 25, No. 7 - 9, pp. $715-725$.

[3] Laurijssen, J., Faaij, A., \& Worrell, E., (2013), "Benchmarking energy use in the paper industry: a benchmarking study on process unit level”, Energy Efficiency, Vol. 6, pp. 49 - 63

[4] Boyd, G., Dutrowb, E., Tunnessen, W., (2008), "The evolution of the ENERGY STAR energy performance indicator for benchmarking industrial plant manufacturing energy use", Science Direct, Vol. 16, No. 6, pp. $709-715$.

[5] Wilde, P.D., Ortiz, C.M., Pearson, D., Beynon, I., Beck, M., Barlow, N., (2013), "Building simulation approaches for the training of automated data analysis tools in building energy management", Advanced Engineering Informatics, Vol. 27, 457-465.

[6] Statistics Canada, (2014), Households and the environment survey: Energy use, Retrieved February 25, 2015 from Statistics Canada.

[7] National Energy Board, (2013), Canada's energy future 2013- Energy supply and demand projections to 2013- an energy market assesment, Retrieved September 15, 2014, from National Enery Board: https://www.neb-one.gc.ca/nrg/ntgrtd/ftr/2013/index-eng.html

[8] Natural Resource Canada, (2013), Energy use data handbook tables (Canada) - industrial sector, Retrieved September 5, 2014, from Natural Resource Canada: http://www.bing.com/search?q=Canada,+Natural+Resource.+\%22Energy+Use+Data+Handbook +Tables+(Canada)+-+Industrial+Sector.\%22+Annually.+2013-0102.+http $\% 3 \mathrm{~A} \% 2 \mathrm{~F} \% 2 \mathrm{Fdata} . \mathrm{gc} . \mathrm{ca} \% 2 \mathrm{Fdata} \% 2 \mathrm{Fen} \% 2 \mathrm{Fdataset} \% 2 \mathrm{Fb} 24 \mathrm{e} 34 \mathrm{~d} 0-2 \mathrm{e} 2 \mathrm{c}-4 \mathrm{~d} 97-9022-$ $\underline{6 b 00288213 b 3 . \& s r c=I E-T o p R e s u l t \& F O R M=I E}$ 
[9] Statistics Canada, (2010), Households and the environment survey: energy use, 2011, Retrieved September 19, 2013 from Statistics Canada: http://www80.statcan.gc.ca/wesesw/page1-eng.htm

[10] International Energy Agency, (2011), World energy outlook: http://www.iea.org/publications/freepublications/publication/weo2011_web.pdf

[11] Ontario Energy Board, (2015), Natural gas rate updates, Retrieved February 1, 2015 from Ontario Energy Board

[12] U.S. Department of Energy, (2011), A Guide to Energy Audits

[13] Environment Canada, (2014), About Canada's greenhouse gas inventory, Retrieved November 1, 2014, from Environment Canada: http://ec.gc.ca/gesghg/default.asp?lang=En\&n=3808457C-1

[14] Ontario Energy Board, (2014), Demand side management framework for natural gas distribution: $\quad$ http://www.ontarioenergyboard.ca/oeb/_Documents/EB-20140134/Report_Demand_Side_Management_Framework_20141222.pdf

[15] Stewart, H., and Gapp, R., (2014), "Achieving effective sustainable management: a smallmedium enterprise case study", Corporate Social Responsibility and Environmental Management, Vol. 21, pp. $52-64$.

[16] European Commission, (2008), Observatory of European SMEs, analytical report: http://ec.europa.eu/public_opinion/flash/fl196_en.pdf

[17] Cagno, E., Trianni, A.,(2012), "Analysis of the most effective energy efficiency opportunities in manufacturing primary metals, plastics, and textiles small- and medium-sized enterprises", Energy Resources Technology, Vol. 134.

[18] Ke, J., Price, L., McNeil, M., Khanna, N.Z., Zhou, N., (2013), "Analysis and practices of energy benchmarking for industry from the perspective of systems engineering", Energy, Vol. 54, pp. 32-44. 
[19] Bhattacharjee, K., (2009), "Energy conservation opportunities in industrial ventilation system”, Energy Engineering, Vol. 106, No. 3, pp. 73-79.

[20] Searles, B., Mann, R.S., Kohl, H., (2013), "Benchmarking 2030 future of benchmarking”, Global Benchmarking Network, http://www.benchmarkingpartnerships.com.au/GBNReport_BM2030_final.pdf

[21] Keirstead, J., (2013), "Benchmarking urban energy efficiency in the UK", Energy Policy, Vol. 63, pp. 575 - 587, doi:10.1016/j.enpol.2013.08.063

[22] Kinney, S., Piette, M. A., (2003), "High performance commercial building systems: California commercial building energy benchmarking final project report”, California Energy Commission, http://energyiq.lbl.gov/EnergyIQ/SupportPages/pdf/E2P2.1T1f-

$\underline{\text { CalArchFinalReport.pdf }}$

[23] Saygin, D., Worrell, E., Patela, M. K., Gielen, D. J., (2011) "Benchmarking the energy use of energy-intensive industries in industrialized and in developing countries", Energy, Vol. 36, No. 11, pp. 6661 - 6673, doi:10.1016/j.energy.2011.08.025

[24] Birchfield, G. S., (2015), "Issues and challenges in energy benchmarking", Energy Engineering, Vol. 98, No. 2, pp. 38 - 52, http://dx.doi.org/10.1080/01998590109509307

[25] Wu, X., Priyadarsini, R., Eang, L. S., (2010), "Benchmarking energy use and greenhouse gas emission in Singapore's hotel industry", Energy Policy, Vol. 38, pp. 4520 - 4527

[26] Thollander, P., Dotzauer, E., (2010), “An energy efficiency program for Swedish industrial small- and medium-sized enterprises", Vol. 18, pp. 1339 - 1346, doi:10.1016/j.jclepro.2010.04.020

[27] Price L., Galitsky, C., Kremer, K. J., (2008), “International experience with key program elements of industrial energy efficiency or greenhouse gas emissions reduction target- setting programs", Environment Energy Technology Division, https://eaei.lbl.gov/sites/all/files/LBNL_63807_Industrial_GHG_Program.March,2008_1.pdf 
[28] Chisholm, E., (2013), "Energy benchmarking tools area available to help measure a building's energy use against similar buildings while accounting for important performances that affect performance", Energy

Management, http://www.halsall.com/pdfs/news/articles/Energy\%20Benchmarking\%20\%20Canadian\%20Consulting\%20Engineer\%20-\%20May\%202013.pdf

[29] Brook, M., Micheal, J.S., (2013), “REAL Pac's energy benchmarking program 2013: real property aims similar buildings while the account for important difference that affects performances", Canadian Consulting Engineers, Retrieve $3^{\text {rd }}$ January, 2015

[30] International Energy Agency, (2008), "Worldwide trends in energy use and efficiency—key insights from IEA indicator analysis": http://www.iea.org/publications/freepublications/publication/worldwide-trends-in-energy-useand-efficiency.html

[31] Tahat, M.A., Ali, A.A., (2012), "Energy saving opportunities in Jordanian pharmaceutical industries", Perspectives of Innovations, Economics \& Business, Vol. 10 - 11, No. 1 - 2, pp. 35 50, http://purl.umn.edu/128664

[32] Kabir, G., Abubakar, A.L., Nafaty, U. E., (2009), "Energy audit and conservation opportunities for pyro processing unit of a typical dry process cement plant", Energy, Vol. 35, No. 3, pp. $1237-1243$

[33] Romero, H., Ambriz, J.J., Ortiz, J.N., (1999), “Joint MexicolUSA Energy Audits: A Case Study", ProQuest Science Journals, Vol. 17

[34] Drzymala, S. J., (2014), "Detailed case study_Titan America”, Energy Engineering, Vol. 111, No. 2, pp. 43 - 61, http://www.tandfonline.com/doi/pdf/10.1080/01998595.2014.10801405

[35] Lalita, V., Dr. Saibabu, C., Prasad, G.R.K.D.S., (2013), "Energy and comfort management in energy efficient buildings using RET SCREEN software - A case study analysis", Int. Journal of Engineering Research and Applications, Vol.3, No. 6, pp. 378 - 381

[36] Lailhacar, C. C., Schaub, D., Venkat, S., Capehart, B.L., Capehart, L.C., Pawlik, K.D.E, (2009), “A case study for energy auditing using an interactive energy balance”, Strategic 
Planning for Energy and the Environment, Vol. 25, No. 1, pp. 34 - 62, Doi http://www.tandfonline.com/action/showCitFormats?doi=10.1080/10485230509509679

[37] Hasmiah, A. R., Majid, M.S., Zheri, L.W., Azemi, C. A., (2004), "Energy efficiency and conservation study of a medium scale industry in Malaysia", National Power \& Energy Conference (PECon)

[38] Zhu, Y., (2006), "Applying computer-based simulation to energy auditing: A case study", Energy and Buildings, Vol. 38, No. 5, pp. 421 - 428, doi:10.1016/j.enbuild.2005.07.007

[39] Chan, D. Y. L., Huang, C. F., Lin, W. C., Hong, G. B., (2014), "Energy efficiency benchmarking of energy-intensive industries in Taiwan", Energy Conversion and Management, Vol. 77, pp. 216 - 220, doi:10.1016/j.enconman.2013.09.027

[40] Mui, K. W., Wong, L. T., Law, L.Y., (2007), “An energy benchmarking model for ventilation systems of air-conditioned offices in subtropical climates", Applied Energy, Vol. 84, No. 1, pp. 89 - 98, doi:10.1016/j.apenergy.2006.04.002

[41] Pommer, L., Fick, J., Sundell, J., Nilsson, C., Sjo"stro“m, M., Stenberg, B., (2004), “Class separation of buildings with high and low prevalence of SBS by principal-component analysis", Indoor Air, http://www.irbnet.de/daten/iconda/CIB7303.pdf

[42] Sorensen, L.S., (2013), "Heat transmission coefficient measurements in buildings utilizing a heat loss measuring device", Sustainability, Vol. - 5, ISSN - 2071-1050, PP. - 3601-3614

[43] Younes, C., Shdid, C.A., Bitsuamlak, G., (2011), "Air infiltration through building envelopes: A review", Building Physics, Vol. - 35, PP. - 267 - 302

[44] Fletcher, B., Johnson, A.E., (1992), "Ventilation of small factory unit", Wind Engineering and Industrial Aerodynamics, Vol. - 40, PP. 293-205.

[45] Jia, T., Jian, L., (2009), "Stability of mine ventilation system based on multiple regression analysis", Mining Science and Technology, Vol. - 19, PP. - 0463-0466. 
[46] Onder, M., Cevik, E., (2008), "Statistical model for the volume rate reaching the end of ventilation duct", Science Direct, Vol. - 23, PP. - $179-184$

[47] Litomisky A., (2006), "New savings opportunity: on-demand industrial ventilation”, Energy Engineering, Vol. 103, No. 3

[48] Jones, A., Baltazar, J. C., Claridge, D.E., (2009), “Joint-frequency bins versus conventional bin weather data in analysis of HVAC system operation", Ninth International Conference for Enhanced Building Operations

[49] Dieckmann, J., (2008), "Improving humidity control with energy recovery ventilation", ASHRAE Journal, Vol. 50, No. 8, pp. $38-42$

[50] Kraljevska, E., (2014), "Estimated benefit of achieving passivhaus and net zero energy standards in the region of Waterloo residential sector and the berries and drivers to achieve them", Waterloo University.

[51] Elkhafif, M. A. T., (1996), "An interactive approach for weather-correcting energy consumption data", Energy Economics, Vol. 18, pp. 221 - 230

[52] Buyukalaca, O., Bulut, H., Yilmaz, T., (2001), "Analysis of variable-base heating and cooling degree-days for Turkey", Applied Energy, Vol. 69, No. 4, pp. 269 - 283

[53] ASHRAE, (2009), “ASHRAE Handbook - Fundamentals (I-P Edition)”, ASHRAE

[54] Huang, Y., (2012), "Energy benchmarking and energy saving assessment in high rise multiunit residential building", Ryerson University

[55] Fels, M. F., (1986), “PRISM: an introduction”, Energy and Building, Vol. 9, pp. 05 - 18

[56] Joseph, H. E., (1988), "On using degree-days to account for the effect of weather on annual energy use in office buildings", Energy and Buildings, Vol. 12 pp. 113 - 127

[57] Natural Resource Canada, "Office of energy efficiency glossary and abbreviations", Retrieve on March $5^{\text {th }}$, 2014, from Natural Resources Canada: https://oee.nrcan.gc.ca/corporate/statistics/neud/dpa/data_e/glossary_e.cfm?attr=0 
[58] Ghajarkhosravi, M., (2013), "Utility benchmarking and potential savings of multi-unit residential building (MURBs) in Toronto", Ryerson University.

[59] Weather Statistics Canada, (2015), "Toronto Historical Heating Degree Days", Retrieve on April 10 ${ }^{\text {th }}, 2015$, from Weather Statistics Canada: http://toronto.weatherstats.ca/metrics/hdd.html

[60] Environment Canada, (2015), "Monthly data report", Retrieve on February 25 $5^{\text {th }}, 2015$ from Environment Canada Website: http://climate.weather.gc.ca/climateData/monthlydata_e.html?timeframe=3\&Prov=ON\&StationI $\mathrm{D}=5097 \&$ hlyRange $=1953-01-01 \% 7 \mathrm{C} 2013-06-13 \&$ Year=2010\&Month=6\&Day=13

[61] Enbrigde Gas Distribution Inc., (2015), "Purchasing gas from Enbridge”, Retrieve on March $2^{\text {nd }}, 2015$ from Enbridge Gas Distribution Inc.: https://www.enbridgegas.com/homes/accountsbilling/residential-gas-rates/purchasing-gas-from-enbridge.aspx

[62] The Canadian Chamber of Commerce, (2006), "A guide to climate change for small- to medium-sized enterprises: how to plan for climate change, reduce operating costs and develop new business opportunities", http://www.chs.ubc.ca/archives/files/A\%20Guide\%20to\%20Climate\%20Change\%20for\%20sma $\underline{11 \% 20 \text { to } \% 20 \text { medium\%20sized\%20enterprises.pdf }}$

[63] Environment Canada, (2013), "Natural gas and natural gas liquids", Retrieve on March $1^{\text {st }}$, 2015 from Environment Canada website: https://ec.gc.ca/gesghg/default.asp?lang=En\&n=AC2B7641-1

[64] Wakkee, M., Hollestein, L.M., Nijsten, T., (2014), "Multivariable analysis", Journal of Investigative Dermatology, Vol. 134, Doi. - 10.1038/jid.2014.132

[65] Mcquiston, F. C., Jerald, D. P.,Jeffrey, D. S., (2005), "Heating, ventilating and air conditioning analysis and design", John Wiley \& Sons, Inc.

[66] Hill M., (2002), "Dictionary of Scientific and Technical Terms", $6^{\mathrm{TH}}$ edition

[67] Patel, P., (2013), "Energy saving by modification of HVAC as a cost saving opportunity of industries", International Journal of Pharmaceutical science and Research, Vol. 4, No. 9, pp. $3347-3356$

[68] Mabbett, A. N., (N.D), "Industrial ventilation and pollution control", Finishing Plant Engineering, pp. 668 - 689 
[69] Jokisalo, J., Kalamees, T., Kunitski, J., Eskola, L., Jokiranta, K., Vinha, J., (2007), “A comparison of measured and simulated air pressure conditions of detached house in a cold climate", Journal of Building Physics, Vol. 32, No. 1

[70] Barringer, F. L., Keith, A., Taylor, R. P., Moynihan, G., (2013), "Industrial energy system and assessment opportunity", ProQuest LLC, University of Alabama http://search.proquest.com/docview/1448550127

[71] Sherman, M., (2009), "Infiltration in ASHRAE's Residential Ventilation Standards", American Society of Heating, Refrigerating and Air-Conditioning Engineers Inc., Vol. 115, https://homes.lbl.gov/sites/all/files/infiltration_in_ashraes_residiential_ventilation_standards.pdf

[72] Environment Canada, (2014), “Canada's emission trend”, ISSN: 2291 - 9392, http://www.ec.gc.ca/ges-ghg/E0533893-A985-4640-B3A2-

008D8083D17D/ETR_E\%202014.pdf

[73] Cohen J., (1988), "Statistical power analysis for the behavioral science", second edition, http://www.Irdc.pitt.edu/schneider/p2465/Readings/Cohen,\%201988\%20(Statistical\%20Power, $\% 20273-406) . p d f$

[74] Manitoba Hydro Power Smart, (2014), "Commercial building envelop program: insulation upgrades for roof and wall" Retrieved on $19^{\text {th }}$ July from Manitoba Hydro website:

https://www.hydro.mb.ca/your_business/building_envelope/building_envelope_roof.pdf

[75] Neter, J., Wasserman W., Kutner M.H., (1989), “Applied linear regression model”, ISBN 0256-07068-7 